
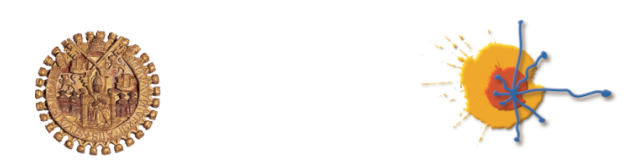

Universidad de Salamanca Departamento de Microbiología y Genética Instituto de Biología Molecular y Celular del Cáncer

\title{
CARACTERIZACIÓN FUNCIONAL DE \\ LAS FOSFATASAS Cdc14 HUMANAS EN \\ LA REGULACIÓN DEL CICLO DE DIVISIÓN CELULAR
}

Tesis Doctoral

María Dolores Vázquez Novelle

Salamanca, 2008

Directores:

Dra. María P. Sacristán Martín

Dr. A. Avelino Bueno Núñez 



\author{
Universidad de Salamanca \\ Departamento de Microbiología y Genética \\ Instituto de Biología Molecular y \\ Celular del Cáncer
}

\title{
Tesis Doctoral: \\ Caracterización funcional de las fosfatasas \\ Cdc14 humanas en la regulación \\ del ciclo de división celular
}

\section{Doctorando: María Dolores Vázquez Novelle}

\section{Directores:}

Dr. A. Avelino Bueno Núñez, Catedrático de Microbiología. Dpto. de Microbiología y Genética de la Facultad de Biología de la Universidad de Salamanca

Dra. María P. Sacristán Martín, Profesora Contratada-Doctora Permanente de la Universidad de Salamanca 



\section{SUMARIO}

\section{AGRADECIMIENTOS}

ÍNDICE

\section{INTRODUCCIÓN}

I. CICLO CELULAR

II. REGULACIÓN DEL CICLO CELULAR

III. MITOSIS

IV. REGULACIÓN DE LA ENTRADA EN MITOSIS

V. REGULACIÓN DE LA SALIDA DE MITOSIS: DESDE ANAFASE HASTA CITOQUINESIS

VI. FOSFATASAS DE LA FAMILIA Cdc14

\section{OBJETIVOS}

\section{RESULTADOS}

HOMOLOGÍA FUNCIONAL ENTRE LAS FOSFATASAS Cdc14 HUMANAS, hCdc14A Y hCdc14B, Y Flp1 DE Schizosaccharomyces pombe

I. LAS FOSFATASAS hCdc14A $\mathrm{Y}$ hCdc14B COMPLEMENTAN LA CARENCIA DEL GEN flp $1^{+}$EN S. pombe

II. LA PROTEÍNA hCdc14A ES CAPAZ DE DESFOSFORILAR A Cdc25 DE S. pombe

III. LAS PROTEÍNAS HUMANAS hCdc14A Y hCdc14B INTERACCIONAN in vivo CON Cdc25 DE S. pombe

IV. EFECTOS DE LA SOBRE-EXPRESIÓN DE LAS FOSFATASAS hCdc14A O hCdc14B EN LA LEVADURA DE FISIÓN S. pombe

ESTUDIO DE LAS FUNCIONES DESEMPEÑADAS POR hCdc14A EN LA REGULACIÓN DEL CICLO DE DIVISIÓN DE CÉLULAS HUMANAS

I. LAS FOSFATASAS Cdc25 HUMANAS: POSIBLES SUSTRATOS in vitro DE hCdc14A Y hCdc14B 
II. FUNCIÓN DESEMPEÑADA POR hCdc14A EN LA REGULACIÓN DE LA TRANSICIÓN G2/M EN CÉLULAS HUMANAS

III. FUNCIÓN DESEMPEÑADA POR hCdc14A EN LA REGULACIÓN DE LA SALIDA DE MITOSIS EN CÉLULAS HUMANAS

\section{DISCUSIÓN}

I. CONSERVACIÓN EVOLUTIVA DE LAS PROTEÍNAS Cdc14

II. hCdc14A REGULA LA ENTRADA EN MITOSIS A TRAVÉS DE hCdc25A

III. FUNCIÓN DESEMPEÑADA POR hCdc14A EN LA REGULACIÓN DE LA SALIDA DE MITOSIS

IV. POSIBLES FUNCIONES DE hCdc14B

\section{CONCLUSIONES}

\section{MATERIALES Y MÉTODOS}

I. CULTIVO Y TRANSFORMACIÓN DE CÉLULAS DE S. pombe

II. CULTIVO Y TRANSFECCIÓN DE LÍNEAS CELULARES HUMANAS

III. TÉCNICAS DE MANIPULACIÓN DE ÁCIDOS NUCLEICOS

IV. CITOMETRÍA DE FLUJO (FACS)

V. ANÁLISIS DE PROTEÍNAS

VI. PURIFICACIÓN DE PROTEÍNAS FUSIONADAS A GST

VII. INMUNOPRECIPITACIÓN

VIII. ENSAYOS in vitro: ANÁLISIS DE LA ACTIVIDAD QUINASA Y/O FOSFATASA

IX. INMUNOCITOQUÍMICA

X. PURIFICACIÓN DE CENTROSOMAS

\section{BIBLIOGRAFÍA}

ABREVIATURAS 


\section{Agradecimientos}

Supongo que todo el mundo se imagina que esta Tesis Doctoral, no sólo es un trabajo científico, sino un período muy importante de mi vida. Todo comenzó hace algunos años en Santiago de Compostela, cuando tomé la decisión de empezar en esto de la investigación científica (¿recuerdas Miri?), sin saber aún muy bien en qué consistía. A día de hoy no me arrepiento en absoluto de aquella determinación de venir a Salamanca para formar parte del laboratorio de Avelino. Y creo que esto no se debe sólo a mi gusto por este trabajo, sino también a las experiencias personales que he vivido aquí y, sobre todo, a las personas que he tenido la suerte de conocer. Por esta razón quiero agradeceros a todos los que habéis compartido conmigo estos años, de una u otra forma, el haber estado ahí y ser como sois. Gracias:

En primer lugar, a Avelino y María por darme la oportunidad de formar parte de este grupo, en el que he aprendido y disfrutado a partes iguales. También a ambos, y en especial a María, gracias por haber dedicado parte de tu tiempo a enseñarme y por las largas conversaciones sobre Ciencia que hacen que esto sea mucho más que un trabajo.

A los "Buenos" que ya no están en el labo, pero sí en mi vida. A Vero, por tus múltiples consejos y explicaciones, por ser tan buena "maestra". A Viole, por tu dulzura, por aportarme la tranquilidad que necesito a veces y por regalarme momentos muy especiales. A Juanjín, mi "novio putativo", gracias por esa capacidad tuya para arrancarme una sonrisa en los momentos bajos, por los bailes, los viajes, los pinchos, etc...,e incluso por las lágrimas compartidas y las escenas de tipo "la madre de la Pantoja" que hemos pasado juntos, ya sabes que para mí eres muy grande.

A los que sí estáis en el laboratorio. A Arturez por dar "vidilla" (a veces demasiada.., je, je) en esos tiempos de espera, por tu sentido del humor y por ser tan buen ejemplo como científico. A Sandrix y Xonix, porque las dos me habéis cuidado un montón (gracias por esos bizcochos tan buenos MariXonix) y aconsejado siempre que lo he necesitado dentro y fuera del laboratorio, ya sabéis que me tenéis para lo que queráis y que os adoro. A Pilar, por ser tan maja y aportar ese punto de ingenuidad que te hace especial y que es tan necesario a veces. A Helenilla, por esa conexión y las "vidas paralelas", por las bañeritas y conversaciones trascendentales (referencia cruzada) y por la "vena" filosófica que compartimos, gracias por entenderme tan bien. Laura y Teresa, aunque no haya coincidido mucho tiempo con vosotras, me parecéis un gran "fichaje"; ah! y muchas gracias por esas gestiones transatlánticas Laura. A Alfonsito, por ser un "bichín-jerbín" tan tierno, porque has sido un gran descubrimiento inesperado, por ser como eres, por 
compartir tanto tiempo conmigo en los últimos meses y porque sabes que te quiero mucho.

A los "Morenos-as" y también a los ex-, como Álvaro y Bea, por formar parte de esta aventura. A Carlos, Martín y Pablo por la resolución de múltiples problemas con aparatos como la "máquina del demonio".

A todos los que habéis estado conmigo en algunas de mis vivencias salmantinas (e incluso holandesas e italianas) fuera del CIC, a David, Antonio, Inda, Katherine, Sonia, Alicia, Inma y Clarita, por esos momentos de ocio, por las múltiples fiestas, por haberme hecho reír tanto, y también, por esas conversaciones profundas. Muchas gracias a Nuri, por haber sido mi compi de piso durante dos años y por aportarme tu alegría en muchas ocasiones.

A mis amigas de siempre, a Gracia, Lisa, Marta, Sonia, Triski, y también a Miriam y a Belén "pitiña", porque estar con todas vosotras me hace sentir como en casa y por vuestra visión del mundo "exterior" (fuera del laboratorio) que me aporta otra perspectiva. Muchas gracias por estar siempre ahí, aunque muchas veces tenga que ser a través del teléfono, y por tantos momentos inolvidables.

Por último, a mi "pinkie"-familia, a mi madre, a mi padre y a Lucía. Aquí sí que no hay palabras..., por vuestro apoyo incondicional, porque todo lo bueno que pueda tener os lo debo a vosotros, por confíar en mí siempre y apoyarme en mis decisiones, aunque eso suponga a veces verme con menos frecuencia. Gracias por quererme como soy, dándome amor y libertad a partes iguales. Os quiero un montón. 


\section{Indice de Contenidos}



INTRODUCCIÓN.........................................................................23

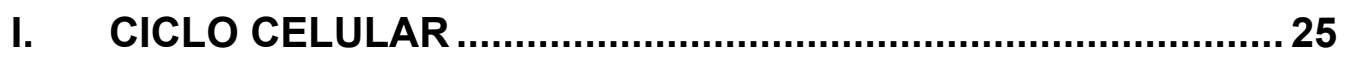

Modificaciones del ciclo celular básico .............................................26

II. REGULACIÓN DEL CICLO CELULAR ....................................... 27

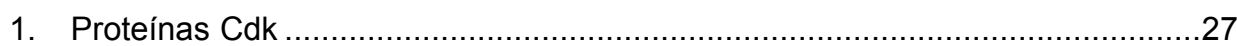

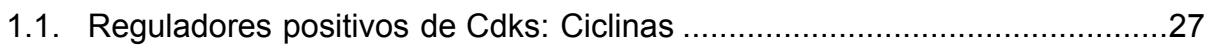

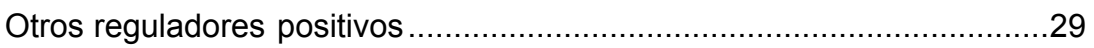

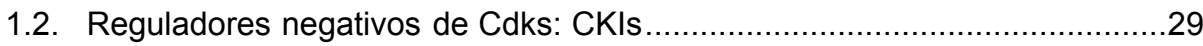

2. Controles de comprobación del ciclo celular: Checkpoints...............................29

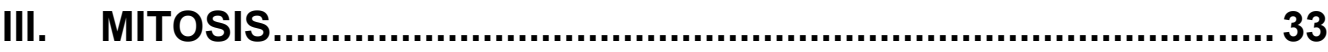

IV. REGULACIÓN DE LA ENTRADA EN MITOSIS .......................... 35

1. Regulación de la entrada en mitosis por complejos CDK mitóticos....................35

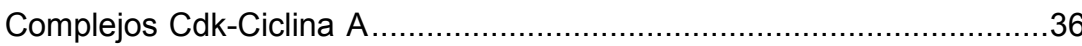

Complejos Cdk1-Ciclina B (MPF) .......................................................

2. Regulación de los complejos CDK mitóticos en G2/M...................................37

2.1. Regulación de la actividad de los complejos CDK mitóticos a través de fosforilación/desfosforilación de Cdk1

2.1.1. Fosforilación activadora en el residuo Treonina $161\left(\mathrm{Thr}^{161}\right)$ durante G2. 37

2.1.2. Fosforilación/desfosforilación de los residuos Treonina $14\left(\operatorname{Thr}^{14}\right)$ y

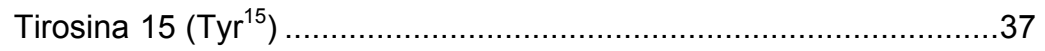

Mecanismo de auto-amplificación de la actividad CDK mitótica ...............38

Fosforilación de los residuos $\operatorname{Thr}^{14}$ y $\operatorname{Tyr}^{15}$ : Las quinasas Wee1 y Myt1 ..39 Desfosforilación activadora de los residuos $\mathrm{Thr}^{14}$ y $\mathrm{Tyr}^{15}$ : Las fosfatasas hCdc25

2.2. Regulación de la actividad de los complejos CDK mitóticos a través de su localización subcelular. 
2.3. Otros mecanismos de regulación de la actividad de los complejos CDK mitóticos 42

Regulación de los complejos CDK mitóticos por parte de CKIs 42

Otros mecanismos de regulación de los complejos CDK, independientes

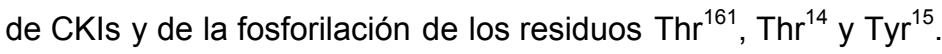
43

3. Regulación de las proteínas hCdc25 43

3.1. Regulación de los niveles proteicos de hCdc25B, A y C .44

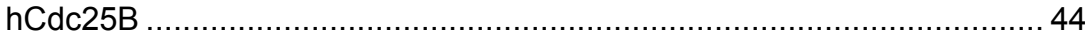

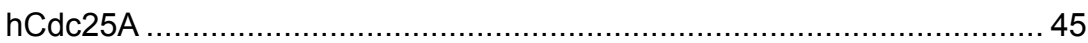

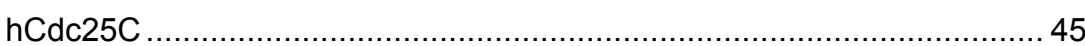

3.2. Regulación de la actividad catalítica de hCdc25B, A y C ........................ 46

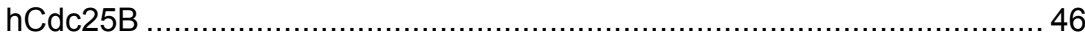

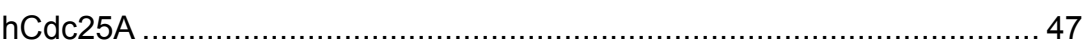

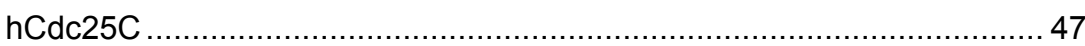

3.3. Regulación de la localización subcelular de hCdc25B, A y C y/o la interacción con sus sustratos (los complejos CDK) ............................. 47

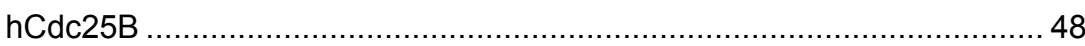

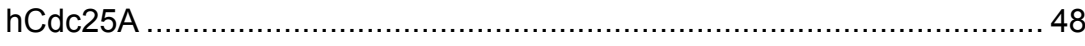

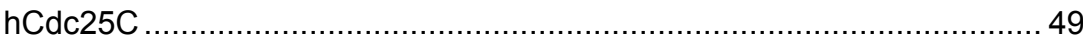

4. Regulación de la entrada en mitosis por otras quinasas.................................50

4.1. Quinasas de la familia Polo, Plks, en la regulación de la entrada en mitosis

4.2. Quinasas de la familia Aurora en la regulación de la entrada en mitosis

4.3. Quinasas de la familia NIMA, proteínas Nek, en la regulación de la entrada en mitosis 52

4.4. Chk1 en la regulación de la entrada en mitosis...... 53

V. REGULACIÓN DE LA SALIDA DE MITOSIS: DESDE ANAFASE

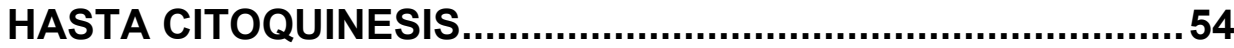

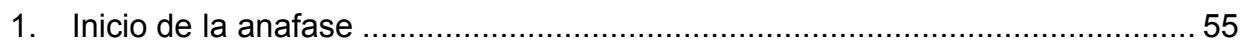

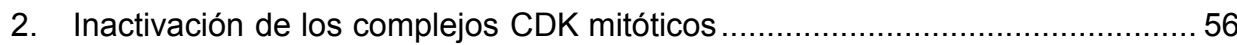


3. Desfosforilación ordenada de sustratos de Cdk1 56

3.1. Sustratos desfosforilados a la salida de mitosis. .57

3.2. Posibles fosfatasas implicadas en la desfosforilación de los sustratos de Cdk1. .58

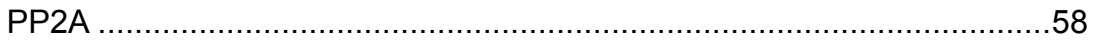

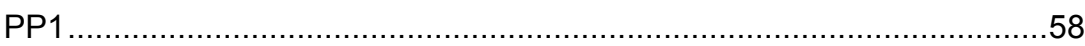

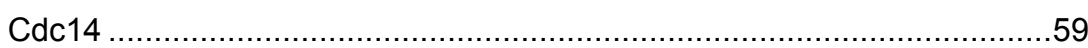

4. Degradación de proteínas por el complejo APC/C .....................................59

4.1. Orden de degradación por $A P C^{\mathrm{Cdc20}}$ de diversos sustratos, regulado por el checkpoint de huso mitótico ..............................................................60

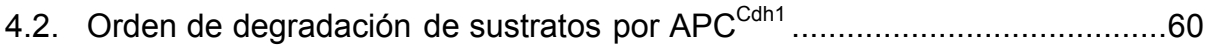

VI. FOSFATASAS DE LA FAMILIA Cdc14 …............................... 61

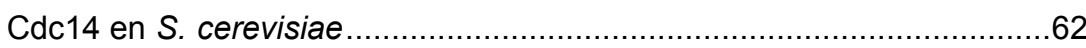

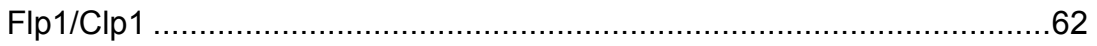

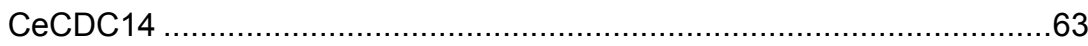

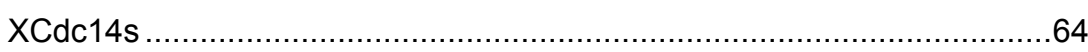

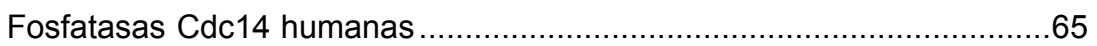




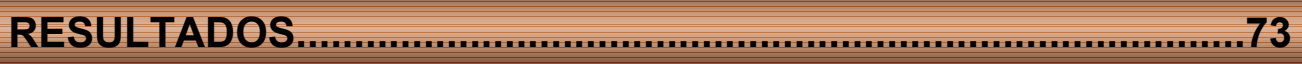

HOMOLOGÍA FUNCIONAL ENTRE LAS FOSFATASAS Cdc14 HUMANAS, hCdc14A Y hCdc14B, Y Flp1 DE Schizosaccharomyces pombe.

I. LAS FOSFATASAS hCdc14A y hCdc14B COMPLEMENTAN LA CARENCIA DEL GEN flp1 ${ }^{+}$EN S. pombe 77

1. Ensayo de viabilidad del mutante termosensible $\Delta f l p 1$ cdc25-22 de S. pombe: La expresión de hCdc14A o hCdc14B da lugar a una considerable recuperación de su viabilidad

2. Análisis del fenotipo de células del mutante $\Delta$ flp1: La expresión de cada una de las proteínas hCdc14 revierte el fenotipo de la deleción de flp $1^{+}$

II. LA PROTEÍNA hCdc14A ES CAPAZ DE DESFOSFORILAR A Cdc25 DE S. pombe

1. La fosfatasa hCdc14A desfosforila in vitro a la proteína de S. pombe Cdc25 en residuos fosforilados por Cdk1

2. La fosfatasa $\mathrm{hCdc} 14 \mathrm{~A}$ promueve de forma directa o indirecta la desfosforilación in vivo de la proteína de $S$. pombe Cdc25

III. LAS PROTEÍNAS HUMANAS hCdc14A $\mathrm{Y}$ hCdc14B INTERACCIONAN in vivo CON Cdc25 DE S. pombe.................83

1. Reducción de la actividad quinasa de los complejos Cdc2-Cdc13 en células $\Delta f l p 1$ que expresan las proteínas hCdc14.

2. La expresión de hCdc14A o hCdc14B altera la localización subcelular de Cdc25 en células de $S$. pombe 85

IV. EFECTOS DE LA SOBRE-EXPRESIÓN DE LAS FOSFATASAS hCdc14A O hCdc14B EN LA LEVADURA DE FISIÓN S. pombe. 86

1. Niveles de expresión y localización subcelular de hCdc14A y hCdc14B en células de $S$. pombe 
2. Las células de $S$. pombe que sobre-expresan hCdc14A o hCdc14B presentan un contenido anómalo de DNA

3. Las células de $S$. pombe que sobre-expresan hCdc14B o hCdc14A presentan anomalías en la morfología nuclear y en la formación del huso mitótico

\section{ESTUDIO DE LAS FUNCIONES DESEMPEÑADAS POR hCdc14A EN LA REGULACIÓN DEL CICLO DE DIVISIÓN DE CÉLULAS}

\section{LAS FOSFATASAS Cdc25 HUMANAS: POSIBLES} SUSTRATOS in vitro DE hCdc14A y hCdc14B ........................95

1. hCdc14A desfosforila in vitro a hCdc25A y hCdc25C en residuos fosforilados por Cdk1 (Cdc2)

2. hCdc14A desfosforila in vitro a hCdc25A en los residuos Serina 115 y Serina $320\left(\operatorname{Ser}^{115}\right.$ y Ser $\left.{ }^{320}\right)$ previamente fosforilados por Cdk1..... .97

II. FUNCIÓN DESEMPEÑADA POR hCdc14A EN LA REGULACIÓN DE LA TRANSICIÓN G2/M EN CÉLULAS

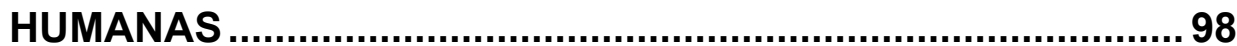

1. La sobre-expresión de hCdc14A induce un retraso en la transición G2/M........98 El retraso de las células en G2/M inducido por la sobre-expresión de hCdc14A es dependiente de su actividad fosfatasa. 101

La sobre-expresión de hCdc14A induce un retraso en "antefase" y en la transición prometafase/metafase 102

Las células que sobre-expresan hCdc14A presentan una menor actividad de los complejos CDK mitóticos

1.1. Caracterización del retraso en la transición G2/M inducido por la sobreexpresión de hCdc14A 105

La sobre-expresión de hCdc14A retrasa la condensación cromosómica

La sobre-expresión de $\mathrm{hCdc} 14 \mathrm{~A}$ da lugar a un retraso anterior a metafase, acompañado por una ausencia de activación de Cdk1 
La presencia de elevados niveles de hCdc14A induce un retraso en "antefase" y en la transición prometafase/metafase

1.2. El retraso en la transición G2/M también ocurre al sobre-expresar hCdc14A en otras líneas celulares

La sobre-expresión de hCdc14A en células U2OS induce un retraso en la entrada en mitosis

La sobre-expresión de hCdc14A en células HCT116 induce un retraso en la entrada en mitosis, asociado a una reducción de la actividad CDK mitótica

2. El silenciamiento de la expresión de hCdc14A acelera la entrada en mitosis

3. Posibles mecanismos de acción de hCdc14A a la entrada en mitosis

3.1. Estudio de la cinética de entrada al núcleo de la Ciclina B1

3.2. Estudio de la regulación de proteínas activadoras de los complejos CDK mitóticos: hCdc25B, hCdc25A y hCdc25C ........................................ 118

3.2.1. Acción de hCdc14A sobre hCdc25B a la entrada en mitosis 118

Los niveles proteicos y la localización subcelular de hCdc25B no se ven afectados en células que sobre-expresan hCdc14A. 119

La sobre-expresión de hCdc14A no afecta a la actividad fosfatasa de hCdc25B 120

La activación de los complejos Cdk1-Ciclina B1 en centrosomas no está alterada por la presencia de elevados niveles de hCdc14A en la célula...

3.2.2. hCdc14A participa en la regulación de hCdc25A a la entrada en mitosis 122

La sobre-expresión de hCdc14A no afecta a los niveles proteicos de hCdc25A durante la transición G2/M 123

El efecto de la sobre-expresión de hCdc14A sobre la localización de hCdc25A no parece ser causa del retraso en G2/M.

La fosfatasa hCdc14A está implicada en la regulación de la actividad catalítica de hCdc25A 
La desfosforilación de los residuos $\operatorname{Ser}^{115}$ y $\operatorname{Ser}^{320}$ de hCdc25A por parte de hCdc14A, no parece afectar a su actividad sobre Cdk1-Ciclina B1...

3.2.3. Acción de hCdc14A sobre hCdc25C a la entrada en mitosis 128

Los niveles proteicos de hCdc25C no se modifican de forma significativa en $\mathrm{G} 2 / \mathrm{M}$ al sobre-expresar hCdc14A. 128

La sobre-expresión de hCdc14A no afecta a la localización ni a la actividad fosfatasa de hCdc25C

129

4. Posible activación de un checkpoint como consecuencia "a largo plazo" de la presencia de elevados niveles de hCdc14A en la célula. 130

4.1. Estudio de la activación de ATM y ATR como consecuencia de la sobreexpresión de hCdc14A "a largo plazo" 133

Fosforilación de Histona H2AX: Consecuencia sólo "a largo plazo" de la sobre-expresión de hCdc14A

4.2. Estudio de la implicación de p38 en el efecto a "largo plazo" de la sobreexpresión de hCdc14A 135

4.2.1. Activación de p38: Consecuencia de la sobre-expresión de hCdc14A "a largo plazo" 135

4.2.2. El retraso en la transición $\mathrm{G} 2 / \mathrm{M}$ inducido por la sobre-expresión de hCdc14A a partir de fase $S$ no está asociado a la activación de p38.

\section{FUNCIÓN DESEMPEÑADA POR hCdC14A EN LA REGULACIÓN DE LA SALIDA DE MITOSIS EN CÉLULAS HUMANAS 138}

1. Efectos de la sobre-expresión de hCdc14A en la salida de mitosis en células humanas 138

1.1. Cinética de la salida de mitosis en células HCT116 que sobre-expresan hCdc14A: Inactivación de los complejos Cdk1-Ciclina B1 y degradación de Ciclina B1

1.2. Cinética de la salida de mitosis en células U2OS-Myc-hCdc14A que sobreexpresan hCdc14A: Degradación de hCdc25A y Ciclina B1

2. Efectos de la desfosforilación de los residuos $\operatorname{Ser}^{115}$ y $\operatorname{Ser}^{320}$ en la estabilidad de la proteína hCdc25A 140 


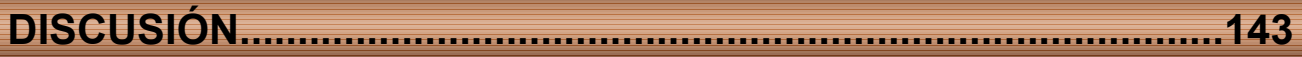

I. CONSERVACIÓN EVOLUTIVA DE LAS PROTEÍNAS Cdc14

Las fosfatasas hCdc25: Posibles sustratos de hCdc14A..................... 146

II. hCdc14A REGULA LA ENTRADA EN MITOSIS A TRAVÉS DE hCdc25A .......................................................................... 147

hCdc14A regula negativamente la entrada en mitosis de forma dependiente de su actividad fosfatasa

El efecto de hCdc14A sobre la entrada en mitosis se asocia a la inactivación de los complejos CDK mitóticos, promovida a través de la inhibición de hCdc25A

Mecanismo mediante el que hCdc14A inhibe la actividad catalítica de hCdc25A

El retraso en G2/M inducido por la sobre-expresión de hCdc14A no se debe a la activación de un checkpoint

III. FUNCIÓN DESEMPEÑADA POR hCdc14A EN LA REGULACIÓN DE LA SALIDA DE MITOSIS

Posibles funciones de hCdc14A en la regulación de la segregación cromosómica y la citoquinesis

Posibles funciones de hCdc14A en la regulación de la degradación de determinados sustratos de APC a la salida de mitosis

IV. POSIBLES FUNCIONES DE hCdc14B 
I. CULTIVO Y TRANSFORMACIÓN DE CÉLULAS DE $S$.

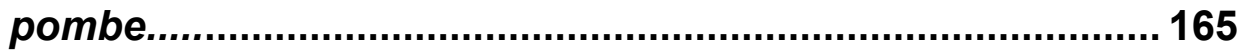

1. Cepas de Schizosaccharomyces pombe empleadas .....................................165

2. Medios y condiciones de cultivo ………......................................................166

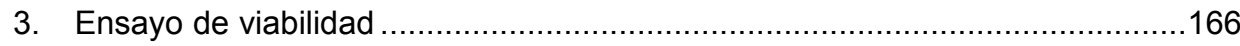

4. Transformación de células de S. pombe ................................................167

II. CULTIVO Y TRANSFECCIÓN DE LÍNEAS CELULARES

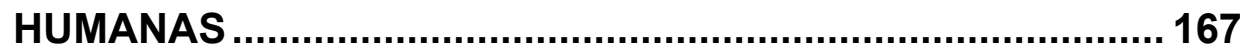

1. Líneas celulares humanas empleadas.........................................................167

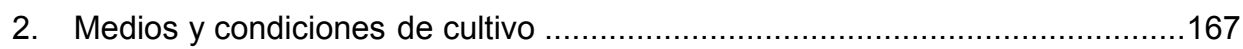

Condiciones de cultivo e inducción de los clones estables U2OS-MychCdc14A y U2OS-Myc-hCdc14A(PD)................................................168

3. Congelación y descongelación de las células ..............................................168

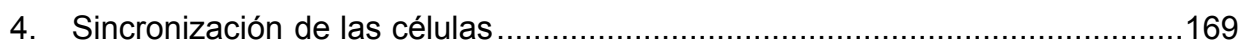

4.1. Sincronización de las células en G1/S por doble tratamiento con timidina 169

4.2. Sincronización de las células en mitosis por tratamiento con nocodazol ...169

5. Tratamiento de células con determinados reactivos .......................................170

Tratamiento con MG132 ..............................................................170

Tratamiento con cafeína ................................................................170

Tratamiento con SB203580 ...........................................................

6. Transfecciones transitorias con DNA o RNA …….......................................170

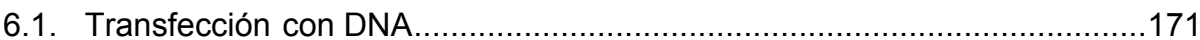

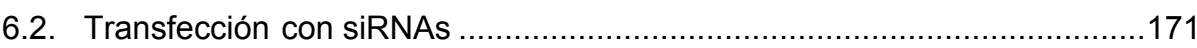

III. TÉCNICAS DE MANIPULACIÓN DE ÁCIDOS NUCLEICOS .. 172

1. Construcción de plásmidos de DNA recombinante........................................172

1.1. Aislamiento de DNA plasmídico a partir de células de E. coli ...................172

1.2. Determinación de la concentración de ácidos nucleicos ............................173 
1.3. Digestión de DNA con endonucleasas de restricción ............................. 173

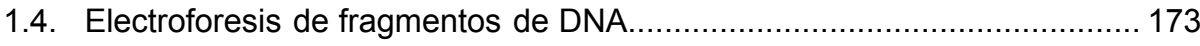

1.5. Purificación y ligación de fragmentos de DNA ................................... 174

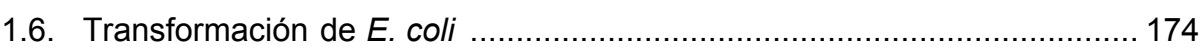

1.7. Reacciones de amplificación de DNA (PCR) ................................... 174

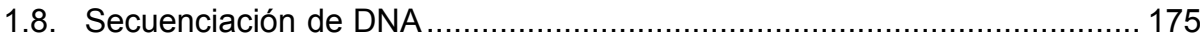

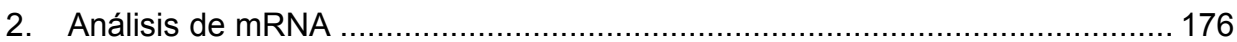

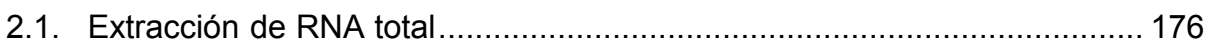

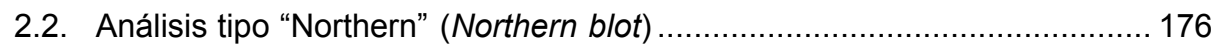

IV. CITOMETRÍA DE FLUJO (FACS) ….....................................176

1. Análisis mediante FACS de muestras de la levadura S. pombe .................. 177

2. Análisis mediante FACS de muestras de cultivos de líneas celulares

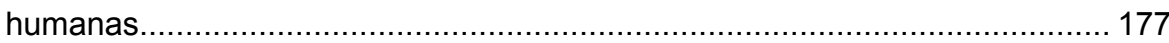

V. ANÁLISIS DE PROTEÍNAS .................................................178

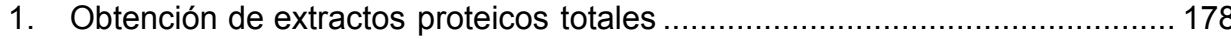

1.1. Obtención de extractos proteicos de S. pombe ................................ 178

1.2. Obtención de extractos proteicos totales a partir de células humanas...... 178

2. Valoración de la concentración de proteína en los extractos totales .............. 179

3. Electroforesis de proteínas en SDS-PAGE ....................................... 179

4. Análisis de proteínas por la técnica de Western blot ............................... 180

5. Tinción con azul de Coomassie.............................................................. 181

VI. PURIFICACIÓN DE PROTEÍNAS FUSIONADAS A GST .........181

1. Purificación a partir de células de S. pombe .......................................... 181

2. Purificación a partir de células de E. coli............................................ 182

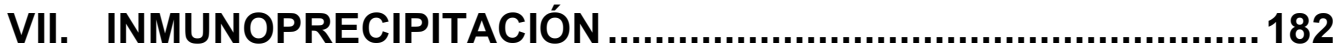

1. Inmunoprecipitación de los complejos Cdc2-Cdc13 a partir de células de $S$. pombe 
VIII. ENSAYOS in vitro: ANÁLISIS DE LA ACTIVIDAD QUINASA

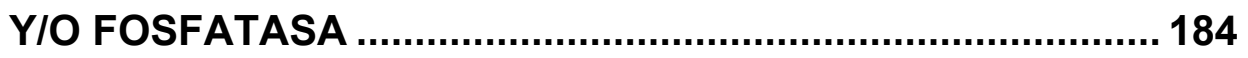

1. Ensayos in vitro de la actividad quinasa de los complejos CDK sobre Histona H1.

2. Ensayos in vitro de la actividad fosfatasa de proteínas hCdc25 sobre complejos CDK.

3. Ensayos in vitro de la actividad fosfatasa de hCdc14 sobre las proteínas Cdc25.

IX. INMUNOCITOQUÍMICA 186

1. Técnica de inmunofluorescencia en células de $S$. pombe. 186

2. Técnica de inmunofluorescencia en células humanas

X. PURIFICACIÓN DE CENTROSOMAS

BIBLIOGRAFÍA...........................................................................189 

Introducción 



\section{CICLO CELULAR}

El modo en el que las células crecen y se dividen ha sido estudiado por muchos investigadores. En relación con esta cuestión, en 1838 y 1839, Theodor Schleiden y Jacob Schwann propusieron la "Teoría Celular", según la cual cada organismo vivo está compuesto por una o más células, y una nueva célula sólo puede proceder de la división de otra pre-existente. En base a esta teoría, la división celular ha sido y es considerada un proceso esencial, que permite la obtención de nuevos individuos unicelulares, y está implicada en el desarrollo de individuos pluricelulares adultos y en el mantenimiento de su status quo por medio del reemplazo de células perdidas por desgaste, deterioro o muerte celular programada.

El ciclo celular se define como el conjunto de procesos por los que a partir de una célula madre se obtienen dos células hijas con la misma información genética. A lo largo del ciclo celular debe existir una coordinación entre el crecimiento de las células y su división. Sin embargo, la condición esencial para que ocurra la división celular es que la célula madre transmita adecuadamente su información genética a las dos células hijas. Para ello, el DNA ha de ser replicado de forma exacta y única en cada ciclo, y las cromátidas hermanas obtenidas (las dos copias de un cromosoma que se encuentran unidas a través de una región denominada centrómero) deben ser segregadas a cada una de las nuevas células, hecho que requiere cambios drásticos en la condensación del DNA y en la organización del citoesqueleto celular. Además, durante el ciclo celular también han de ser duplicados todos los componentes de la célula madre, para ser repartidos entre las células hijas.

El ciclo celular eucariótico se divide en cuatro fases distintas, siendo las principales la fase $S$ y la fase $M$, definidas por los dos procesos más importantes durante la división

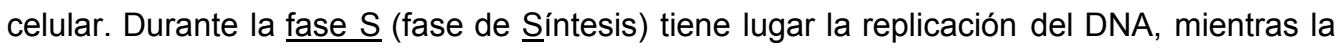
segregación cromosómica se produce en la fase M (de Mitosis), que a su vez comprende la mitosis o división nuclear y la citoquinesis o división celular propiamente dicha. Entre la fase $S$ y la fase $M$ se distinguen dos períodos denominados $\underline{G 1}$ y $\underline{G 2}$ (del inglés $\underline{G} a p$, intervalo), siendo $\mathrm{G} 1$ el período posterior a la fase $\mathrm{M}, \mathrm{y} \mathrm{G} 2$ el posterior a la fase $\mathrm{S}$ (Figura I-1). Durante estos dos períodos la célula crece y además comprueba que los procesos ocurridos en la fase anterior se han producido adecuadamente, en cuyo caso ocurre la transición a la siguiente fase del ciclo, de ahí la importancia de las transiciones G1/S y G2/M. Al conjunto de las fases G1, S y G2 se le denomina interfase. 


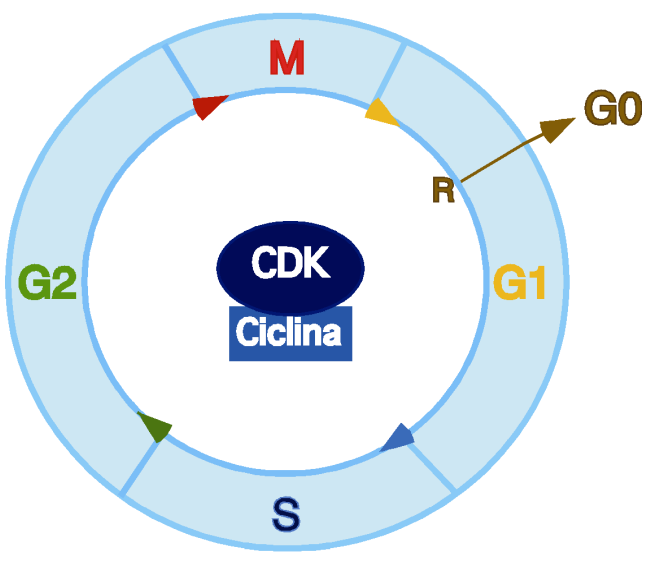

Figura I-1. Esquema general del ciclo celular. En la figura se observan las cuatro fases del ciclo, las fases $G 1$ y $G 2$, la fase $S$ (de síntesis de DNA) y la fase M (Mitosis y citoquinesis). Las flechas señalan las transiciones entre las distintas fases. También hemos indicado el punto de restricción $(R)$ o Start, en el que las células pueden abandonar el ciclo celular para entrar en G0 (estado de quiescencia). En el centro se representan los complejos Cdk-Ciclina, cuya actividad regula la progresión por las distintas fases del ciclo.

\section{Modificaciones del ciclo celular básico}

Aunque el ciclo celular básico presenta las características descritas, existen variaciones de éste dependiendo del organismo o del tipo celular.

De este modo, la duración del ciclo de división es variable en función de las citadas circunstancias y/o de las condiciones del medio en el que se encuentren dichas células. En este sentido, cabe destacar que mientras la división celular es casi inmediata en los primeros estadíos de algunos embriones, el ciclo celular de levaduras dura varias horas y el de muchas células de mamíferos incluso más de 24 horas. Además, la duración relativa de las distintas fases del ciclo también puede variar, así la fase G1 es mucho más larga que G2 en la levadura de gemación Saccharomyces cerevisiae, al contrario de lo que ocurre en la levadura de fisión Schizosaccharomyces pombe.

Respecto a la mitosis, ésta puede ser abierta (como en células de mamíferos) o cerrada (en levaduras), en función de si durante esta fase se produce la ruptura de la envoltura nuclear o no, respectivamente.

Por último, también existen tipos celulares en los que ocurre la endorreduplicación, que consiste en dos fases $S$ consecutivas, sin que se produzca la división celular entre ellas; y otros tipos celulares en los que, por el contrario, tiene lugar la meiosis en lugar de la mitosis, produciéndose dos divisiones celulares consecutivas tras una única fase $\mathrm{S}$. 


\section{REGULACIÓN DEL CICLO CELULAR}

\section{Proteínas Cdk}

En células eucariotas, el control de la progresión por las distintas fases del ciclo celular se fundamenta en la actividad de unas proteínas denominadas $\underline{\text { Cdks }}$ (del inglés Cyclin- $\underline{d e p e n d e n t ~ k i n a s e s, ~ q u i n a s a s ~ d e p e n d i e n t e s ~ d e ~ C i c l i n a s) . ~}$

Las Cdks presentan actividad quinasa sobre residuos Serina o Treonina, siendo capaces de fosforilar diversas proteínas en dichos residuos. Estas quinasas constituyen una familia muy conservada evolutivamente en los organismos eucariotas. En levaduras existe una sola Cdk responsable de la progresión por el ciclo celular, que en S. cerevisiae se denomina $\underline{\text { Cdc28 }}$ (Reed et al., 1982; Reed et al., 1985) y en S. pombe recibe el nombre de Cdc2 (Simanis y Nurse, 1986). Por el contrario, en células de mamíferos varias Cdks participan en la regulación del ciclo, de modo que $\underline{\mathrm{Cdk} 4}$ y $\underline{\mathrm{Cdk} 6}$ están implicadas en la regulación de $\mathrm{G} 1, \underline{\mathrm{Cdk}} \mathbf{2}$ regula principalmente la entrada y progresión por la fase $\mathrm{S}$, y por último, $\underline{C d k 1}$ (también denominada $\mathrm{Cdc} 2$ ) es necesaria para la entrada y la progresión por las primeras etapas de la mitosis (Lees, 1995; Morgan, 1995). Sin embargo, estudios recientes han puesto de manifiesto la existencia de redundancia funcional entre las distintas Cdks en células de mamíferos (en ratones), ya que sólo Cdk1 parece esencial para la regulación del ciclo celular (Santamaria et al., 2007).

Por otra parte, las quinasas Cdk mantienen sus niveles constantes, mientras su actividad fluctúa a lo largo del ciclo celular, en parte a consecuencia de su asociación con distintas proteínas activadoras de tipo Ciclina, que les confieren especificidad de sustrato. Estas oscilaciones de la actividad CDK no sólo dependen de la formación de los complejos Cdk-Ciclina, sino también de procesos de fosforilación y desfosforilación, y de la presencia de proteínas inhibidoras de tipo $\underline{\mathrm{CKI}}$ (del inglés $\underline{C}$ clin-dependent $\underline{K}$ inase Inhibitor, inhibidor de Cdks).

\subsection{Reguladores positivos de Cdks: Ciclinas}

Inicialmente, las Ciclinas fueron identificadas en embriones de invertebrados marinos como proteínas que oscilaban periódicamente durante el ciclo celular, debido a su regulación transcripcional y degradación (Evans et al., 1983). Se conocen Ciclinas en todos los organismos eucariotas estudiados, aunque su conservación evolutiva no es muy grande, estando limitada a la región de interacción con Cdks (Kobayashi et al., 1992; Lees y Harlow, 1993). 
Se pueden distinguir cuatro tipos distintos de Ciclinas, en función de la fase del ciclo en la que aparecen y de la Cdk a la que se asocian, aunque no todos los tipos están presentes en todos los organismos eucariotas:

- Ciclinas de G1: Promueven el paso por Start (inicio) en levaduras, o punto de restricción en células animales, lo que en definitiva conlleva la entrada de la célula en un nuevo ciclo celular. En células de mamíferos son las Ciclinas $\mathrm{D}$, que se asocian a Cdk4 y Cdk6 durante G1.

- Ciclinas G1/S: Requeridas para el inicio de la replicación del DNA. La Ciclina E asociada a Cdk2 parece la encargada de esta función en células de mamíferos.

- Ciclinas de fase S: Permiten la progresión por la fase S. Con este fin, en células de mamíferos la Ciclina A se asocia a Cdk2 durante la fase $\mathrm{S}$.

- Ciclinas mitóticas: Su función es necesaria en mitosis. En células de mamíferos esta función la desempeñan la Ciclina $\mathrm{A}$ y sobre todo las $\underline{\text { Ciclinas } \mathrm{B}}$, cuando forman complejos con Cdk1.

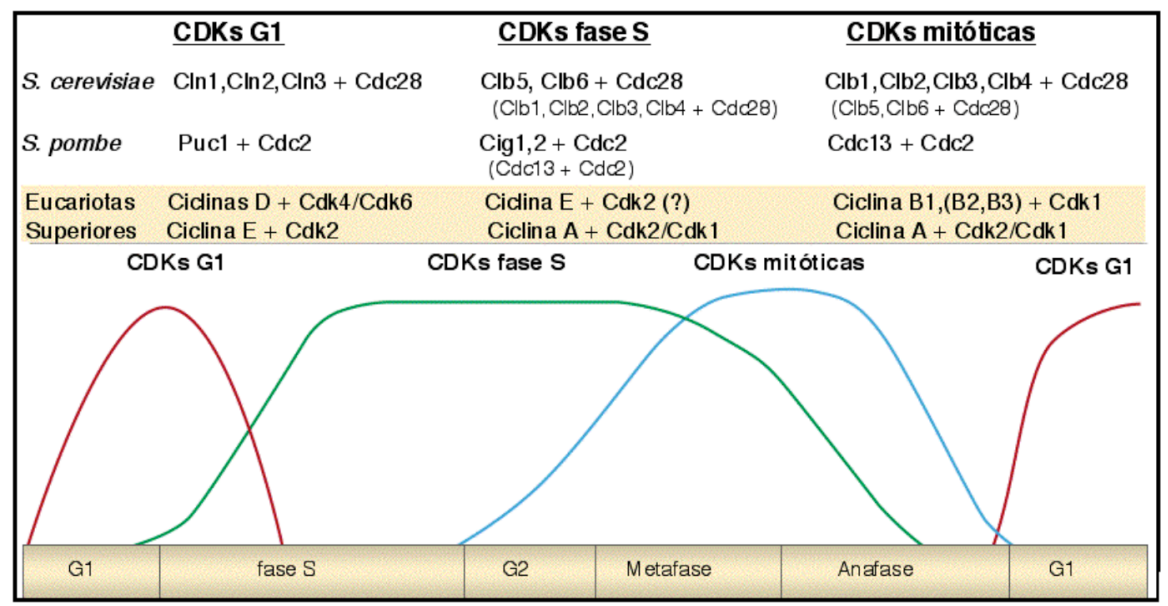

Figura I-2. La actividad de los complejos CDK y la regulación del ciclo celular. En este esquema se observan las fluctuaciones de la actividad de los distintos complejos CDK a lo largo del ciclo celular (línea roja: CDKs de G1; línea verde: CDKs de fase S; línea azul: CDKs mitóticos). La actividad de los complejos CDK de G1 promueve el paso de Start o punto de restricción, la actividad de los CDKs de fase $S$ permite la replicación del DNA, y por último, los complejos CDK mitóticos inducen la entrada y progresión por mitosis, aunque su actividad debe reducirse al final de esta fase. En la parte superior se muestran las distintas Ciclinas y las quinasas Cdk que componen estos complejos en $S$. cerevisiae, S. pombe y en eucariotas superiores (barra de color crema). Entre paréntesis se muestran los complejos que pueden llevar a cabo esa función en ausencia de los mecanismos habituales y el símbolo (?) indica una posible intervención de forma indirecta. Este esquema ha sido modificado a partir de una figura presente en el artículo de Bardin y Amon, 2001. 
Funcionalmente, en $S$. cerevisiae se diferencian tres grupos de Ciclinas asociadas a Cdc28 (de las cuales ninguna es esencial para la supervivencia): las Ciclinas de G1, Cln1, Cln2 y Cln3; las Ciclinas de fase S, Clb5 y Clb6, y por último, las Ciclinas mitóticas, Clb1, Clb2, Clb3 y Clb4. En la levadura de fisión S. pombe se han identificado cuatro Ciclinas que se pueden asociar a Cdc2: Puc1, Cig1 y Cig2, y la Ciclina mitótica Cdc13, que promueve la transición G2/M y es la única esencial (Fig. I-2).

\section{Otros reguladores positivos}

Recientemente se ha identificado otra familia de proteínas que pueden unirse y regular positivamente a las Cdks, tanto en oocitos de Xenopus, como en células de mamíferos. Estas proteínas se denominan RINGO/Speedy (Nebreda, 2006).

\subsection{Reguladores negativos de Cdks: CKIs}

Para la correcta progresión por el ciclo celular es necesaria la actividad CDK, pero se requiere su inhibición para poder finalizar un ciclo y comenzar el siguiente, o en respuesta a determinadas señales. En este sentido, las proteínas inhibidoras de Cdks (CKIs) participan en la parada del ciclo celular producida en respuesta a señales intrínsecas y/o extrínsecas al propio ciclo, como las relacionadas con procesos de senescencia, inhibición por contacto, señales antiproliferativas, o activación de un checkpoint o control de comprobación del ciclo celular (el-Deiry et al., 1993; Alcorta et al., 1996; Harper, 1997).

En células de mamíferos se han distinguido dos familias de CKIs, CIP/KIP (del inglés Kinase Inhibitor Protein, proteína inhibidora de quinasa) que incluye a p21, p27 y p57, y la familia INK4 (del inglés Inhibitor of Cdkㅡ, inhibidor de Cdk4) que comprende a p15, p16, p18 y p19. Los miembros de la familia INK4 son específicos de Cdks de G1, mientras que las proteínas de la familia KIP tienen un espectro más amplio (Harper, 1997; Pavletich, 1999).

En la levadura S. cerevisiae existen varios CKls, como Far1, o también Sic1 y Cdc6, que desempeñan importantes funciones a la salida de mitosis y al inicio de G1 (Chang y Herskowitz, 1990; Schwob et al., 1994; Calzada et al., 2001). En S. pombe se ha descrito un CKI, Rum1, que está implicado en el control de la duración de G1(Correa-Bordes y Nurse, 1995).

\section{Controles de comprobación del ciclo celular: Checkpoints}

Los controles de comprobación o checkpoints son cascadas de señalización que aseguran la estabilidad, la correcta replicación y la distribución adecuada del material 
genético en las células, además de garantizar el mantenimiento de la homeostasis interna de éstas, fundamentalmente por medio de la regulación de su progresión por el ciclo celular. Estos controles se pueden ejercer principalmente en dos puntos del ciclo celular; el primero es la transición $\mathrm{G} 2 / \mathrm{M}$, cuyo bloqueo o retraso afecta a la entrada de las células en mitosis y ocurre en respuesta a daño al DNA o a una replicación anómala o incompleta (circunstancias que también pueden inducir un retraso o bloqueo en fase $\mathrm{S}$ ) y también en caso de activación del checkpoint de "antefase"; y el segundo punto corresponde a la transición metafase/anafase, en la cual las células pueden sufrir una parada con el fin de impedir la segregación irregular de los cromosomas en caso de activación del checkpoint de huso mitótico.

Los checkpoints son vías de señalización, por lo tanto están integrados por distintas proteínas que se pueden clasificar según su función, en:

- Sensores, proteínas encargadas de reconocer la perturbación que afecta al DNA o a la homeostasis celular.

- Adaptadores, permiten la transmisión de la señal desde las proteínas de tipo sensor a las transductoras.

- Transductores, quinasas que amplifican la señal procedente de las proteínas de tipo sensor mediante la fosforilación de otras quinasas o proteínas diana.

- Efectores, proteínas diana de la cascada, cuya acción evita la progresión de las células por el ciclo en condiciones inadecuadas.

Las proteínas que desempeñan estas funciones varían en función del tipo de checkpoint. A continuación, se muestran los principales tipos de checkpoint descritos en células humanas:

- Checkpoint de daño al DNA: Se activa cuando se detectan roturas o alteraciones de la estructura normal de la cadena de DNA, con el fin de parar el ciclo celular y reparar el DNA si es posible. Este checkpoint evita la transmisión de mutaciones a las células hijas, y por lo tanto, contribuye al mantenimiento de la estabilidad genómica de dichas células.

- Checkpoint de replicación o de estrés replicativo: Se activa en respuesta a determinados problemas que afectan, en ausencia de daño directo al DNA, a la replicación, pudiendo inducir incluso su parada. Algunas de las principales proteínas implicadas tanto en el checkpoint de daño al DNA, como en el checkpoint de replicación en células humanas se muestran en la Figura I-3. 


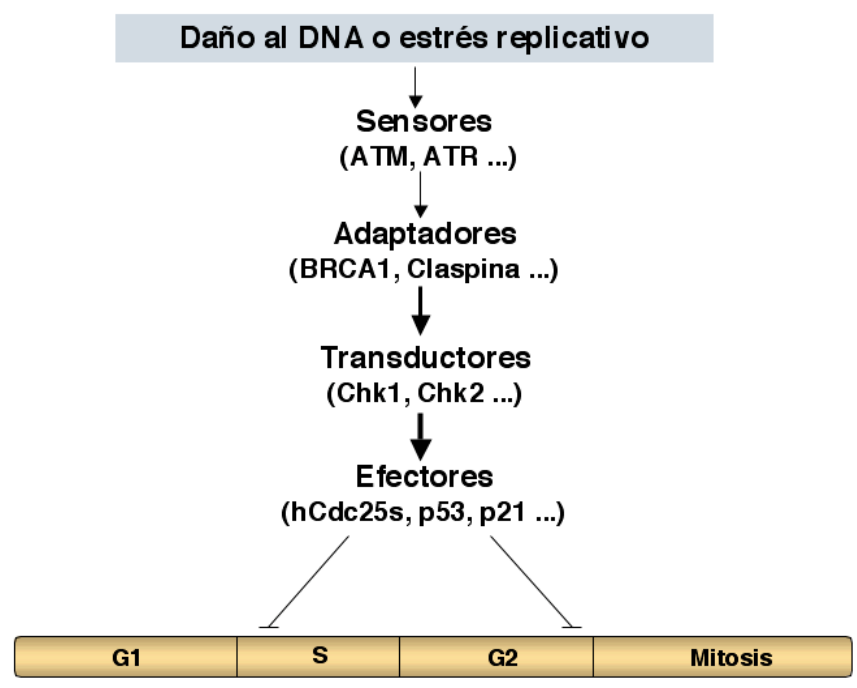

Figura l-3. Proteínas implicadas en los checkpoints de replicación y daño al DNA. En este esquema se observan los distintos tipos de proteínas (sensores, adaptadores, transductores y efectores) implicados en la activación de checkpoints. Entre paréntesis se muestran algunos ejemplos (interesantes para nuestro estudio) de cada tipo de proteína implicado en checkpoints activados en respuesta a estrés replicativo o a daño al DNA. Las flechas indican el sentido de transmisión de la señal y como ésta es amplificada a lo largo de la ruta. Por último, la acción de esta ruta sobre las proteínas efectoras puede dar lugar directamente a un retraso o parada de las células en distintos puntos del ciclo, como fase $S$ o la transición G2/M, señalados en la Figura.

- Checkpoint de "antefase": Este checkpoint promueve la parada de las células en un punto concreto de la transición G2/M, la "antefase", en respuesta a problemas en el ensamblaje del huso mitótico, a cambios en la topología de la cromatina, o a un estrés de tipo térmico u osmótico. La "antefase", es un concepto clásico con el que se designó el periodo al final de la fase $\mathrm{G} 2$, inmediatamente anterior a los signos visibles de condensación cromosómica, durante el cual células normales pueden sufrir un retraso reversible a causa de diferentes tipos de estrés (Bullough y Johnson, 1951; Rieder, 1981; Rieder y Cole, 2000). En el checkpoint de "antefase" pueden participar diversas proteínas de tipo sensor en función de la naturaleza de la perturbación, pero todas ellas inducen la activación de la quinasa

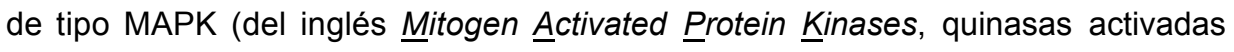
por mitógenos) $\mathrm{p} 38$, que a su vez promueve la inhibición de proteínas reguladoras del ciclo celular, como hCdc25B (cuyas funciones y mecanismos de regulación serán descritos en detalle más adelante), y/o la activación de p $\underline{53}$, importante supresor tumoral implicado en diversos tipos de checkpoint (Mikhailov et al., 2005) (Fig. I-4). 


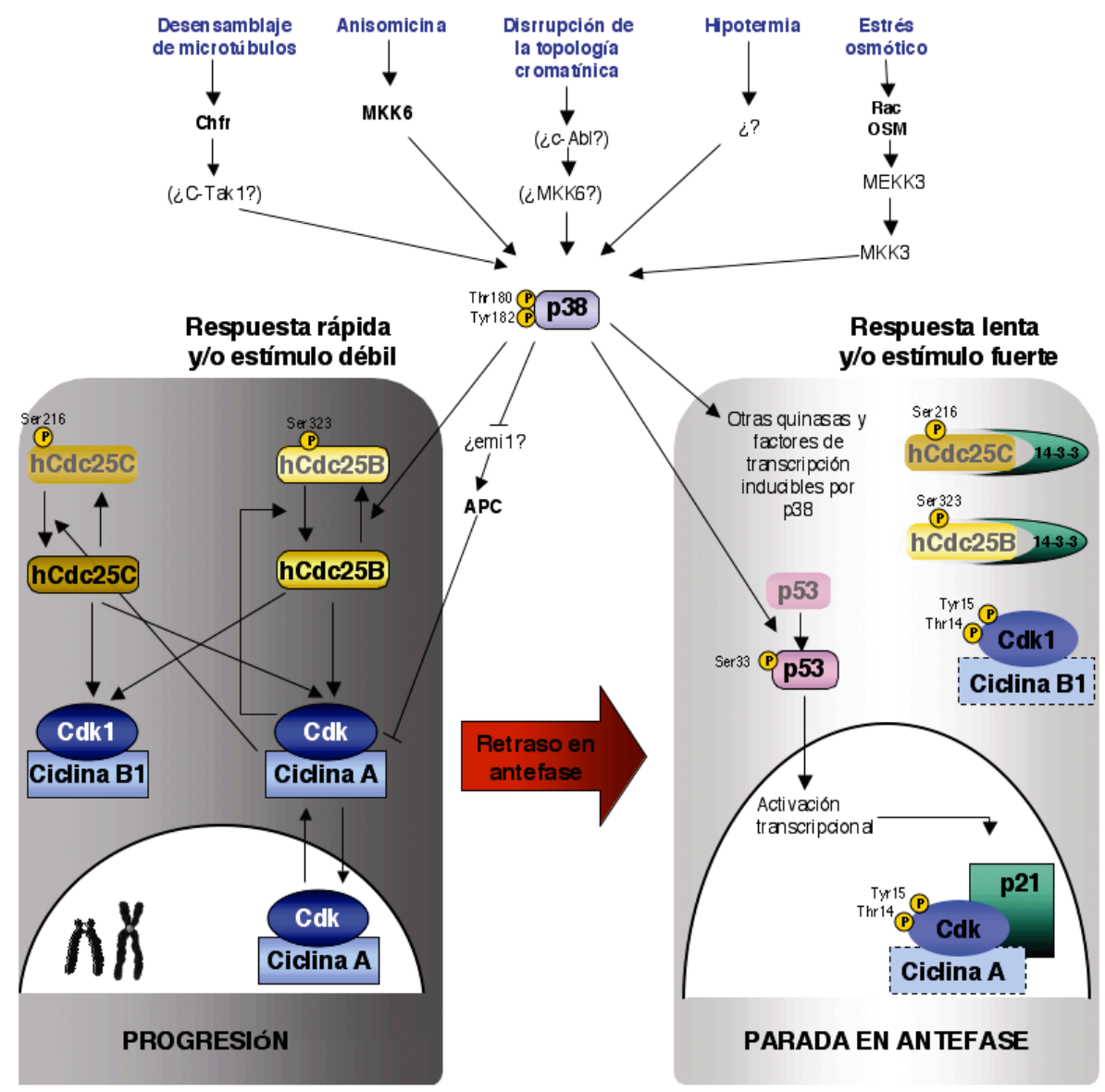

Figura I-4. Esquema de la ruta de activación del checkpoint de "antefase". En el esquema se observa que esta ruta puede ser activada por distintos tipos de estrés (mostrados en la parte superior en azul, junto con las proteínas que actúan como sensores en cada caso), aunque todas estas vías de señalización convergen en la proteína p38. El retraso en "antefase" producido por la activación de este checkpoint está causado finalmente por la inactivación de los complejos CDK, a través de la inhibición de hCdc25B y/o de la degradación de las Ciclinas vía APC (panel de la izquierda). Si la activación de esta ruta se produce de forma prolongada (panel de la derecha), p38 promueve la fosforilación de otras proteínas como p53, que a su vez induce la expresión del CKI p21. Todo esto da lugar a la parada del ciclo y/o a apoptosis. Figura modificada a partir del artículo de Mikhailov et al., 2005.

- Checkpoint de huso mitótico: Es el mecanismo de control que asegura la correcta segregación cromosómica en mitosis, evitando así la aparición de aneuploidías. Este checkpoint se mantiene activo desde la ruptura de la envoltura nuclear hasta la metafase tardía, asegurando que todos los cromosomas estén correctamente anclados al huso mitótico y alineados en la "placa metafásica" (Baker et al., 2005; Musacchio y Salmon, 2007). 


\section{MITOSIS}

En una típica célula somática de mamíferos, la fase $M$ comprende la mitosis y la citoquinesis. Como hemos indicado anteriormente, durante la mitosis o división nuclear se produce un proceso esencial, la segregación cromosómica, pero además durante esta fase cada célula hija debe recibir un centrosoma, y la parte correspondiente del citoplasma y los orgánulos celulares. La citoquinesis, entendida como la división física de las dos células hijas, comienza al final de mitosis. Los mecanismos que regulan la citoquinesis y la mitosis están íntimamente relacionados entre sí, siendo esenciales para ambos procesos los cambios que afectan al citoesqueleto, ya que permiten la organización del huso mitótico a partir de los dos centrosomas (duplicados durante interfase) y la formación del anillo contráctil, punto de división física de la célula. A nivel molecular, el control de la progresión por fase $\mathrm{M}$ se basa principalmente en dos mecanismos post-traduccionales: la fosforilación/desfosforilación de proteínas y la proteolisis, que a su vez se regulan mutuamente (Nigg, 2001).

En células de mamíferos, a lo largo de la mitosis se distinguen tradicionalmente varias fases, definidas hace más de 100 años en base al análisis microscópico de la morfología celular (Pines y Rieder, 2001). En concreto se diferencian 5 fases clásicas: profase, prometafase, metafase, anafase (A y B) y telofase. La profase es considerada la fase inicial de la mitosis, se caracteriza por la condensación visible de los cromosomas y finaliza con la ruptura de la envoltura nuclear, proceso que a su vez señala el comienzo de la prometafase, durante la cual los cromosomas se unen, a través de una estructura multiproteica llamada cinetocoro, a los microtúbulos del huso mitótico. Una vez que se han producido estas uniones correctamente, consideramos que la célula se encuentra en $\underline{\text { metafase, }}$ etapa en la que ocurre la alineación de los cromosomas en la parte central de la célula, en la llamada "placa metafásica". A continuación, durante la anafase las cromátidas hermanas se separan de forma rápida y casi simultánea, y migran por la acción de los microtúbulos del huso mitótico hacia los dos polos opuestos de éste (anafase A), lo que precede a la propia elongación del huso mitótico durante la anafase B. Por último, en la telofase las cromátidas comienzan a descondensarse, se restaura la membrana nuclear y se inicia la desorganización de los microtúbulos del huso mitótico.

En trabajos recientes, se ha intentado dividir la mitosis en nuevas fases, con el fin de reflejar de forma más precisa los procesos moleculares por los que se encuentran reguladas las transiciones claves durante la división nuclear. Para definir la entrada en mitosis, Jonathon Pines y Conly L. Rieder retoman el término "antefase" con el que se refieren a una fase previa a la mitosis, caracterizada por su reversibilidad y que 
comprende un período desde el final de G2 (concepto clásico de "antefase") hasta el final de profase, momento en el cual se produce la completa activación de los complejos Cdk1Ciclina B1 que marca el "punto de no retorno" de la entrada en mitosis (Pines y Rieder, 2001).

A continuación, esta Introducción se centrará principalmente en los mecanismos que controlan la entrada en mitosis y la salida de esta fase, procesos del ciclo celular en los que se ha enfocado nuestro trabajo. 


\section{REGULACIÓN DE LA ENTRADA EN MITOSIS}

La entrada en mitosis, entendida como un período que comprende el final de G2 y el inicio de la mitosis hasta prometafase (incluída), se caracteriza por numerosas modificaciones a nivel molecular y morfológico. Durante este período se producen procesos esenciales, como son la separación y activación de los centrosomas, la condensación cromosómica, la desestructuración de los nucléolos y la posterior ruptura de la envoltura nuclear.

En nuestro estudio diferenciaremos tres etapas a la entrada en mitosis, definidas por diversas modificaciones a nivel molecular y morfológico detectables en la célula:

- Una primera etapa a la que nosotros denominaremos "antefase", que es inmediatamente anterior a la mitosis clásica y está caracterizada por la fosforilación de Histona H3 en la Serina $10\left(\operatorname{Ser}^{10}\right)$ en ausencia de condensación cromosómica visible. La fosforilación de la Histona H3 en este residuo es condición necesaria para que se inicie la condensación cromosómica, pero no para su mantenimiento (Van Hooser et al., 1998), y parece estar mediada principalmente por la quinasa Aurora B (Crosio et al., 2002; Goto et al., 2002), aunque también por las quinasas MSK1/2 (Dyson et al., 2005) y JNK1/2 (Lee y Song, 2008).

- La segunda etapa de la entrada en mitosis es la profase, en la que se produce la condensación visible de los cromosomas.

- La tercera etapa es la prometafase, durante la que tienen lugar la activación de los complejos Cdk1-Ciclina B1 y la ruptura de la envoltura nuclear.

Como hemos indicado anteriormente, en células de mamíferos la entrada en mitosis está fundamentalmente regulada por la actividad de Cdk1 (Cdc2), aunque también hay otras quinasas implicadas, como algunos miembros de las familias Polo, Aurora y NIMA (Nigg, 2001).

\section{Regulación de la entrada en mitosis por complejos CDK mitóticos}

Los complejos Cdk-Ciclina mitóticos tienen como subunidad catalítica a Cdk1, que se asocia inicialmente a la Ciclina A y después a las Ciclinas B. Durante mitosis Cdk1 fosforila numerosos sustratos, como por ejemplo Láminas nucleares, diversas proteínas asociadas a microtúbulos, Condensinas y componentes de la matriz de Golgi. Estas fosforilaciones son esenciales para que ocurran procesos clave como la ruptura de la 
membrana nuclear, la separación de centrosomas y el ensamblaje del huso mitótico, la condensación cromosómica y la fragmentación del aparato de Golgi, respectivamente (Nigg, 1995; Kimura et al., 1998; Lowe et al., 1998; Andersen, 1999). Además, Cdk1

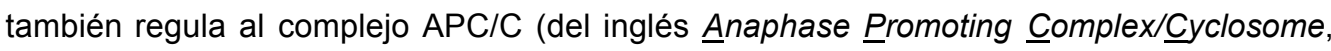
complejo promotor de anafase), que promueve la degradación ordenada de proteínas que inhiben la entrada en anafase, a través de su ubiquitinación (Kramer et al., 2000).

\section{Complejos Cdk-Ciclina A}

La Ciclina A presenta un alto grado de identidad de secuencia con las Ciclinas B. En células de mamíferos se han descrito dos tipos de Ciclina A, la Ciclina A1, forma embrionaria, y la Ciclina A2, forma somática de la proteína. La localización subcelular de la Ciclina A2 es predominantemente nuclear (Pines y Hunter, 1991) y esta proteína se acumula en la célula desde la fase $S$ hasta el final de prometafase, momento en el que es degradada (Minshull et al., 1990; Pines y Hunter, 1990). Además, la Ciclina A es capaz de formar complejos tanto con la quinasa Cdk1, como con Cdk2.

Los complejos Cdk-Ciclina A parece que son necesarios para que tenga lugar la transición G2/M hasta la entrada de la Ciclina B1 al núcleo al final de profase, cuando se vuelven dispensables (Pines y Rieder, 2001). En concreto, los complejos Cdk-Ciclina A participan directamente en la regulación de procesos tempranos, como la condensación cromosómica y la acumulación de la Ciclina B1 en el núcleo (Furuno et al., 1999; Gong et al., 2007). Además, estos complejos promueven la propia activación de Cdk1-Ciclina B1 a la entrada en mitosis, a través de su efecto sobre diversas proteínas implicadas en su regulación, de las que hablaremos en más detalle posteriormente. Así, Cdk-Ciclina A participa en la regulación positiva de hCdc25B y hCdc25C (Mitra y Enders, 2004), la inhibición de Wee1 (Fung et al., 2007), y la acumulación de Plk1 y la propia Ciclina B1, a consecuencia de la inhibición de APC ${ }^{\text {Chn1 }}$ (Lukas et al., 1999a; Mitra et al., 2006).

\section{Complejos Cdk1-Ciclina B (MPF)}

En la regulación de la transición G2/M es esencial el papel desempeñado por los complejos Cdk1-Ciclina B, capaces de inducir la mitosis en células de vertebrados. Estos complejos también se denominan MPF (del inglés Maduration/M-phase Promoting Factor, factor promotor de fase M), que fue descrito originalmente como inductor de la maduración meiótica en oocitos de rana (Masui y Markert, 1971; Lohka et al., 1988).

En mamíferos existen tres formas de la Ciclina B. La Ciclina B1, que es la principal Ciclina mitótica, cuya ausencia en ratones KO (del inglés $\underline{K}$ nock $\underline{\text { O}} u t$, que carecen de esa proteína) induce la muerte de éstos en el útero (Brandeis et al., 1998; Fung et al., 2007). 
Los niveles proteicos de la Ciclina B1 se incrementan durante G2 debido a un aumento de la estabilidad de su mRNA (RNA mensajero) (Pines y Hunter, 1989), hecho indicativo de la importancia de su función a la entrada en mitosis. La Ciclina B2 no presenta una función esencial en ratones (Brandeis et al., 1998; Fung et al., 2007) y la Ciclina B3 se encuentra restringida a células germinales durante el desarrollo y a testículos en adultos (Nguyen et al., 2002; Fung et al., 2007).

\section{Regulación de los complejos CDK mitóticos en G2/M}

La regulación de los complejos Cdk1-Ciclina B1 a la entrada en mitosis se produce a través de dos mecanismos moleculares principales: la modulación de la actividad de la subunidad catalítica, Cdk1, a través de procesos de fosforilación y desfosforilación, y el control de la localización subcelular de la Ciclina B1. De este modo, la activación de los complejos Cdk1-Ciclina B1 se inicia al final de G2 en los centrosomas y se completa posteriormente en el núcleo al inicio de mitosis (De Souza et al., 2000; Jackman et al., 2003).

\subsection{Regulación de la actividad de los complejos CDK mitóticos a través de fosforilación/desfosforilación de Cdk1}

\subsubsection{Fosforilación activadora en el residuo Treonina $161\left(\mathrm{Thr}^{161}\right)$ durante $\mathbf{G} 2$}

La activación de los complejos MPF requiere en primer lugar la fosforilación del residuo $\mathrm{Thr}^{161}$, situado en la región $T$-loop de Cdk1, siendo éste un mecanismo común de regulación de las quinasas Cdk. Esta fosforilación la lleva a cabo el complejo CAK (del

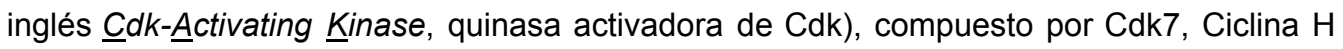
y Mat1 (Solomon et al., 1992; Lolli y Johnson, 2005), y se ha descrito que puede ser inhibida por el CKI p21 en respuesta a daño al DNA (Smits et al., 2000).

\subsubsection{Fosforilación/desfosforilación de los residuos Treonina $14\left(\mathrm{Thr}^{14}\right)$ y Tirosina $15\left(\right.$ Tyr $\left.^{15}\right)$}

La fosforilación de los residuos $\operatorname{Thr}^{14}$ y $\operatorname{Tyr}^{15}$ de Cdk1, situados en la región de unión al ATP, tiene un efecto inhibidor sobre la actividad de los complejos CDK mitóticos, al contrario que su desfosforilación. Las quinasas encargadas de esta fosforilación inhibidora en células humanas son Wee1 y Myt1 (Parker y Piwnica-Worms, 1992; Mueller et al., 1995), siendo las fosfatasas activadoras que desfosforilan los citados residuos a la entrada en mitosis, los hCdc25s (Strausfeld et al., 1991). El equilibrio entre estos procesos de fosforilación y desfosforilación es un importante mecanismo regulador de la transición 
G2/M, que no sólo tiene lugar en células de mamíferos, sino que también fue descrito en la levadura S. pombe. En la levadura de fisión, los complejos Cdc2-Cdc13 se encuentran inactivos a la entrada en mitosis debido a la fosforilación en el residuo Tyr ${ }^{15}$ de Cdc2 por las quinasas Wee1 y Mik1 (Russell y Nurse, 1987; Featherstone y Russell, 1991; Lundgren et al., 1991), y han de ser activados en ese punto del ciclo mediante la desfosforilación de este residuo por la fosfatasa activadora de la entrada en mitosis Cdc25 (Russell y Nurse, 1986; Millar et al., 1991).

\section{Mecanismo de auto-amplificación de la actividad CDK mitótica}

La auto-amplificación de la actividad de los complejos CDK mitóticos es esencial para

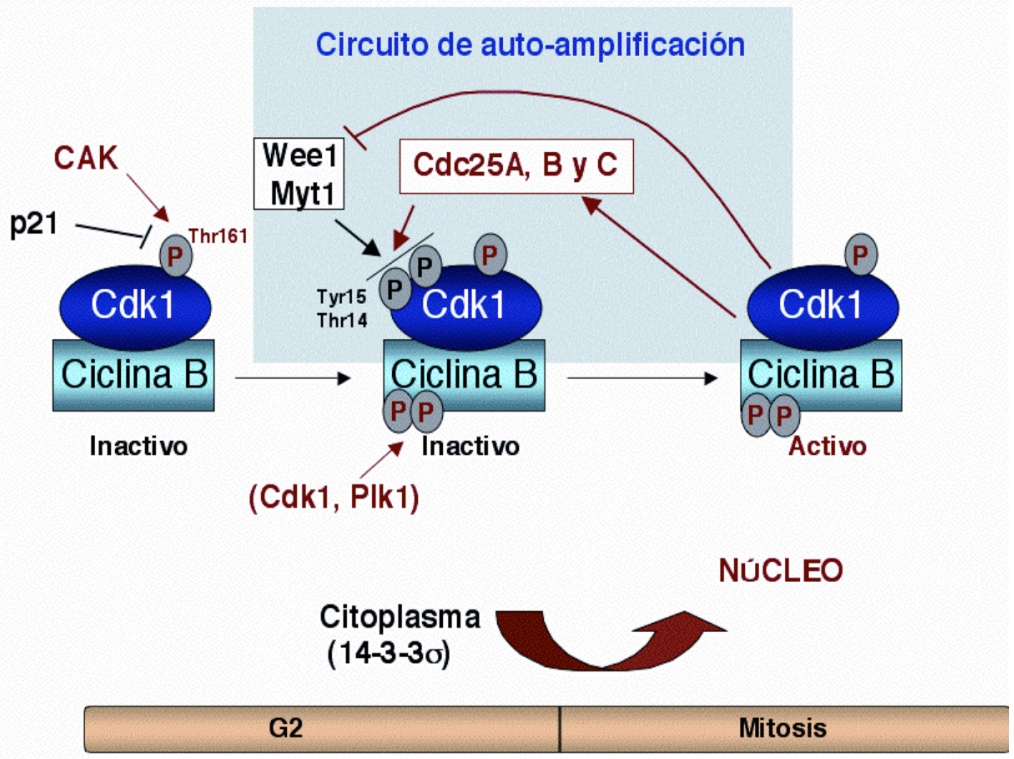

Figura I-5. Regulación de los complejos CDK mitóticos. En la figura se muestran las modificaciones que sufren los complejos Cdk1-Ciclina B1 para su activación durante la transición G2/M. En primer lugar, es necesaria la fosforilación activadora por CAK del residuo $\mathrm{Thr}^{161}$ de Cdk1 durante G2. A la entrada en mitosis, las fosfatasas hCdc25s revierten las dos fosforilaciones inhibidoras en $\mathrm{Thr}^{14}$ y $\mathrm{Tyr}^{15}$, llevadas a cabo por las quinasas Wee1 y Myt1. También se muestra en esta figura el circuito de auto-amplificación de la actividad CDK mitótica (fondo gris), por medio del cual estos complejos CDK promueven la actividad de los hCdc25s e inhiben la de las quinasas inhibidoras (al menos de Wee1). Por otra parte, los complejos Cdk1-Ciclina B1 también son regulados a través de su localización subcelular, siendo su entrada al núcleo al inicio de mitosis necesaria para su completa activación. La localización nuclear de estos complejos es promovida por determinadas fosforilaciones en la Ciclina B1 (posiblemente por la propia Cdk1 y por Plk1) e inhibida por su unión a la proteína

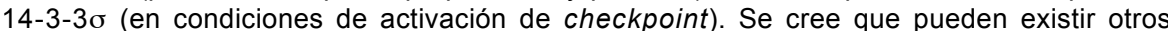
mecanismos de regulación de dicha localización subcelular (no mostrados en este esquema). Las fosforilaciones y proteínas que inducen la activación de los complejos se muestran en rojo, mientras que aquellas con un papel inhibidor están señaladas en color negro. 
que tenga lugar la entrada en mitosis de forma irreversible, por permitir un rápido incremento de la actividad CDK, necesaria durante las primeras etapas de esta fase. El mecanismo de auto-amplificación consiste, tanto en la regulación positiva de las fosfatasas activadoras de los complejos CDK mitóticos (hCdc25A, hCdc25B y hCdc25C), como en la regulación negativa de las quinasas que los inhiben (al menos de Wee1), a través de su fosforilación por parte de los propios complejos Cdk1-Ciclina B1 a la entrada en mitosis (Fig. I-5). A su vez, estas fosforilaciones reguladoras pueden afectar a la actividad catalítica y/o a la estabilidad de las citadas proteínas.

\section{Fosforilación de los residuos $\mathrm{Thr}^{14}$ y $\mathrm{Tyr}^{15}$ : Las quinasas Wee1 y Myt1}

Wee1 y Myt1 son las encargadas de fosforilar el residuo $\mathrm{Tyr}^{15}$ de Cdk1 en células de vertebrados (Parker y Piwnica-Worms, 1992; Squire et al., 2005), además Myt1 también fosforila la Thr $^{14}$ (Mueller et al., 1995; Liu et al., 1997), teniendo ambas fosforilaciones un efecto inhibidor sobre la actividad de Cdk1 durante interfase (Perry y Kornbluth, 2007). Wee1 lleva a cabo esta inhibición en el núcleo, lugar donde se localiza principalmente (Heald et al., 1993; Baldin y Ducommun, 1995), mientras que Myt1 se encuentra predominantemente asociada a las membranas citoplasmáticas, donde inactiva a Cdk1 por fosforilación y a través de su secuestro en dichas membranas (Liu et al., 1997; Liu et al., 1999; Wells et al., 1999).

Las quinasas Wee1 y Myt1 son activas durante interfase y se inactivan en la transición G2/M, en parte a causa del mecanismo de auto-amplificación de la actividad CDK mencionado. Así, la degradación de Wee1 mediada por ubiquitinación por complejos

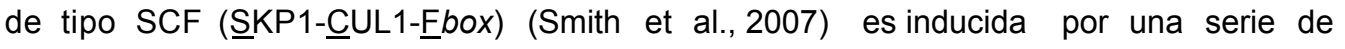
fosforilaciones iniciadas por Cdk1, y continuadas por CK2 y Plk1, en células humanas (Watanabe et al., 2004; Watanabe et al., 2005). Por su parte, la proteína Myt1 se encuentra hiperfosforilada durante fase $\mathrm{M}$, lo que coincide con su inactivación, siendo la quinasa Plk1 una de las responsables de dicha fosforilación (Nakajima et al., 2003). Aunque Cdk1 es capaz de fosforilar a Myt1 aún no se conocen las consecuencias de esta modificación (Booher et al., 1997).

\section{Desfosforilación activadora de los residuos $\mathrm{Thr}^{14}$ y $\mathrm{Tyr}^{15}$ : Las fosfatasas hCdc25}

Las proteínas altamente conservadas de la familia Cdc25 son "fosfatasas de especificidad dual" (cuyos sustratos presentan residuos fosfo-tirosina y fosfo-serina o fosfo-treonina, adyacentes o separados por un aminoácido), capaces de activar a los complejos CDK, revirtiendo la fosforilación de los residuos $\mathrm{Thr}^{14}$ y $\mathrm{Tyr}^{15}$, llevada a cabo previamente por Wee1 y Myt1 (Malumbres y Barbacid, 2005). De este modo, las proteínas 
de la familia Cdc25 desempeñan papeles esenciales en la regulación de un ciclo celular normal y también participan como efectores en determinadas rutas de checkpoint.

Existen tres isoformas de Cdc25 en células humanas: $\underline{\mathrm{hCdc} 25 \mathrm{~A}}, \underline{\mathrm{hCdc} 25 \mathrm{~B}}$ y $\underline{\mathrm{hCdc} 25 \mathrm{C}}$.

Inicialmente se consideró que hCdc25A ejercía un papel fundamental en la entrada en fase $\mathrm{S}$ por medio de la desfosforilación y consiguiente activación de los complejos Cdk2Ciclina E y Cdk2-Ciclina A (Hoffmann et al., 1994; Blomberg y Hoffmann, 1999), y posiblemente también a través de la inhibición a nivel transcripcional de p21 (Coqueret et al., 1998). Mientras hCdc25B y hCdc25C parecian estar implicadas exclusivamente en la regulación de la entrada en mitosis.

Sin embargo, actualmente se cree que las tres isoformas en células de mamíferos, participan en el control de las transiciones G1/S y G2/M, mediante la regulación de Cdk2 y Cdk1. En este sentido, se ha descrito la implicación de hCdc25B y hCdc25C en la regulación de la entrada en fase S (Garner-Hamrick y Fisher, 1998; Turowski et al., 2003), y también se ha demostrado que las tres isoformas desempeñan importantes funciones en el control de la transición G2/M. En concreto, hCdc25B participa en la activación de complejos Cdk-Ciclina A en el núcleo durante G2 (Gabrielli et al., 1997; Goldstone et al., 2001) y ya durante la transición $G 2 / M$, tiene un papel importante como iniciador de la activación de los complejos Cdk1-Ciclina B1 en centrosomas (Lammer et al., 1998; De Souza et al., 2000; Jackman et al., 2003). Esta activación es completada por hCdc25C en el núcleo durante las primeras fases de mitosis (Hoffmann et al., 1993; Dalal et al., 1999). La fosfatasa hCdc25A también está implicada en la regulación de los complejos Cdk1Ciclina B1 a la entrada en mitosis, posiblemente induciendo la condensación de los cromosomas (Lindqvist et al., 2005).

Esta aparente redundancia funcional entre estas tres isoformas de Cdc25 en células de mamíferos resulta controvertida. Por una parte, los ratones doble $\mathrm{KO}$ ( $\mathrm{hCdc} 25 \mathrm{~B}^{-1}$; $\mathrm{hCdc} 25 \mathrm{C}^{-/}$) se desarrollan de forma normal, y sus células presentan un ciclo celular, una repuesta a daño al DNA y una regulación de hCdc25A normales; lo que sugiere que quizás el propio hCdc25A podría estar desempeñando por sí solo las funciones de las tres isoformas de hCdc25 en el ciclo celular (Ferguson et al., 2005). Sin embargo, hCdc25B parece ser esencial para que ocurra la meiosis en las hembras de ratón, hecho que indica que la redundancia de estas proteínas podría no afectar a todas sus funciones ni a todos los tipos celulares (Lincoln et al., 2002).

La regulación de estas fosfatasas, a su vez, está controlada mediante diversos mecanismos, incluyendo su fosforilación por parte de los complejos Cdk1-Ciclina B1 
(circuito de auto-amplificación). Dada su importancia para nuestro trabajo, las distintas formas de regulación de la actividad de las proteínas hCdc25 se describirán en detalle posteriormente.

\subsection{Regulación de la actividad de los complejos CDK mitóticos a través de su localización subcelular}

En células de mamíferos la regulación de los complejos Cdk1-Ciclina B1 es fuertemente dependiente de su distribución subcelular. Así, al inicio de la transición G2/M es necesaria la activación de estos complejos en centrosomas, y para que esto ocurra la quinasa Aurora A induce dicha localización de Cdk1-Ciclina B1 en este momento del ciclo (Hirota et al., 2003). Una vez iniciada la mitosis, estos complejos deben ejercer su función sobre numerosos sustratos en el núcleo (Heald et al., 1993; Li et al., 1997a), lo que explica que la Ciclina B1, a pesar de ser predominantemente citoplasmática durante interfase, se acumule en el núcleo al final de profase (Pines y Hunter, 1991; Heald et al., 1993; Li et al., 1997a).

La Ciclina B1 está sometida a un continuo movimiento entre núcleo y citoplasma durante interfase, pero a la entrada en mitosis la fosforilación de la señal de retención

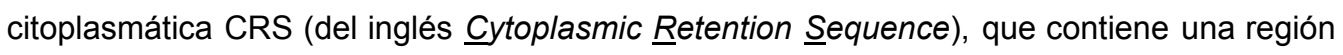
NES (del inglés Nuclear Expor Sequence, secuencia de exportación nuclear), parece favorecer su entrada al núcleo (Hagting et al., 1998; Toyoshima et al., 1998; Yang et al., 1998). La quinasa Plk1 puede fosforilar dos residuos de CRS, Ser ${ }^{133}$ y $\operatorname{Ser}^{147}$, aunque su acción no parece esencial para la entrada de la Ciclina B1 al núcleo (Toyoshima-Morimoto et al., 2001; Jackman et al., 2003). También se han identificado residuos de CRS fosforilados in vitro por Cdk1, cuya actividad quinasa podría estar implicada en la entrada al núcleo de los propios complejos Cdk1-Ciclina B1 al inicio de mitosis (Izumi y Maller, 1991; Takizawa et al., 1999).

Otros mecanismos sugeridos para la entrada de Ciclina B1 al núcleo en profase son su interacción con la Ciclina F (Kong et al., 2000) y la intervención de la Importina $\beta$, de forma independiente de Ran (Takizawa et al., 1999).

Por último, se ha propuesto recientemente otro mecanismo por el cual la Ciclina B1 podría acumularse en el núcleo al final de profase, de forma independiente de su transporte entre núcleo y citoplasma. En concreto, ha sido identificada una nueva ubiquitín-ligasa nuclear, SCF ${ }^{\mathrm{NIPA}}$, definida por la proteína NIPA (Nuclear Interaction $\underline{\text { Partner }}$ of $\underline{A} L K)$, que induce la ubiquitinación y degradación de la fracción nuclear de la Ciclina B1 durante interfase, permitiendo sin embargo, su acumulación en el núcleo durante la 
transición G2/M, como consecuencia de la disociación del complejo $\mathrm{SCF}^{\mathrm{NIPA}}$ debido a la fosforilación inhibidora de la proteína NIPA (Bassermann et al., 2005a; Bassermann et al., 2005b).

La regulación de la localización nuclear de la Ciclina B1 no sólo está modulada a lo largo de un ciclo celular normal, sino también tras la activación de distintos tipos de checkpoint que inducen una parada en G2/M. Así, en respuesta a daño al DNA se promueve la exclusión nuclear de la Ciclina B1 por medio de la unión a 14-3-3б, cuyo control transcripcional depende de p53 (Hermeking et al., 1997; Jin et al., 1998; Chan et al., 1999); mientras en determinadas condiciones de activación del checkpoint de "antefase", dicha exclusión nuclear parece ser inducida de forma indirecta por la proteína Chfr (Summers et al., 2005).

\subsection{Otros mecanismos de regulación de la actividad de los complejos CDK mitóticos}

\section{Regulación de los complejos CDK mitóticos por parte de CKIs}

Se ha descrito que la proteína p21 ejerce una función reguladora sobre los complejos CDK mitóticos, Cdk1-Ciclina A y Cdk1-Ciclina B1, durante la transición G2/M en un ciclo celular normal o en respuesta a la activación de un checkpoint.

En primer lugar, se ha descrito que p21 participa en rutas de checkpoint activadas en respuesta a daño al DNA, promoviendo el mantenimiento a largo plazo de la parada de las células en G2, de forma dependiente de su activación transcripcional por p53 (Bunz et al., 1998; Dulic et al., 1998; Taylor y Stark, 2001). De este modo, en respuesta a daño al DNA p21 tiene un efecto inhibidor sobre Cdk1 que puede ocurrir por diversos mecanismos, a través del bloqueo de la fosforilación activadora en el residuo $\operatorname{Thr}^{161}$ (Smits et al., 2000), por medio de la acumulación de complejos Cdk1-Ciclina B1 inactivos en el núcleo antes de la entrada en mitosis, lo que evita su activación inicial en centrosomas (Smits et al., 2000; Charrier-Savournin et al., 2004), o bien a través de la inhibición del mecanismo de auto-amplificación de la actividad de los complejos, al impedir la activación de hCdc25C por parte de Cdk1 (Ando et al., 2001).

Por otra parte, se consideró que p21 podría ejercer también una función reguladora en la transición G2/M durante un ciclo celular normal, ya que su mRNA se acumula en este momento del ciclo (Li et al., 1994). Sin embargo, los datos obtenidos en este sentido no son coherentes con su función como CKI, ni con su papel inhibidor como efector de rutas de checkpoint, puesto que relacionan la interacción entre p21 y la Ciclina B1 con la 
activación de los complejos Cdk1-Ciclina B1 en un ciclo celular normal (Dash y El-Deiry, 2005).

Otros mecanismos de regulación de los complejos CDK, independientes de CKIs y de la fosforilación de los residuos $\mathrm{Thr}^{161}, \mathrm{Thr}^{14}$ y $\mathrm{Tyr}^{15}$

Recientemente se ha descrito que la proteína SET, identificada por primera vez en una leucemia aguda indiferenciada, es capaz de interaccionar con la Ciclina B1 in vivo, lo que induce la inhibición de los complejos Cdk1-Ciclina B1 (Canela et al., 2003), efecto que puede ser revertido por la interacción de SET con GAPDH (Carujo et al., 2006).

También la proteína nuclear DEDD, que se acumula en G2/M, parece tener un efecto inhibidor sobre la entrada en mitosis, posiblemente a través de su interacción con la Ciclina B1 (Miyazaki y Arai, 2007).

\section{Regulación de las proteínas hCdc25}

Las proteínas humanas Cdc25 se encuentran estrictamente reguladas, dadas sus importantes funciones en el control del ciclo celular, tanto en condiciones normales como en situaciones que conllevan la activación de un checkpoint. Esta regulación se lleva a cabo mediante diversos mecanismos, los cuales controlan sus niveles proteicos, su localización subcelular o la afinidad por sus sustratos, o su actividad catalítica. A su vez, la mayoría de estas modificaciones experimentadas por los hCdc25s están mediadas por fosforilaciones activadoras de estas fosfatasas, como las llevadas a cabo por los propios complejos Cdk1-Ciclina B1 (formando parte del circuito de auto-amplificación de la actividad CDK mitótica mencionado), o por fosforilaciones inhibidoras, que afectan principalmente a su dominio regulador en el extremo amino (N-terminal) (Fig. I-6).

Con respecto a la proteína Cdc25 de $S$. pombe, ésta se regula a través de sus niveles proteicos a lo largo del ciclo, siendo éstos máximos al final de G2 (Moreno et al., 1989; Ducommun et al., 1990) y también a través de su actividad catalítica, incrementada en la transición G2/M por hiperfosforilación de la proteína (Kovelman y Russell, 1996).

A continuación se indican de forma detallada los distintos mecanismos por los que se encuentran reguladas las proteínas Cdc25 humanas. Cabe decir que la regulación de estas fosfatasas es muy compleja, y no siempre está clara la intervención de un determinado proceso de fosforilación en una forma u otra de control de cada isoforma de hCdc25. En todos los casos hemos seguido el orden hCdc25B, hCdc25A y hCdc25C, que refleja el orden probable de actuación de estas fosfatasas en la transición G2/M. 

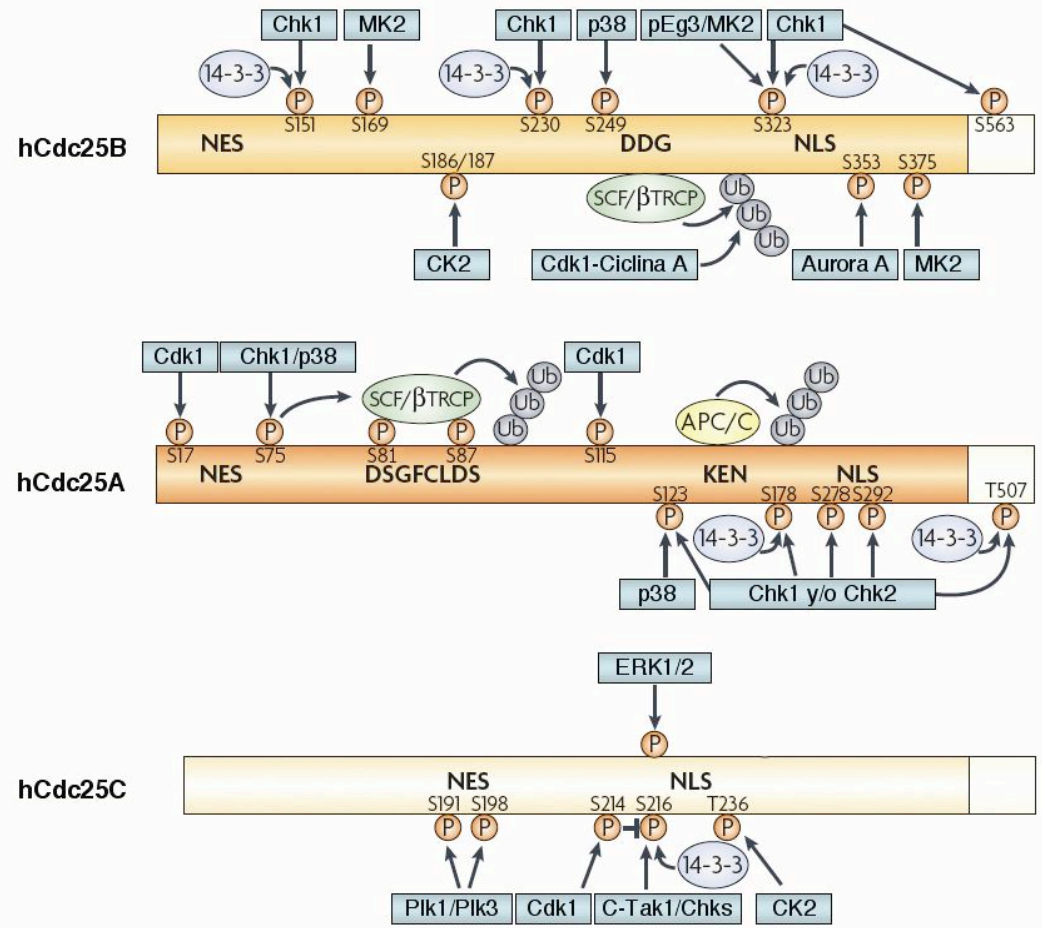

Figura l-6. Regulación de las proteínas hCdc25 (hCdc25B, hCdc25A y hCdc25C). En este esquema se señalan los distintos residuos fosforilados conocidos que participan en la regulación de los hCdc25s. La mayoría de estos residuos fosforilables se encuentran en la región N-terminal, dominio regulador de estas proteínas (el dominio catalítico C-terminal se representa en un color más claro y no está a escala). Las fosfatasas hCdc25B, hCdc25A y hCdc25C son fosforiladas de forma específica por diversas quinasas que regulan tanto su degradación, dependiente de ubiquitinación por los complejos SCF y/o APC/C, como su actividad catalítica, su interacción con proteínas 14-3-3 y/o su localización subcelular. No se han mostrado algunos sitios putativos de fosforilación por complejos CDK para simplificar el esquema, modificado a partir de la revisión de Boutros et al.,2007.

\subsection{Regulación de los niveles proteicos de hCdc25B, A y C}

\section{hCdc25B}

Durante un ciclo celular normal los niveles de hCdc25B se incrementan a partir de la mitad de la fase $S$, alcanzando su máximo en la transición G2/M, tras lo que se reducen rápidamente (Gabrielli et al., 1996; Kieffer et al., 2007). La degradación de esta proteína está mediada por el complejo ubiquitín-ligasa $\mathrm{SCF}^{{ }^{\mathrm{TRCP}}}$, posiblemente tras su fosforilación por Cdk1-Ciclina A (Baldin et al., 1997), si bien recientemente se ha identificado una secuencia no fosforilada de hCdc25B que también es reconocida por el complejo SCF ${ }^{\mathrm{TRCP}}$ y participa en su degradación durante un ciclo celular normal (Kanemori et al., 2005). 


\section{hCdc25A}

En el caso de hCdc25A, su RNA mensajero y sus niveles proteicos comienzan a detectarse al final de G1 (Jinno et al., 1994) siendo su expresión desde G1 a S dependiente de los factores de transcripción c-Myc y E2F (Galaktionov et al., 1996; Vigo et al., 1999). A pesar de que durante interfase ocurre un recambio continuo de la proteína hCdc25A (Donzelli et al., 2002), sus niveles aumentan a lo largo de las fases S y G2, y son máximos en mitosis a consecuencia de su estabilización inducida por la fosforilación de sus residuos $\operatorname{Ser}^{17}$ y $\operatorname{Ser}^{115}$ llevada a cabo por Cdk1-Ciclina B1 (Mailand et al., 2002b). A la salida de mitosis, ocurre una rápida degradación de hCdc25A, mediada por el proteasoma y dependiente de su ubiquitinación por el complejo ubiquitín-ligasa APC/C ${ }^{\mathrm{Cdh} 1}$ (Donzelli et al., 2002). Sin embargo, durante la interfase de un ciclo celular normal y en caso de activación de determinados tipos de checkpoint, la degradación de hCdc25A depende de su ubiquitinación por otro complejo, SCF ${ }^{\beta^{T R C P}}$ (Donzelli et al., 2002; Busino et al., 2003). Este modo de degradación de hCdc25A parece estar promovido por la fosforilación de residuos Serina específicos por parte de diversas quinasas, como Chk1 durante un ciclo celular normal, Chk1 y/o Chk2 en caso de activación de un checkpoint de daño al DNA o p38 en respuesta a un checkpoint de "antefase" (Falck et al., 2001; Zhao et al., 2002; Goloudina et al., 2003; Hassepass et al., 2003; Sorensen et al., 2003). Por otra

parte, como se ha descrito en el caso de hCdc25B, el complejo SCF ${ }^{\beta^{T R C P}}$ podría también mediar la degradación de hCdc25A de forma independiente de su fosforilación durante un ciclo celular normal (Kanemori et al., 2005).

\section{hCdc25C}

Los niveles proteicos de hCdc25C permanecen prácticamente constantes a lo largo de un ciclo celular normal (Garner-Hamrick y Fisher, 1998), aunque se ha detectado un ligero incremento durante fase $S$ (Turowski et al., 2003). Se ha descrito que los niveles de esta proteína en mitosis se encuentran regulados por el supresor tumoral Fez1/Lzts1, que ejerce un efecto inhibidor sobre la degradación de hCdc25C durante esta fase del ciclo (Baldassarre et al., 2007; Vecchione et al., 2007). Por otra parte, en condiciones de activación de determinados tipos de checkpoint, la proteína p53 es capaz de inducir un incremento en la degradación de $\mathrm{hCdc} 25 \mathrm{C}$ vía proteasoma o una reducción de la transcripción de esta fosfatasa (Raj et al., 2001; St Clair et al., 2004). Recientemente, también se ha descrito que la quinasa ERK1/2 induce la degradación de hCdc25C a través de la fosforilación del residuo $\operatorname{Ser}^{216}$ posiblemente en respuesta a daño al DNA (Eymin et al., 2006; Yan et al., 2007). En la Tabla I-I se muestra un esquema de los 


\begin{tabular}{|c|c|c|c|c|}
\hline & & hCdc25B & hCdc25A & $\mathrm{hCdc} 25 \mathrm{C}$ \\
\hline \multicolumn{2}{|c|}{ NIVELES PROTEICOS en el ciclo celular } & $\begin{array}{l}\text { Fase } S \triangleright \text { Salida Mitosis } \\
\text { (máximo en } \mathrm{G} 2 / \mathrm{M} \text { ) }\end{array}$ & $\begin{array}{c}\text { Final G1 Salida Mitosis } \\
\text { (incremento a partir de fase } S \text { y G2) }\end{array}$ & $\begin{array}{c}\text { Casi constantes } \\
\text { (ligero aumento en fase S) }\end{array}$ \\
\hline \multirow[b]{2}{*}{$\begin{array}{c}\text { Mecanismos } \\
\text { de } \\
\text { Regulación }\end{array}$} & $\begin{array}{l}\text { Regulación Positiva } \\
\text { Estabilización en Mitosis }\end{array}$ & & $\begin{array}{c}\text { Por fosforilación en Ser17 y Ser115 } \\
\text { Quinasa: Cdk1-Ciclina B1 }\end{array}$ & Por Fez1/Lzts1 \\
\hline & $\begin{array}{l}\text { Regulación Negativa } \\
\text { Degradación }\end{array}$ & $\begin{array}{l}\frac{\text { Via } \underline{S C F}^{\beta T R C P}}{\text { Reconoce: }} \\
\text {-Fosforilación } \\
\text { por Cdk1-Ciclina A } \\
\text {-Secuencias específicas } \\
\text { no fosforiladas }\end{array}$ & 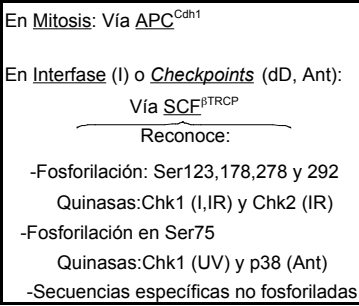 & $\begin{array}{l}\text { En Checkpoint : } \\
\text {-Por activación de p53 } \\
\text { (también inhibición transcripcional) } \\
\text {-Por fosforilación en Ser216 } \\
\text { Quinasa: ERK1/2 }\end{array}$ \\
\hline
\end{tabular}

Tabla I-I. Regulación de los niveles proteicos de las proteínas Cdc25 humanas a lo largo del ciclo celular: mecanismos y proteínas implicados. Las abreviaturas empleadas para indicar las condiciones en las que actúan determinadas proteínas en esta regulación son: (I) se refiere a la interfase de un ciclo celular normal; (dD) indica checkpoint de daño al DNA, debido a IR (del inglés lonizing Radiation, radiación ionizante) o a UV (radiación ultravioleta); (Ant) se refiere al checkpoint de "antefase" en respuesta a estrés osmótico.

mecanismos que regulan los niveles proteicos de los hCdc25s, indicando aquellos residuos específicos cuya fosforilación participa en dicha regulación.

\subsection{Regulación de la actividad catalítica de hCdc25B, A y C}

Se ha comprobado que la actividad catalítica de estas fosfatasas puede ser modificada a través de procesos de fosforilación/desfosforilación específicos. A continuación se muestran algunas de las quinasas implicadas en la regulación de la actividad de los hCdc25s, aunque no siempre se ha comprobado que realmente afecten a la actividad catalítica intrínseca de estas fosfatasas.

\section{hCdc25B}

En el caso de la regulación de la actividad de hCdc25B, parece que los complejos Cdk2-Ciclina A podrían llevar a cabo una fosforilación activadora de esta proteína en G2 (Mitra y Enders, 2004), y también se ha descrito que la quinasa CK2 fosforila y activa a esta fosfatasa durante la transición G2/M (Theis-Febvre et al., 2003). Por el contrario, las fosforilaciones llevadas a cabo por MAPKAP2/MK2 (activada por p38) y por el propio p38 o por pEg3 tienen un efecto inhibidor sobre la actividad de hCdc25B en respuesta a la activación del checkpoint de daño al DNA o durante la transición G2/M de un ciclo celular normal, respectivamente (Bulavin et al., 2001; Davezac et al., 2002; Manke et al., 2005; Mirey et al., 2005; Karlsson-Rosenthal y Millar, 2006; Lemaire et al., 2006).

Por otra parte, en un ciclo celular normal, a la entrada en mitosis la fracción de 
hCdc25B localizada en centrosomas es fosforilada por Aurora A en $\mathrm{Ser}^{353}$, hecho que induce su actividad sobre los complejos CDK mitóticos (aunque no parece alterar su actividad catalítica intrínseca) y por lo tanto promueve la transición G2/M (Dutertre et al., 2004; Cazales et al., 2005). El efecto contrario es el producido por la fosforilación por Chk1, proteína que se localiza también en centrosomas durante las fases $S$ y G2 de un ciclo celular normal, en donde inhibe la fracción de hCdc25B allí localizada (Kramer et al., 2004; Schmitt et al., 2006).

\section{hCdc25A}

En el caso de hCdc25A, parece que el control de su actividad catalítica está asociado a su papel en la transición G1/S, puesto que los complejos Cdk2-Ciclina E son capaces de fosforilar y activar a dicha fosfatasa (Hoffmann et al., 1994), mientras que su fosforilación en ese punto del ciclo de forma dependiente de la activación de RhoA y de p $160^{\text {ROCK }}$, parece inhibir su actividad catalítica (Bhowmick et al., 2003).

\section{hCdc25C}

A la entrada en mitosis, los complejos mitóticos Cdk1-Ciclina B1 fosforilan a hCdc25C y promueven su actividad catalítica, induciendo mediante el circuito de auto-amplificación descrito la entrada en mitosis de forma irreversible (Hoffmann et al., 1993). También se ha descrito que Plk1 y ERK1/2 son capaces de fosforilar a hCdc25C, dando lugar a un incremento en su actividad catalítica durante la transición G2/M (Roshak et al., 2000; Wang et al., 2007).

\subsection{Regulación de la localización subcelular de hCdc25B, A y C y/o la interacción con sus sustratos (los complejos CDK)}

La localización subcelular de las proteínas hCdc25 se encuentra regulada mediante su unión a proteínas de la familia 14-3-3 y por la presencia de secuencias de exportación nuclear NES (del inglés Nuclear Export Sequences) y señales de localización nuclear NLS (del inglés Nuclear Localisation Signals). Ambos mecanismos están a su vez modulados por procesos de fosforilación específicos. Cabe decir que aunque la función principal de la unión de los hCdc25s a las proteínas 14-3-3 es mantener a estas fosfatasas lejos de sus sustratos, también puede tener otros efectos inhibidores sobre su actividad (Boutros et al., 2007). 


\section{hCdc25B}

La localización de la proteína hCdc25B durante el ciclo celular resulta controvertida, probablemente a consecuencia de las diferencias entre las cinco variantes de splicing (proceso de maduración del mRNA) de esta proteína. Sin embargo, se ha descrito que hCdc25B varía su localización entre el núcleo y el citoplasma desde la fase $S$ hasta la mitosis (Davezac et al., 2000; Boutros et al., 2006), y que en la regulación de dicha localización interviene la fosforilación llevada a cabo por PKB/Akt, que promueve su retención en el citoplasma (Baldin et al., 2003). Durante la transición G2/M, hCdc25B ha de localizarse en los centrosomas y sus inmediaciones, en donde inicia la activación de los complejos Cdk1-Ciclina B1 (Cazales et al., 2005; Schmitt et al., 2006).

Por otra parte, la proteína hCdc25B es fosforilada en diversos residuos que promueven su unión a proteínas 14-3-3, dando lugar a la formación de un puente intramolecular que afecta a su localización subcelular y posiblemente a su actividad catalítica (Giles et al., 2003). Las principales quinasas implicadas en la fosforilación de dichos residuos, que regulan negativamente a hCdc25B, son Chk1, MAPKAP2/MK2, p38 y pEg3 (Bulavin et al., 2001; Davezac et al., 2002; Manke et al., 2005; Mirey et al., 2005; Lemaire et al., 2006; Schmitt et al., 2006).

\section{hCdc25A}

Respecto a la localización subcelular de hCdc25A, esta fosfatasa es principalmente nuclear (Hoffmann et al., 1994), si bien recientemente se ha demostrado que está continuamente variando entre el citoplasma y el núcleo, debido a la presencia de señales NLS y NES (Kallstrom et al., 2005).

Por otra parte, la interacción de hCdc25A con proteínas 14-3-3 y con la Ciclina B1 está controlada a través de la fosforilación de determinados residuos por Chk1 (Zhachos y Gillespie, 2007; Chen et al., 2003). En concreto, Chk1 fosforila a esta fosfatasa en dos residuos que promueven su unión a 14-3-3, $\operatorname{Ser}^{178}$ y $\mathrm{Thr}^{507}$, estando la fosforilación del último implicada en la inhibición de su interacción con los complejos Cdk1-Ciclina B1 durante interfase en un ciclo celular normal, y posiblemente, también en respuesta a determinados tipos de checkpoint (Chen et al., 2003). Además, Plk3 parece fosforilar también dos residuos de hCdc25A cercanos al extremo carboxilo (C-terminal), en la región de unión a Ciclina B1, cuya fosforilación se ha propuesto que podría favorecer su unión a ésta y su liberación de 14-3-3 en mitosis (Myer et al., 2005). 


\section{hCdc25C}

En células humanas, tanto en un ciclo celular normal, como en situaciones de daño al DNA, la fosforilación de hCdc25C en el residuo Ser $^{216}$ por parte de Chk1, Chk2 y/o C-Tak1 permite su unión a proteínas 14-3-3, promoviendo su retención en el citoplasma durante interfase. La disociación de estas proteínas a la entrada en mitosis es necesaria para que ocurran la activación y la rápida acumulación nuclear de hCdc25C, implicadas en la activación de los complejos Cdk1-Ciclina B1 (Peng et al., 1997; Matsuoka et al., 1998; Peng et al., 1998; Donzelli y Draetta, 2003). Para ello, durante mitosis la fosforilación en $\mathrm{Ser}^{216}$ de hCdc25C se encuentra bloqueada mediante la fosforilación de $\operatorname{Ser}^{214}$ por Cdk1Ciclina B1, mecanismo de regulación que parece ocurrir de forma similar también en el caso de hCdc25B (Bulavin et al., 2003; Boutros et al., 2006). Además, también se ha

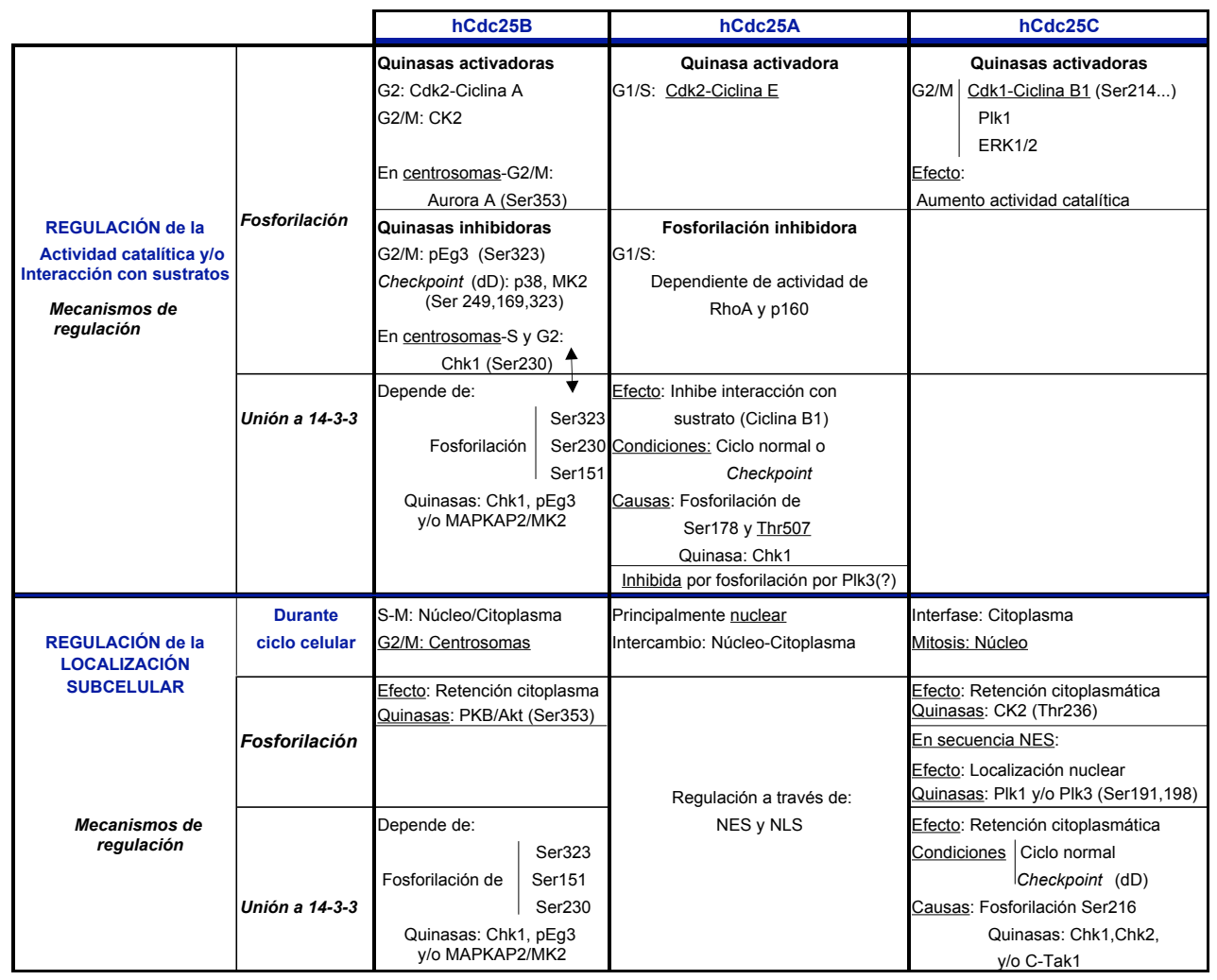

Tabla I-II. Regulación de la actividad y localización subcelular de las proteínas Cdc25 humanas durante el ciclo celular: mecanismos y proteínas implicados. La abreviatura dD indica que se trata de checkpoint de daño al DNA. La flecha de doble punta señala la relación entre esos dos mecanismos de regulación, ya que las quinasas inhibidoras fosforilan, entre otros, algunos de los residuos implicados en la unión a proteínas 14-3-3. También se han mencionado las secuencias NES y NLS. 
descubierto que la fosforilación de determinados residuos situados en la región NES por Plk1 y/o Plk3 promueve la localización nuclear de hCdc25C (Toyoshima-Morimoto et al., 2002; Bahassi el et al., 2004), mientras la fosforilación llevada a cabo por CK2, en residuos distintos de la $\mathrm{Ser}^{216}$, induce su retención citoplasmática (Schwindling et al., 2004). En la Tabla I-II se muestran los distintos mecanismos que regulan la actividad catalítica, localización y/o interacción con sustratos, de hCdc25B, hCdc25A y hCdc25C, indicando las quinasas y los procesos de fosforilación implicados en dicha regulación.

\section{Regulación de la entrada en mitosis por otras quinasas}

\subsection{Quinasas de la familia Polo, Plks, en la regulación de la entrada en mitosis}

Las proteínas de esta familia, las Plks (del inglés $\underline{P}$ olo Like Kinases), son quinasas de tipo Serina/Treonina. En mamíferos existen cuatro miembros de esta familia: Plk1, Plk2, Plk3 y Plk4, siendo la primera de ellas la más estudiada.

En la transición G2/M, Plk1 se localiza en los centrosomas y está implicada en su maduración, al promover la acumulación de $\gamma$-Tubulina en ellos, proceso necesario para la nucleación de los microtúbulos y la consiguiente formación del huso mitótico. Sin embargo, durante la mitosis Plk1 no se asocia sólo a los polos del huso mitótico, sino también a los cinetocoros, a los que han de unirse los microtúbulos durante el ensamblaje del huso mitótico para garantizar una correcta segregación cromosómica (Barr et al., 2004). Además, en vertebrados Plk1 fosforila determinadas subunidades de las Cohesinas (proteínas que mantienen la cohesión entre cromátidas hermanas) localizadas en los brazos de los cromosomas, lo que permite su disociación al inicio de mitosis (Hauf et al., 2005).

Por otra parte, Plk1 también participa en la activación de los complejos CDK mitóticos, como se ha mencionado en el apartado anterior. En este sentido, se ha descrito que Plk1 promueve la degradación de Wee1 (previamente fosforilada por Cdk1) (Elia et al., 2003; Watanabe et al., 2004) y fosforila e inactiva a Myt1 a la entrada de mitosis (Nakajima et al., 2003). Además, Plk1 interacciona con hCdc25C (previamente fosforilada por Cdk1) induciendo su activación y entrada en el núcleo, que también es promovida por Plk3 (Roshak et al., 2000; Toyoshima-Morimoto et al., 2002; Elia et al., 2003; Bahassi el et al., 2004; van Vugt y Medema, 2005). Por último, Plk1 parece estar implicada en la regulación de la localización nuclear de la Ciclina B1, aunque su efecto sobre dicha localización no es esencial (Toyoshima-Morimoto et al., 2001; Yuan et al., 2002; Jackman et al., 2003). La contribución de estos efectos de Plk1 a la regulación de la entrada en mitosis podría ser 
variable en función del tipo celular o la especie, ya que se ha descrito que células que carecen de Plk1 son capaces de entrar en mitosis (van Vugt et al., 2004).

Por otra parte, las quinasas Plk1 y Plk3 también están implicadas en rutas de checkpoint. Plk1 es inactivado en presencia de daño al DNA, mientras Plk3 parece encontrarse activado en estas condiciones (Xie et al., 2002; Jang et al., 2007). En caso de activación del checkpoint de "antefase", Plk1 puede ser ubiquitinada por la proteína Chfr, sin que esto promueva su degradación (Kang et al., 2002; Matsusaka y Pines, 2004).

Por último, cabe decir que la proteína Plk1 ejerce funciones esenciales durante la salida de mitosis y la citoquinesis (Petronczki et al., 2007).

\subsection{Quinasas de la familia Aurora en la regulación de la entrada en mitosis}

En células de mamíferos existen tres proteínas pertenecientes a esta subfamilia de quinasas Serina/Treonina, son Aurora A, Aurora B y Aurora C. Estas proteínas presentan estructuras similares, pero difieren en su patrón de expresión, de localización subcelular y de activación, lo que finalmente conlleva distintas funciones en la regulación de mitosis (Meraldi et al., 2004).

La quinasa Aurora A, que ejerce su acción principalmente en la transición G2/M, se localiza en centrosomas durante interfase, y en los extremos de los microtúbulos cercanos a los polos del huso mitótico y en los propios polos tras la ruptura de la envoltura nuclear (Barr y Gergely, 2007). Por su parte, Aurora B alcanza su máximo de actividad a la salida de mitosis, estando durante esta fase asociada inicialmente a los cinetocoros y centrómeros de los cromosomas, y localizándose más tarde en la zona central del huso mitótico (Shannon y Salmon, 2002). Por último, Aurora C sólo se ha descrito en mamíferos, y su expresión parece estar restringida a testículos y ciertas células tumorales en las que se localiza en los polos del huso mitótico al final de mitosis (Meraldi et al., 2004).

La proteína Aurora A desempeña un papel esencial en la transición G2/M a través de la regulación de los centrosomas, el ensamblaje del huso mitótico y la activación de los complejos CDK mitóticos (Fu et al., 2007). De este modo, la quinasa Aurora A participa en la maduración de centrosomas, por medio del reclutamiento y/o fosforilación de proteínas como la $\gamma$-Tubulina, permitiendo la nucleación de los microtúbulos al final de G2 (Hannak et al., 2001; Mori et al., 2007). También está implicada en la regulación de la separación de los centrosomas durante G2/M (Marumoto et al., 2003) y en la ruta de Ran que regula el ensamblaje del huso mitótico en prometafase (Fu et al., 2007). Además, como hemos 
mencionado anteriormente, la quinasa Aurora A también participa en la activación de los complejos Cdk1-Ciclina B1 en la transición G2/M, promoviendo su localización en centrosomas y la activación de la fracción de hCdc25B localizada en los mismos (Hirota et al., 2003; Dutertre et al., 2004; Cazales et al., 2005).

Por otra parte, Aurora B está implicada en modificaciones de cromatina relacionadas con el inicio de la condensación cromosómica, en la regulación de la unión de los cromosomas al huso mitótico y, ya a la salida de mitosis, en el checkpoint del huso mitótico y en la citoquinesis (Fu et al., 2007). Respecto a su efecto sobre la condensación cromosómica, Aurora B es la principal quinasa encargada de la fosforilación de la Histona $\mathrm{H} 3$ en el residuo $\mathrm{Ser}^{10}$, condición necesaria para que se inicie la condensación, aunque no para su mantenimiento (Van Hooser et al., 1998; Hsu et al., 2000; Giet y Glover, 2001; Crosio et al., 2002). Además, esta quinasa también fosforila la variante de la Histona $\mathrm{H} 3$ asociada a centrómeros, CENP-A, lo que permite que la unión entre los microtúbulos y los cinetocoros ocurra de forma adecuada (Kunitoku et al., 2003). Por último, Aurora B, al igual que Plk1, también participa al inicio de mitosis en la fosforilación de una subunidad de la Cohesinas en los brazos de los cromosomas, promoviendo su disociación de los mismos (Gimenez-Abian et al., 2004; Hauf et al., 2005).

\subsection{Quinasas de la familia NIMA, proteínas Nek, en la regulación de la entrada en mitosis}

Reciben este nombre de la proteína codificada por el gen NIMA (del inglés Never $\underline{\text { In }}$

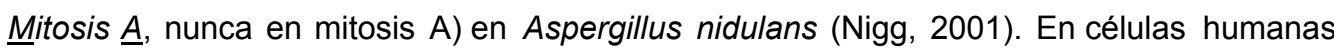
se han identificado 11 homólogos distintos, de los cuales al menos Nek2, Nek6, Nek7 y Nek9 parecen estar implicados en la regulación de la mitosis (O'Connell et al., 2003; O'Regan et al., 2007).

Nek2 presenta perfiles de expresión y actividad dependientes del ciclo celular, siendo su expresión máxima en fase S y G2 (O'Regan et al., 2007). Además, durante la transición G2/M esta quinasa es un componente de MTOC (del inglés Microtubule organizing Center, centro organizador de microtúbulos) y participa en la separación de los centrosomas (Fry et al., 1998). A nivel molecular, se ha descrito que Nek2 es capaz de fosforilar e inactivar a la fosfatasa PP1 a la entrada en mitosis (Eto et al., 2002) y puede participar en la regulación del reclutamiento de Plk1 a los centrosomas (O'Regan et al., 2007).

En cuanto a Nek9, sus niveles de expresión permanecen constantes durante el ciclo celular, pero su activación depende de su fosforilación en mitosis. Esta forma activa se 
concentra en los polos del huso mitótico, participando posiblemente en la organización de éste (Roig et al., 2005; O'Regan et al., 2007).

\subsection{Chk1 en la regulación de la entrada en mitosis}

En las células de vertebrados la proteína Chk1 es un componente esencial en la activación de muchos tipos de checkpoint. Sin embargo, esta quinasa también parece desempeñar funciones importantes en la regulación de un ciclo celular normal (Zachos et al., 2003; Zachos y Gillespie, 2007). En este sentido, se ha demostrado que durante interfase Chk1 se localiza en los centrosomas, donde previene la activación prematura de Cdk1 a través de la fosforilación de hCdc25B (Kramer et al., 2004; Schmitt et al., 2006). Además, Chk1 también parece inhibir la actividad de hCdc25A sobre los complejos Cdk1Ciclina B1, por medio de la fosforilación de determinados residuos, que conlleva su consiguiente unión a proteínas 14-3-3 y la inhibición de su interacción con la Ciclina B1 (Chen et al., 2003). 


\section{REGULACIÓN DE LA SALIDA DE MITOSIS: DESDE ANAFASE HASTA CITOQUINESIS}

A continuación, consideraremos la salida de mitosis como todos aquellos procesos que tienen lugar durante las últimas etapas de la mitosis, desde el comienzo de la segregación de los cromosomas duplicados gracias a la acción del huso mitótico (anafase), el posterior desensamblaje del huso mitótico y descondensación de los cromosomas en cada una de las células hijas (telofase), hasta la citoquinesis.

Si bien una elevada actividad CDK mitótica ha sido necesaria para la entrada en mitosis y la progresión por sus primeras fases (hasta alcanzar metafase), la salida de mitosis se caracteriza por una bajada drástica de esta actividad CDK.

Al igual que en las primeras fases de la mitosis, para que la salida de mitosis se produzca adecuadamente, los distintos procesos que la componen han de ocurrir en un orden estricto. Se considera que hay dos mecanismos principales que gobiernan la progresión a través de estas últimas etapas de la mitosis: la desfosforilación ordenada de sustratos fosforilados principalmente por Cdk1 (aunque también por otras quinasas mitóticas) y la destrucción también ordenada de proteínas por el complejo APC/C. Así, el modelo propuesto por Matt Sullivan y David O. Morgan considera que el orden en el que

\section{I TO S I S}

G2 (antefase) Profase Prometafase Metafase Anafase Telofase G1

Inactivación de quinasas mitóticas

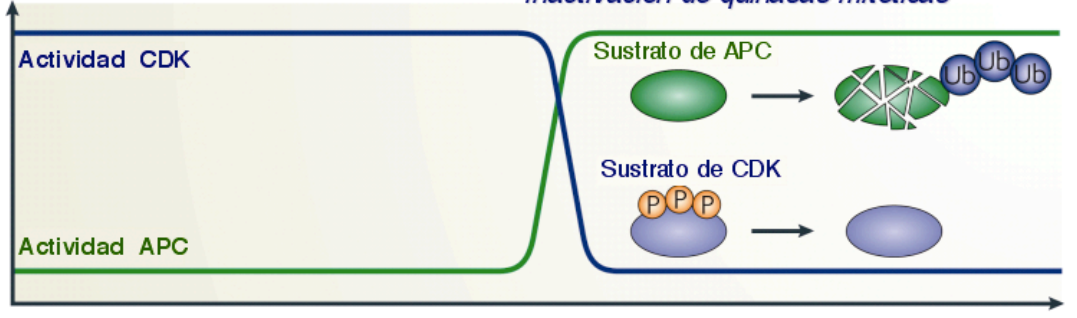

Figura 1-7. Regulación de la salida de mitosis. En la parte superior se muestran las distintas fases de mitosis a las que corresponden las condiciones indicadas en el esquema inferior. Las fases tempranas de la mitosis se caracterizan por una elevada actividad de los complejos CDK mitóticos y una baja actividad del complejo APC. Durante la transición metafase/anafase se produce un aumento de la actividad asociada al complejo APC, responsable de la ubiquitinación de determinadas proteínas y de su degradación vía proteasoma. Por otro lado, la inactivación de los complejos Cdk en este punto de mitosis permite la desfosforilación de sus sustratos por parte de fosfatasas específicas al final de la mitosis. Ambos mecanismos regulan la progresión por las últimas fases de mitosis y el comienzo de un nuevo ciclo celular. Este esquema ha sido modificado a partir de la revisión de Sullivan y Morgan, 2007. 
los distintos sustratos de Cdk1 y APC son desfosforilados y degradados respectivamente, marca a su vez el orden en el cual ocurren los procesos que conducen a la salida de mitosis (Sullivan y Morgan, 2007) (Fig. I-7).

En la levadura $S$. cerevisiae, existe una importante ruta de regulación de la salida de mitosis y quizás también de citoquinesis, MEN (del inglés Mitotic Exit Network, ruta reguladora de la salida de mitosis), en la que se integran una serie de proteínas, entre las cuales se encuentra Cdc14, proteína esencial que desfosforila diversos sustratos de CDK a la salida de mitosis. En el caso de $S$. pombe se ha descrito una ruta similar llamada SIN (del inglés Septation Initiation Network, ruta de inicio de la septación) que garantiza que la citoquinesis (septación) ocurra tras la correcta segregación cromosómica, y en la cual también se integra la proteína Cdc14, en este caso denominada Flp1/Clp1 (Bardin y Amon, 2001).

\section{Inicio de la anafase}

En la levadura S. cerevisiae se ha demostrado que un paso clave para la segregación cromosómica es la activación de la Separasa (Esp1), que es una proteasa que degrada a la Cohesina (Scc1), proteína responsable de la cohesión entre cromátidas hermanas (Michaelis et al., 1997; Uhlmann et al., 1999). La activación de la Separasa no debe ocurrir antes de que todos los cromosomas estén correctamente orientados en el huso mitótico, por lo que la Separasa está inhibida hasta ese momento por una chaperona, la Securina (Pds1) (Ciosk et al., 1998). Tras el alineamiento de los cromosomas, la Securina es ubiquitinada por APC/C y degradada, dando lugar a la liberación y activación de la Separasa (Ciosk et al., 1998). En la levadura de fisión S. pombe existe un mecanismo de regulación similar basado en la Separasa (Cut1) y en la Securina (Cut2) (Yanagida, 2000).

Los mecanismos que regulan la pérdida de cohesión entre cromátidas hermanas están muy conservados en células de vertebrados, siendo también necesaria la Separasa para la segregación de cromátidas hermanas, que se encuentra inhibida por la Securina hasta ese momento (Kumada et al., 2006; Wirth et al., 2006). Sin embargo, a diferencia de lo que ocurre en levaduras, en células de vertebrados la mayor parte de la cohesión es eliminada durante profase (Losada et al., 1998; Waizenegger et al., 2000), a través de la fosforilación por Plk1 y Aurora B de la subunidad SA2 de la Cohesina, que induce su disociación de los cromosomas (Sumara et al., 2002; Gimenez-Abian et al., 2004; Hauf et al., 2005). En este proceso parte de la Cohesina, principalmente la situada en los centrómeros de los cromosomas, es protegida por la proteína Sgo1 para evitar que la separación de las cromátidas se produzca antes de anafase (Salic et al., 2004). Por otra 
parte, en células humanas la Securina no parece ser el único mecanismo que previene la activación prematura de la Separasa, puesto que no es esencial para mantener la cohesión de las cromátidas (Mei et al., 2001; Pfleghaar et al., 2005), y dado que también se ha descrito que la Ciclina B1 puede ejercer una función inhibidora sobre la Separasa (Gorr et al., 2005; Holland y Taylor, 2006).

\section{Inactivación de los complejos CDK mitóticos}

Como ya hemos mencionado, la activación de los complejos CDK mitóticos en células humanas depende de la asociación de Cdk1 en primer lugar a la Ciclina A, la cual se degrada durante prometafase, y posteriormente a la Ciclina B1, que permite la progresión hasta el final de metafase. La degradación de la Ciclina B1 coincide con el inicio de anafase y ha sido considerada necesaria para la salida de mitosis (Clute y Pines, 1999; Wolf et al., 2006). En este sentido, en células humanas se ha observado que distintos niveles de Ciclina B1 no degradable dan lugar a la parada de las células en distintas etapas de mitosis, lo que sugiere un modelo según el cual distintos niveles de actividad Cdk1 son necesarios para fosforilar e inhibir diversas proteínas reguladoras de la salida de mitosis, que actúan de forma secuencial (Clute y Pines, 1999; Wolf et al., 2006; Wolf et al., 2007).

En cualquier caso, existe cierta controversia acerca de si la degradación de las Ciclinas mitóticas resulta esencial a la salida de mitosis en células humanas o no. Así, por un lado Potapova et al. consideran que la degradación de la Ciclina B1 aporta direccionalidad e irreversibilidad a la transición $M / G 1$, puesto que la inhibición de la actividad Cdk1 en ausencia de degradación de la Ciclina B1 sólo permite la salida de mitosis de forma reversible (Potapova et al., 2006). Por otro lado, recientemente Skoufias et al. concluyen que los reguladores esenciales de la salida de mitosis son la actividad fosfatasa y la actividad proteasa, independientemente de que se produzca o no la degradación de la Ciclina B1 o la Securina, lo que podría indicar la existencia de otro sustrato esencial del proteasoma al final de mitosis (Skoufias et al., 2007).

\section{Desfosforilación ordenada de sustratos de Cdk1}

A pesar de la importancia que parece tener este proceso a la salida de mitosis, sólo algunos de estos sustratos han sido identificados, y se sabe poco respecto a su relación con procesos concretos de la mitosis tardía y al orden en el que ocurre su desfosforilación. 


\subsection{Sustratos desfosforilados a la salida de mitosis}

Sustratos desfosforilados antes de anafase: En $S$. cerevisiae la Separasa es desfosforilada antes de anafase. En Xenopus, Cdk1 fosforila a la Separasa al inicio de mitosis, participando en la inhibición de su actividad proteasa, por lo que su desfosforilación unida a la degradación de la Securina y posiblemente a la de la Ciclina B1, favorecen la entrada en anafase (Stemmann et al., 2001). La fosforilación de la Separasa en células humanas es llevada a cabo por complejos Cdk1-Ciclina B1, que además se asocian a la Separasa, lo que a su vez impide tanto la actividad proteasa de esta última, como la propia actividad quinasa de los complejos (Gorr et al., 2005). La fosfatasa que desfosforila a la Separasa al final de metafase no ha sido identificada por el momento.

Sustratos en la anafase temprana: En S. cerevisiae, un sustrato importante de CDK es INCENP, cuya desfosforilación por Cdc14, activado a su vez por la Separasa (Esp1), se relaciona con su traslado desde los cinetocoros hasta la zona central del huso mitótico, donde promueve la estabilidad de éste (Stegmeier et al., 2002; Pereira y Schiebel, 2003). En células humanas, parece que hCdc14A realiza una función similar a la de Cdc14 a través de la desfosforilación de INCENP, también relacionada con su traslado desde los cinetocoros a la zona central del huso (Gruneberg et al., 2004).

Sustratos en la anafase tardía: En S. cerevisiae, Hct1/Cdh1 (activador del complejo APC), Sic1 (inhibidor de complejos Cdk) y Swi5 (factor de transcripción que permite la expresión de Sic1 y Cdc6, entre otros genes) son sustratos de CDK que han de ser desfosforilados por Cdc14 durante anafase, lo que promueve la acumulación de Sic1, y la actividad de Cdh1 y Swi5 a través de su entrada al núcleo (Visintin et al., 1998; Jaspersen et al., 1999; Sullivan y Morgan, 2007).

Desfosforilación de sustratos en mitosis tardía: Muchos sustratos de Cdk1 implicados en la regulación del huso mitótico, la condensación cromosómica o la ruptura de la envoltura nuclear han de ser desfosforilados para revertir estos procesos en telofase. No se conoce el mecanismo por el que determinados sustratos de Cdk1 permanecen todavía fosforilados hasta ese momento, siendo lo más probable que fosfatasas específicas se encuentren implicadas en su desfosforilación (Sullivan y Morgan, 2007). 


\subsection{Posibles fosfatasas implicadas en la desfosforilación de sustratos de Cdk1}

Las fosfatasas encargadas de desfosforilar a los distintos sustratos de Cdk1 a la salida de mitosis pueden ser fosfatasas generales (como PP1 o PP2A) o específicas (como las proteínas Cdc14).

PP1 y PP2A son complejos con actividad fosfatasa sobre residuos Serina o Treonina que presentan una o varias subunidades reguladoras que afectan a su localización subcelular y/o a su especificidad de sustrato (Trinkle-Mulcahy y Lamond, 2006).

\section{PP2A}

Esta fosfatasa está consituída por un complejo trimérico, que puede ser regulado mediante fosforilación y metilación (Trinkle-Mulcahy y Lamond, 2006). PP2A puede participar en la regulación de la segregación cromosómica en anafase en células humanas, puesto que interacciona con Sgo1 y promueve su localización en centrómeros posiblemente a través de la desfosforilación de residuos fosforilados por Plk1 (Kitajima et al., 2006; Riedel et al., 2006; Tang et al., 2006). Además, estudios realizados en levaduras sugieren que PP2A también es capaz de proteger a la Cohesina de forma independiente de Sgo1 (Kitajima et al., 2006; Riedel et al., 2006).

Por otra parte, en S.cerevisiae se ha descrito un importante papel de PP2A (Cdc55) a la salida de mitosis, promoviendo la retención de Cdc14 en el nucléolo, y por lo tanto previniendo la salida de mitosis (Wang y $\mathrm{Ng}, 2006$ ). Este efecto es contrarrestado por la inhibición directa de PP2A por la Separasa, permitiendo la salida de mitosis (Queralt et al., 2006). Mientras, en mamíferos se ha descrito que el complejo PP2A parece estabilizar directa o indirectamente los niveles de la proteína Securina hipofosforilada (Gil-Bernabe et al., 2006), además de regular negativamente a hCdc25C a la salida de mitosis (Forester et al., 2007).

\section{PP1}

PP1 presenta 3 isoformas en células humanas con alta homología entre ellas, $\alpha, \beta / \delta$ y $\gamma$, cuyos patrones de localización subcelular a lo largo del ciclo son muy distintos, lo que sugiere diversidad en sus funciones (Trinkle-Mulcahy y Lamond, 2006).

PP1 parece tener un importante papel en el mantenimiento de la estructura de los cromosomas a partir de la transición metafase/anafase y posiblemente en su descondensación al final de mitosis (Landsverk et al., 2005; Vagnarelli et al., 2006). Además, se ha descrito que PP1 también participa en la formación de la envoltura nuclear al final de mitosis a través de la desfosforilación de Láminas de tipo B en telofase (Steen 
et al., 2000; Steen et al., 2003). Por último, a raíz de las diversas localizaciones de las isoformas de PP1 en mitosis y de los efectos del silenciamiento de la expresión de esta fosfatasa, se deduce su implicación en otros procesos al final de mitosis, aunque se desconocen los sustratos sobre los que actuaría.

\section{Cdc14}

Puesto que las fosfatasas de esta familia son el objeto de nuestro estudio hablaremos de ellas con más detalle al final de esta Introducción.

\section{Degradación de proteínas por el complejo APC/C}

Como se ha demostrado en varios estudios, la degradación ordenada de diversas proteínas por el proteasoma parece esencial para que tenga lugar la correcta salida de mitosis en células eucariotas.

La degradación de proteínas durante la mitosis parece estar regulada principalmente por un complejo ubiquitín-ligasa, el complejo ACP/C, que poliubiquitina proteínas, marcándolas de este modo para su destrucción por parte del proteasoma $26 \mathrm{~S}$ (gran complejo proteasa). La importancia de la función desempeñada por APC/C en mitosis se pone de manifiesto al demostrarse que su inactivación genética es letal en todas las especies en las que se ha investigado, desde levaduras a ratones (Wirth et al., 2004).

Dada la importancia de una activación apropiada de APC durante mitosis, su función es regulada mediante diversos mecanismos. Hasta iniciarse la anafase, su actividad está regulada por su unión al co-activador Cdc20, que se expresa ya durante las fases S y G2 pero sólo se asocia a APC en mitosis, tras la fosforilación de varias subunidades de APC por las quinasas mitóticas Cdk1 y Plk1 (Kramer et al., 2000; Golan et al., 2002). Después, en anafase, Cdc20 es degradado por el propio APC unido a otro co-activador, APC ${ }^{\text {Cdh1 }}$ (Prinz et al., 1998; Sorensen et al., 2000; Huang et al., 2001). Por contraste, la interacción entre APC/C y este segundo co-activador, Cdh1, es inhibida por la fosforilación de éste llevada a cabo por diferentes Cdks durante fase S, G2 y mitosis temprana (Zachariae et al., 1998; Jaspersen et al., 1999; Blanco et al., 2000; Kramer et al., 2000). Ello permite que la actividad de $\mathrm{APC}^{\mathrm{Cdc20}}$ se mantenga hasta que comienza a reducirse la actividad de Cdk1, al iniciarse la degradación de Ciclinas mitóticas. La asociación de APC con Cdh1 está favorecida por la desfosforilación de este co-activador por fosfatasas como Cdc14 en S. cerevisiae (Visintin et al., 1998; Jaspersen et al., 1999), y quizás por hCdc14A en células humanas a juzgar por datos obtenidos in vitro (Bembenek y Yu, 2001). La actividad del complejo APC ${ }^{\text {Can1 }}$ gobierna las últimas fases de mitosis y su inactivación se 
produce durante la transición G1/S (Kramer et al., 2000; Peters, 2006). En levaduras este proceso depende de complejos $\mathrm{CDK}$ de fase $\mathrm{S}$ que fosforilan $\mathrm{Hct} 1 / \mathrm{Cdh} 1$ previniendo su interacción con APC/C (Huang et al., 2001), pero en células humanas su regulación parece ser más complicada (Lukas et al., 1999a).

Ambos co-activadores, Cdc20 y Cdh1, poseen un dominio C-terminal WD40 (rico en residuos Triptófano y Ácido aspártico) que reconoce sustratos a través de su interacción con regiones de tipo D-boxes y KEN-boxes (Pfleger y Kirschner, 2000; Peters, 2006). Sin embargo, Cdc20 y Cdh1 presentan especificidad por distintos sustratos, posiblemente a consecuencia de que las secuencias de tipo KEN-box son reconocidas por Cdc20 pero no por Cdh1 (Pfleger y Kirschner, 2000), y/o por la existencia de sutiles diferencias en las secuencias de tipo D-box reconocidas por cada uno de estos co-activadores.

\subsection{Orden de degradación por $A P C^{C d c 20}$ de diversos sustratos, regulado por el checkpoint de huso mitótico}

En S. cerevisiae, los sustratos principales de $\mathrm{APC}^{\mathrm{Cdc20}}$ son la Securina y Clb5, los cuales se degradan simultáneamente antes de anafase. En células humanas, algunos sustratos de $\mathrm{APC}^{\mathrm{Cdc20}}$ son degradados durante prometafase, como la Ciclina A y la quinasa Nek2A (den Elzen y Pines, 2001; Geley et al., 2001; Hames et al., 2001; Hayes et al., 2006), y otros como la Securina y la Ciclina B1 no se degradan hasta metafase (Clute y Pines, 1999; Hagting et al., 2002). Este orden depende de un sistema de regulación, el denominado checkpoint de huso mitótico, que impide la degradación de la Securina y la Ciclina B1 hasta que los cromosomas están correctamente unidos al huso mitótico (Musacchio y Salmon, 2007).

\subsection{Orden de degradación de sustratos por $A P C^{C d h 1}$}

En células humanas, se sabe que $A P C^{\mathrm{Cdh} 1}$, ya en anafase degrada en primer lugar a Cdc20, seguido de Plk1, Aurora A y por último Aurora B (Lindon y Pines, 2004; Pines, 2006; Sullivan y Morgan, 2007). Posibles explicaciones de este orden, son diferencias en la eficiencia de poliubiquitinación de los distintos sustratos (Rape et al., 2006), o determinados cambios tanto en el estado de fosforilación como en la localización subcelular de los distintos sustratos, que afectan a su reconocimiento por APC (Huang y Raff, 1999; Mailand y Diffley, 2005).

Puesto que Cdh1 no parece ser esencial para la viabilidad de las células, quizás este orden en la degradación de sus sustratos no sea esencial, aunque probablemente permita garantizar la adecuada progresión por las últimas fases de la mitosis. 


\section{FOSFATASAS DE LA FAMILIA Cdc14}

Puesto que las proteínas hCdc14s presentan un dominio catalítico de tipo PTP (del inglés Protein-Tyrosine $\underline{P}$ hosphatases, fosfatasas proteína-tirosina), se incluyen en la superfamilia de las fosfatasas de tipo "Proteína-Tirosina". Dentro de esta superfamilia son consideradas "fosfatasas de especificidad dual" por su capacidad para desfosforilar sustratos con residuos fosfo-tirosina y fosfo-serina o fosfo-treonina, fosforilados por CDK o MAPK (Gray et al., 2003; Ducruet et al., 2005). Todos los miembros de esta familia desempeñan pues funciones relacionadas con la regulación del ciclo celular, que implican su papel como antagonistas de la actividad CDK. Si bien, dado el papel central de los complejos CDK en la regulación del ciclo celular las distintas proteínas de la familia Cdc14 pueden controlar muy diversos procesos a lo largo de éste. En la Figura I-8 se muestran de forma esquemática los dominios principales presentes en las distintas fosfatasas de la familia Cdc14.
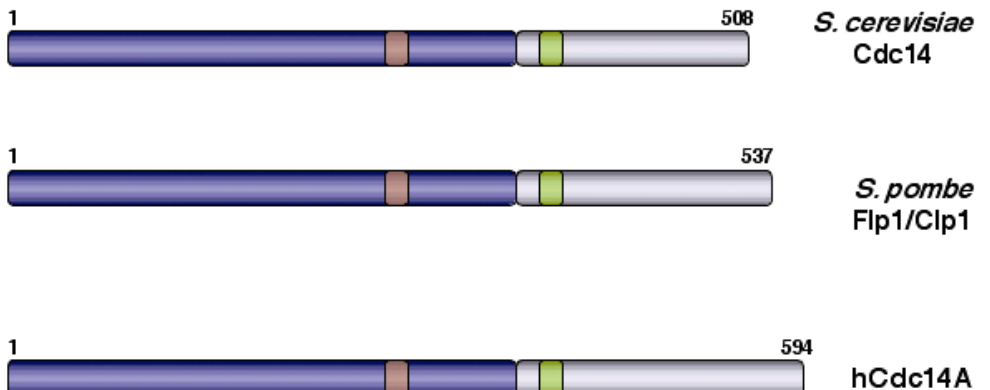

Secuencia de

localzación nucleola

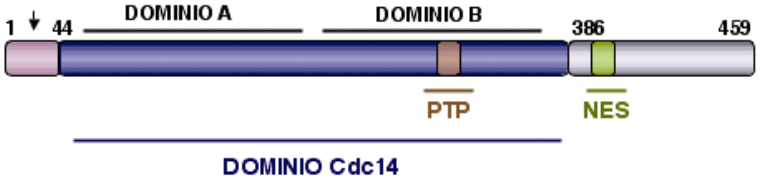

hCdc14B

DOMINIO Cdc14

Figura I-8. Relación estructural entre las proteínas de la familia Cdc14. En la figura se muestran esquemas de la estructura primaria de las proteínas Cdc14 de levaduras (Cdc14 y Flp1/Clp1) y de células humanas (hCdc14A y hCdc14B). El dominio altamente conservado de las proteínas Cdc14 (350 aminoácidos aproximadamente) se representa en color violeta. Dentro de esta región se han identificado dos dominios A y B, que son estructuralmente equivalentes. También hemos señalado el dominio catalítico de tipo PTP y la región de exportación nuclear NES (color verde). La secuencia de localización nucleolar de la proteína hCdc14B en el extremo amino se ha marcado con color rosa. Esta figura está basada en el esquema mostrado en el artículo de Gray et al.,2003. 


\section{Cdc14 en S. cerevisiae}

Cdc14 es una proteína esencial en la levadura $S$. cerevisiae que, como efector de la ruta MEN, permite la coordinación de distintos procesos a la salida de mitosis a través de la inhibición de la actividad CDK mitótica (Bardin y Amon, 2001). La proteína Cdc14 se encuentra confinada en el nucléolo hasta el inicio de anafase, momento en el que comienza la liberación de parte de esta proteína, promovida por la ruta FEAR (del inglés Fourteen Early Anaphase Release, liberación de Cdc14 en anafase temprana) (Stegmeier et al., 2002; Azzam et al., 2004). Esta primera etapa de liberación y activación de Cdc14 induce, por medio de la desfosforilación de determinados sustratos de CDK, procesos importantes para la anafase. En este sentido, Cdc14 parece ejercer un papel esencial en la regulación del huso mitótico a través de la desfosforilación del complejo Sli5-INCENP (Aurora B-INCENP), que permite su localización en la zona central del huso en anafase (Pereira y Schiebel, 2003), y a través de la desfosforilación de otras proteínas implicadas en la regulación del huso mitótico, como Ase1 y Ask1 (Higuchi y Uhlmann, 2005; Khmelinskii et al., 2007). Además, Cdc14 promueve la activación de la ruta MEN, necesaria para la completa liberación y activación de esta proteína durante anafase (Jaspersen et al., 1998; Shou et al., 1999; Bardin et al., 2000; Jensen et al., 2002). Así, al final de anafase, Cdc14 induce la inactivación de los complejos CDK mitóticos, requisito necesario para la salida de mitosis, a través de la desfosforilación de varios sustratos de los propios complejos CDK, como Hct1/Cdh1, lo que conlleva la degradación de las Ciclinas mitóticas mediada por APC ${ }^{\text {Hct }}$, y como Swi5 y Sic1, promoviendo un aumento de la expresión y la estabilización del propio CKI Sic1 (Visintin et al., 1998; Jaspersen et al., 1999).

\section{Flp1/Clp1}

Flp1 (del inglés Fourteen-like phosphatase 1), también denominada Clp1 (del inglés $\underline{C} d c$-Fourteen-like protein 1), no es una proteína esencial en la levadura S. pombe (Cueille et al., 2001; Trautmann et al., 2001), sin embargo desempeña una importante función a la salida de mitosis, probablemente coordinando la división nuclear y la citoquinesis, a través de la desfosforilación y consiguiente degradación de la proteína Cdc25, activador esencial de los complejos CDK mitóticos en S. pombe (Esteban et al., 2004; Wolfe y Gould, 2004). Además, la proteína Flp1 es necesaria para el checkpoint de citoquinesis (Trautmann et al., 2001; Trautmann y McCollum, 2005), y algunos autores consideran que también para la correcta segregación cromosómica (Trautmann et al., 2004). Recientemente, se ha demostrado que Flp1 además está implicado en el checkpoint de replicación, de modo 
que su localización subcelular se ve alterada de forma dependiente de su fosforilación por Cds1 (Chk2) en respuesta a estrés replicativo (Diaz-Cuervo y Bueno, 2008).

La fosfatasa Flp1 se localiza en el nucléolo y en el SPB (del inglés Spindle Pole $\underline{B}$ ody, cuerpo polar del huso, análogo del centrosoma de células humanas) durante interfase, y en el núcleo, huso mitótico y anillo medial durante la mitosis (Cueille et al., 2001). A diferencia de Cdc14 de S. cerevisiae, Flp1 es liberado desde el nucléolo a la entrada en mitosis, en profase, por un mecanismo aún desconocido (Cueille et al., 2001; Trautmann et al., 2001), si bien parece que su actividad puede encontrarse atenuada hasta anafase debido a su fosforilación por Cdc2 (Wolfe et al., 2006). Se ha descrito también que la localización de Flp1 en los cinetocoros y el huso mitótico durante mitosis puede ser necesaria para evitar defectos en la segregación cromosómica (Trautmann et al., 2004). Por otra parte, Flp1 se mantiene fuera del nucléolo hasta que ha finalizado la citoquinesis en cuya regulación participa gracias a la ruta SIN (del inglés Septation Initiation Network, ruta de inicio de la septación o citoquinesis, homóloga de MEN) (Cueille et al., 2001; Mishra et al., 2005).

\section{CeCDC14}

La proteína CeCDC14 se consideró inicialmente esencial para que ocurra la citoquinesis en embriones de C. elegans (Gruneberg et al., 2002). Esta proteína se encuentra localizada en la zona central del huso mitótico durante anafase y en el cuerpo medio en telofase, donde parece estar implicada en la estabilización de esa zona del huso y en la regulación de la localización de la cinesina ZEN-4, hechos de los que a su vez dependerá que la citoquinesis se produzca de forma adecuada (Williams et al., 1995; Adams et al., 1998; Raich et al., 1998). De este modo, CeCDC14 co-localiza en la zona central del huso con la cinesina ZEN-4 (su ortólogo en células humanas es Mklp1), siendo la localización de cada una de estas proteínas dependiente de la otra. Además, la localización y función de ZEN-4/Mklp1 es inhibida por la fosforilación de Cdk1-Ciclina B1, la cual podría ser revertida por CeCDC14 (Gruneberg et al., 2002; Mishima et al., 2004).

Posteriormente, otros autores han descrito que Ce-CDC14 no parece ser esencial para la mitosis, aunque ejerce una importante función promoviendo una parada en G1 a través de la regulación de CKI-1 (p27 en células humanas), posiblemente induciendo su acumulación en un estado hipofosforilado y estable. De nuevo esta función podría estar regulada a través de su localización subcelular, pues en estas células paradas en G1 CeCDC14 se acumula en el citoplasma (Kipreos, 2004; Saito et al., 2004). 


\section{XCdc14s}

En células de Xenopus laevis se han identificado dos proteínas Cdc14, XCdc14A $(\alpha / \beta)$ y XCdc14B (Kaiser et al., 2004; Krasinska et al., 2007). XCdc14A se considera esencial para el ciclo de división celular, dado que la inyección de anticuerpos frente a dicha proteína bloquea la división celular en embriones de Xenopus. XCdc14A $(\alpha / \beta)$ se localiza en el nucléolo y en el centrosoma durante interfase, permaneciendo en ambos centrosomas durante la mitosis. Además, los niveles proteicos de XCdc14A $(\alpha)$ permanecen estables a lo largo del ciclo celular, si bien esta proteína parece estar regulada mediante fosforilación a la entrada en mitosis (Kaiser et al., 2004). La sobreexpresión de XCdc14A parece afectar a la capacidad de los centrosomas para la nucleación de los microtúbulos, e induce un retraso en la transición G2/M en células humanas (HeLa) y extractos de oocitos de Xenopus, posiblemente a través de la desfosforilación de proteínas Cdc25. Por otra parte, la sobre-expresión de XCdc14A también afecta a la citoquinesis y a la transición G1/S (Krasinska et al., 2007).

\begin{tabular}{|c|c|c|c|c|c|}
\hline & S. cere visiae & S. pombe & C.elegans & $X$ laevis & H. sapiens \\
\hline Nombre & Cdc14 & Flp1/Clp1 & $\mathrm{Ce} C D C 14$ & XCdc14 & $\begin{array}{l}\text { hCdc14A } \\
\text { hCdc14B }\end{array}$ \\
\hline $\begin{array}{l}\text { Localización } \\
\text { Interfase }\end{array}$ & Nucledar & $\begin{array}{c}\text { Nucledar } \\
\text { SPB }\end{array}$ & Difusa & $\begin{array}{c}\text { Nucledar } \\
\text { Centrosomas }\end{array}$ & $\begin{array}{l}\text { A: Centrosomas } \\
\text { B: Nucleolar }\end{array}$ \\
\hline \multicolumn{6}{|l|}{ Mitosis } \\
\hline $\begin{array}{l}\text { Funciones } \\
\text { mitóticas }\end{array}$ & $\begin{array}{l}\text { Salida de mitosis } \\
\text { Formación: zona } \\
\text { central huso } \\
\text { mitótico } \\
\text { Segregación IDNA }\end{array}$ & $\begin{array}{l}\text { Segregación } \\
\text { cromosómica } \\
\text { Orientación cinetocoros } \\
\text { Checkpoint Citoquinesis }\end{array}$ & $\begin{array}{l}\text { Formación: zona } \\
\text { central huso } \\
\text { Quiescencia G1 }\end{array}$ & $\begin{array}{l}\text { Transición G2/M } \\
\text { Citoquinesis }\end{array}$ & $\begin{array}{l}\text { A Ciclo centrosoma } \\
\text { Segregación cromosómica } \\
\text { Citoquinesis } \\
\text { B Estabilización microtúbulos } \\
\text { Estructura nuclear } \\
\text { Parada de ciclo: G1 }\end{array}$ \\
\hline
\end{tabular}

Figura I-9. Localización subcelular y funciones de las proteínas Cdc14 de distintas especies. En la figura se muestra la localización subcelular, durante interfase y mitosis, de las proteínas Cdc14 presentes en cinco especies de organismos eucariotas (S. cerevisiae, S. pombe, C. elegans, Xenopus laevis y $\mathrm{H}$. sapiens). Los núcleos se muestran en color verde, los centrosomas o SPB se muestran en rojo, los microtúbulos en rosa y los cromosomas en azul. La localización de Cdc14 está señalada en amarillo. Las funciones mitóticas de estas fosfatasas se indican en la parte inferior de la figura. Este esquema ha sido modificado a partir de la figura mostrada en la revisión de Trinkle-Mulcahy y Lamond, 2006. 


\section{Fosfatasas Cdc14 humanas}

En células humanas existen dos fosfatasas de la familia Cdc14, hCdc14A y hCdc14B, que comparten aproximadamente un $65 \%$ de identidad de secuencia, correspondiente principalmente a una región de unos 350 aminoácidos localizada en la región amino, muy conservada en esta familia de proteínas (Gray et al., 2003). Ambas proteínas hCdc14, al igual que los otros miembros de la familia, son "fosfatasas de especificidad dual", que presentan afinidad por residuos fosforilados por CDKs o MAPKs (Kaiser et al., 2002).

Los niveles proteicos y de actividad de hCdc14A y hCdc14B no parecen sufrir variaciones relevantes durante el ciclo celular (Kaiser et al., 2002), lo que indica que quizás su regulación pueda ocurrir a través de cambios en su localización subcelular, del mismo modo que son reguladas las fosfatasas de esta familia en otros organismos. En la Figura I-9 se puede observar un esquema comparativo de la localización subcelular de las distintas proteínas de la familia Cdc14 a lo largo del ciclo celular y de sus funciones en la regulación de éste.

\section{$\underline{\mathrm{hCdc} 14 \mathrm{~A}}$}

La proteína hCdc14A desempeña importantes funciones en la regulación del ciclo de división del centrosoma y también en la segregación cromosómica y la citoquinesis (Kaiser et al., 2002; Mailand et al., 2002a). De este modo, la sobre-expresión de esta fosfatasa induce la separación prematura de los centrosomas, la generación de husos mitóticos supernumerarios y la segregación anormal de los cromosomas, efectos que se asocian a inestabilidad genómica y, en consecuencia, a un incremento en la muerte celular. Por el contrario, el silenciamiento de la expresión de hCdc14A da lugar a defectos en la separación de los centrosomas duplicados y en la citoquinesis (Mailand et al., 2002a). Estas funciones de hCdc14A afectan al mantenimiento de la estabilidad genómica de las células, y por lo tanto, son coherentes con su posible intervención en procesos de carcinogénesis, hecho que se ve apoyado por la presencia de niveles anormales de esta proteína en diversos tipos de células tumorales (Paulsen et al., 2006).

Recientemente, también se ha relacionado la sobre-expresión de hCdc14A, y de forma más evidente la sobre-expresión de su extremo amino (que presenta mayor actividad catalítica) con un retraso de las células en la transición G2/M, previo a metafase (Yuan et al., 2007).

Desde que se identificaron las dos proteínas Cdc14 humanas (Li et al., 1997b) no se han descrito todavía muchos de sus sustratos fisiológicos que nos permitan conocer con más detalle las funciones concretas que desempeña esta fosfatasa en células humanas. 
No obstante, sí se ha demostrado que hCdc14A es capaz de desfosforilar una serie de sustratos de los complejos CDK, implicados en la regulación de mitosis, como: el supresor tumoral p53, cuya desfosforilación por hCdc14A (in vitro e in vivo) podría afectar a la regulación del ciclo de división del centrosoma (Li et al., 2000; Paulsen et al., 2006); Cdh1,

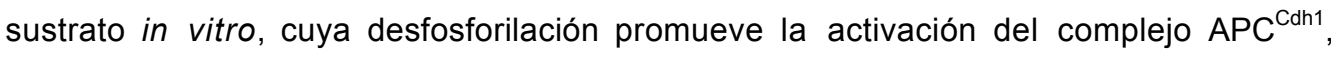
relacionada con la salida de mitosis (Bembenek y Yu, 2001), y Sirt2, una NADC (del inglés $\underline{N A D}$-dependent Deacetylase, desacetilasa dependiente de NAD) implicada en la regulación de mitosis, que es desfosforilada in vivo por hCdc14A, aunque no está claro cómo afecta esta modificación a su función (North y Verdin, 2007). Por otra parte, en estudios recientes la identificación de nuevos sustratos de hCdc14A pone de manifiesto la posible intervención de esta proteína en el control de otros procesos relacionados con la regulación del ciclo celular. De este modo, la desfosforilación por hCdc14A de la proteína

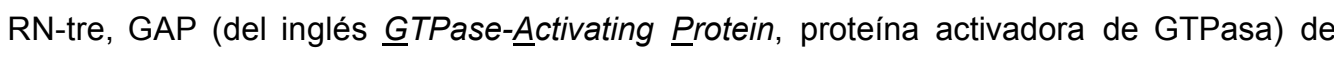
Rab5, sugiere la intervención de esta fosfatasa en la regulación de procesos de endocitosis (Lanzetti et al., 2007). Por otro lado, el efecto de hCdc14A sobre Erk3 (una MAPK atípica) parece promover la estabilización del complejo Erk3-Ciclina D3, lo que a su vez está implicado en la inducción de una parada del ciclo en G1 y en procesos de diferenciación celular, función similar a la desempeñada por CeCDC14 en C. elegans (Saito et al., 2004; Hansen et al., 2008).

Los mecanismos que regulan las funciones de hCdc14A no son muy conocidos, pero parecen afectar principalmente a su localización subcelular.

Durante interfase, la proteína hCdc14A se consideró inicialmente nuclear (Li et al., 1997b; Bembenek y Yu, 2001), aunque posteriormente se demostró que es principalmente centrosomal, gracias a la existencia de una región NES en su extremo carboxilo (Cterminal) (Bembenek y Yu, 2001; Mailand et al., 2002a) y quizás a su interacción con Plk1 (Yuan et al., 2007). Ya en la transición G2/M, hCdc14A comienza a disociarse de los centrosomas (Mailand et al., 2002a), aunque según otros autores se sigue manteniendo en éstos durante mitosis, además de localizarse en los centrómeros de los cromosomas posiblemente a consecuencia de su interacción con Plk1 (Yuan et al., 2007). A la salida de mitosis, durante anafase y telofase, hCdc14A, además de encontrarse en los polos del huso mitótico, también co-localiza con Plk1, el complejo INCENP-Aurora B y la cinesina MKIp2 en la zona central del huso mitótico. Mklp2 parece ser la responsable de la localización de estas proteínas en la zona central del huso, aunque hCdc14A a su vez induce, a través de la desfosforilación de INCENP, la localización del complejo INCENP- 
Aurora B en esa zona, condición necesaria para que la salida de mitosis y la citoquinesis ocurran de forma adecuada (Gruneberg et al., 2004).

Además de la regulación de hCdc14A a través de su localización subcelular, también su actividad catalítica puede ser modificada por medio de la fosforilación por parte de Plk1 de dos residuos de la proteína, $\operatorname{Ser}^{351}$ y $\operatorname{Ser}^{363}$ en la región carboxilo, lo que a su vez conlleva la disociación de un puente intramolecular, con un papel inhibidor, en esta fosfatasa (Yuan et al., 2007).

\section{$\underline{\mathrm{hCdc} 14 \mathrm{~B}}$}

Las funciones de esta fosfatasa aún son menos conocidas que las de la otra Cdc14 humana, hCdc14A. Se ha descrito que hCdc14B participa en la regulación de la dinámica del huso mitótico de forma independiente de su actividad catalítica, a través de su unión a los microtúbulos, promoviendo la agrupación y estabilización de éstos (Cho et al., 2005). Además, hCdc14B parece estar implicada, junto con la proteína Plk1, en el control de la arquitectura nuclear (Nalepa y Harper, 2004), y participa también en el control de la duración de G1 (Rodier et al., 2008) y en la regulación del ciclo de división del centrosoma (Wu et al., 2008). Por otra parte, recientemente se ha probado, mediante el análisis de células humanas $\mathrm{KO} \mathrm{hCdc} 14 \mathrm{~B}^{-/}$, que $\mathrm{hCdc} 14 \mathrm{~B}$ no parece ser esencial para la segregación cromosómica ni la citoquinesis (Berdougo et al., 2008).

Con respecto a los sustratos conocidos de esta proteína, inicialmente se identificó el supresor tumoral p53 como sustrato in vitro de hCdc14B (Li et al., 2000). Posteriormente, también se describió que hCdc14B desfosforila in vivo a Sirt2, NADC cuyos niveles proteicos se incrementan de forma importante durante mitosis y cuya fosforilación por parte de Cdk1-Ciclina B1 parece jugar un papel importante en la regulación de esta fase del ciclo. Sin embargo, el efecto que tiene hCdc14B sobre Sirt2 resulta controvertido, puesto que inicialmente se asoció con la desestabilización de la proteína, que a su vez podría afectar a la salida de mitosis y a la citoquinesis, si bien actualmente no está muy claro si se trata de un efecto general o depende del tipo celular (Dryden et al., 2003; North y Verdin, 2007). Por otra parte, se ha descrito recientemente que la fosfatasa hCdc14B desfosforila a la proteína Skp2 en un residuo fosforilado por Cdk2, promoviendo así su degradación y la inhibición del complejo ubiquitín-ligasa $\mathrm{SCF}^{\mathrm{Skp2}}$, encargado de la degradación de diversos CKIs, como p27 o p21. De este modo hCdc14B parece estar implicado en la regulación de la duración de la fase $\mathrm{G} 1$, función conservada respecto a CeCDC14 en C. elegans (Saito et al., 2004; Rodier et al., 2008).

A su vez, las funciones propuestas para hCdc14B, como aquellas relacionadas con el control de la duración de G1 y con la regulación del ciclo de duplicación del centrosoma, 
concuerdan con la presencia de bajos niveles de esta proteína en células tumorales, siendo esto indicativo de un posible papel desempeñado por hCdc14B como supresor tumoral (Rodier et al., 2008; Wu et al., 2008).

Por último, parece probable que las funciones desempeñadas por proteína hCdc14B puedan estar reguladas a través de cambios en su localización subcelular. Dicha localización es principalmente nucleolar durante interfase, debido a la presencia de 54 aminoácidos específicos en el extremo amino (Kaiser et al., 2002; Mailand et al., 2002a), aunque también se ha detectado proteína asociada a los centrosomas y a los filamentos intranucleares (Nalepa y Harper, 2004). Sin embargo, durante mitosis la proteína hCdc14B es liberada desde los nucléolos, hecho que parece deberse a la inactivación de Cdk1 (Berdougo et al., 2008). De este modo, en células mitóticas se ha descrito que hCdc14B se encuentra en la zona central del huso mitótico durante anafase, y en el cuerpo medio durante telofase y citoquinesis (Cho et al., 2005). 
Objetivos 

- Estudio de las funciones de las fosfatasas hCdc14A y hCdc14B en el control de procesos relacionados con la mitosis.

- Identificación de sustratos fisiológicos de hCdc14A y hCdc14B implicados en la regulación del ciclo celular en células humanas 


HOMOLOGÍA FUNCIONAL ENTRE LAS FOSFATASAS

Cdc14 HUMANAS, hCdc14A Y hCdc14B, Y FIp1 DE Schizosaccharomyces pombe 

Como hemos mencionado en la Introducción, en células eucariotas la entrada en mitosis se encuentra regulada por la actividad CDK mitótica, que debe ser revertida al final de esta fase para que ocurra la transición M/G1, y de este modo, el inicio de un nuevo ciclo celular. En las levaduras Saccharomyces cerevisiae y Schizosaccharomyces pombe, las proteínas Cdc14 y Flp1 respectivamente, desempeñan importantes funciones como fosfatasas antagonistas e inhibidoras de la actividad CDK a la salida de mitosis y en citoquinesis. Por su parte, los homólogos de Cdc14 en células humanas, hCdc14A y hCdc14B, también son capaces de desfosforilar diversos sustratos de complejos CdkCiclina, y además, hCdc14A parece desempeñar funciones implicadas en la regulación del ciclo de división del centrosoma, la mitosis y la citoquinesis (Kaiser et al., 2002; Mailand et al., 2002a). Estos datos, junto con los obtenidos en otros organismos, indicaban que probablemente todos los homólogos de Cdc14 podrían participar en la regulación de la actividad de los complejos CDK, aunque mediante mecanismos diferentes y posiblemente afectando a distintos procesos.

Dado el escaso conocimiento existente al comienzo de este trabajo acerca de las funciones desempeñadas por hCdc14A y hCdc14B, nuestro primer objetivo fue estudiar su posible papel como reguladores de la actividad CDK mitótica. Con este fin, se desarrolló una primera estrategia experimental, consistente en el análisis de una posible homología funcional entre las proteínas hCdc14 y Flp1 (Vazquez-Novelle et al., 2005). Para realizar dicho estudio llevamos a cabo ensayos de complementación de la carencia del gen flp $1^{+}$ en $S$. pombe con cada una de las dos formas de hCdc14, y además estudiamos el mecanismo de acción por el que éstas podrían ejercer dicho efecto. Por otra parte, para obtener más información sobre las funciones desempeñadas por los Cdc14 humanos, también analizamos los efectos de la sobre-expresión de hCdc14A y hCdc14B en células de S. pombe.

\section{LAS FOSFATASAS hCdc14A y hCdc14B COMPLEMENTAN LA CARENCIA DEL GEN flp1 $1^{+}$EN S. pombe}

Para comprobar si los homólogos humanos de Cdc14 son capaces de complementar la carencia del gen $f l p 1^{+}$se empleó la cepa $\Delta f l p 1$. Estas células que carecen de $f l p 1^{+}$son viables y capaces de formar colonias, pero presentan un tamaño menor que las células de tipo silvestre (wt) y una clara tendencia a formar agregados celulares, defectos que se ven acentuados con el aumento de la temperatura de cultivo o la escasez de nutrientes. Además, un cierto porcentaje de las células $\Delta f / p 1$ presenta defectos asociados con el final 
de la mitosis y la septación (como células multiseptadas, células septadas con un compartimento vacío y el otro con dos núcleos, o células en las que el septo corta al núcleo) (Cueille et al., 2001).

Para poder expresar en células de $S$. pombe las proteínas humanas, hCdc14A y hCdc14B, y sus correspondientes formas mutantes sin actividad fosfatasa, hCdc14(PD)

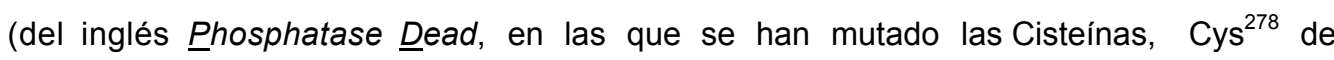
hCdc14A y $\mathrm{Cys}^{314}$ de hCdc14B, por Serinas), sus cDNAs fueron clonados en el plásmido de expresión en $S$. pombe pREPKZ, bajo el control del promotor $n m t 1$ y fusionados a GST. En las células transformadas con este vector, la presencia de tiamina reprime la expresión, de modo que cuanto menor es la concentración de tiamina en el medio, mayores son los niveles de expresión de las proteínas hCdc14.

A continuación, para determinar si la expresión de cada uno de los homólogos humanos complementa el fenotipo de la deleción del gen flp $1^{+}$, llevamos a cabo dos aproximaciones. En primer lugar se realizó un ensayo de viabilidad para examinar cómo afecta la expresión de las citadas fosfatasas humanas a la viabilidad del doble mutante $\Delta f l p 1 c d c 25-22$ a $32^{\circ} \mathrm{C}$, y en segundo lugar, el análisis de posibles modificaciones del fenotipo propio de las células $\Delta f / p 1$ a consecuencia de la expresión de hCdc14A o hCdc14B en dicha cepa.

\section{Ensayo de viabilidad del mutante termosensible $\Delta$ flp1 $c d c 25-$ 22 de S. pombe: La expresión de hCdc14A o hCdc14B da lugar a una considerable recuperación de su viabilidad}

Puesto que las células de la cepa $\Delta f / p 1$ son viables (Cueille et al., 2001; Trautmann et al., 2001), para realizar este ensayo de complementación decidimos utilizar el doble mutante termosensible $\Delta f l p 1 c d c 25-22$, cuya viabilidad se ve comprometida a la temperatura de $32^{\circ} \mathrm{C}$ como consecuencia de los defectos en el ciclo celular generados por la deleción del gen $f / p 1^{+}$(Esteban et al., 2004). En concreto, la pérdida de viabilidad de este mutante $\Delta f \mid p 1 c d c 25-22$ a esta temperatura, se puede explicar teniendo en cuenta los defectos en la regulación de los niveles y la localización subcelular de Cdc25 asociados a la falta de Flp1 (Esteban et al., 2004), sumados al hecho de que en el mutante termosensible simple $c d c 25-22$ a $32^{\circ} \mathrm{C}$ se produce una pérdida parcial de la función de Cdc25 (Russell y Nurse, 1986).

Para saber si la expresión de las proteínas hCdc14 podía recuperar la viabilidad de este doble mutante a $32^{\circ} \mathrm{C}$, transformamos la cepa $\Delta f / p 1$ cdc25-22 con el plásmido pREPKZ vacío o con este vector conteniendo los cDNAs de las proteínas hCdc14A, 
hCdc14B, sus respectivas formas inactivas $h C d c 14(P D)$ o el gen flp $1^{+}$. A continuación, estas células transformadas fueron cultivadas en medio mínimo sin Leucina y con una concentración $2 \mu \mathrm{M}$ de tiamina, que permite una expresión moderada de los cDNAs clonados en pREPKZ.

En la Figura $1 \mathrm{~A}$ se muestra que la expresión de niveles moderados de las proteínas de fusión GST-hCdc14A o GST-hCdc14B, determinados por Western blot (datos no mostrados), induce la recuperación de la viabilidad de las células del doble mutante $\Delta f l p 1$ $c d c 25-22$ a $32^{\circ} \mathrm{C}$, al igual que lo hace la expresión de GST-Flp1 (empleado como control positivo). Sin embargo, la expresión de las proteínas mutantes sin actividad catalítica no da lugar a una recuperación de la viabilidad de las células de 4 flp1 cdc25-22 comparable a la anterior, ya que GST-hCdc14A(PD) no permite recuperar en absoluto dicha viabilidad, mientras que GST-hCdc14B(PD) da lugar a una recuperación inferior a la producida por la expresión de la fosfatasa activa hCdc14B.

Estos resultados fueron obtenidos también en presencia de una menor concentración de tiamina, $0,2 \mu \mathrm{M}$ (datos no mostrados).

\section{Análisis del fenotipo de células del mutante $\Delta$ flp1: La expresión de cada una de las proteínas hCdc14 revierte el fenotipo de la deleción de flp1 ${ }^{+}$}

Como hemos descrito, las células $\Delta f / p 1$ (que carecen de Flp1) presentan un fenotipo característico, que se encuentra agravado al ser incubadas a $37^{\circ} \mathrm{C}$, ya que en estas condiciones se forman agregados de células de tamaño reducido.

Con el fin de comprobar si la expresión de las fosfatasas Cdc14 humanas revierte el fenotipo asociado a la falta del gen $f / p 1^{+}$, las células $\Delta f / p 1$ fueron transformadas con el plásmido pREPKZ vacío (como control negativo), o con los cDNAs de hCdc14A, hCdc14B o de sus correspondientes variantes sin actividad catalítica, clonados en dicho plásmido. Tras su incubación durante 20 horas a $37^{\circ} \mathrm{C}$, las células control (transformadas con el plásmido vacío) presentan el fenotipo característico de la cepa $\Delta f / p 1$, del mismo modo que aquellas que expresan las proteínas sin actividad fosfatasa; sin embargo, la expresión de las fosfatasas activas, hCdc14A o hCdc14B, revierte el fenotipo de la cepa $\Delta f / p 1$, dando lugar a células que presentan un tamaño similar al de células de tipo silvestre (wt), y que significativamente, no forman agregados (Fig. 1B). 
A

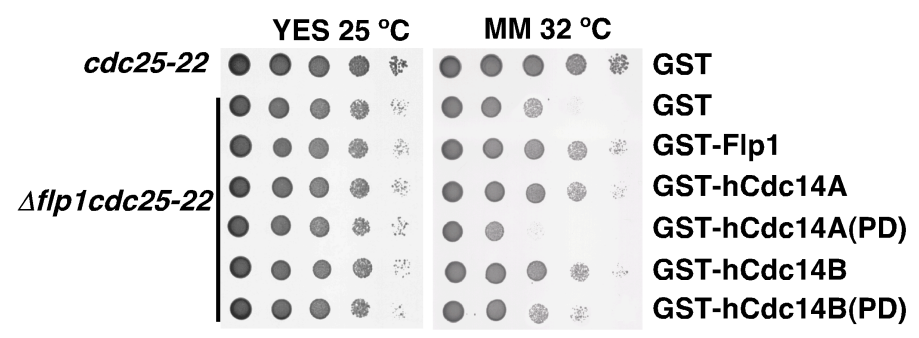

B
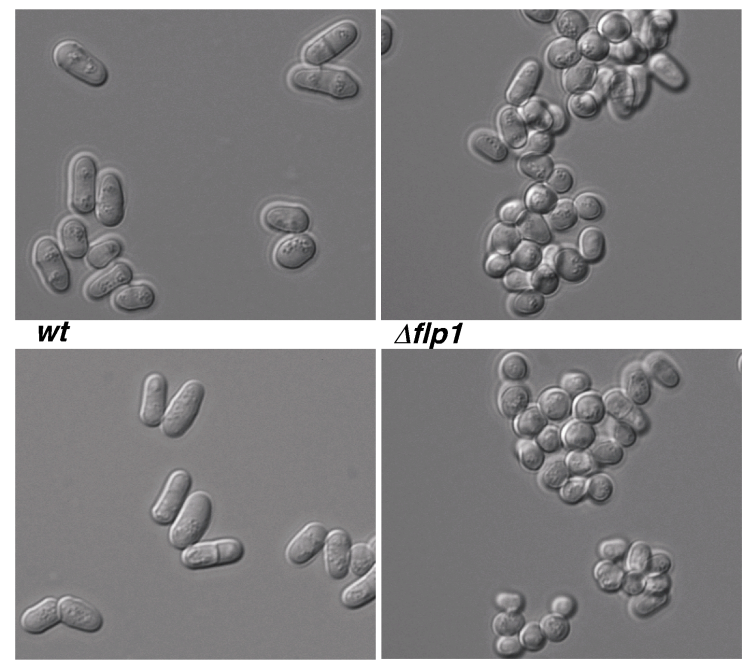

$\Delta f l p 1$
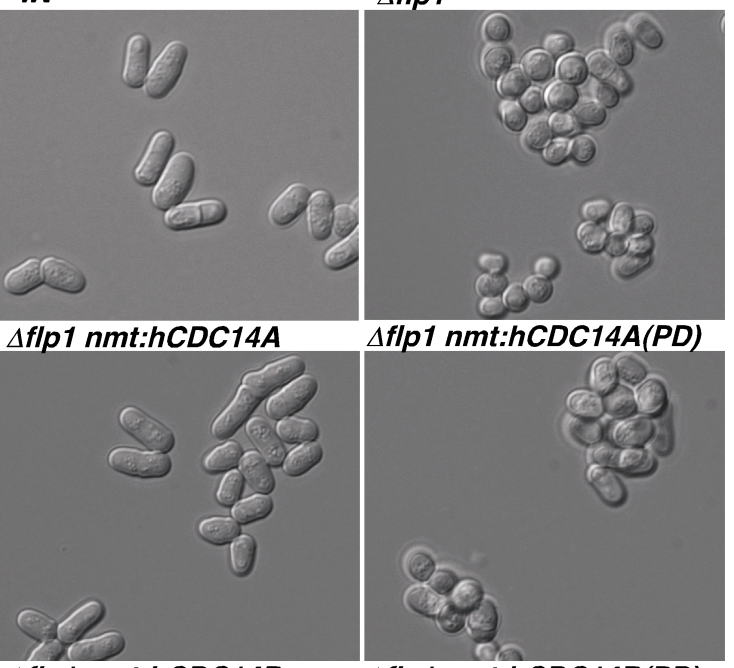

$\Delta$ flp1 nmt:hCDC14A(PD)

$\triangle f l p 1$ nmt:hCDC14B

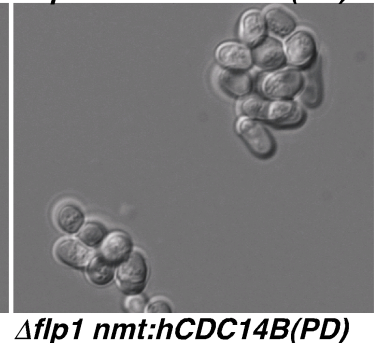

Figura 1. Complementación de células $\Delta$ flp1 por la expresión de las proteínas Cdc14 humanas. $\boldsymbol{A}$ : Las células $\Delta f l p 1 c d c 25-22$ de $S$. pombe fueron transformadas con el vector vacío pREPKZ o con el vector pREPKZ que contiene GST-flp $1^{+}$, GST-hCDC14A, GST$h C D C 14 A(P D), G S T-h C D C 14 B$ o GST-hCDC14B(PD), y después fueron sembradas en medio rico, YES, o en medio mínimo sin Leucina, MM-Leu, con una concentración $2 \mu \mathrm{M}$ de tiamina, a $25^{\circ} \mathrm{C}$ ó $32^{\circ} \mathrm{C}$, respectivamente. El mutante sencillo cdc25-22 también se transformó con el vector vacío. B: Fenotipo de células de $S$. pombe de tipo silvestre (wt), $\Delta f l p 1$, y células $\Delta f l p 1$ (transformadas como se ha indicado) que expresan hCdc14A, hCdc14B o sus respectivas formas inactivas hCdc14(PD), incubadas en MM sin Leucina y con 0,2uM de tiamina, durante 20 horas.

Los resultados mostrados, correspondientes al ensayo de viabilidad del doble mutante $\Delta f / p 1 c d c 25-22$ y al análisis del fenotipo de células $\Delta f / p 1$, nos indican que ambas fosfatasas humanas, hCdc14A y hCdc14B, son capaces de complementar la carencia del 
gen $f / p 1^{+}$en células de S. pombe, y que dicha complementación depende de su actividad fosfatasa.

\section{LA PROTEÍNA hCdc14A ES CAPAZ DE DESFOSFORILAR A Cdc25 DE S. pombe}

Se ha demostrado que el homólogo de Cdc14 en S. pombe, Flp1, es capaz de desfosforilar in vitro a Cdc25 en residuos fosforilados por Cdc2, y además está implicado en la regulación del estado de fosforilación de dicha proteína in vivo (Esteban et al., 2004; Wolfe y Gould, 2004). Para comprobar si Cdc25 es un sustrato de las fosfatasas humanas, hCdc14A y hCdc14B, en primer lugar se realizaron ensayos quinasa-fosfatasa in vitro empleando las proteínas de fusión GST-hCdc14 y GST-Cdc25, esta última previamente fosforilada por Cdk1. A continuación, para poder relacionar el resultado de los ensayos in vitro con un efecto de hCdc14 in vivo, analizamos mediante Western blot, cómo afectaba la expresión de estas fosfatasas humanas al estado de fosforilación de Cdc25 en células de $S$. pombe carentes de Flp1.

\section{La fosfatasa hCdc14A desfosforila in vitro a la proteína de $S$. pombe Cdc25 en residuos fosforilados por Cdk1}

Con el fin de analizar la capacidad de las proteínas humanas Cdc14 para desfosforilar in vitro a Cdc25, se realizaron ensayos quinasa-fosfatasa (en las condiciones descritas en Materiales y Métodos). En estos ensayos se empleó como sustrato una cantidad constante de la proteína de fusión GST-Cdc25 fosforilada in vitro por complejos Cdk1Ciclina B1 (ensayo quinasa), a la que se le añadieron en cada caso cantidades crecientes de GST-hCdc14A, GST-hCdc14B, o de sus formas sin actividad catalítica (empleadas como control negativo), purificadas todas ellas a partir de células $\Delta c d c 25 c d c 2-3 w$ de $S$. pombe transformadas con los correspondientes plásmidos para inducir su expresión. Estos experimentos nos permitieron determinar que en las condiciones descritas, y de forma dependiente de la cantidad de proteína, hCdc14A es capaz de desfosforilar a Cdc25 en residuos fosforilados por Cdk1, capacidad que no presentan hCdc14B ni hCdc14(PD) (Fig. 2). 
A

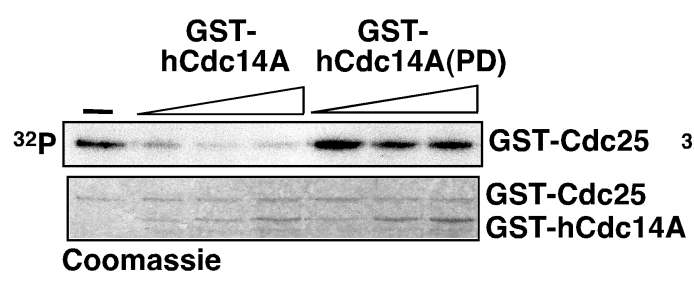

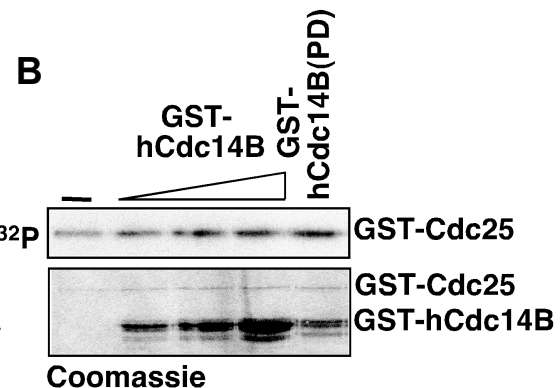

Coomassie

Figura 2. hCdc14A desfosforila in vitro a Cdc25, previamente fosforilado por Cdk1. A y B: La proteína purificada a partir de Escherichia coli GST-Cdc25 fue fosforilada in vitro por complejos Cdk1-Ciclina B1, y posteriormente incubada con cantidades crecientes de GSThCdc14A o GST-hCdc14A(PD) ( $\boldsymbol{A})$, o bien, de GST-hCdc14B o GST-hCdc14B(PD) (B), o sólo con tampón fosfatasa (control negativo) $(\boldsymbol{A})$ y $(\boldsymbol{B})$, durante 45 minutos a $30^{\circ} \mathrm{C}$. Las proteínas de cada reacción se separaron mediante electroforesis en SDS-PAGE y fueron analizadas por auto-radiografía (panel superior) y por tinción con azul de Coomassie (panel inferior).

\section{La fosfatasa hCdc14A promueve de forma directa o indirecta la desfosforilación in vivo de la proteína de S. pombe Cdc25}

En anteriores trabajos se había demostrado que la ausencia del gen $f l p 1^{+}$daba lugar a la acumulación de una forma hiperfosforilada de Cdc25, independientemente de la fase del ciclo en la que se encontrase la célula (Esteban et al., 2004), lo que sugería que la fosfatasa Flp1 estaba implicada directa o indirectamente en la regulación del estado de fosforilación de Cdc25 in vivo.

A la vista de estos datos previos, y puesto que los cambios observados en la movilidad electroforética de la proteína Cdc25 estaban relacionados con alteraciones en su estado de fosforilación (Creanor y Mitchison, 1996; Cueille et al., 2001), en nuestro estudio empleamos la técnica de Western blot para analizar el estado de fosforilación de Cdc25 en células $\Delta$ flp1 que expresaban cada una de las dos formas de hCdc14 o hCdc14A(PD). En la Figura 3 se observa que la expresión de hCdc14A revierte la hiperfosforilación de Cdc25 característica de células $\Delta f l p 1$, efecto que no se produce al expresar su forma sin actividad fosfatasa o hCdc14B.

De los resultados anteriores concluimos que hCdc14A, de forma dependiente de su actividad fosfatasa y a diferencia de hCdc14B, es capaz de desfosforilar in vitro a Cdc25 en residuos fosforilados por $\mathrm{Cdc} 2$, y además, parece estar implicada directa o indirectamente en la desfosforilación de Cdc25 in vivo. 


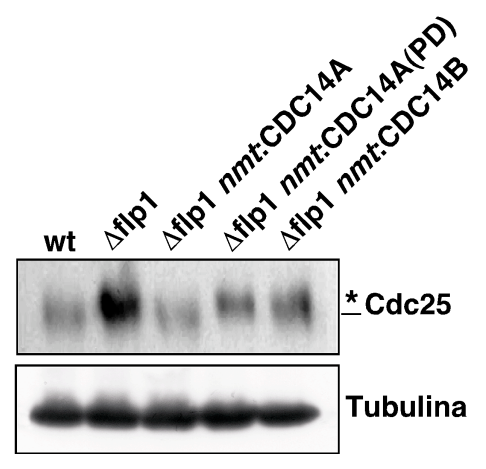

Figura 3. hCdc14A promueve la desfosforilación in vivo de Cdc25. Se obtuvieron extractos proteicos a partir de células de $S$. pombe wt, $\Delta f l p 1$ ó $\Delta$ flp1 que expresan hCdc14A, hCdc14A(PD) o hCdc14B bajo el promotor $n m t 1$. Las proteínas de estos extractos fueron separadas por electroforesis en SDS-PAGE, tras lo que se llevó a cabo la inmunodetección de Cdc25 con un anticuerpo policlonal anti-Cdc25. El asterisco indica la posición de la proteína Cdc25 hiperfosforilada. La Tubulina, detectada con un anticuerpo específico, fue empleada como control de carga.

\section{LAS PROTEÍNAS HUMANAS hCdc14A Y hCdc14B INTERACCIONAN in vivo CON Cdc25 DE S. pombe}

Dado que Flp1 interacciona in vivo con la proteína Cdc25 (Esteban et al., 2004) y que, como acabamos de mostrar, hCdc14A es capaz de desfosforilar a Cdc25, nos pareció interesante saber si las proteínas Cdc14 humanas podían interaccionar in vivo con Cdc25. Para ello se realizaron diversos experimentos en colaboración con la Dra. Verónica Esteban, de nuestro grupo. En primer lugar, expresamos en células $\Delta f l p 1$ cultivadas en medio sin tiamina, las proteínas de fusión GST-hCdc14A, GST-hCdc14B o sus correspondientes formas sin actividad catalítica, GST-hCdc14A(PD) y GST-hCdc14B(PD), cuya afinidad por sus sustratos podría estar incrementada (Tonks y Neel, 1996). El análisis por Western blot, utilizando un anticuerpo específico frente a Cdc25, de estas proteínas de fusión purificadas a partir de la cepa $\Delta f l p 1$, nos permitió demostrar que Cdc25 interacciona in vivo con GST-hCdc14A, GST-hCdc14B y sus respectivas formas inactivas, con una afinidad similar, interacción que no ocurre con GST (empleado como control negativo) (Fig. 4A). Resultados parecidos se obtuvieron al realizar este experimento incubando las células $\Delta f / p 1$ transformadas en presencia de $2 \mu \mathrm{M}$ de tiamina, lo que indica que la interacción también ocurre en células con menores niveles de las proteínas humanas (datos no mostrados). 


\section{Reducción de la actividad quinasa de los complejos Cdc2- Cdc13 en células $\Delta$ flp1 que expresan las proteínas hCdc14}

Como hemos indicado anteriormente, Flp1 desfosforila e inactiva a Cdc25, lo cual explica la acumulación de la proteína Cdc25 hiperfosforilada en células $\Delta f l p 1$, que a su vez da lugar a un incremento de la actividad asociada a Cdc2-Cdc13 en estas células (Esteban et al., 2004; Wolfe y Gould, 2004). Esto nos llevó a comprobar el posible efecto de la expresión de proteínas hCdc14 sobre la actividad CDK mitótica en las células de $S$. pombe que carecen de Flp1. Con este fin se expresaron las proteínas de fusión GSThCdc14 y sus formas mutantes inactivas en células $\Delta$ flp 1 durante 16 horas, tiempo de inducción que no afecta a la progresión por el ciclo celular (datos de citometría de flujo no mostrados), y a partir de estas células se inmunoprecipitaron los complejos Cdc2-Cdc13 y se examinó su actividad por medio de un ensayo quinasa sobre Histona $\mathrm{H} 1$.

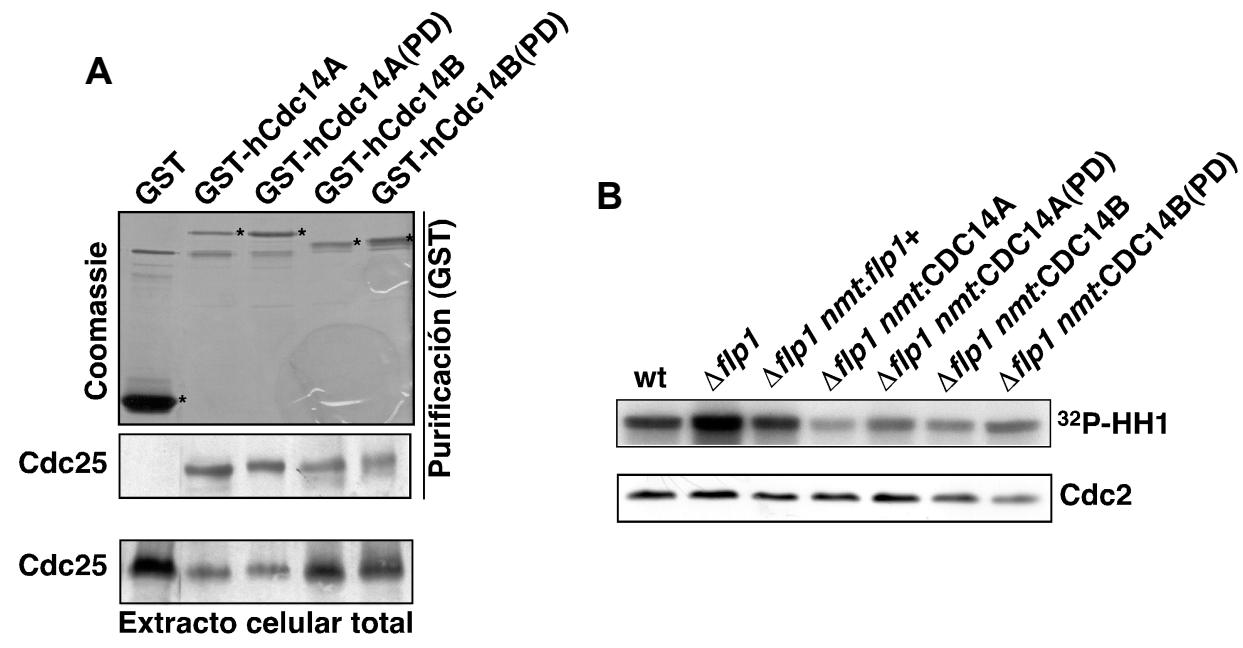

Figura 4. hCdc14A y hCdc14B interaccionan in vivo con Cdc25. A: GST, GST-hCdc14A, GSThCdc14A(PD), GST-hCdc14B y GST-hCdc14B(PD) fueron expresadas en células $\Delta$ flp1 bajo el control de un promotor nmt1. Tras 20 horas de inducción en un medio sin tiamina, se recogieron muestras a partir de las que se purificaron estas proteínas de fusión, empleando glutatión-sefarosa. Las muestras purificadas fueron procesadas mediante SDS-PAGE y las proteínas se detectaron por tinción con azul de Coomassie (panel superior) o con un anticuerpo anti-Cdc25 (panel medio). Los asteriscos señalan el tamaño esperado de las proteínas de fusión. El panel inferior muestra los niveles Cdc25 detectados en los extractos proteicos totales de dichas muestras de forma previa a la purificación (control). $\boldsymbol{B}$ : Las células $\Delta$ flp1 que expresan las diferentes formas de hCdc14 presentan niveles inferiores de actividad quinasa asociada a Cdc2 que células $\Delta$ flp1. Los complejos Cdc2-Cdc13 fueron inmunoprecipitados con un anticuerpo policlonal SP4 anti-Cdc13 a partir de extractos proteicos de células de $S$. pombe de tipo silvestre (wt), $\Delta$ flp1, y de células $\Delta$ flp1, que expresan GST-Flp1, GSThCdc14A, GST-hCdc14B o las formas inactivas GST-hCdc14(PD) durante 16 horas en un medio sin tiamina. Los complejos inmunoprecipitados a partir de dichas muestras fueron procesados para la medida de su actividad quinasa sobre Histona H1. En los extractos proteicos totales se llevó a cabo la inmunodetección de los niveles proteicos de Cdc2, como control. 
La expresión de las fosfatasas GST-hCdc14A, GST-hCdc14B o de sus formas mutantes sin actividad catalítica da lugar a la reducción de la actividad quinasa asociada a Cdc13 en células $\Delta f l p 1$, incluso de forma más clara que la expresión de Flp1 (Fig. 4B). El efecto de estas proteínas humanas sobre la actividad de Cdc2-Cdc13, posiblemente es consecuencia de su interacción con Cdc25, descrita en este mismo apartado, la cual podría evitar la activación de los complejos CDK mitóticos por parte de Cdc25.

\section{La expresión de hCdc14A o hCdc14B altera la localización subcelular de Cdc25 en células de $S$. pombe}

Puesto que hCdc14B no es capaz de desfosforilar in vitro a Cdc25, pero sin embargo sí afecta a la actividad CDK mitótica, quisimos analizar si la interacción in vivo de hCdc14B con Cdc25 afectaba a la localización subcelular de esta última, lo que podría evitar la activación de Cdc2-Cdc13 por parte de Cdc25. Para examinar la localización subcelular de Cdc25 se empleó la cepa de S. pombe Myc-cdc25, transformada con los correspondiente plásmidos pREPKZ, y tras 18 horas de expresión de GST-hCdc14A o GST-hCdc14B llevamos a cabo un análisis de inmunofluorescencia indirecta empleando un anticuerpo específico anti-Myc que nos permitió visualizar la proteína Cdc25.

En células de tipo silvestre (wt) de $S$. pombe, la fosfatasa Cdc25 se acumula en el núcleo, especialmente durante G2 y mitosis (Lopez-Girona et al., 1999), del mismo modo que en la cepa Myc-cdc25 transformada con el plásmido pREPKZ vacío, utilizada como control. Sin embargo, la expresión de GST-hCdc14B da lugar a la exclusión nuclear de Cdc25, lo que podría evitar la activación de los complejos Cdc2-Cdc13, cuya localización es también nuclear (Booher et al., 1989). En el caso de la expresión de GST-hCdc14A, ésta induce una localización de Cdc25 tanto citoplasmática como nuclear, y además produce una reducción en la intensidad de la señal específica de Myc-Cdc25 en un elevado porcentaje de células (Fig. 5). 


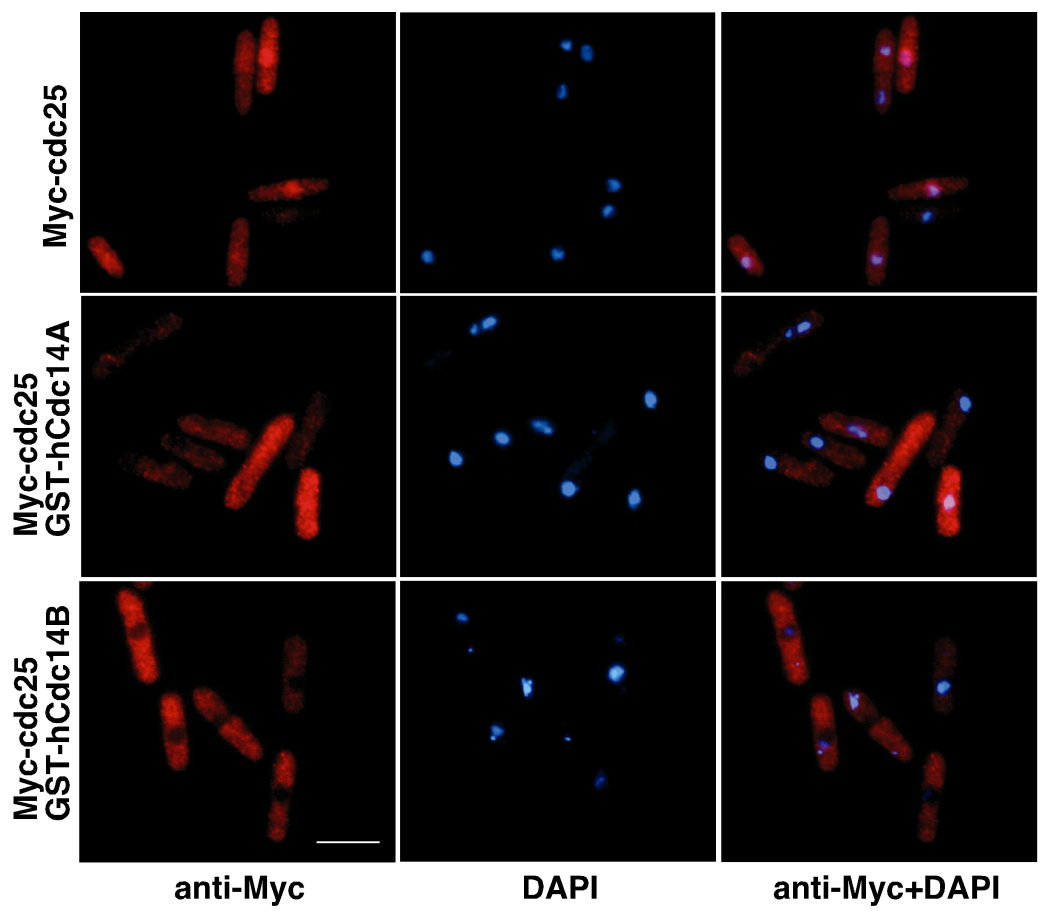

Figura 5. Localización subcelular de Cdc25 en células de $S$. pombe que sobre-expresan hCdc14A o hCdc14B. Las células asíncronas de la cepa Myc-cdc25 que expresan GST, GSThCdc14A o GST-hCdc14B durante 18 horas en un medio sin tiamina, fueron fijadas con paraformaldehído y sometidas a inmunofluorescencia indirecta con anticuerpos anti-Myc. Estas células también se tiñeron con DAPI para visualizar el DNA. La barra de escala mostrada corresponde a $10 \mu \mathrm{m}$.

\section{EFECTOS DE LA SOBRE-EXPRESIÓN DE LAS FOSFATASAS hCdc14A O hCdc14B EN LA LEVADURA DE FISIÓN S. pombe}

Los efectos de la sobre-expresión de las fosfatasas humanas Cdc14 se estudiaron en células de $S$. pombe de tipo silvestre (wt) por medio de su transformación con los cDNA de hCdc14A o hCdc14B clonados en pREPKZ, o bien con el plásmido vacío o pREPKZflp $1^{+}$(ambos empleados como controles). Como se indica a continuación, en las células transformadas e incubadas en medio sin tiamina, condiciones de máxima expresión, se comprobaron los niveles y localización subcelular de las distintas proteínas, tras lo que analizamos el contenido de DNA, la morfología nuclear y la estructura del huso mitótico de dichas células. 


\section{Niveles de expresión y localización subcelular de hCdc14A y hCdc14B en células de $S$. pombe}

En primer lugar era necesario corroborar que las células de $S$. pombe (wt) transformadas con pREPKZ-hCDC14A o pREPKZ-hCDC14B expresaban las respectivas proteínas de fusión. Con esta finalidad se obtuvieron extractos proteicos de dichos transformantes tras 24 horas de inducción de la expresión, y mediante la técnica de Western blot, empleando un anticuerpo específico frente a GST, detectamos ambas proteínas de fusión (datos no mostrados).

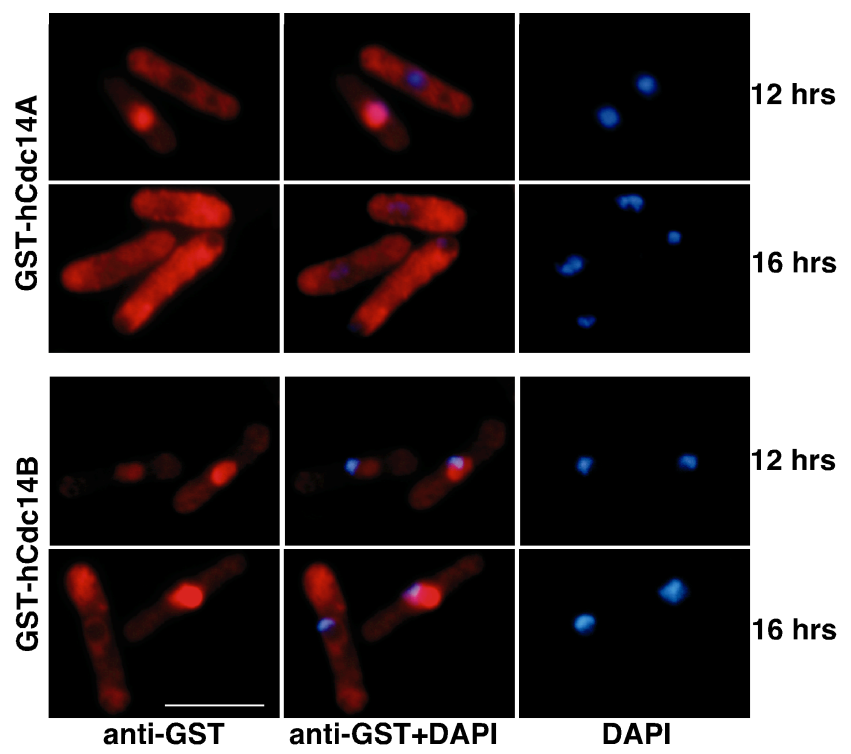

Figura 6. Localización subcelular de hCdc14A y hCdc14B en células de $S$. pombe (wt). Las células fueron incubadas en medio sin tiamina durante 12 y 16 horas, para inducir la sobre-expresión de GST-hCdc14A o GST-hCdc14B. Tras esto, dichas células se fijaron con paraformaldehído y fueron analizadas mediante inmunofluorescencia indirecta con anticuerpos anti-GST y mediante tinción con DAPI. Nótese que GST-hCdc14B se asocia principalmente a la región del núcleo no teñida con DAPI, posiblemente al nucléolo. Barra de escala,10 $\mu \mathrm{m}$.

A continuación, se examinó la localización subcelular de estas fosfatasas humanas, hCdc14A y hCdc14B, en $S$. pombe, mediante inmunocitoquímica con un anticuerpo específico anti-GST. La localización subcelular de ambas proteínas hCdc14 es principalmente nuclear tras 12 horas de inducción de la expresión. A tiempos más prolongados de inducción, como 16 horas, la fosfatasa hCdc14A se encuentra distribuída por toda la célula, mientras hCdc14B presenta una localización nuclear en algunas células y citoplasmática en otras (Fig. 6). 


\section{Las células de $S$. pombe que sobre-expresan hCdc14A o hCdc14B presentan un contenido anómalo de DNA}

Para determinar el contenido en DNA de las células de $S$. pombe que sobre-expresan las proteínas hCdc14A y hCdc14B, éstas se incubaron en un medio de cultivo sin tiamina a $32^{\circ} \mathrm{C}$ y durante 24 horas. La toma de muestras para su análisis mediante citometría de flujo (FACS), a intervalos regulares durante la inducción, nos permitió observar que el contenido de DNA de las células que sobre-expresan hCdc14A o hCdc14B es anómalo tras 20 horas de inducción, de forma similar al de células que sobre-expresan Flp1. En concreto, muchas de las células que sobre-expresan hCdc14A durante más de 20 horas presentan contenidos de DNA inferiores o superiores a $2 \mathrm{C}$, mientras la sobre-expresión de hCdc14B durante más de 18 horas da lugar a células con contenidos superiores a 2C (Fig. $7)$. Estos resultados nos hicieron pensar que quizás la sobre-expresión de las fosfatasas hCdc14 en S. pombe genera defectos mitóticos.

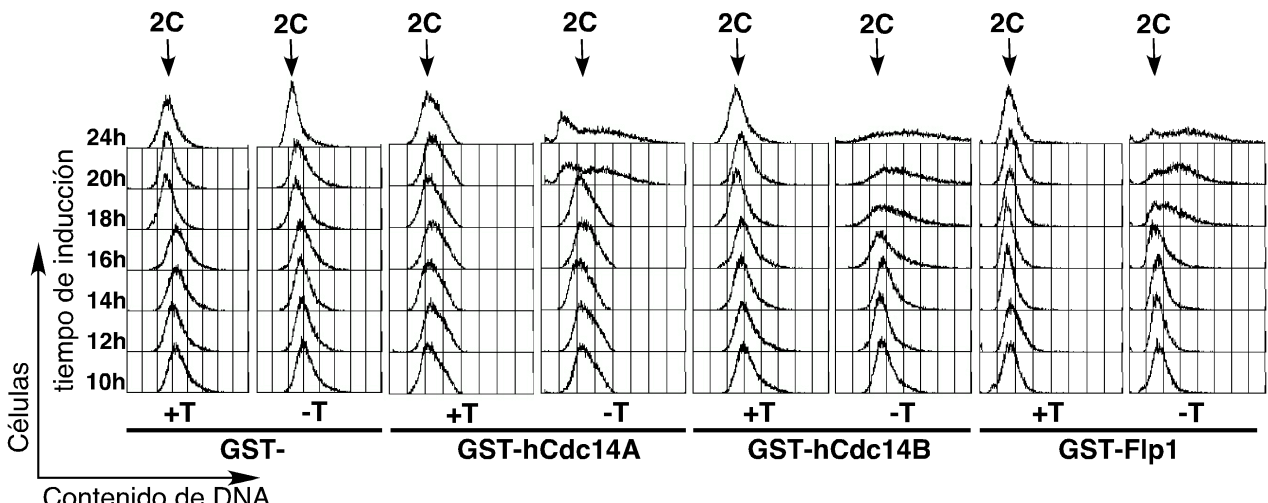

Figura 7. Análisis citométrico de células de $S$. pombe que sobre-expresan las proteínas hCdc14A, hCdc14B y FIp1. Las células transformadas con el plásmido vacío pREPKZ o el mismo plásmido que contiene GST-hCDC14A, GST-hCDC14B o GST-flp $1^{+}$fueron incubadas en medio mínimo líquido con tiamina $(+\mathrm{T})$ o sin tiamina $(-\mathrm{T})$ durante 24 horas a $32^{\circ} \mathrm{C}$. Se recogieron muestras tras los tiempos indicados de inducción, y $10^{7}$ células fueron fijadas con etanol y teñidas con yoduro de propidio para la determinación de su contenido de DNA por citometría de flujo (FACS). 


\section{Las células de $S$. pombe que sobre-expresan hCdc14B o hCdc14A presentan anomalías en la morfología nuclear y en la formación del huso mitótico}

En estudios anteriores se había demostrado que la sobre-expresión de Flp1 daba lugar a células alargadas, como consecuencia de un retraso en G2, y que si dicha sobreexpresión se mantenía en el tiempo, estas células alargadas formaban finalmente husos mitóticos, entraban en mitosis y, en algunos casos, incluso llegaban a formar sus septos sin haber segregado los cromosomas adecuadamente (Cueille et al., 2001; Trautmann et al., 2001). Estos datos previos unidos al hecho de que la sobre-expresión de las proteínas hCdc14 en S. pombe da lugar a una acumulación de células con contenidos anómalos de DNA, nos llevaron a comprobar si la morfología nuclear y/o la estructura del huso mitótico se encontraban alteradas en dichas células. Para llevar a cabo este análisis se indujo la expresión de hCdc14B o hCdc14A en células de tipo silvestre (wt) durante 22 horas, tras lo cual, dichas células fueron fijadas para realizar una doble tinción, de núcleos con DAPI y de microtúbulos mediante inmunofluorescencia indirecta, utilizando un anticuerpo específico frente a Tubulina.

Como resultado de estos experimentos sabemos que la sobre-expresión de hCdc14B en células de $S$. pombe induce la aparición de núcleos fragmentados distribuidos de forma irregular y una falta de tinción correspondiente a los microtúbulos, efecto que sugiere problemas en la formación del huso mitótico (Fig. 8A). Por otra parte, la sobre-expresión de hCdc14A en células de $S$. pombe genera fenotipos caracterizados por problemas en la compactación de la cromatina, descondensación cromosómica y segregación irregular de los cromosomas. Además, la proporción de células con husos mitóticos propios de anafase se incrementa al sobre-expresar esta fosfatasa humana $(5,8 \%$ frente a $3 \%$ en células control) y la gran mayoría de estas células en anafase presentan cromosomas anómalos o descondensados, un solo núcleo descentrado o los efectos derivados de una segregación cromosómica irregular (Figura 8 y Tabla I). Por último, cabe decir que estos efectos causados por la sobre-expresión de cada una de las fosfatasas hCdc14 también se observan al sobre-expresar las correspondientes formas mutantes sin actividad catalítica (datos no mostrados).

En conclusión, los resultados mostrados en este apartado sugieren la posible implicación de hCdc14A en la regulación de la mitosis, en concreto en los procesos de condensación y segregación de los cromosomas, mientras el papel desempeñado por hCdc14B podría estar relacionado con la formación del huso mitótico y con fenómenos relacionados con la morfología nuclear. 
A

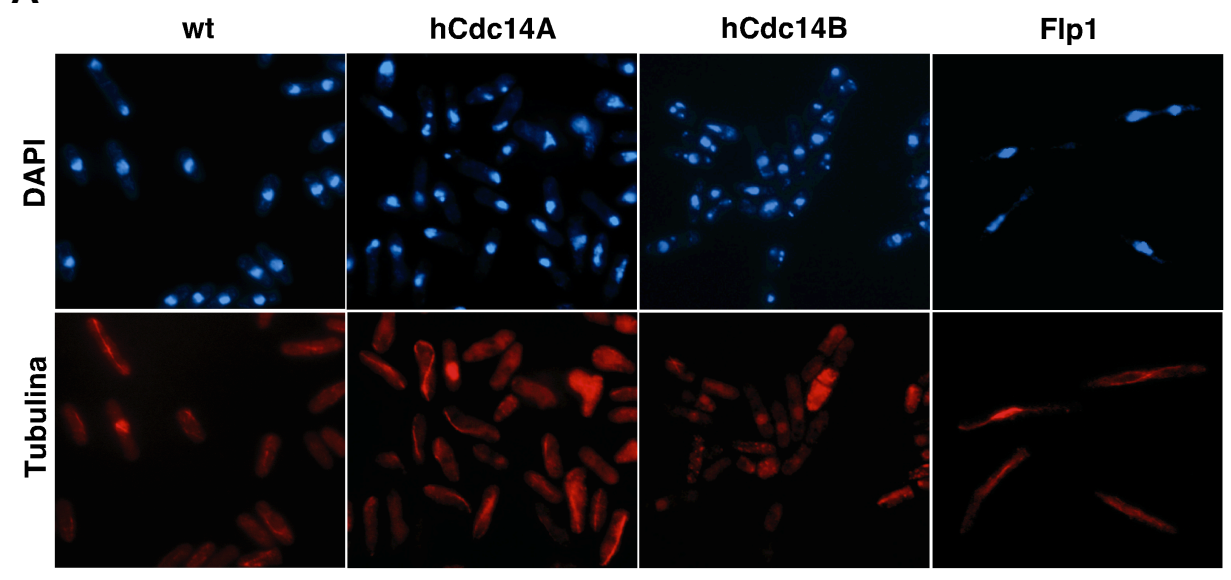

B

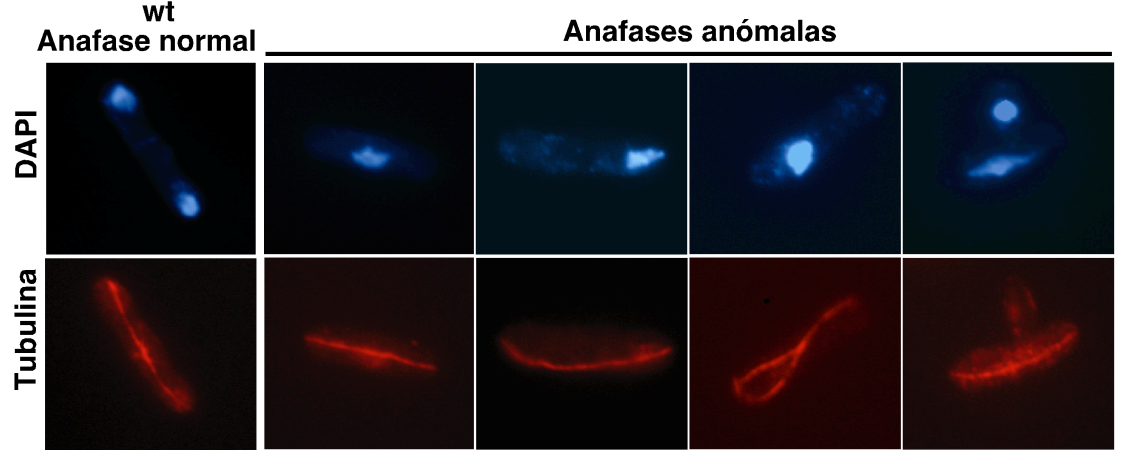

Figura 8. Estructura nuclear y del huso mitótico de células de $S$. pombe que sobreexpresan las proteínas hCdc14A, hCdc14B y Flp1. A: Las células que sobre-expresan GSThCdc14A, GST-hCdc14B o GST-Flp1 han sido incubadas durante 22 horas en medio sin tiamina, y posteriormente fijadas con paraformaldehído y analizadas mediante inmunofluorescencia con anticuerpos anti-Tubulina (TAT1) y por tinción con DAPI. B: Un alto porcentaje de células que sobre-expresan hCdc14A ( $86 \%$ de las células mitóticas) presentan anafases anómalas con cromosomas descondensados o con un núcleo desplazado (no central). Una anafase normal, correspondiente a una célula de tipo silvestre (wt), se muestra a la izquierda como control. 


\begin{tabular}{|cc|c|}
\hline \multicolumn{3}{|c|}{$\begin{array}{c}\text { Fenotipos aberrantes inducidos por la } \\
\text { sobre-expresión de hCdc14A }\end{array}$} \\
\hline Núcleo descentrado & 65 \\
Anafase con DNA descondensado & 40 \\
Segregación irregular & 30 \\
\hline
\end{tabular}

(Número total de células analizadas: 224)

Tabla I. Fenotipos aberrantes en células de S. pombe que sobre-expresan hCdc14A 

ESTUDIO DE LAS FUNCIONES DESEMPEÑADAS

POR hCdc14A EN LA REGULACIÓN DEL CICLO DE DIVISIÓN DE CÉLULAS HUMANAS 



\section{LAS FOSFATASAS Cdc25 HUMANAS: POSIBLES SUSTRATOS in vitro DE hCdc14A y hCdc14B}

Dado que las fosfatasas humanas hCdc14A y hCdc14B son capaces de complementar la falta de Flp1, y puesto que además hCdc14A desfosforila a Cdc25 de $S$. pombe, nos preguntamos si los Cdc25s humanos (hCdc25A, B y C) eran sustratos de hCdc14A y/o hCdc14B. Para comprobar esto, en nuestro grupo hemos llevado a cabo diversos ensayos in vitro, en cuya realización he colaborado.

\section{1. hCdc14A desfosforila in vitro a hCdc25A y hCdc25C en residuos fosforilados por Cdk1 (Cdc2)}

Con el fin de determinar si hCdc14A era capaz de desfosforilar alguna o varias de las proteínas hCdc25 in vitro, empleamos las proteínas de fusión GST-hCdc14A y GSThCdc14A(PD) purificadas de células $\Delta c d c 25 c d c 2-3 w$ de S. pombe, y las proteínas GSThCdc25A, GST-hCdc25B y GST-hCdc25C, purificadas a partir de E. coli. Los ensayos in vitro realizados constaban de: un primer ensayo quinasa, en el que cada uno de los hCdc25 es fosforilado por Cdk1, y un ensayo fosfatasa posterior, en el que cada proteína hCdc25 ya fosforilada se emplea como sustrato de cantidades crecientes de GSThCdc14A y de la forma mutante sin actividad fosfatasa GST-hCdc14A(PD) (utilizada como control negativo). Estos experimentos nos permitieron saber que hCdc25A y hCdc25C (fosforilados por Cdk1) son sustratos in vitro de hCdc14A. Sin embargo, hCdc25B no parece serlo (Figura 9).

En paralelo, para determinar si hCdc14B era capaz de desfosforilar a alguna de las tres proteínas Cdc25 humanas en residuos fosforilados por Cdk1, también se realizaron ensayos quinasa-fosfatasa similares, empleando las proteínas de fusión GST-hCdc14B y GST-hCdc14B(PD), purificadas también a partir de células $\Delta c d c 25 c d c 2-3 w$ de S. pombe. El resultado de estos ensayos fue negativo para cualquiera de los tres Cdc25 humanos (datos no mostrados). 


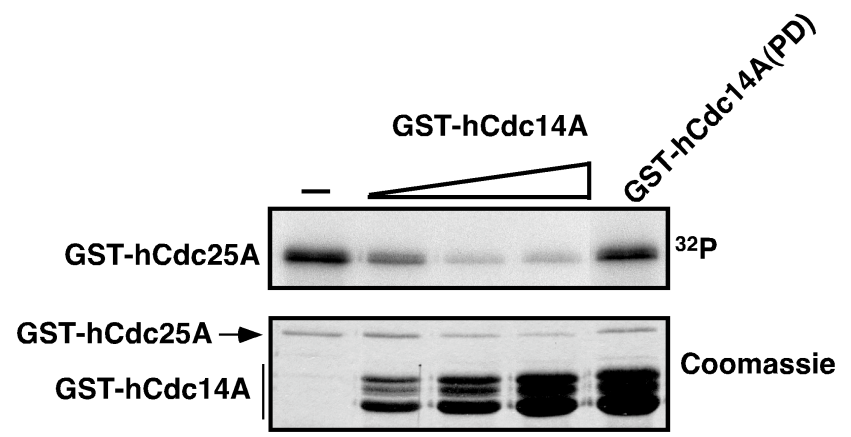

B

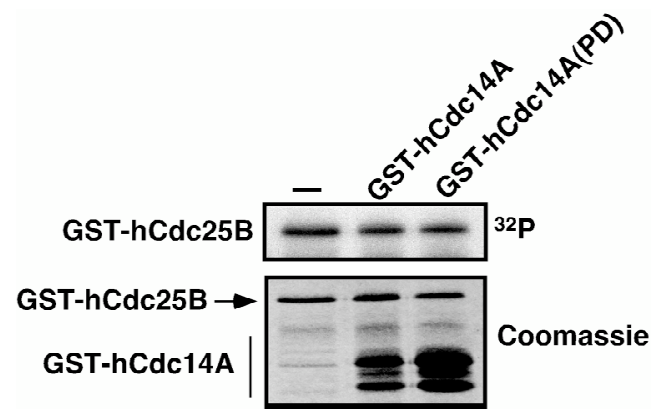

C

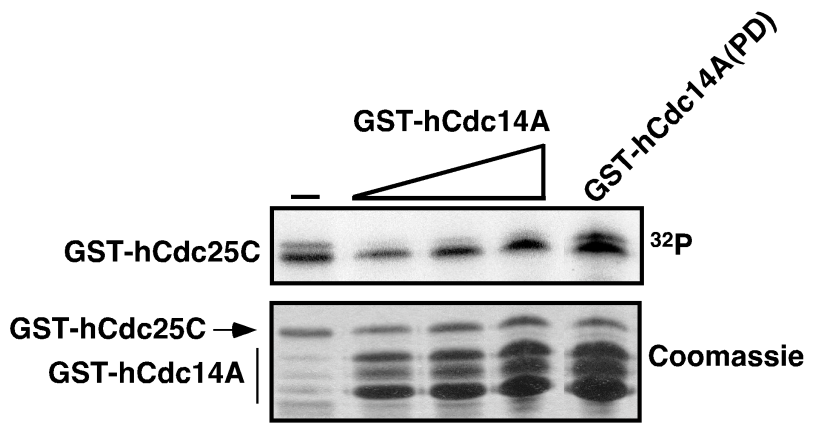

Figura 9. hCdc14A desfosforila in vitro a hCdc25A y hCdc25C, previamente fosforilados por Cdk1-Ciclina B1. Las proteínas GST-hCdc25A (A), GST-hCdc25B (B) y GST-hCdc25C (C) purificadas a partir de E. coli fueron fosforiladas in vitro por complejos Cdk1-Ciclina B1, y posteriormente incubadas con cantidades crecientes de GST-hCdc14A, con la forma inactiva GST-hCdc14A(PD) o sólo con tampón fosfatasa (-) durante 45 minutos a $30^{\circ} \mathrm{C}$. Las proteínas de cada reacción se separaron mediante electroforesis en SDS-PAGE, y fueron analizadas por auto-radiografía (panel superior) y por tinción con azul de Coomassie (panel inferior). 


\section{2. hCdc14A desfosforila in vitro a hCdc25A en los residuos Serina 115 y Serina $320\left(\operatorname{Ser}^{115}\right.$ y Ser $\left.{ }^{320}\right)$ previamente fosforilados por Cdk1}

A continuación, decidimos identificar los residuos de hCdc25A que hCdc14A es capaz de desfosforilar in vitro. Para ello, realizamos experimentos similares a los ensayos quinasa-fosfatasa descritos en el apartado anterior, pero en el que se utilizó exclusivamente ATP no radiactivo; tras esto, la proteína hCdc25A fue sometida a un análisis de fosfo-péptidos realizado mediante espectrometría de masas en el Servicio de Proteómica del Centro Nacional de Investigaciones Cardiovasculares, Madrid (datos no mostrados, (Esteban et al., 2006)). De este modo observamos que hCdc14A desfosforila in vitro los residuos $\operatorname{Ser}^{115}$ y Ser ${ }^{320}$ de hCdc25A fosforilados por Cdk1, siendo la $\operatorname{Ser}^{320}$ un residuo fosforilado por Cdk1 no descrito hasta el momento, identificado por primera vez en nuestro trabajo. Este resultado fue corroborado por medio de ensayos quinasa-fosfatasa en los que GST-hCdc14A tenía como sustratos a las proteínas mutantes de hCdc25A que simulan la desfosforilación de los citados residuos, GST-hCdc25A ${ }^{\mathrm{S115A}}$, GST-hCdc25A $\mathrm{A}^{\mathrm{S} 220 \mathrm{~A}}$

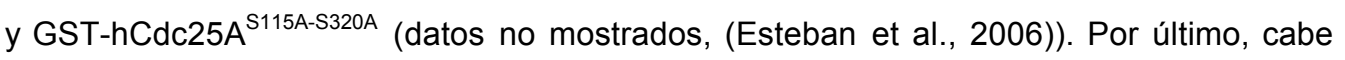
decir que la desfosforilación de estos residuos afecta a la estabilidad de hCdc25A como mostraremos más adelante. 


\section{FUNCIÓN DESEMPEÑADA POR hCdc14A EN LA REGULACIÓN DE LA TRANSICIÓN G2/M EN CÉLULAS HUMANAS}

Ya hemos mencionado que fosfatasas de la familia Cdc14, entre ellas Flp1, actúan como inhibidores de la actividad de los complejos CDK mitóticos. Además, a raíz de nuestro estudio de complementación en $S$. pombe y de los datos que hemos obtenidos in vitro, se deduce un posible mecanismo de acción por el que hCdc14A puede ejercer su función sobre la actividad CDK mitótica. En consecuencia, a partir de este momento decidimos centrar nuestro estudio en el posible papel desempeñado por hCdc14A en la regulación de la mitosis en células humanas, a través de su efecto sobre la actividad de los complejos Cdk-Ciclina mitóticos. Este estudio se ha llevado a cabo por medio del análisis de los efectos de la sobre-expresión y del silenciamiento de la expresión (empleando RNAis, RNAs de interferencia) de hCdc14A, en varias líneas celulares humanas.

\section{La sobre-expresión de hCdc14A induce un retraso en la transición G2/M}

Para estudiar los efectos de la sobre-expresión de hCdc14A, en primer lugar fueron utilizados clones estables de la línea celular U2OS (osteosarcoma humano) que expresan de forma inducible Myc-hCdc14A o Myc-hCdc14A(PD) (forma carente de actividad fosfatasa) por el sistema Tet-Off, reprimible por tetraciclina. En este sistema, la presencia de tetraciclina en el medio de cultivo (+Tet) reprime la expresión de Myc-hCdc14A o MychCdc14A(PD), mientras la eliminación de la tetraciclina (-Tet) induce su expresión. Estas líneas celulares fueron cedidas por el laboratorio del Dr. Jiri Lukas en el "Institute of Cancer Biology", Copenhaguen (Dinamarca). El empleo de estos clones, en primer lugar, nos permitió trabajar con cultivos homogéneos en los que todas las células sobreexpresan la proteína en cuestión, y en segundo lugar, ofrecía la ventaja de que estas células no han de sufrir el proceso de transfección. Por otra parte, los resultados obtenidos usando estos clones también fueron corroborados mediante transfecciones transitorias en las líneas celulares U2OS, HCT116 (carcinoma de colon humano) y/o HEK293T (células embrionarias humanas de riñón).

Para comenzar este estudio, analizamos inicialmente los posibles efectos de la sobreexpresión de hCdc14A en la progresión por el ciclo celular. Así, por medio del análisis por 
FACS del contenido de DNA, observamos que la sobre-expresión de esta fosfatasa induce, por un lado una acumulación de células con doble contenido de DNA, lo que sugiere un retraso en $\mathrm{G} 2 / \mathrm{M}$, y por otro, un aumento progresivo de la mortalidad celular, como indica la presencia de partículas con contenidos de DNA pre-G1 (inferiores a 2n) tras 72 horas de inducción (Fig. 10A). Además, la observación de las células en cultivo nos permitió confirmar que la sobre-expresión de hCdc14A da lugar a un incremento progresivo de la mortalidad y una pérdida de capacidad de proliferación (Fig. 10B). En paralelo, se comprobó que las células U2OS-Myc-hCdc14A cultivadas en presencia de

A

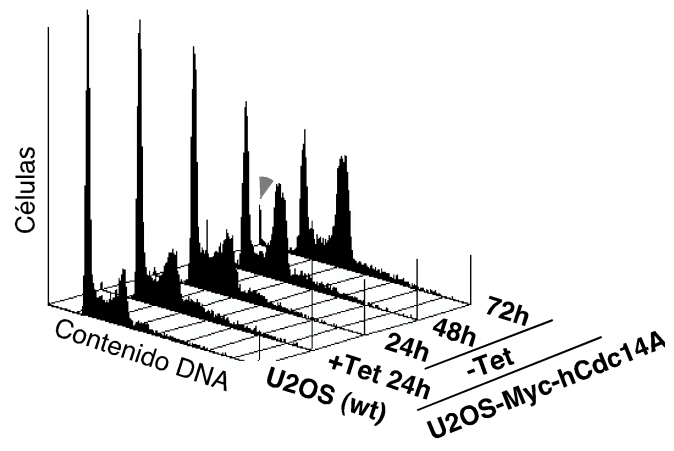

Figura 10. La sobre-expresión de hCdc14A en células U2OS da lugar a una acumulación de células en G2/M y a un incremento de la mortalidad celular. Los cultivos de células U2OS (wt) se incubaron en medio DMEM durante 24 horas; mientras, las células U2OS-Myc-hCdc14A fueron incubadas en medio DMEM con tetraciclina (+Tet, control) durante 24 horas, y sin tetraciclina (-Tet, inducción) durante 24 , 48 y 72 horas. A: Análisis citométrico de células U2OS que sobre-expresan hCdc14A. A partir de cada uno de estos cultivos celulares se recogieron muestras que fueron fijadas con etanol y teñidas con yoduro de propidio para determinar su contenido en DNA, mediante FACS. La flecha señala partículas pre-G1.

B: Fotografías de células U2OS que sobre-expresan hCdc14A en cultivo. Se obtuvieron fotografías de contraste interferencial en el microscopio de los distintos cultivos celulares a los tiempos indicados, para analizar la capacidad de proliferación de estas células.

B

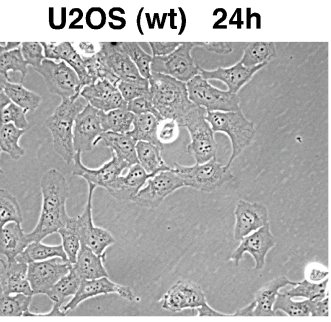

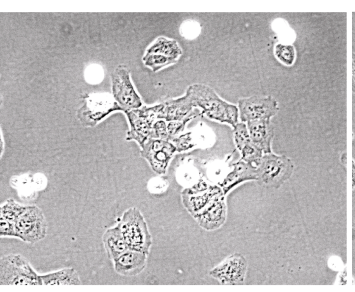

$24 h$

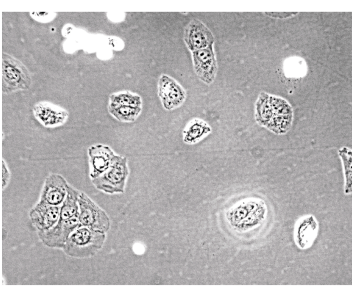

$48 \mathrm{~h}$

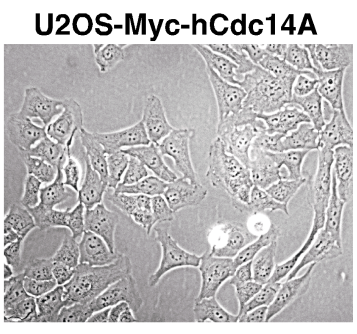

24h

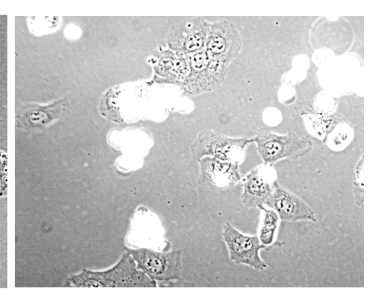

$72 \mathrm{~h}$
+Tet

-Tet 
tetraciclina (+Tet), empleadas como control, presentan un perfil de FACS (Fig. 10A), morfología y capacidad de proliferación, similares a las células U2OS (wt) (Fig. 10B).

Por otro lado, teniendo en cuenta los efectos producidos por la sobre-expresión de hCdc14A sobre la condensación y segregación cromosómicas en $S$. pombe, pasamos a analizar mediante tinción con DAPI del DNA, tanto la morfología nuclear en interfase, como el aspecto de los cromosomas en mitosis de células U2OS que sobre-expresan hCdc14A (-Tet). En estos experimentos pudimos comprobar que la sobre-expresión de hCdc14A durante 48 horas, da lugar a fenotipos característicos de inestabilidad genómica, como son células con micronúcleos (pequeños fragmentos de material genético que han quedado excluidos del núcleo como consecuencia de una segregación cromosómica irregular), núcleos lobulados o células multinucleadas, así como mitosis aberrantes (metafases anómalas o células con problemas en la segregación cromosómica) (Fig. 11 y Tabla II).

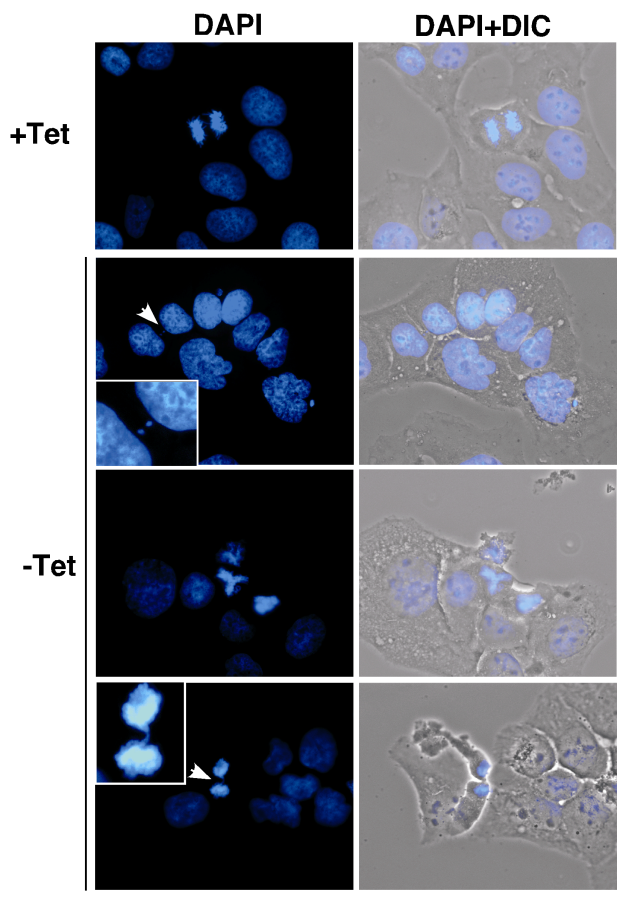

Figura 11. La sobre-expresión de hCdc14A durante 48 horas afecta a la morfología nuclear y a la mitosis, dando lugar a inestabilidad genómica. Las células U2OS-Myc-hCdc14A fueron incubadas en presencia de tetraciclina (+Tet) o en medio sin tetraciclina (-Tet) durante 48 horas, tras lo que se fijaron con paraformaldehído y su DNA fue teñido con DAPI. A continuación, se realizaron fotografías al microscopio de estas células (de fluorescencia o de contraste interferencial), observándose entre aquellas que sobre-expresan hCdc14A (-Tet): células con micronúcleos (en la fotografía superior, detalle señalado y ampliado), células multipolares (fotografía central) y células mitóticas con una segregación cromosómica irregular (fotografía inferior, detalle señalado y ampliado). En el panel superior se muestran fotografías correspondientes a células U2OS-hCdc14A (+Tet), empleadas como control. 


\begin{tabular}{|c|c|c|}
\hline & \multicolumn{2}{|l|}{$48 \mathrm{~h}$} \\
\hline & (+)Tet & $(-)$ Tet \\
\hline Micronúcleos (\%) & 3,31 & 7,56 \\
\hline Núcleos lobulados (\%) & 3,72 & 9,64 \\
\hline Binucleadas (\%) & 2,07 & 3,21 \\
\hline Mitosis aberrantes (\%) & 0 & 1,13 \\
\hline MUERTE (\%) & 2,89 & 9,83 \\
\hline$n$ ( $n^{\circ}$ total de células) & 484 & 529 \\
\hline
\end{tabular}

Tabla II. Fenotipos aberrantes inducidos por la sobre-expresión de hCdc14A. En células asíncronas U2OS-Myc-hCdc14A, control (+Tet) e inducidas 48 horas (Tet), se muestran los porcentajes de células binucleadas, con micronúcleos o núcleos lobulados. También se indica la tasa de mortalidad y los porcentajes de células mitóticas con fenotipos aberrantes, que presentan cromosomas mal orientados en metafase $o$ anafase.

\section{EI retraso de las células en G2/M inducido por la sobre-expresión de hCdc14A} es dependiente de su actividad fosfatasa

Nuestro siguiente objetivo fue determinar si el retraso en G2/M, detectado por la acumulación de células con doble contenido en DNA, es dependiente de la actividad fosfatasa de hCdc14A. Para ello, analizamos por FACS el contenido de DNA tanto de células que sobre-expresan hCdc14A, como de aquellas que sobre-expresan la proteína mutante sin actividad catalítica, hCdc14A(PD). En la Figura 12A se muestra que la sobreexpresión de hCdc14A(PD) no da lugar a cambios significativos en el perfil de FACS, respecto al control (+Tet). Este resultado indica que el retraso en G2/M de la células que sobre-expresan hCdc14A depende de la actividad fosfatasa de esta proteína.

A continuación, en estas células se analizaron, mediante Western blot, los niveles de diversas proteínas implicadas en la regulación de la transición G2/M, como son hCdc25A, B y C, Ciclina B1, Cdk1 y p21. De este modo comprobamos que los niveles de estas proteínas no se ven afectados por la sobre-expresión de la forma inactiva, hCdc14A(PD). Sin embargo, al sobre-expresar la fosfatasa activa durante 48 horas detectamos un claro incremento de hCdc25A, Ciclina B1 y p21, quizás como consecuencia del propio retraso en G2/M, así como una ligera reducción de los niveles de hCdc25C. Por otra parte, en todos los casos la cantidad de Cdk1 permanece constante, como cabía esperar (Fig. 12B). Estos datos confirman de nuevo que el retraso en G2/M inducido por la sobre-expresión de hCdc14A depende de su actividad fosfatasa. 
A

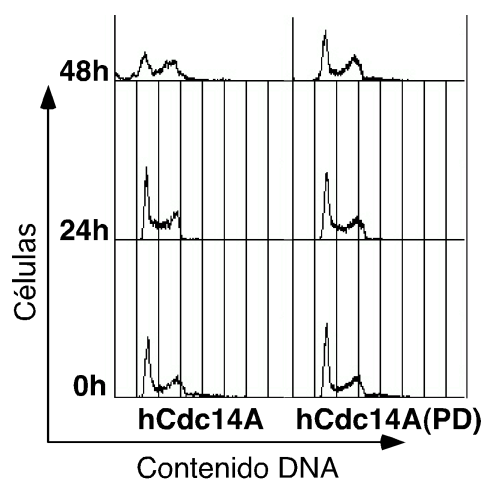

B

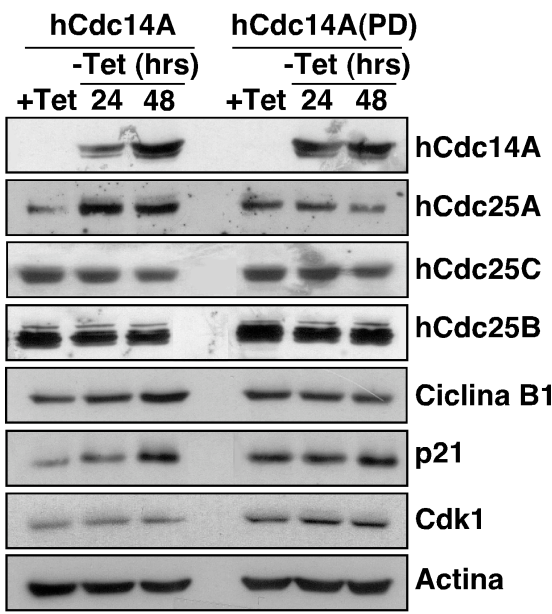

Figura 12. La sobre-expresión de la forma sin actividad fosfatasa hCdc14A(PD) no da lugar a un retraso en G2/M. Las células U2OS-Myc-hCdc14A y U2OS-Myc$\mathrm{hCdc14A(PD)} \mathrm{fueron} \mathrm{incubadas} \mathrm{en} \mathrm{medio} \mathrm{con} \mathrm{tetraciclina} \mathrm{(+Tet} \mathrm{ó} \mathrm{Oh)} \mathrm{o} \mathrm{sin} \mathrm{tetraciclina} \mathrm{(-Tet)}$ durante 24 y 48 horas. A: Análisis citométrico de células U2OS que sobre-expresan hCdc14A o hCdc14A(PD). A partir de cada uno de estos cultivos celulares se recogieron muestras que fueron fijadas con etanol y teñidas con yoduro de propidio para determinar su contenido en DNA por FACS. B: Análisis de los niveles de proteínas implicadas en la regulación de mitosis en células que sobre-expresan hCdc14A o hCdc14A(PD). Obtuvimos los extractos proteicos a partir de cada cultivo celular, y las proteínas se separaron por electroforesis en SDS-PAGE y fueron detectadas por Western Blot, empleando anticuerpos específicos frente a: hCdc14A, hCdc25A, hCdc25C, hCdc25B, Ciclina B1, p21, Cdk1 y $\beta$-Actina (control de carga).

\section{La sobre-expresión de hCdc14A induce un retraso en "antefase" y en la transición prometafase/metafase}

Puesto que el perfil de FACS no nos permitía conocer el punto concreto del ciclo en el que se produce el retraso en $\mathrm{G} 2 / \mathrm{M}$ de las células que sobre-expresan hCdc14A, decidimos determinar su índice mitótico para poder distinguir las células que se encuentran en la fase $\mathrm{G} 2$ de aquellas que están en mitosis. Esto lo llevamos a cabo mediante inmunocitoquímica con un anticuerpo específico frente a Histona $\mathrm{H} 3$ fosforilada en $\mathrm{Ser}^{10}$, empleada como marcador mitótico (Van Hooser et al., 1998). Este análisis nos permitió detectar las distintas fases mitóticas y una fase inmediatamente anterior a la mitosis caracterizada por la fosforilación de Histona H3 en ausencia de condensación cromosómica aparente, a la que denominamos "antefase" (Fig. 13), como hemos explicado en Introducción. De este modo, la medida del índice mitótico puso de manifiesto que la sobre-expresión de hCdc14A durante 48 horas en cultivos celulares asíncronos da 


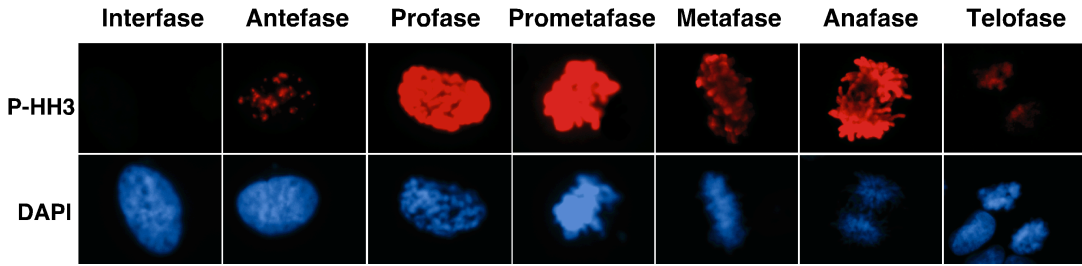

\begin{tabular}{|c||c|c|c|c|c|c|c|c|}
\hline $\begin{array}{c}(\mathbf{+}) \text { Tet } \\
\mathrm{n}=1236\end{array}$ & $\mathbf{9 7 , 3 3} \%$ & $18,2 \%$ & $15,1 \%$ & $36,4 \%$ & $6,0 \%$ & $12,1 \%$ & $12,2 \%$ & $\mathbf{2 , 6 7 \%}$ \\
\hline $\begin{array}{c}\mathbf{( - ) T e t} \\
\mathrm{n}=1418\end{array}$ & $\mathbf{7 8 , 1 4} \%$ & $\mathbf{8 5 , 1} \%$ & $\mathbf{1 , 6} \%$ & $12,3 \%$ & $0,0 \%$ & $0,3 \%$ & $0,3 \%$ & $\mathbf{2 1 , 8 6 \%}$ \\
\hline
\end{tabular}

Figura 13. Fosforilación de la Histona $\mathrm{H3}\left(\mathrm{Ser}^{10}\right)$ en células que sobre-expresan hCdc14A. Las células U2OS fueron fijadas con paraformaldehído y sometidas a inmunocitoquímica, empleando un anticuerpo específico frente a Histona $\mathrm{H} 3$ fosforilada en el residuo $\mathrm{Ser}^{10}$, y a la tinción de su DNA con DAPI. En las fotografías se distinguen las fases clásicas de mitosis, profasetelofase, en las que la Histona H3 se encuentra fosforilada y la tinción con DAPI pone de manifiesto la condensación cromosómica. Además, se muestra una célula en "antefase", en la cual no existe una condensación cromosómica aparente (DAPI), pero sí la fosforilación de Histona H3. A la izquierda también se observa una célula en interfase, sin condensación de los cromosomas ni fosforilación de Histona H3. En la parte inferior se muestran los porcentajes de células control (+Tet) y células que sobre-expresan hCdc14A durante 48 horas en cultivo asincrónico (-Tet) que se encuentran en interfase (izquierda) o presentan Histona $\mathrm{H} 3$ fosforilada (derecha), en la zona central se distinguen los porcentajes de células con Histona H3 fosforilada en las distintas fases de mitosis y "antefase".

lugar a una acumulación de células en "antefase", indicativa de un retraso a la entrada en mitosis. Además, también pudimos detectar cierta dificultad de estas células para progresar por las últimas fases de mitosis (metafase, anafase y telofase) (Fig. 13).

\section{Las células que sobre-expresan hCdc14A presentan una menor actividad de los complejos CDK mitóticos}

Como ya hemos mencionado, varias fosfatasas de la familia Cdc14 están implicadas en la inhibición de la actividad de los complejos CDK mitóticos. Por esta razón, resultaba lógico pensar que los altos niveles de hCdc14A inducidos en nuestra línea celular pudieran inhibir la actividad de estos complejos, lo que explicaría la dificultad de estas células para entrar en mitosis. Para comprobar esta posibilidad, analizamos la actividad quinasa de los complejos mitóticos Cdk1-Ciclina B1 y Cdk-Ciclina A sobre Histona H1. Estos complejos CDK se inmunoprecipitaron con anticuerpos específicos frente a las Ciclinas B1 y A, respectivamente, a partir de extractos proteicos de células que sobreexpresan hCdc14A o hCdc14A(PD) y de sus correpondientes células control. Como se observa en la Figura 14, la actividad de los complejos Cdk1-Ciclina B1 se encuentra reducida en las células con elevados niveles de hCdc14A, mientras que por el contrario, altos niveles de la proteína inactiva inducen un incremento de la actividad de dichos 
complejos. A su vez, la actividad asociada a complejos Cdk-Ciclina A también es menor a consecuencia de la sobre-expresión de hCdc14A (Fig. 15).

Estos resultados nos permitieron concluir que el retraso en la transición G2/M, promovido por la sobre-expresión de hCdc14A, está asociado a una reducción de la actividad CDK mitótica, posible causa a su vez de dicho retraso.

A

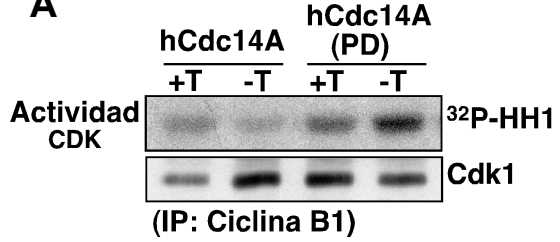

Figura 14. La sobre-expresión de hCdc14A induce una reducción de la actividad quinasa de los complejos Cdk1-Ciclina B1, de forma dependiente de su actividad fosfatasa. Las células U2OS-Myc-hCdc14A y U2OS-MychCdc14A(PD) fueron incubadas en presencia de tetraciclina $(+$ Tet) 0 en ausencia de ésta (-Tet) durante 48 horas. Obtuvimos los extractos proteicos a partir de cada cultivo celular e inmunoprecipitamos los complejos Cdk1-Ciclina B1, empleando un anticuerpo frente a Ciclina B1. Estos complejos fueron sometidos a un ensayo quinasa sobre Histona $\mathrm{H} 1$, realizado durante 30 minutos a $30^{\circ} \mathrm{C}$. A: Las proteínas de cada reacción fueron separadas mediante electroforesis en SDSPAGE, y analizadas por auto-radiografía (panel superior) y por Western blot con un anticuerpo anti-Cdk1 (panel inferior). $\boldsymbol{B}$ : Realizamos tres repeticiones del experimento mostrado en $(\boldsymbol{A})$. En cada experimento se llevó a cabo una cuantificación de la actividad quinasa de los complejos y su normalización con respecto a los niveles de Cdk1 inmunoprecipitados. En la gráfica se representa la media aritmética de la actividad quinasa (representada en unidades arbitrarias, en células control se considera 1) y las desviaciones estándar correspondientes a los tres experimentos independientes. 
A

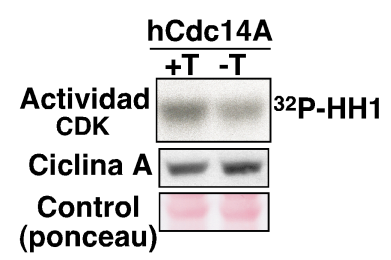

B

Actividad Cdk- Ciclina A

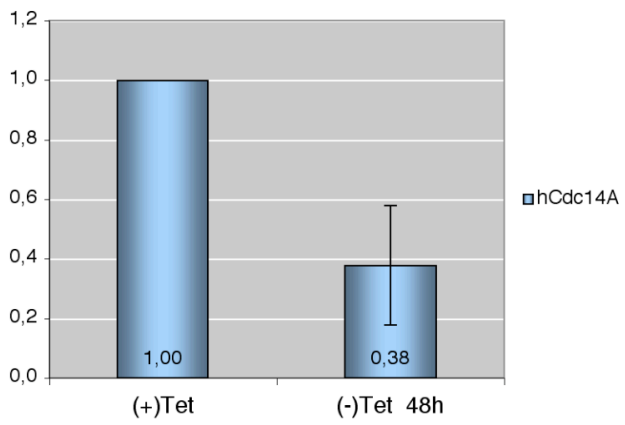

Figura 15. La sobre-expresión de hCdc14A induce una reducción de la actividad quinasa de los complejos Cdk-Ciclina A. Las células U2OS-Myc-hCdc14A fueron incubadas en presencia de tetraciclina (+Tet) o en ausencia de ésta (-Tet), durante 48 horas. Obtuvimos los extractos proteicos a partir de cada cultivo celular e inmunoprecipitamos los complejos Cdk-Ciclina A, empleando un anticuerpo frente a la Ciclina A. Estos complejos fueron sometidos a un ensayo quinasa sobre Histona $\mathrm{H} 1$, realizado durante 30 minutos a $30^{\circ} \mathrm{C}$. $\boldsymbol{A}$ : Las proteínas de cada reacción fueron separadas mediante electroforesis en SDS-PAGE y analizadas por auto-radiografía (panel superior). Los niveles de la proteína Ciclina A se detectaron mediante Western blot en los extractos celulares totales correspondientes a cada cultivo (panel inferior). B: Realizamos tres experimentos independientes. En cada uno de ellos se llevó a cabo una cuantificación de la actividad quinasa de los complejos Cdk-Ciclina A, que a su vez fue normalizada con respecto a los niveles de Ciclina A en extractos totales. En la gráfica se representa la media aritmética y la desviación estándar de las tres cuantificaciones. La actividad quinasa se encuentra representada en unidades arbitrarias considerando que la de las células control es 1.

\subsection{Caracterización del retraso en la transición G2/M inducido por la sobre-expresión de hCdc14A}

Dado que hasta el momento, el retraso en la transición G2/M se había observado en cultivos asíncronos tras 48 horas de sobre-expresión, no podíamos descartar que éste fuese consecuencia de los efectos ejercidos por un exceso de hCdc14A durante la mitosis y/o la citoquinesis de un ciclo anterior (Kaiser et al., 2002; Mailand et al., 2002a). Por esta razón, para intentar asociar el retraso en la entrada en mitosis con un posible efecto de la sobre-expresión de hCdc14A sobre ese punto concreto del ciclo celular, diseñamos experimentos con cultivos sincrónicos que nos permitieron analizar la cinética de entrada en mitosis y conocer así la naturaleza del retraso en la transición G2/M.

Con este fin, en primer lugar sincronizamos las células en G1/S, por medio de un doble tratamiento con timidina (inhibidor de la replicación), e inducimos la expresión de 
hCdc14A o hCdc14A(PD) al inicio del segundo período de tratamiento con timidina. Una vez sincronizadas las células en G1/S, se eliminó la timidina del medio (“liberación”) para permitir su progresión por el ciclo y monitorizamos su cinética de paso a través de mitosis mediante el análisis por FACS de su contenido de DNA. Como se observa en la Figura 16A, la sobre-expresión de la fosfatasa hCdc14A en estas condiciones da lugar a un retraso en el paso por G2/M, que no ocurre al sobre-expresar la forma inactiva $\mathrm{hCdc} 14 \mathrm{~A}(\mathrm{PD})$, lo que confirma que este retraso es dependiente de la actividad fosfatasa de hCdc14A.

En segundo lugar, quisimos descartar que la sobre-expresión de hCdc14A ya durante el segundo "bloqueo" con timidina pudiera ser la causa del retraso en G2/M, y para ello acotamos con mayor precisión el momento del ciclo en el que hCdc14A podría ejercer la función que induce el retraso en la entrada en mitosis. Con este fin, las células se sincronizaron también en G1/S por medio de un doble tratamiento con timidina, pero en esta ocasión inducimos la expresión de hCdc14A en el momento de la eliminación de la timidina tras el segundo tratamiento (“liberación”). A continuación, se estudió su cinética de paso por mitosis mediante análisis por FACS. Con este experimento se demuestra que

A
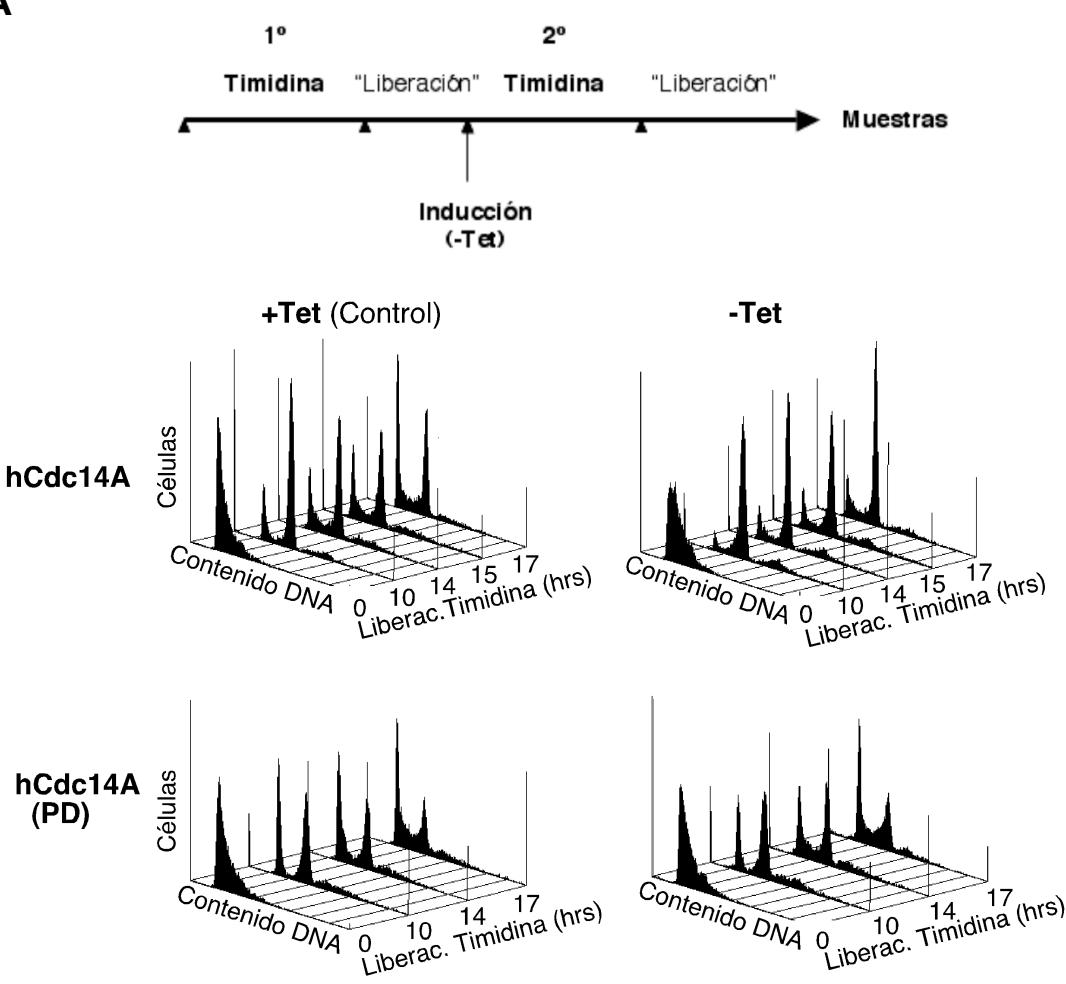
B
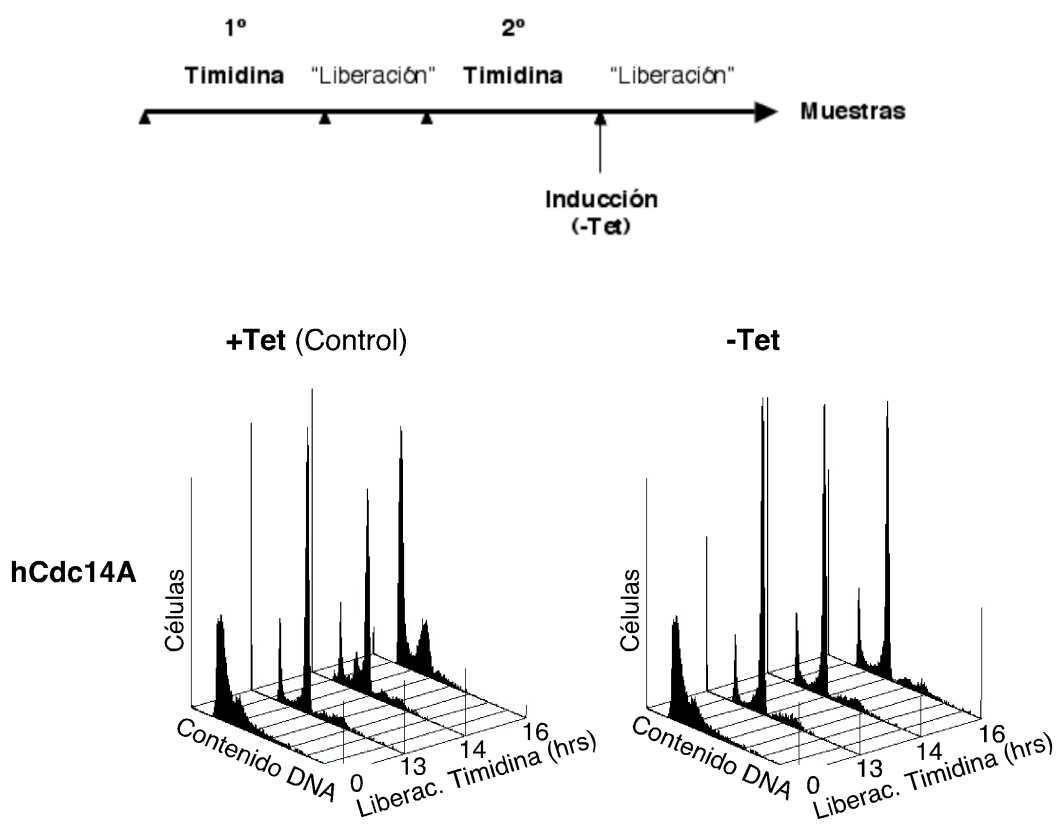

Figura 16. La sobre-expresión de hCdc14A, de forma dependiente de su actividad catalítica, promueve un retraso en G2/M de células U2OS sincronizadas con timidina. Los cultivos celulares U2OS-Myc-hCdc14A y U2OS-Myc-hCdc14A(PD) fueron sincronizados mediante un doble tratamiento con timidina y posterior "liberación", tras lo que se recogieron muestras de estas células a los tiempos indicados en cada caso, que fueron preparadas para el posterior análisis citométrico de su contenido de DNA (FACS). A: Al comienzo del segundo tratamiento con timidina, la mitad de las células se mantienen con tetraciclina (+Tet) y la otra mitad son inducidas (-Tet) (Esquema). Tras el doble tratamiento con timidina, se recogieron muestras de las células sincronizadas en G1/S ( 0 horas) y después de 10,14, 15 y 17 horas de "liberación". B : En este experimento sólo se emplearon células U2OS-Myc-hCdc14A, tratadas como se ha indicado. En este caso, la inducción de la mitad de las células (-Tet), no se llevó a cabo hasta la "liberación" del segundo tratamiento con timidina (Esquema). Recogimos muestras a las $0,13,14$ y 16 horas de "liberación" desde el doble tratamiento con timidina.

elevados niveles de la fosfatasa activa hCdc14A a partir de la fase $S$ ya son capaces de inducir un retraso en la transición G2/M (Fig. 16B).

Por último, a pesar de que la timidina es utilizada de forma habitual para la sincronización de cultivos celulares en G1/S, se trata de un compuesto que puede causar daño en el DNA y activar los mecanismos de respuesta a dicho daño o checkpoints (Kurose et al., 2006). Para descartar que estos efectos de la timidina afectasen a nuestro resultado (si bien el retraso en G2/M no ocurría en los controles, también tratados con timidina) decidimos analizar la cinética de progresión por mitosis de células sincronizadas mediante otro método, en concreto, por un tratamiento con nocodazol, cuya acción inhibe 
la polimerización de los microtúbulos y permite sincronizar las células en mitosis. Tras este tratamiento, las células mitóticas fueron seleccionadas y "liberadas" para su progresión por el ciclo. Después de 8 horas en cultivo (ya en G1), la mitad de las células se mantuvieron en presencia de tetraciclina (células control) y en la otra mitad se indujo la sobre-expresión de hCdc14A, eliminando la tetraciclina del medio. Transcurridas 6,5 horas de inducción, se comenzó a monitorizar la progresión por mitosis de dichas células mediante análisis por FACS. Como se observa en la Figura 17, en estas condiciones las células que sobre-expresan hCdc14A presentan de nuevo un retraso en G2/M, lo que confirma los resultados obtenidos mediante la sincronización en G1/S por el tratamiento con timidina.

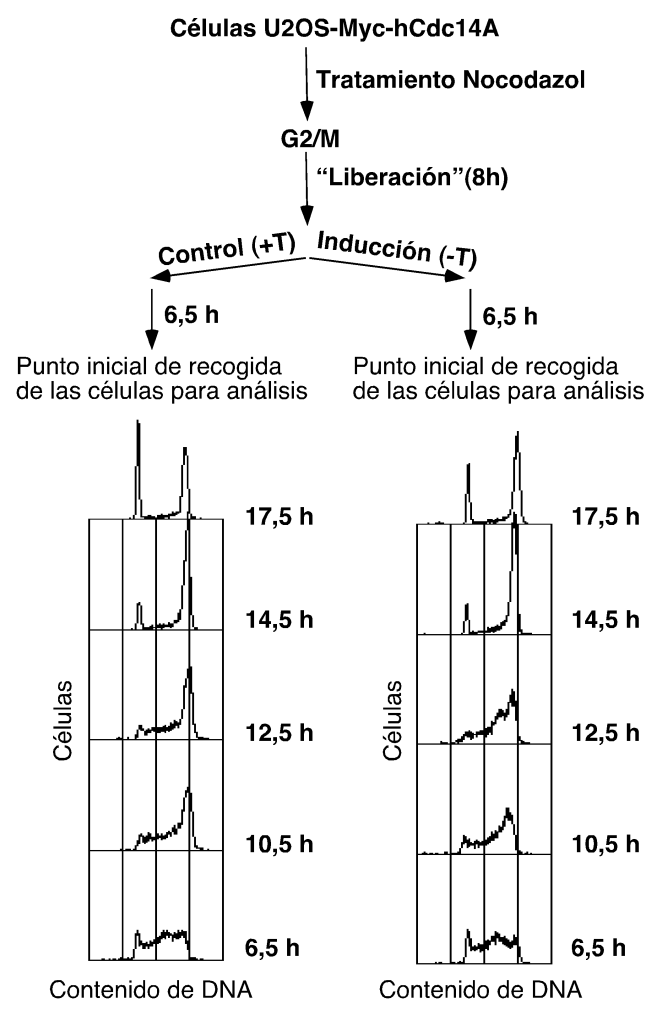

Figura 17. La sobre-expresión de hCdc14A induce un retraso en G2/M de células U2OS sincronizadas con nocodazol. Los cultivos celulares U2OS-Myc-hCdc14A fueron tratados con nocodazol, tras lo que las células mitóticas (redondeadas) fueron seleccionadas y se incubaron durante 8 horas en medio sin nocodazol ("liberación"). A partir de este momento, la mitad de las células se mantuvieron en presencia de tetraciclina $(+T)$ y en la otra mitad se indujo la sobre-expresión, eliminando la tetraciclina (-T). Se recogieron muestras a partir del momento de la inducción, a las 6,5, 10,5, 12,5, $14,5,17,5$ horas, para su análisis por FACS. 
Estos resultados obtenidos con cultivos sincronizados mediante las dos estrategias indicadas, sugieren que la fosfatasa hCdc14A puede estar implicada en la regulación de la entrada en mitosis, probablemente por su acción inhibidora sobre la actividad de los complejos CDK mitóticos.

Cabe decir, que la mayoría de los experimentos que mostraremos a continuación se han realizado empleando células sincronizadas como se indica en la Figura 16A, observando en todos los casos el mismo retraso en G2/M de las células que sobreexpresan hCdc14A (-Tet). No obstante, los perfiles de FACS correspondientes a dichas figuras no serán mostrados para su simplificación.

\section{La sobre-expresión de hCdc14A retrasa la condensación cromosómica}

En paralelo al análisis del contenido de DNA de las células sincronizadas con timidina, realizado a distintos tiempos a lo largo de su progresión por G2/M (Fig. 16A), estudiamos también la cinética de condensación cromosómica de estas células mediante la tinción con DAPI del DNA. Como se observa en la gráfica de la Figura 18, la sobre-expresión de hCdc14A induce un retraso significativo en la condensación cromosómica con respecto a

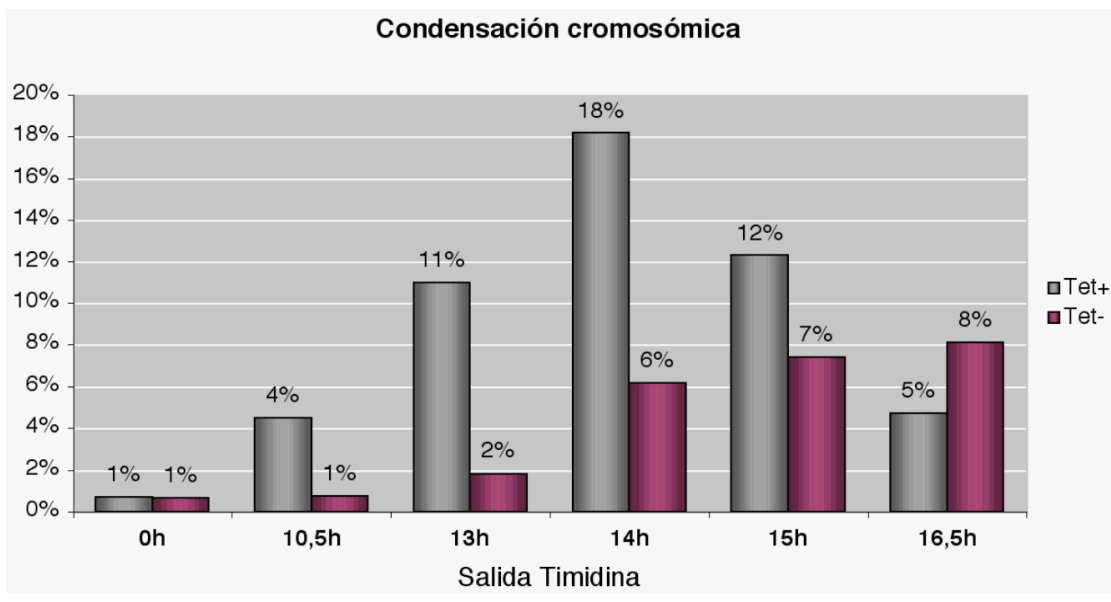

Figura 18. La sobre-expresión de hCdc14A promueve un retraso en la condensación cromosómica. Los cultivos celulares U2OS-Myc-hCdc14A fueron sincronizados e inducidos como se indica en la Figura 16A. De modo que se recogieron muestras de células inducidas (-Tet) y control (+Tet), sincronizadas en G1/S (0 horas), y tras 10,5, 13, 14, 15 y 16,5 horas desde la "liberación" del doble tratamiento con timidina. Estas muestras fueron fijadas con paraformaldehído y su DNA teñido con DAPI para la cuantificación (empleando el microscopio de fluorescencia) de las células que presentaban condensación cromosómica y de aquellas que no. En cada una de las muestras se cuantificaron como mínimo un total de 1000 células. 
las células control. Así, mientras en los cultivos celulares control (+Tet) se alcanza el máximo porcentaje de células con condensación cromosómica a las 14 horas, las células que sobre-expresan nuestra fosfatasa no llegan a alcanzar este porcentaje durante todo el período estudiado.

La sobre-expresión de hCdc14A da lugar a un retraso anterior a metafase, acompañado por una ausencia de activación de Cdk1

Para caracterizar con más exactitud el retraso en G2/M inducido por la sobreexpresión de hCdc14A en células sincronizadas (ver esquema Fig. 16A), en primer lugar determinamos mediante Western blot los niveles de las Ciclinas mitóticas (Ciclina A y Ciclina B1) durante el curso del experimento (G2/M). Los niveles proteicos de estas Ciclinas constituyen parámetros adecuados para nuestro objetivo puesto que se sabe que la Ciclina A comienza a degradarse al final de prometafase y la Ciclina B1 durante metafase (Minshull et al., 1990; Pines y Hunter, 1990; Clute y Pines, 1999). En paralelo, examinamos también la cinética de activación de Cdk1, a través de los cambios en su estado de fosforilación, detectables por modificaciones en su movilidad electroforética.

De esta forma, como se observa en la Figura 19, en las células control la Ciclina A comienza a degradarse a las 14 horas tras la "liberación del bloqueo" en G1/S, cuando también se hace evidente la activación (por desfosforilación) de Cdk1, mientras que la cantidad de Ciclina B1 no comienza a disminuir hasta las 15,5 horas. Por el contrario, en los extractos de células que sobre-expresan hCdc14A a las 15,5 horas todavía no se ha comenzado a degradar la Ciclina A, lo cual nos indica que el retraso en la entrada en mitosis es anterior a su degradación al final de prometafase, y además a las 15,5 horas, tampoco se ha hecho evidente la activación de Cdk1 (por fosforilación), lo que podría explicar el propio retraso en la entrada en mitosis.

Por otra parte, hemos comprobado también que estos parámetros, altos niveles de Ciclinas mitóticas y falta de activación de Cdk1, se mantienen durante varias horas en las células que sobre-expresan hCdc14A, hasta 19,5 horas tras la "liberación del bloqueo", lo que pone de manifiesto que este retraso en el ciclo es severo (datos no mostrados).

A partir de estos resultados podemos concluir que el retraso en la transición G2/M, inducido por la sobre-expresión de hCdc14A, ocurre con anterioridad al final de prometafase. $Y$ además, que durante este retraso en la entrada en mitosis no se produce la correcta activación de Cdk1, lo que a su vez podría constituir una de sus causas, hecho que es coherente de nuevo con una función de hCdc14A en la regulación de la actividad CDK mitótica en G2/M. 


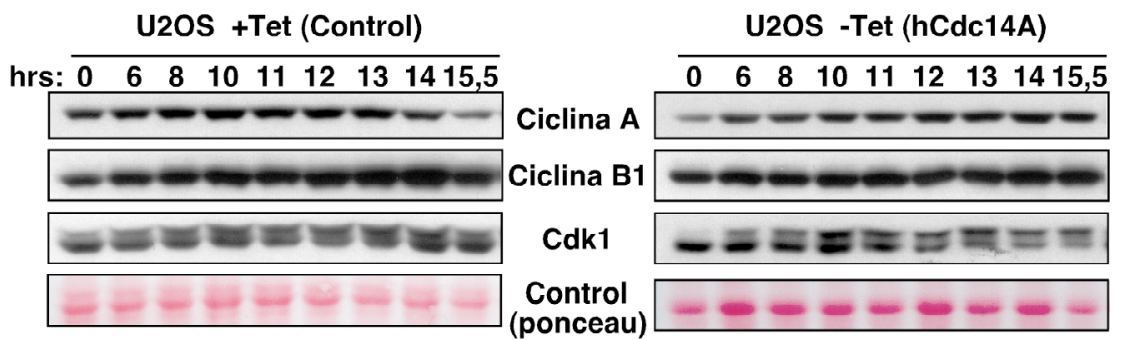

Figura 19. El retraso de las células U2OS inducido por la sobre-expresión de hCdc14A es anterior a metafase. Los cultivos celulares U2OS-Myc-hCdc14A fueron sincronizados e inducidos como se indica en la Figura 16A. Se recogieron muestras de células inducidas (-Tet) y control, sincronizadas en G1/S (0 horas), y tras $6,8,10,11,12$, 13,14 y 15,5 horas desde la "liberación" del doble tratamiento con timidina. Obtuvimos extractos proteicos de cada muestra, cuyas proteínas fueron separadas por electroforesis en SDS-PAGE. A continuación, se analizaron los niveles de Ciclina A, Ciclina B1 y Cdk1, mediante Western blot, empleando anticuerpos específicos frente a cada una de esta proteínas. Nótese que se distinguen dos bandas correspondientes a la proteína Cdk1, la superior es la forma inactiva, fosforilada en los residuos $\mathrm{Thr}^{14}$ y $\mathrm{Tyr}^{15}$, mientras la inferior corresponde a la forma activa, desfosforilada en estos residuos. Se empleó como control de carga la tinción con Ponceau de los extractos proteicos (panel inferior).

\section{La presencia de elevados niveles de hCdc14A induce un retraso en "antefase" y en la transición prometafase/metafase}

Con el fin de determinar de forma aún más precisa el punto del ciclo en el que se produce el retraso inducido por la sobre-expresión de hCdc14A en células sincronizadas (Fig. 16A), analizamos la cinética de fosforilación de Histona $\mathrm{H} 3$ en $\mathrm{Ser}^{10}$ a la entrada en mitosis (del mismo modo que se ha mostrado en el apartado 1 para cultivos asíncronos, Fig. 13). Como ya nos indicaba la cinética de condensación cromosómica, a las 13 horas de "liberación del bloqueo" en G1/S, se observa que las células con elevados niveles de hCdc14A ya se retrasan en su progresión por G2/M de forma previa a la "antefase" (puesto que el porcentaje de estas células que presentan fosforilación en Histona $\mathrm{H} 3$ es inferior al de las células control, $7,06 \%$ frente a $9,96 \%$ ) y dicho retraso se mantiene durante la "antefase" (49,5\% de las células con Histona H3 fosforilada están en "antefase", frente a $22,5 \%$ en el control) (Tabla IIla). Si avanzamos más a través de mitosis, a las 17 horas, se pone de manifiesto que mientras la mayoría de las células control (+Tet) ya han salido de mitosis (sólo hay $1,29 \%$ con Histona H3 fosforilada), todavía hay un alto porcentaje de células (-Tet) en mitosis (8\%) como consecuencia del retraso, y además los bajos porcentajes de estas células en las últimas fases de mitosis nos hacen pensar que la sobre-expresión de hCdc14A también afecta a la progresión por la transición prometafase/metafase (Tabla IIIb). Estos datos sugieren que la sobre-expresión de hCdc14A tiene un efecto sobre la progresión por G2/M de las células, caracterizado por un 
a

\begin{tabular}{|r|r|r|}
\cline { 2 - 3 } \multicolumn{1}{c|}{} & \multicolumn{2}{c|}{ 13h liberación timidina } \\
\cline { 2 - 3 } \multicolumn{1}{c|}{} & \multicolumn{1}{c|}{ (+)Tet } & \multicolumn{1}{c|}{$(-)$ Tet } \\
\hline P-HH3 (\%)- Indice mitótico & $\mathbf{9 , 9 6}$ & $\mathbf{7 , 0 4}$ \\
\hline Antefase (\% de mitosis) & 22,5 & 49,5 \\
Profase (\% de mitosis) & 22,5 & 11,7 \\
Prometafase (\% de mitosis) & 37,5 & 33,4 \\
Metafase (\% de mitosis) & 5,8 & 4,5 \\
Anafase (\% de mitosis) & 7,5 & 0 \\
Telofase/Citoquinesis (\% de mitosis) & 4,2 & 0,9 \\
\hline MUERTE (\%) & $\mathbf{0 , 2 6}$ & $\mathbf{2 , 7 4}$ \\
\hline $\mathbf{n}$ (n' ${ }^{\circ}$ total células) & $\mathbf{1 2 3 7}$ & $\mathbf{1 1 2 5}$ \\
\hline
\end{tabular}

b

\begin{tabular}{|c|r|r|}
\cline { 2 - 3 } \multicolumn{1}{c|}{} & \multicolumn{2}{c|}{ 17h liberación timidina } \\
\cline { 2 - 3 } \multicolumn{1}{c|}{} & \multicolumn{1}{c|}{ (+)Tet } & \multicolumn{1}{c|}{$(-)$ Tet } \\
\hline P-HH3 (\%)- Indice mitótico & $\mathbf{1 , 2 9}$ & $\mathbf{8}$ \\
\hline Antefase (\% de mitosis) & 6 & 4,4 \\
Profase (\% de mitosis) & 18 & 4,4 \\
Prometafase (\% de mitosis) & 45 & 84,6 \\
Metafase (\% de mitosis) & 19 & 5,5 \\
Anafase (\% de mitosis) & 6 & 0 \\
Telofase/Citoquinesis (\% de mitosis) & 6 & 1,1 \\
\hline MUERTE (\%) & $\mathbf{0 , 0 8}$ & $\mathbf{3 , 2 9}$ \\
\hline $\mathbf{n}$ (n' ${ }^{\circ}$ total células) & $\mathbf{1 3 1 6}$ & $\mathbf{1 0 1 0}$ \\
\hline
\end{tabular}

Tabla III. Cinética de fosforilación de Histona H3 en células U2OS-Myc-hCdc14A (+Tet y -Tet) tras 13 (a) y 17 horas (b) de "liberación del bloqueo" en G1/S. Se indica el porcentaje total de células con $\mathrm{HH} 3$ fosforilada y de muerte celular (negrita). También se muestran los porcentajes de células con Histona $\mathrm{H} 3$ fosforilada que se encuentran en las distintas fases mitóticas y "antefase. El número total de células contadas (n) se indica en la parte inferior.

retraso previo a la entrada en mitosis, que comienza antes de "antefase" y se mantiene durante ésta, y otro retraso que afecta a la transición prometafase/metafase.

\subsection{El retraso en la transición $\mathrm{G} 2 / \mathrm{M}$ también ocurre al sobre-expresar hCdc14A en otras líneas celulares}

Tras el análisis de los resultados mostrados hasta el momento, obtenidos empleando clones estables inducibles U2OS-Myc-hCdc14A, quisimos comprobar si el retraso en la transición G2/M se producía en la misma línea celular U2OS, y en HCT116, transfectadas ambas de forma transitoria. El objetivo de dicha comprobación fue determinar que el efecto descrito, de la sobre-expresión de hCdc14A en la entrada de mitosis, no era específico de los clones empleados ni de la línea celular U2OS. 


\section{La sobre-expresión de hCdc14A en células U2OS induce un retraso en la entrada en mitosis}

En primer lugar, analizamos la entrada en mitosis de células U2OS sincronizadas a partir de G1/S y transfectadas de forma transitoria con los plásmidos pcDNA3-MychCdc14A o pcDNA3-Myc vacío (control), como se muestra en el esquema (Fig. 20A). Transcurridas 13 horas tras el segundo tratamiento con timidina, momento adecuado para el análisis de la entrada en mitosis de estas células (como se dedujo de otros experimentos), determinamos el índice mitótico mediante inmunocitoquímica frente a Histona H3 fosforilada en Ser $^{10}$.

Como se muestra en la Figura 20B, a las 13 horas las células que sobre-expresan hCdc14A presentan un retraso en la transición G2/M que comienza antes de la fosforilación de Histona H3 (células que presentan Histona H3 fosforilada: 4,85\% frente a

A

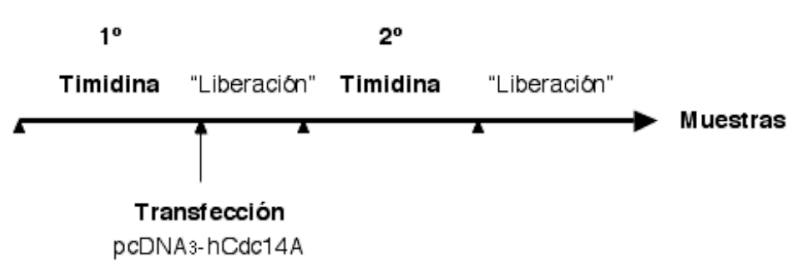

B

\begin{tabular}{|r|r|r|}
\cline { 2 - 3 } \multicolumn{1}{c|}{} & \multicolumn{2}{c|}{ 13h liberación timidina } \\
\cline { 2 - 3 } \multicolumn{1}{c|}{ Control } & hCdc14A \\
\hline P-HH3 (\%)- Indice mitótico & $\mathbf{2 2 , 2 1}$ & $\mathbf{4 , 8 5}$ \\
\hline Antefase+ Profase (\% de mitosis) & 75 & 96,3 \\
Prometafase (\% de mitosis) & 14,2 & 0 \\
Metafase (\% de mitosis) & 6,2 & 0 \\
Anafase (\% de mitosis) & 4,3 & 3,7 \\
\hline $\mathbf{n}$ ( $\mathbf{n}^{\mathbf{0}}$ total células) & $\mathbf{7 2 8}$ & $\mathbf{5 6 1}$ \\
\hline
\end{tabular}

Figura 20. La sobre-expresión de hCdc14A induce un retraso a la entrada en mitosis de células U2OS. A: Esquema. Las células U2OS fueron sincronizadas mediante un doble tratamiento con timidina y "liberación". Inmediatamente tras el primer tratamiento con timidina, las células se transfectaron de forma transitoria con el plásmido pcDNA3 vacío o conteniendo el cDNA de hCdc14A. Tras 13 horas de "liberación", las células que fueron fijadas con paraformaldehído y sometidas a inmunocitoquímica frente a Histona H3 fosforilada en $\operatorname{Ser}^{10}(\mathrm{P}-\mathrm{HH} 3)$. B: Tabla. Porcentajes de células U2OS, control y que sobre-expresan hCdc14A, con fosforilación de Histona $\mathrm{H} 3$ tras 13 horas de "liberación del bloqueo" en G1/S. Se indica el porcentaje total de células con P-HH3, los porcentajes de células con $\mathrm{P}-\mathrm{HH} 3$ en las distintas fases mitóticas, incluyendo "antefase", y el número total de células contadas $(n)$. 
$22,21 \%$ de las células control), y se mantiene a la entrada de mitosis ("antefase"+profase, $96,3 \%$ frente a $75 \%$ en células control), lo que concuerda con los datos obtenidos en la línea celular U2OS-Myc-hCdc14A.

Este resultado demuestra que el efecto de la sobre-expresión de hCdc14A en la transición G2/M no es un efecto específico de los clones estables U2OS-Myc-hCdc14A.

La sobre-expresión de hCdc14A en células HCT116 induce un retraso en la entrada en mitosis, asociado a una reducción de la actividad CDK mitótica

En el caso de la línea celular HCT116 también se realizaron experimentos de sincronización y transfección transitoria, como el descrito en el apartado anterior para la línea celular U2OS (Fig. 20A).

\begin{tabular}{|c|c|c|}
\hline & \multicolumn{2}{|c|}{ 13h liberación timidina } \\
\hline & Control & hCdc14A \\
\hline P-HH3 (\%)- Índice mitótico & 7,13 & 4,76 \\
\hline Antefase (\% de mitosis) & 8,4 & 32,2 \\
\hline Profase (\% de mitosis) & 15,5 & 14,3 \\
\hline Prometafase (\% de mitosis) & 57,7 & 42,9 \\
\hline Metafase (\% de mitosis) & 11,3 & 4,8 \\
\hline Anafase (\% de mitosis) & 1,4 & 4,8 \\
\hline Telofase/Citoquinesis(\% de mitosis) & 5,6 & 1,2 \\
\hline $\mathrm{n}$ ( $\mathrm{n}^{\circ}$ total células) & 999 & 749 \\
\hline
\end{tabular}

Tabla IV. Fosforilación de Histona H3 en células HCT116, control y que sobre-expresan hCdc14A, tras 13 horas de "liberación del bloqueo" en G1/S. Se indica el porcentaje total de células con $\mathrm{P}-\mathrm{HH} 3$, los porcentajes de células con $\mathrm{P}-\mathrm{HH} 3$ en las distintas fases mitóticas y en "antefase", y el número total de células contadas (n).

En la Tabla IV, se observa que tras 13 horas desde la salida del "bloqueo" en G1/S, las células HCT116 que sobre-expresan hCdc14A presentan un retraso en la transición G2/M que ocurre de forma previa (células que presentan Histona $\mathrm{H} 3$ fosforilada: 4,76\% frente a un $7,13 \%$ de las células control) y durante la "antefase" (32,2\% de células con $\mathrm{P}$ HH3 están en "antefase", frente a 8,4\% de las células control).

Estos resultados confirman que el retraso en la entrada en mitosis causado por la sobre-expresión de hCdc14A no es un efecto dependiente de la línea celular.

Por otra parte, analizamos también en esta línea celular los niveles de actividad CDK mitótica para determinar si en las células HCT116 el retraso en la transición G2/M también está asociado con una reducción de dicha actividad. Para ello, se examinó la actividad quinasa de los complejos Cdk1-Ciclina B1 de células HCT116 que habían sobreexpresado hCdc14A durante 48 horas frente a células control. Como se observa en la 
Actividad Cdk1-Ciclina B1

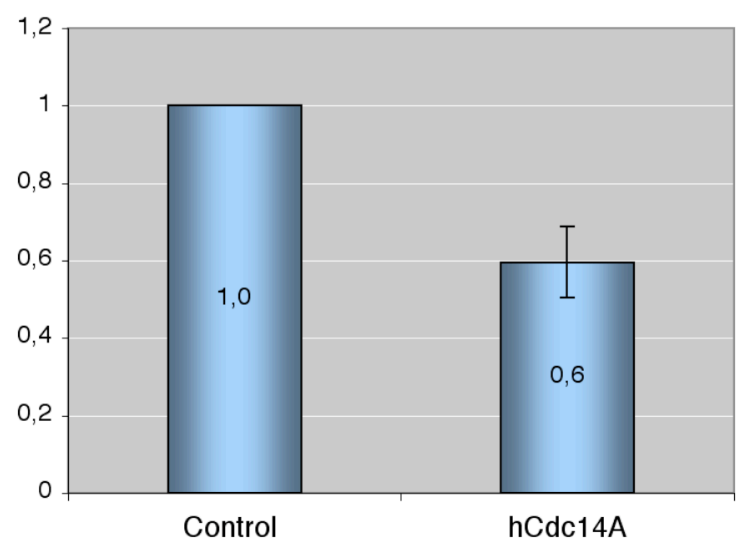

Figura 21. La sobreexpresión de hCdc14A da lugar a una reducción de la actividad quinasa de los complejos Cdk1-Ciclina B1 en células HCT116. Las células HCT116 fueron transfectadas de forma transitoria con el plásmido pcDNA3 vacío o conteniendo el cDNA de hCdc14A. Estas células se recogieron 48 horas tras la transfección, obtuvimos los extractos proteicos e inmunoprecipitamos los complejos Cdk1-Ciclina B1, empleando un anticuerpo frente a Ciclina B1.

Estos complejos fueron sometidos a un ensayo quinasa sobre Histona $\mathrm{H} 1$ realizado durante 30 minutos a $30^{\circ} \mathrm{C}$. Las proteínas de cada reacción fueron procesadas mediante electroforesis en SDS-PAGE, y analizadas por auto-radiografía y por Western blot con un anticuerpo anti-Cdk1. Se llevó a cabo una cuantificación de la actividad quinasa de los complejos CDK, que a su vez fue normalizada con respecto a los niveles de Cdk1 inmunoprecipitados. Consideramos 1 la actividad normalizada en células control. En la gráfica se representa la media aritmética de las cuantificaciones y la desviación estándar correspondiente a tres experimentos independientes.

Figura 21, la sobre-expresión de hCdc14A en células HCT116 también promueve una reducción de la actividad de los complejos Cdk1-Ciclina B1, posible causa del retraso en la entrada en mitosis de estas células.

\section{El silenciamiento de la expresión de hCdc14A acelera la entrada en mitosis}

Los resultados obtenidos hasta el momento sugieren que la fosfatasa hCdc14A podría ejercer una función específica en la regulación de la entrada en mitosis, actuando quizás sobre la actividad CDK mitótica. Con el fin de corroborar esta hipótesis, decidimos analizar cómo afecta la carencia o reducción de los niveles proteicos de hCdc14A a la cinética de entrada en mitosis.

El silenciamiento de la expresión de la proteína endógena hCdc14A se llevó a cabo mediante la utilización de RNAs de interferencia, en concreto siRNAs (del inglés short interference RNAs) diseñados específicamente frente a hCdc14A, cuya presencia en la célula no afectaba al otro homólogo humano de Cdc14, hCdc14B, como pudimos comprobar en experimentos iniciales (datos no mostrados). El silenciamiento de hCdc14A en la transición G2/M se llevó a cabo en células U2OS sincronizadas, como se muestra en el esquema (Fig. 22A). Estas células fueron transfectadas de forma transitoria con los 
siRNAs frente a hCdc14A y a Luciferasa, los últimos empleados como control negativo (Fig. 22B). La "liberación" del tratamiento con timidina se realizó en presencia de nocodazol para evitar que posibles efectos en la salida de mitosis alterasen los resultados de estos experimentos. Transcurridas 10 y 13 horas de "liberación" a partir de G1/S, recogimos muestras que fueron analizadas mediante inmunocitoquímica, utilizando un anticuerpo específico frente a Histona $\mathrm{H} 3$ fosforilada en $\mathrm{Ser}^{10}$, lo que nos permitió conocer la cinética de entrada en mitosis de estas células. El análisis de esta cinética indica que la reducción de los niveles de hCdc14A induce una entrada en mitosis más rápida, lo cual

A

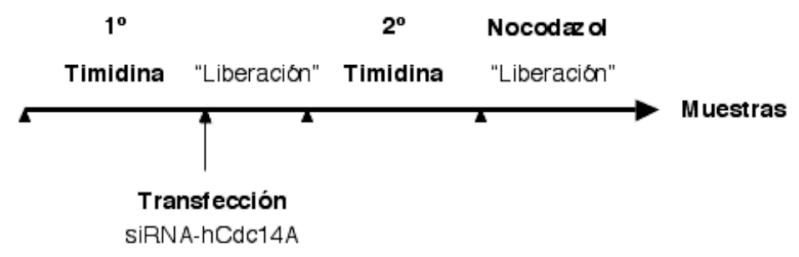

B

C

Entrada en mitosis (células con P-HH3)
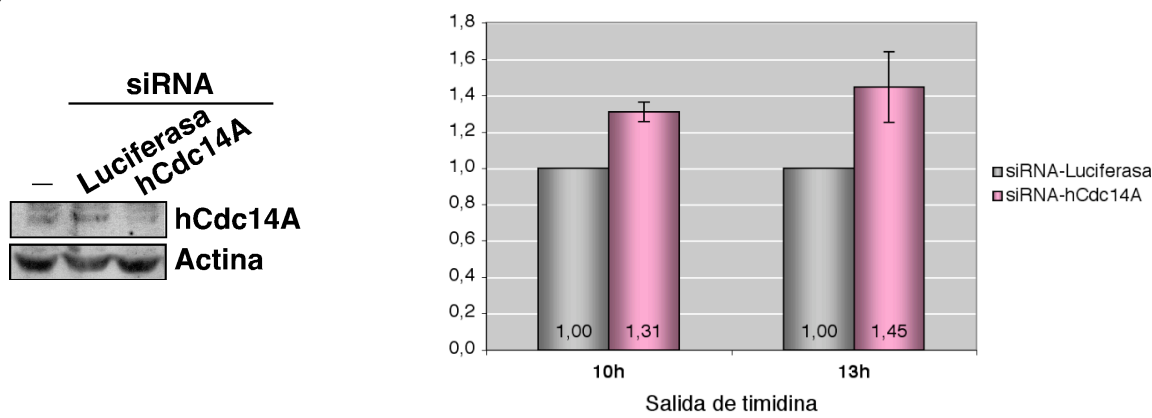

Figura 22. El silenciamiento de la expresión de hCdc14A acelera la entrada en mitosis de células U2OS. A: Esquema. Las células U2OS fueron sincronizadas mediante un doble tratamiento con timidina y "liberación" en presencia de nocodazol. Inmediatamente tras el primer tratamiento con timidina, las células se transfectaron con RNAs de interferencia específicos frente a hCdc14A o frente a Luciferasa (como control). B: 24 horas después de la "liberación" del doble tratamiento con timidina, recogimos muestras y obtuvimos los extractos celulares correspondientes. Las proteínas fueron procesadas por electroforesis en SDSPAGE, y analizadas mediante Western blot con un anticuerpo monoclonal específico frente a hCdc14A y otro anti- $\beta$ Actina (contro de carga). C: A las 10 y 13 horas tras la "liberación", las células sincronizadas fueron fijadas con paraformaldehído y sometidas a inmunocitoquímica frente a Histona $\mathrm{H} 3$ fosforilada en $\mathrm{Ser}^{10}$ (P-HH3, marcador de mitosis). En cada muestra se cuantificaron las células con P-HH3 y las células en interfase, contando un total de 1200 células como mínimo. En la gráfica se muestra la media de tres experimentos independientes, en los que consideramos que en las células control la proporción de células mitóticas respecto al total es 1 (unidad arbitraria), con la que comparamos la proporción de células mitóticas existente en las células con bajos niveles de hCdc14A (en cada experimento). 
constituye el efecto contrario al producido por la sobre-expresión de esta fosfatasa en la transición G2/M (Figura 22C). Quizás debido a que hCdc14A es una proteína muy estable, en estos experimentos no fuimos capaces de lograr su total eliminación o una mayor reducción de sus niveles proteicos, por lo que consideramos que probablemente el efecto observado sobre la cinética de entrada en mitosis podría ser aún más claro de lograrse una reducción mayor de los niveles de hCdc14A.

En definitiva, todos los resultados mostrados hasta el momento, obtenidos por medio de la sobre-expresión y del silenciamiento de hCdc14A, ponen de manifiesto que hCdc14A desempeña una función dependiente de su actividad fosfatasa en la regulación de la entrada en mitosis, seguramente a través de su efecto sobre la actividad CDK mitótica.

\section{Posibles mecanismos de acción de hCdc14A a la entrada en mitosis}

Puesto que la regulación de la actividad CDK mitótica es la vía más probable, a través de la cual hCdc14A puede ejercer su función a la entrada en mitosis, nos planteamos analizar los distintos mecanismos de regulación de los complejos CDK mitóticos por los que esta fosfatasa pudiera actuar:

En primer lugar, en nuestro laboratorio se comprobó, mediante ensayos in vitro, que hCdc14A no inhibe de forma directa a los complejos CDK mitóticos por desfosforilación de la $\mathrm{Thr}^{161}$ de la subunidad catalítica, Cdk1 (datos no mostrados).

A la vista de este resultado, consideramos que hCdc14A podría regular la actividad CDK mitótica a través de la modulación de la entrada al núcleo de los complejos CDK mitóticos en profase, o bien, de forma indirecta, a través de su efecto sobre proteínas reguladoras de estos complejos, como los Cdc25 humanos.

\subsection{Estudio de la cinética de entrada al núcleo de la Ciclina B1}

Como hemos mencionado en la Introducción, la Ciclina B1 forma parte de los complejos Cdk1-Ciclina B1, cuyo transporte al núcleo al final de profase es esencial para que tenga lugar la mitosis, y parece estar modulado a través de la fosforilación de dicha Ciclina. Por esta razón, nos planteamos si la alteración de dicho transporte podría ser una de las causas del efecto de hCdc14A sobre la entrada en mitosis.

Con el fin de comprobar esta posibilidad, examinamos la localización subcelular de la Ciclina B1 a lo largo de una cinética de entrada en mitosis en células que sobreexpresaban hCdc14A. Así, sincronizamos las células como hemos venido haciendo hasta 
ahora (Fig. 16A) y, mediante inmunofluorescencia con un anticuerpo específico antiCiclina B1, analizamos su localización subcelular a lo largo de la transición G2/M. En paralelo se estudió la cinética de condensación cromosómica mediante tinción con DAPI del DNA.

Estos experimentos pusieron de manifiesto que en las células con elevados niveles de hCdc14A la entrada de la Ciclina B1 al núcleo está retrasada, pero de forma proporcional al retraso observado en la condensación cromosómica, y probablemente a consecuencia de éste (datos no mostrados).

Este resultado, unido al hecho de que la entrada de la Ciclina B1 al núcleo (al final de profase) ocurre de forma posterior al comienzo del retraso observado en nuestras células (previo a la condensación cromosómica, "antefase"), sugiere que el efecto ejercido por hCdc14A en la transición G2/M no se produce a través de la regulación del transporte de los complejos Cdk1-Ciclina B1 al núcleo.

\subsection{Estudio de la regulación de proteínas activadoras de los complejos CDK mitóticos: hCdc25B, hCdc25A y hCdc25C}

En base a los resultados mostrados, parece probable que en la transición G2/M, hCdc14A pueda ejercer un efecto inhibidor sobre los complejos CDK mitóticos a través de la regulación de sus proteínas activadoras, los hCdc25s.

Como hemos indicado anteriormente, las tres fosfatasas Cdc25 humanas participan en la activación de los complejos CDK mitóticos durante la transición G2/M y su función parece estar regulada a través de diversos mecanismos: sus niveles proteicos, localización subcelular y/o actividad catalítica. Por esta razón, decidimos analizar si estos parámetros se encontraban alterados para cada una de estas proteínas, hCdc25B, hCdc25A y hCdc25C, como consecuencia de la presencia de niveles anómalos de hCdc14A en la célula (sobre-expresión o silenciamiento de la expresión).

\subsubsection{Acción de hCdc14A sobre hCdc25B a la entrada en mitosis}

hCdc25B es considerado el activador inicial de los complejos Cdk1-Ciclina B1 en centrosomas durante la transición G2/M (Lammer et al., 1998; De Souza et al., 2000; Jackman et al., 2003). Por otra parte, a pesar de que en nuestros ensayos in vitro hCdc14A no parece desfosforilar a hCdc25B en residuos fosforilados por Cdk1-Ciclina B1, se sabe que ambas proteínas, hCdc25B y hCdc14A, se localizan en centrosomas al final de G2 (Kaiser et al., 2002; Mailand et al., 2002a; Cazales et al., 2005; Schmitt et al., 
2006). Estos datos nos llevaron a postular que hCdc14A podría ejercer su efecto sobre la entrada en mitosis a través de la regulación, quizás de forma indirecta, de hCdc25B.

\section{Los niveles proteicos y la localización subcelular de hCdc25B no se ven afectados en células que sobre-expresan hCdc14A}

La proteína hCdc25B en un ciclo celular normal es detectada a partir de fase $S$ y se degrada al final de mitosis (Lammer et al., 1998; De Souza et al., 2000; Jackman et al., 2003). Dada esta variación de sus niveles proteicos a lo largo del ciclo celular, decidimos comprobar si la sobre-expresión de hCdc14A afectaba a dichos niveles durante la transición G2/M, momento en el que hCdc25B desempeña su función como activador de los complejos CDK mitóticos. Para ello, diseñamos experimentos de sincronización en G1/S y posterior "liberación" (como el descrito en la Fig. 16A), en los que observamos que los niveles proteicos de hCdc25B a la entrada en mitosis (11 y 15 horas tras la "liberación del bloqueo" en G1/S) no se encuentran alterados en células que sobre-expresan hCdc14A (Fig. 23).

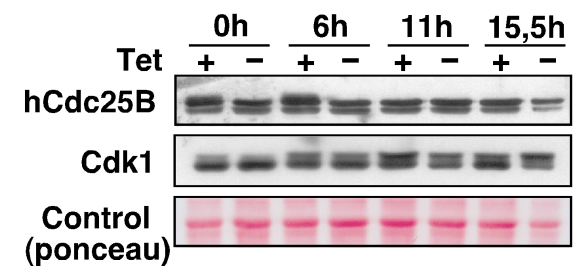

Figura 23. La sobre-expresión de hCdc14A no afecta a los niveles de hCdc25B durante la transición G2/M. Los cultivos celulares U2OS-Myc-hCdc14A fueron sincronizados e inducidos como se indica en la Figura 16A. Se recogieron muestras de células inducidas (-Tet) y control (+Tet), sincronizadas en G1/S (0 horas), y tras 6, 11 y 15,5 horas desde la "liberación" del doble tratamiento con timidina. Obtuvimos extractos proteicos de cada muestra, que fueron procesados por electroforesis en SDS-PAGE. y en los que analizamos los niveles de hCdc25B y Cdk1, mediante Western blot. Nótese que los cambios en el estado de fosforilación de Cdk1 reflejan su cinética de activación (como se ha especificado en la Fig. 19), señalando la progresión de las células por G2/M, lo que pone de manifiesto el retraso en la transición G2/M de las células inducidas (-Tet).

Puesto que la localización de hCdc25B en los centrosomas durante la transición G2/M es esencial para que ejerza su función como iniciador de la activación de los complejos CDK mitóticos, decidimos comprobar si era afectada por la sobre-expresión de hCdc14A. Para ello, utilizando la misma estrategia de sincronización e inducción de células U2OSMyc-hCdc14A (Fig. 16A), tomamos muestras a las 14 y 15 horas de "liberación" (transición $\mathrm{G} 2 / \mathrm{M}$ ) y realizamos una inmunocitoquímica con anticuerpos específicos frente a hCdc25B, en paralelo a una tinción de núcleos con DAPI. En estas condiciones comprobamos que 
los elevados niveles de hCdc14A no alteran la localización de hCdc25B en centrosomas a la entrada en mitosis (datos no mostrados).

\section{La sobre-expresión de hCdc14A no afecta a la actividad fosfatasa de hCdc25B}

La actividad catalítica de hCdc25B puede ser modulada mediante procesos de fosforilación (Boutros et al., 2007). Dado que la sobre-expresión de hCdc14A no altera los niveles ni la localización de hCdc25B a la entrada en mitosis, decidimos ver si por el contrario afectaba a su actividad fosfatasa. Con este fin, la proteína hCdc25B fue inmunoprecipitada con un anticuerpo específico a partir de extractos de células que sobreexpresaban hCdc14A y de células control. A continuación, analizamos su actividad fosfatasa sobre complejos Cdk1-Ciclina B1 inactivos, cuya actividad quinasa fue determinada a su vez sobre Histona $\mathrm{H} 1$. El resultado de estos ensayos fosfatasa-quinasa nos indica que la actividad catalítica de hCdc25B sobre Cdk1-Ciclina B1 no parece estar afectada por la sobre-expresión de hCdc14A (Fig. 24).

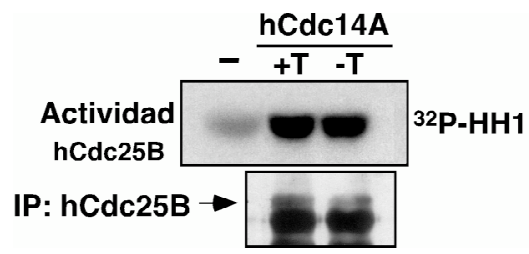

Figura 24. La sobre-expresión de hCdc14A no altera la actividad fosfatasa de hCdc25B en la célula. Las células U2OS-Myc-hCdc14A fueron incubadas en presencia de tetraciclina $(+T)$ o en ausencia de ésta $(-T)$ durante 48 horas. Obtuvimos los extractos proteicos a partir de cada cultivo celular e inmunoprecipitamos la proteína hCdc25B con un anticuerpo específico frente a esta proteína. La fosfatasa hCdc25B inmunoprecipitada en cada cultivo se incubó durante una hora a $30^{\circ} \mathrm{C}$ con una cantidad fija de complejos Cdk1Ciclina B1 inactivos (inmunoprecipitados a partir de células sincronizadas en G1/S). Estos complejos y otros incubados sólo con tampón (control negativo) fueron sometidos a un ensayo quinasa sobre Histona $\mathrm{H} 1$. Las proteínas de cada reacción (ensayo fosfatasaquinasa) fueron separadas por electroforesis en SDS-PAGE y analizadas mediante autoradiografía (panel superior) y Western blot con un anticuerpo anti-hCdc25B (panel inferior).

\section{La activación de los complejos Cdk1-Ciclina B1 en centrosomas no está alterada por la presencia de elevados niveles de hCdc14A en la célula}

Como acabamos de mostrar, la actividad catalítica de hCdc25B, inmunoprecipitado a partir de extractos celulares totales, no parece estar alterada debido a la sobre-expresión de hCdc14A. Sin embargo, consideramos que con este resultado no podíamos descartar la posibilidad de que la actividad catalítica de la fracción de hCdc25B localizada en centrosomas (responsable de la activación inicial de los complejos CDK mitóticos) sufriera algún cambio en estas condiciones. Por esta razón, decidimos analizar directamente la 
actividad de los complejos Cdk1-Ciclina B1 en centrosomas durante la transición G2/M, reflejo de un posible efecto de hCdc14A sobre la fracción de hCdc25B allí localizada.

Para ello, se realizó una purificación de centrosomas a partir de células con elevados niveles de hCdc14A o hCdc14A(PD) y de sus correspondientes controles en la transición G2/M (14 horas tras la "liberación" del tratamiento con timidina, según el esquema mostrado en la Figura 16A). La eficiencia de dicha purificación fue corroborada mediante el análisis por Western blot de la presencia de $\gamma$-Tubulina, proteína específica de

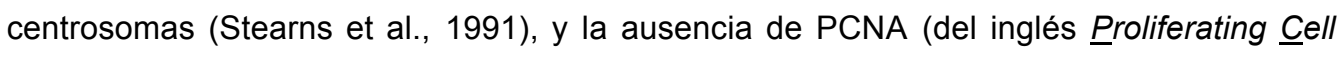
Nuclear Antigen), proteína nuclear. En este experimento también confirmamos la disminución de los niveles de $\gamma$-Tubulina en las células que sobre-expresan hCdc14A, ya descrita por otros autores con anterioridad (Kaiser et al., 2002) (Fig. 25A).

El análisis de la actividad de Cdk1 en estas preparaciones se llevó a cabo, en primer lugar, mediante la comprobación del estado de fosforilación de Cdk1 por Western blot, y después, por medio de un ensayo quinasa para determinar de forma directa la actividad de los complejos Cdk1-Ciclina B1. Como se observa en la Figura 25B, la proteína Cdk1 en las células que sobre-expresan $\mathrm{hCdc} 14 \mathrm{~A}$ muestra el mismo patrón de bandas que en las células control, lo que indica que la proporción de proteína fosforilada (en $\operatorname{Thr}^{14}$ y $\operatorname{Tyr}^{15}$ ), y por lo tanto inactiva, en centrosomas es la misma. Sin embargo, cabe destacar que en la fracción correspondiente a extractos nucleares existe una mayor proporción de la quinasa Cdk1 fosforilada, por lo tanto inactiva, en las células que sobre-expresan hCdc14A respecto a las células control. A su vez, el análisis de la actividad quinasa de los complejos Cdk1-Ciclina B1 localizados en centrosomas durante la transición G2/M, nos permitió confirmar que su actividad no parece encontrarse afectada por la presencia de elevados niveles de hCdc14A en la célula (Fig. 25C).

Estos resultados sugieren que la función desempeñada por hCdc14A sobre los complejos CDK mitóticos a la entrada en mitosis no ocurre a través de la regulación de hCdc25B. 
A

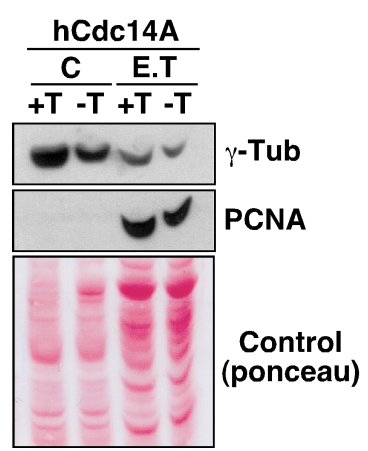

B

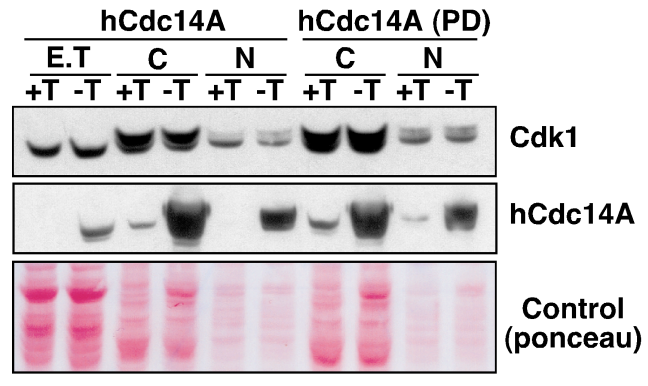

C

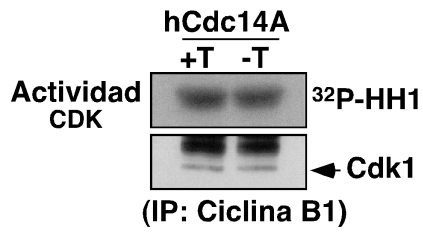

Figura 25. La activación de los complejos Cdk1-Ciclina B1 en centrosomas no se encuentra afectada por la sobre-expresión de hCdc14A. Los cultivos celulares U2OS-Myc-hCdc14A y U2OS-Myc-hCdc14A(PD), fueron sincronizados mediante un doble tratamiento con timidina y posterior "liberación", e inducidos como se indica en la Figura 16A. Tras 14 horas de "liberación" se recogieron muestras, a partir de las que obtuvimos extractos proteicos totales (E.T.), extractos proteicos correspondientes a la fracción subcelular de centrosomas $(\mathrm{C})$ y de núcleos $(\mathrm{N})$. $\boldsymbol{A}$ : En las muestras correspondientes a extractos totales y de centrosomas de U2OS-Myc-hCdc14A, +T y -T, se detectó la presencia $\gamma$-Tubulina y el PCNA mediante Western blot, como controles de purificación de centrosomas. B: Mediante Western blot se detectaron las proteínas Cdk1 y hCdc14A en todas las muestras. Se empleó como control de carga la tinción con Ponceau de los extractos proteicos (panel inferior). C: A partir de los extractos proteicos correspondientes a la fracción subcelular de centrosomas (C), se inmunoprecipitaron los complejos Cdk1-Ciclina B1 con un anticuerpo específico anti-Ciclina B1 y se realizó un ensayo quinasa sobre Histona H1. Las proteínas de estas reacciones fueron separadas mediante electroforesis y analizadas por auto-radiografía (panel superior) y por Western blot con un anticuerpo anti-Cdk1 (control, panel inferior).

\subsection{2. hCdc14A participa en la regulación de hCdc25A a la entrada en mitosis}

La fosfatasa hCdc25A también desempeña un papel importante en la regulación de la transición G2/M, posiblemente relacionado con la condensación cromosómica (Mailand et al., 2002b; Lindqvist et al., 2005), lo que nos llevó a considerar la posibilidad de que hCdc14A pudiera ejercer su función en la entrada en mitosis a través de hCdc25A. 


\section{La sobre-expresión de hCdc14A no afecta a los niveles proteicos de hCdc25A durante la transición G2/M}

En un ciclo celular normal, hCdc25A aparece hacia el final de G1, se acumula en G2/M por estabilización de la proteína, y al final de mitosis desaparece como consecuencia de su degradación mediada por APC (Donzelli et al., 2002).

Como se ha mostrado en la Figura 12B, los niveles de hCdc25A se encuentran incrementados en cultivos celulares asíncronos que sobre-expresan hCdc14A, posiblemente a causa del retraso en la transición G2/M descrito en estas condiciones. Para comprobar esta posibilidad, sincronizamos las células (como se indica en la Fig. 16A) y determinamos los niveles proteicos de hCdc25A a lo largo de G2/M. La sobreexpresión de hCdc14A no afecta a los niveles de hCdc25A en células sincronizadas en $\mathrm{G} 2 / \mathrm{M}$, lo que prueba que el incremento de hCdc25A observado en cultivos asíncronos es, efectivamente, consecuencia del retraso en la entrada en mitosis, y no de un efecto directo de hCdc14A sobre los niveles de dicha proteína en este punto del ciclo (Fig. 26).

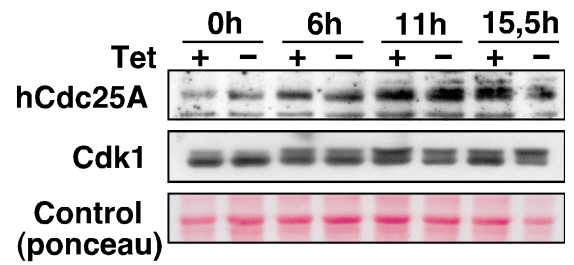

Figura 26. La sobre-expresión de hCdc14A no afecta a los niveles de hCdc25A durante la transición G2/M. Los cultivos celulares U2OS-Myc-hCdc14A fueron sincronizados e inducidos como se indica en la Figura $16 \mathrm{~A}$. Se recogieron muestras de células inducidas (-Tet) y control (+Tet) sincronizadas en G1/S (0 horas) y tras 6,11 y 15,5 horas desde la "liberación" del doble tratamiento con timidina. Obtuvimos extractos proteicos de cada muestra, cuyas proteínas fueron separadas por electroforesis en SDSPAGE. A continuación, se analizaron los niveles de hCdc25A y Cdk1, mediante la técnica de Western blot, empleando anticuerpos específicos frente a cada una de esta proteínas. Nótese la progresiva acumulación y fosforilación que sufre hCdc25A. Los cambios en el estado de fosforilación de Cdk1 reflejan su cinética de activación (como se ha especificado en la Fig. 19), señalando la progresión de las células por G2/M, que a su vez pone de manifiesto el retraso en la transición G2/M de las células inducidas (-Tet).

\section{El efecto de la sobre-expresión de hCdc14A sobre la localización de hCdc25A no parece ser causa del retraso en G2/M}

La fosfatasa hCdc25A se considera una proteína principalmente nuclear, si bien se ha demostrado que su localización está continuamente cambiando entre el núcleo y el 
citoplasma, debido a la presencia de secuencias de tipo NES y NLS (Hoffmann et al., 1994; Kallstrom et al., 2005).

A raíz de esto, nos planteamos si hCdc14A podría participar en la regulación de la localización subcelular de hCdc25A, quizás impidiendo su entrada al núcleo y evitando así la completa activación de los complejos CDK mitóticos. Para comprobar esta hipótesis, analizamos si la localización subcelular de hCdc25A se encontraba alterada en células que sobre-expresaban hCdc14A, para lo que realizamos experimentos de inmunocitoquímica con anticuerpos específicos frente a hCdc25A, en paralelo a la tinción del DNA con DAPI. De este modo, en las células con elevados niveles de hCdc14A, se observó una cierta acumulación de hCdc25A alrededor de la membrana nuclear, sin que por ello, aparentemente la fracción presente en el núcleo fuese menor que en las células control (Fig. 27). Este resultado sugiere que la sobre-expresión de hCdc14A no impide, al menos totalmente, la entrada de hCdc25A al núcleo, y que por lo tanto, la modificación de la localización subcelular de hCdc25A observada no parece ser una de las causas del retraso en la transición $\mathrm{G} 2 / \mathrm{M}$ descrito.

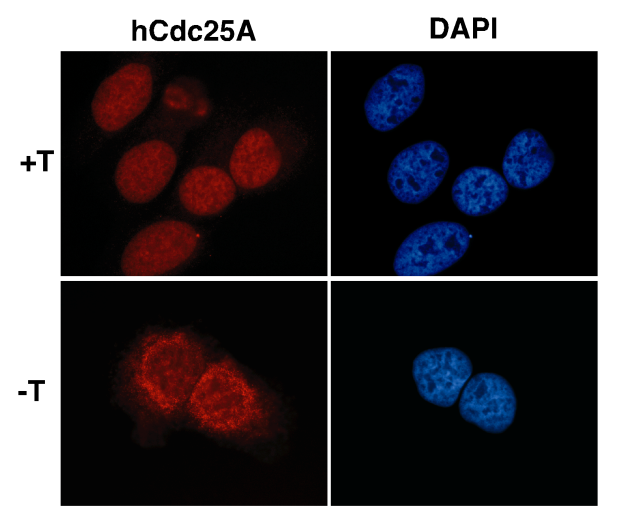

Figura 27. Efecto de la sobreexpresión de hCdc14A sobre la localización subcelular de hCdc25A. Las células U2OS-Myc-hCdc14A fueron incubadas en presencia de tetraciclina $(+T)$ o en ausencia de ésta $(-T)$ durante 48 horas. Tras lo cual se fijaron con paraformaldehído y fueron sometidas a inmunocitoquímica con un anticuerpo monoclonal específico frente a hCdc25A. En paralelo, los núcleos de estas células se tiñeron con DAPI.

\section{La fosfatasa hCdc14A está implicada en la regulación de la actividad catalítica de hCdc25A}

En un ciclo celular normal, la función de hCdc25A en la transición G2/M parece estar regulada principalmente mediante su estabilización propiciada por la fosforilación llevada a cabo por Cdk1-Ciclina B1 (Mailand et al., 2002b).

De todos modos, en base a la falta de evidencias de otro efecto sobre hCdc25A, decidimos analizar la actividad catalítica de hCdc25A en condiciones de sobre-expresión de hCdc14A. Para ello, en primer lugar se inmunoprecipitó la proteína hCdc25A con un 
anticuerpo específico a partir, tanto de extractos celulares de cultivos asíncronos, como de cultivos sincronizados en G2/M (como en la Figura 16A). A continuación, determinamos su actividad catalítica sobre complejos Cdk1-Ciclina B1, lo que nos permitió comprobar que la actividad fosfatasa de hCdc25A se encuentra reducida a consecuencia de la presencia de elevados niveles de la proteína hCdc14A activa, tanto en cultivos asíncronos (Fig. 28A y B), como en células sincronizadas a la entrada en mitosis (Fig. 28C). Estos resultados demuestran que la sobre-expresión de hCdc14A, de forma dependiente de su actividad catalítica, da lugar a una reducción de la actividad fosfatasa de hCdc25A a la entrada en mitosis, que explica la menor actividad de los complejos CDK mitóticos y el consiguiente retraso en la transición $\mathrm{G} 2 / \mathrm{M}$, observados en estas condiciones.

A

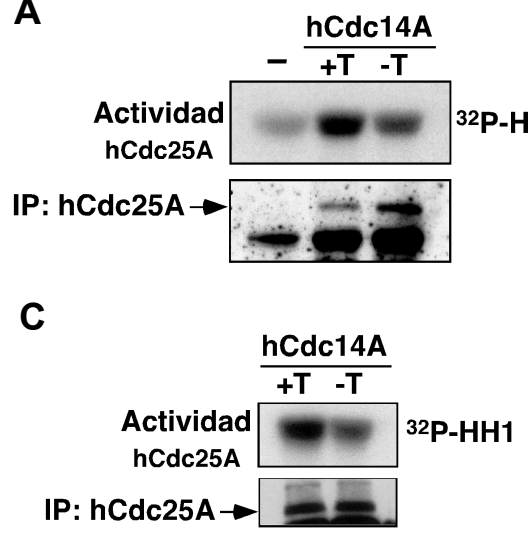

B

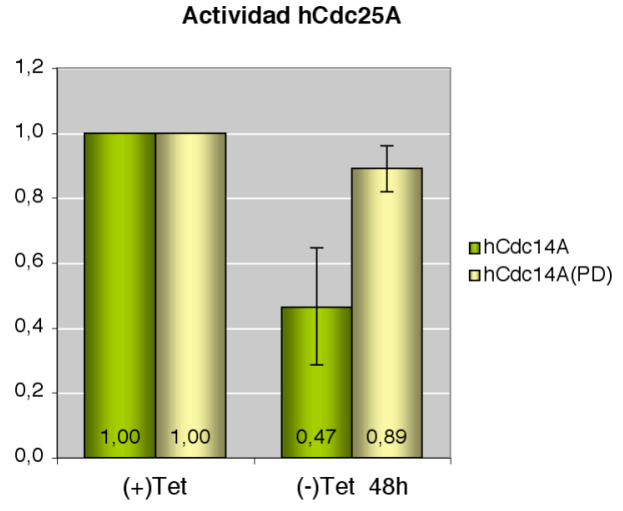

Figura 28. La sobre-expresión de hCdc14A reduce la actividad fosfatasa de hCdc25A. $A$ : Las células U2OS-Myc-hCdc14A fueron incubadas en presencia de tetraciclina (+Tet) o en ausencia de ésta (-Tet) durante 48 horas. Obtuvimos los extractos proteicos a partir de cada cultivo celular e inmunoprecipitamos la proteína hCdc25A con un anticuerpo policlonal específico. La fosfatasa hCdc25A inmunoprecipitada se incubó con una cantidad fija de complejos Cdk1-Ciclina B1 inactivos (de células sincronizadas en G1/S). Estos complejos, y también aquellos incubados sólo con tampón fosfatasa (control -), fueron empleados en un ensayo quinasa sobre Histona H1. Las proteínas de cada reacción fueron separadas mediante electroforesis y analizadas por autoradiografía (panel superior) y Western blot con un anticuerpo monoclonal anti-hCdc25A (panel inferior). B: Realizamos tres experimentos independientes, empleando también células U2OS-MychCdc14A(PD) en las mismas condiciones. En cada experimento se llevó a cabo una cuantificación de la actividad quinasa de los complejos CDK, que a su vez fue normalizada con respecto a la cantidad de hCdc25A inmunoprecipitada. En la gráfica se muestra la media aritmética de las cuantificaciones y las desviaciones estándar correspondientes a los tres experimentos. La actividad de hCdc25A se representa en unidades arbitrarias, considerando que la actividad correspondiente a células control (+Tet) es 1. C: Los cultivos celulares U2OS-Myc-hCdc14A fueron sincronizados e inducidos como se indica en la Figura $16 \mathrm{~A}$ y se recogieron muestras tras 14 horas de "liberación". A continuación se inmunoprecipitó la proteína hCdc25A y se realizó un ensayo fosfatasa-quinasa del mismo modo descrito en $\boldsymbol{A}$. 
Para comprobar este efecto inhibidor de hCdc14A sobre la actividad catalítica de hCdc25A, también analizamos su actividad fosfatasa en células U2OS en las que habíamos reducido significativamente los niveles de hCdc14A por medio de siRNAs específicos (Fig. 29A). Con este fin, hCdc25A fue inmunoprecipitado a partir de extractos proteicos de células transfectadas con siRNA-hCdc14A o con siRNA-Luciferasa (como control), y determinamos su actividad catalítica sobre complejos Cdk1-Ciclina B1. Como se observa en la Figura 29B, estos experimentos nos permitieron comprobar que la reducción de los niveles de hCdc14A en células U2OS, al contrario que su sobreexpresión, induce un incremento de la actividad de hCdc25A. Este resultado a su vez podría explicar que la entrada en mitosis de estas células se encuentre acelerada con respecto a células control (como se ha mostrado en la Fig. 22). El efecto del silenciamiento de hCdc14A sobre la actividad catalítica de hCdc25A también fue corroborado en la línea celular HEK293T (datos no mostrados).

A

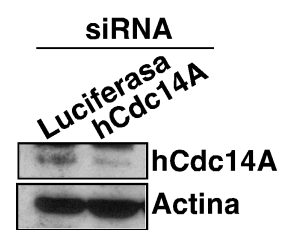

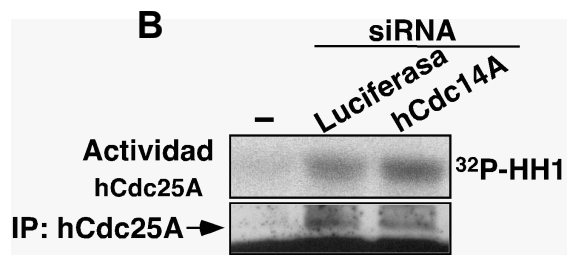

Figura 29. El silenciamiento de la expresión de hCdc14A induce un incremento de la actividad fosfatasa de hCdc25A. A: Las células U2OS fueron transfectadas con RNAs de interferencia específicos frente a hCdc14A o frente a Luciferasa (como control). Tras 84 horas desde la transfección se recogieron muestras y se obtuvieron los extractos celulares correspondientes. Las proteínas fueron separadas mediante electroforesis en SDS-PAGE y analizadas por Western blot con un anticuerpo monoclonal específico frente a hCdc14A y otro anti- $\beta$-Actina (control). B: A partir de cada extracto proteico, inmunoprecipitamos la proteína hCdc25A con un anticuerpo policlonal específico. La fosfatasa hCdc25A inmunoprecipitada en cada cultivo, se incubó con una cantidad fija de complejos Cdk1-Ciclina B1 inactivos. Estos complejos, junto con otros incubados sólo con tampón fosfatasa (control negativo, -), fueron utilizados en un ensayo quinasa sobre Histona H1. Las proteínas de cada reacción fueron separadas mediante electroforesis y analizadas mediante auto-radiografía (panel superior) y por Western blot con un anticuerpo monoclonal anti-hCdc25A (panel inferior).

En conclusión, los efectos producidos sobre la actividad fosfatasa de hCdc25A, tanto por la sobre-expresión como por el silenciamiento de nuestra fosfatasa, sugieren que hCdc14A podría ejercer una función reguladora de los complejos CDK mitóticos a la entrada de mitosis a través de la inhibición de la actividad catalítica de hCdc25A. 


\section{La desfosforilación de los residuos $\operatorname{Ser}^{115}$ y $\operatorname{Ser}^{320}$ de hCdc25A por parte de hCdc14A, no parece afectar a su actividad sobre Cdk1-Ciclina B1}

Como hemos descrito anteriormente, la proteína hCdc14A es capaz de desfosforilar in vitro dos residuos de $\mathrm{hCdc} 25 \mathrm{~A}, \operatorname{Ser}^{115}$ y $\operatorname{Ser}^{320}$ (S115-320), previamente fosforilados por Cdk1-Ciclina B1. Además, hemos demostrado también que hCdc14A, de forma dependiente de su actividad fosfatasa, está implicada en la inhibición de la actividad catalítica de hCdc25A. Ambos resultados sugerian que quizás la actividad de hCdc25A podría estar reducida como consecuencia de la desfosforilación directa de los residuos $\operatorname{Ser}^{115}$ y Ser ${ }^{320}$ por parte de hCdc14A. Para comprobar esta hipótesis, determinamos la actividad de mutantes de hCdc25A en los que ambos residuos fueron sustituidos por Alanina (A, aminoácido no fosforilable, GST-hCdc25A ${ }^{\text {S115A-S320A }}$, o por ácido Ácido glutámico ( $E$, aminoácido que mimetiza una fosforilación constitutiva, GST-hCdc25A ${ }^{\text {S115E- }}$ ${ }^{S 320 E}$ ). La actividad fosfatasa de estos mutantes, analizada sobre los complejos Cdk1Ciclina B1, se comparó con la de hCdc25A (GST-hCdc25A ${ }^{\text {wt }}$ ). Este ensayo puso de manifiesto que no hay diferencias significativas entre la actividad fosfatasa in vitro de los distintos mutantes y de la proteína hCdc25A de tipo silvestre (wt), purificadas todas ellas de E. coli (datos no mostrados). Este dato sugiere que la desfosforilación de los dos residuos mencionados, al menos por sí sola, no afecta a la actividad catalítica intrínseca de la proteína.

Sin embargo, este resultado no descartaba que la desfosforilación de estos residuos por parte de hCdc14A pudiera alterar la interacción de hCdc25A con otras proteínas en la célula, lo que a su vez podría afectar a su afinidad por los complejos Cdk1-Ciclina B1. Para comprobar esta posibilidad (la cual no se podía descartar empleando proteínas purificadas de E. coli) se transfectaron células HEK293T y HCT116 con los cDNAs correspondientes a las proteínas $\mathrm{hCdc} 25 \mathrm{~A}^{\mathrm{wt}}, \mathrm{hCdc} 25 \mathrm{~A}^{\mathrm{S} 115 \mathrm{~A}-\mathrm{S} 320 \mathrm{~A}}$ y $\mathrm{hCdc} 25 \mathrm{~A}^{\mathrm{S} 115 \mathrm{E}-\mathrm{S} 320 \mathrm{E}}$, y a las 24 horas de la transfección, inmunoprecipitamos los distintos hCdc25As y determinamos su actividad fosfatasa sobre complejos Cdk1-Ciclina B1. El resultado de estos experimentos fue variable, pero sugiere que no hay diferencias significativas entre la actividad fosfatasa de las distintas formas de hCdc25A (datos no mostrados).

En definitiva, la desfosforilación de los dos residuos descritos de hCdc25A por parte de hCdc14A no parece ser la responsable, al menos de forma exclusiva, de la reducción de la actividad fosfatasa de hCdc25A sobre los complejos Cdk1-Ciclina B1, inducida por la sobre-expresión de la proteína hCdc14A activa. 


\subsubsection{Acción de hCdc14A sobre hCdc25C a la entrada en mitosis}

Como hemos indicado en Introducción, la fosfatasa hCdc25C desempeña también un papel importante como reguladora de la transición G2/M a nivel nuclear, participando en la activación de los complejos Cdk1-Ciclina B1 iniciada en centrosomas por hCdc25B. Por otro lado, en nuestro estudio hemos comprobado que hCdc14A desfosforila in vitro a hCdc25C (Fig. 9). En consecuencia decidimos determinar si hCdc14A participaba en la regulación de la actividad CDK mitótica a través de hCdc25C. Con este fin, analizamos, de la misma forma que hemos hecho para hCdc25A y hCdc25B, sus niveles proteicos, localización subcelular y actividad catalítica en células que sobre-expresan hCdc14A.

\section{Los niveles proteicos de hCdc25C no se modifican de forma significativa en G2/M al sobre-expresar hCdc14A}

Los niveles proteicos de hCdc25C se consideran constantes en un ciclo celular normal, aunque en trabajos recientes se ha descrito que la cantidad de esta proteína se incrementa ligeramente en la fase S (Garner-Hamrick y Fisher, 1998; Turowski et al., 2003).

Para saber si la regulación de los niveles de hCdc25C está relacionada con la función desempeñada por hCdc14A a la entrada en mitosis, analizamos dichos niveles proteicos durante $\mathrm{G} 2 / \mathrm{M}$ en células que sobre-expresan hCdc14A (esquema del experimento en Figura 16A). De esta forma observamos que los niveles proteicos de hCdc25C en la transición G2/M no se encuentran alterados de forma significativa por la sobre-expresión de hCdc14A (Fig. 30). Este resultado sugiere que en un ciclo celular normal hCdc14A no ejerce su función en la regulación de la transición G2/M a través de la regulación de los niveles de hCdc25C.

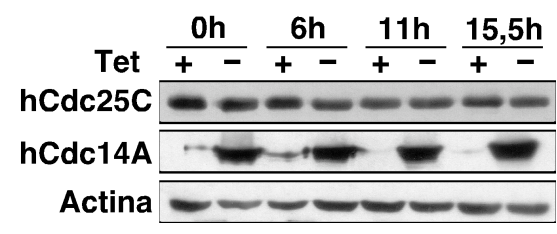

Figura 30. La sobre-expresión de hCdc14A no afecta a los niveles de hCdc25C durante la transición G2/M. Los cultivos celulares U2OS-Myc-hCdc14A fueron sincronizados e inducidos como se indica en la Figura 16A. Se recogieron muestras de células inducidas (-Tet) y control (+Tet), sincronizadas en G1/S (0 horas), y tras 6,11 y 15,5 horas desde la "liberación" del doble tratamiento con timidina. Obtuvimos extractos proteicos de cada muestra, cuyas proteínas fueron separadas por electroforesis, y se analizaron los niveles de hCdc25C, hCdc14A y Actina mediante Western blot, empleando anticuerpos específicos. 


\section{La sobre-expresión de hCdc14A no afecta a la localización ni a la actividad fosfatasa de hCdc25C}

La función de hCdc25C en la transición G2/M de un ciclo celular normal se encuentra regulada a través de su localización subcelular y de su actividad catalítica, modificadas ambas por la fosforilación de determinados residuos (Boutros et al., 2006; Boutros et al., 2007).

Para comprobar si hCdc14A participa en la regulación de la localización subcelular de hCdc25C, analizamos ésta en células que sobre-expresaban hCdc14A por medio de inmunofluorescencia indirecta con anticuerpos específicos frente a hCdc25C, realizada en paralelo a una tinción de DNA con DAPI. De este modo, observamos que la localización de hCdc25C no parece estar afectada por la presencia de elevados niveles de hCdc14A en la célula (datos no mostrados).

A continuación, también consideramos la posibilidad de que su actividad catalítica pudiera estar modulada por hCdc14A. Para ello, se inmunoprecipitó hCdc25C a partir de células que sobre-expresaban hCdc14A y células control, tras lo que fue analizada su actividad fosfatasa sobre complejos Cdk1-Ciclina B1. En este experimento pudimos observar que tras 48 horas de sobre-expresión de hCdc14A, la cantidad de proteína hCdc25C inmunoprecipitada es menor que en células control, lo que posiblemente refleja la caída de los niveles de hCdc25C observada en estas condiciones (Fig. 12B), y a su vez podría explicar que la actividad catalítica asociada a hCdc25C en estas condiciones sea menor (Fig. 31A). De hecho, la cuantificación y normalización de dicha actividad fosfatasa (con respecto a la cantidad de hCdc25C inmunoprecipitada) puso de manifiesto que la actividad fosfatasa intrínseca no parece ser inhibida por elevados niveles de hCdc14A en la célula (Fig. 31B).

Por consiguiente, podemos concluir que hCdc14A no parece participar en la regulación de la actividad fosfatasa de hCdc25C, ni en su localización subcelular. Si bien, la sobre-expresión prolongada de hCdc14A (tras 48 horas de inducción) da lugar a un efecto a largo plazo sobre los niveles proteicos de esta fosfatasa. 
B

A

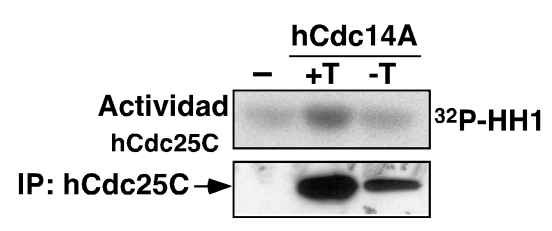

Actividad de hCdc25C

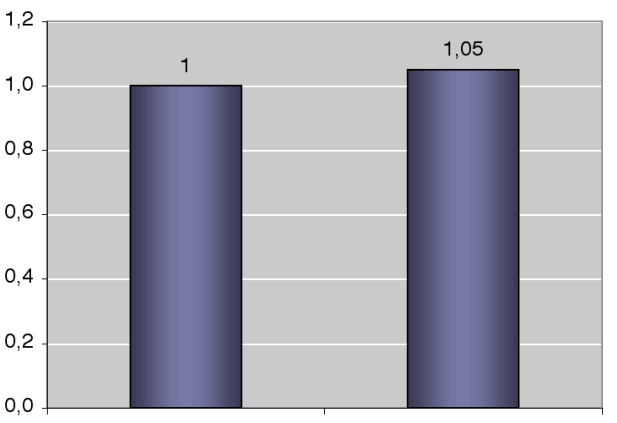

$(+)$ Tet

$(-)$ Tet $48 \mathrm{~h}$

Figura 31. La sobre-expresión de hCdc14A no altera la actividad fosfatasa de hCdc25C. A: Las células U2OS-Myc-hCdc14A fueron incubadas en presencia de tetraciclina (+Tet) o en ausencia de ésta (-Tet) durante 48 horas. Obtuvimos los extractos proteicos a partir de cada cultivo celular e inmunoprecipitamos la proteína hCdc25C con un anticuerpo policlonal específico. La fosfatasa hCdc25C inmunoprecipitada en cada cultivo se incubó con una cantidad fija de complejos Cdk1-Ciclina B1 inactivos (de células sincronizadas en G1/S). Estos complejos, junto con otros incubados sólo con tampón fofatasa (control -), fueron sometidos a un ensayo quinasa sobre Histona H1. Las proteínas de cada reacción fueron separadas mediante electroforesis y analizadas mediante auto-radiografía (panel superior) y por Western blot con un anticuerpo monoclonal antihCdc25C (panel inferior). B: Gráfica: Se llevó a cabo una cuantificación de la actividad quinasa de los complejos CDK (auto-radiografía), que a su vez fue normalizada con respecto a los niveles de hCdc25C inmunoprecipitados (Western blot). La actividad de hCdc25C se representa en unidades arbitrarias

\section{Posible activación de un checkpoint como consecuencia "a largo plazo" de la presencia de elevados niveles de hCdc14A en la célula}

Es evidente que una de las posibles causas de un retraso en G2/M como el descrito en el caso de la sobre-expresión de hCdc14A, podría ser la activación de un checkpoint. Además, en base a los datos mostrados se puede deducir que el mantenimiento de elevados niveles de hCdc14A durante 48 horas en cultivos celulares asíncronos, da lugar a la reducción de los niveles de hCdc25C y a la acumulación de p21 (Fig. 12B y Fig. 32), efectos que pueden relacionarse con la activación de un checkpoint, y más concretamente, con un aumento de la actividad de p53. Por esta razón, también analizamos cómo afectaba la sobre-expresión prolongada de hCdc14A (48 horas) a los niveles proteicos de p53, comprobando que efectivamente la cantidad de p53 se encuentra ligeramente incrementada en estas condiciones (Fig. 32), lo que de nuevo puede ser indicativo de la activación de un checkpoint. 


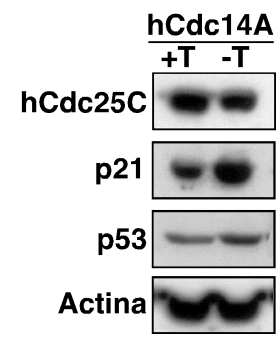

Figura 32. La sobre-expresión de hCdc14A induce la acumulación de las proteínas p53 y p21, y la reducción de los niveles de hCdc25C. Las células U2OS-MychCdc14A fueron incubadas en presencia de tetraciclina $(+\mathrm{T})$ o en ausencia de ésta (-T), durante 48 horas. Obtuvimos extractos proteicos a partir de cada cultivo celular, y las proteínas fueron separadas mediante electroforesis y analizadas por Western blot con anticuerpos específicos frente a hCdc25C, p21, p53 y Actina (control de carga).

Por otra parte, se sabe que la reducción de los niveles de la proteína hCdc25C en respuesta a daño al DNA, puede ocurrir como consecuencia de un incremento en su degradación proteica o de su inhibición transcripcional, efectos que parecen estar mediados por p53 (Raj et al., 2001; St Clair et al., 2004). Con el fin de conocer el mecanismo mediante el que se reducen los niveles proteicos $\mathrm{hCdc} 25 \mathrm{C}$ en las células que sobre-expresan hCdc14A, en primer lugar analizamos si se trataba de un efecto sobre la degradación de esta proteína. Esta posibilidad fue descartada mediante el tratamiento de estos cultivos con el inhibidor del proteasoma MG132, al observar que este compuesto no afectaba a la reducción de los niveles de hCdc25C observada en las citadas condiciones (Fig. 33A). Para comprobar, entonces, si la reducción de esta proteína estaba inducida a nivel transcripcional, analizamos los niveles de RNA mensajero (mRNA) de hCdc25C mediante la técnica de Northern blot. En efecto, la sobre-expresión de la fosfatasa activa

A

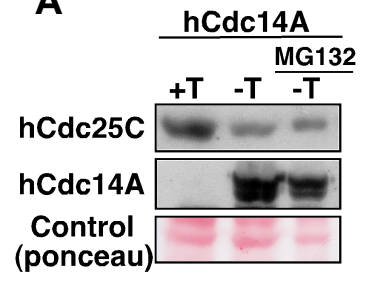

B

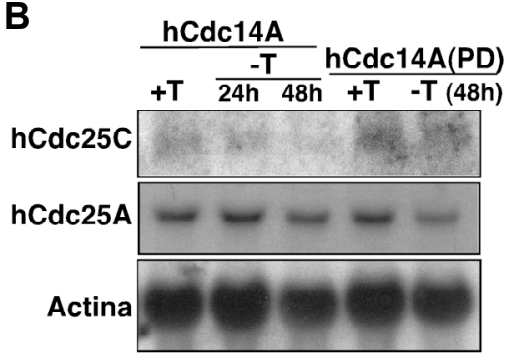

Figura 33. La sobre-expresión de hCdc14A induce la reducción de los niveles de hCdc25C a nivel transcripcional. $\boldsymbol{A}$ : Las células U2OS-Myc-hCdc14A fueron incubadas con $(+T)$ o $\sin (-T)$ tetraciclina, durante 48 horas. La mitad de las células $(-T)$ fueron tratadas durante las últimas 8 horas con el compuesto MG132, inhibidor del proteasoma; mientras al resto de las células se les añadió el mismo volumen del disolvente del compuesto (DMSO). A continuación, obtuvimos extractos proteicos a partir de cada cultivo celular, y las proteínas fueron separadas mediante electroforesis y analizadas por Western blot con anticuerpos específicos frente a hCdc25C y hCdc14A. Los extractos celulares se tiñeron con Ponceau como control de carga. $B$ : Las células U2OS-Myc-hCdc14A fueron incubadas en presencia de tetraciclina (+T) durante 48 horas o en ausencia de ésta (-T) durante 24 ó 48 horas, y las células U2OS-Myc-hCdc14A(PD) fueron incubadas con o sin tetraciclina durante 48 horas. Se tomaron muestras para la extracción de RNAs y se analizaron los niveles de mRNA de hCdc25C, de hCdc25A y Actina (control de carga) mediante Northern blot. 
hCdc14A durante 24 ó más horas en cultivos asíncronos, da lugar a la reducción de los niveles de mRNA de hCdc25C (hecho que no ocurre en el caso de hCdc25A o Actina, utilizados como controles) (Fig. 33B). Estos resultados señalan que la sobre-expresión prolongada de hCdc14A en cultivos asíncronos provoca una reducción de los niveles proteicos de hCdc25C a consecuencia de su regulación a nivel transcripcional.

A continuación, los niveles de p21 y p53 (parámetros que se pueden relacionar con la activación de un checkpoint) fueron analizados a lo largo de G2/M (células sincronizadas como se muestra en la Figura 16A). De este modo, comprobamos que de forma similar a lo que ocurre en el caso de hCdc25C (Fig. 30), los niveles de estas proteínas no están alterados a la entrada de mitosis tras la sobre-expresión de hCdc14A (en un solo ciclo celular normal) (Fig. 34).

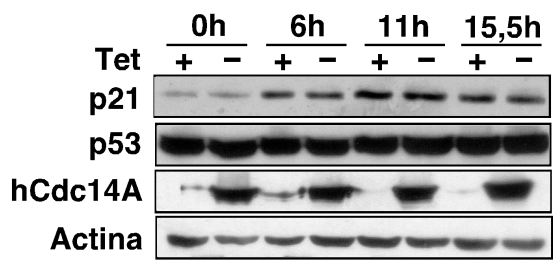

Figura 34. La sobre-expresión de hCdc14A no afecta a los niveles proteicos de p53 y p21 durante la transición G2/M. Los cultivos celulares U2OS-Myc-hCdc14A fueron sincronizados e inducidos como se indica en la Figura 16A. Se recogieron muestras de células inducidas $(-\mathrm{T})$ y control $(+\mathrm{T})$ a las $0,6,11$ y 15,5 horas tras la "liberación del bloqueo" en $\mathrm{G} 1 / \mathrm{S}$. Obtuvimos extractos proteicos de cada muestra, y las proteínas fueron separadas por electroforesis. Los niveles de p21, p53, hCdc14A y Actina (control de carga), fueron determinados mediante la técnica de Western blot.

En conclusión, estos resultados nos obligan a diferenciar entre los efectos producidos por la sobre-expresión de hCdc14A en un solo ciclo, que conllevan un retraso en la entrada a mitosis debido, al menos en parte, a su acción sobre la actividad de hCdc25A en G2/M; y por otra parte, los efectos observados tras la sobre-expresión durante más de un ciclo celular (más de 24 horas en cultivos asíncronos), a los que denominaremos efectos "a largo plazo". De este modo, sólo entre los efectos "a largo plazo" de la sobreexpresión de hCdc14A encontramos evidencias de la activación de un checkpoint, posiblemente debido a los defectos mitóticos y/o en citoquinesis ya descritos en estas condiciones (Kaiser et al., 2002; Mailand et al., 2002a) o a otros aún no identificados.

Puesto que la activación de p53 es un efecto común a varias rutas de checkpoint, quisimos saber cual de estas rutas podría estar implicada en el retraso en la transición G2/M observado "a largo plazo". 


\subsection{Estudio de la activación de ATM y ATR como consecuencia de la sobre-expresión de hCdc14A "a largo plazo"}

Las quinasas ATM y ATR son dos de las proteínas de tipo sensor de daño al DNA y/o de estrés replicativo más importantes, por esta razón eran una buena diana para comprobar si alguno de estos checkpoints (de daño al DNA o de replicación) se encontraba activo debido a los efectos "a largo plazo" de la sobre-expresión de hCdc14A.

Con el fin de ver si ATM y ATR estaban implicadas en el retraso G2/M producido como efecto a "a largo plazo" de la sobre-expresión de hCdc14A, analizamos si este retraso se producía en presencia de cafeína, inhibidor de ambas quinasas. De este modo, mediante análisis por FACS comprobamos que el retraso a la entrada en mitosis producido en estas condiciones se revierte parcialmente como consecuencia de la adición de cafeína al medio (Fig. 35A). Además, el análisis de la morfología nuclear, mediante tinción con DAPI del DNA, nos permitió comprobar que los fenotipos característicos de inestabilidad genómica, consecuencia de la sobre-expresión prolongada de hCdc14A (Fig. 11 y Tabla II), se encuentran agravados en presencia de cafeína, posiblemente a consecuencia de haber revertido en parte el retraso en G2/M (datos no mostrados).

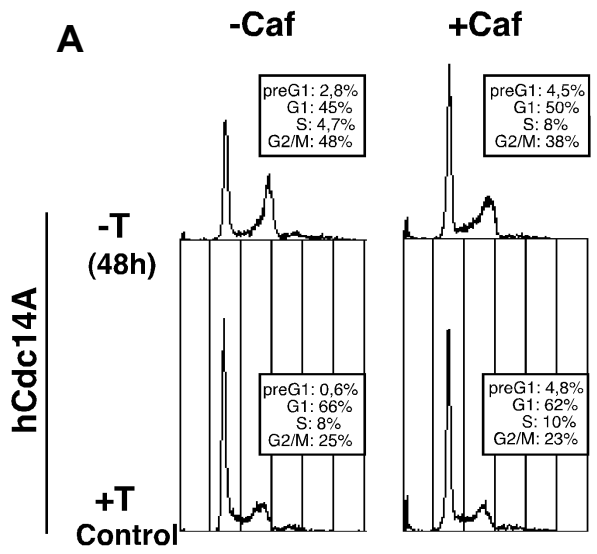

B

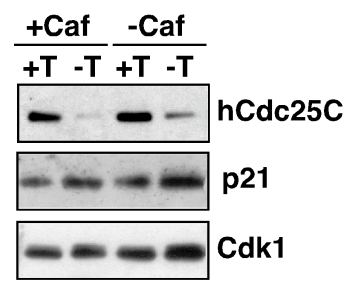

Figura 35. Las proteínas ATM y/o ATR parecen estar implicadas en el retraso en G2/M producido "a largo plazo" por la sobre-expresión de hCdc14A, pero no revierte su efecto sobre hCdc25C y p21. Las células U2OS-Myc-hCdc14A fueron incubadas con (+T) o $\sin (-T)$ tetraciclina durante 48 horas. A la mitad de estas células se les añadió cafeína (+Caf), inhibidor de ATM y ATR, a una concentración final de $3 \mathrm{mM}$ y durante las 48 horas. A: Se recogieron muestras de estos cultivos para el análisis de su contenido de DNA por FACS, y se determinaron los porcentajes de células en las distintas fases del ciclo celular. $\boldsymbol{B}$ : $\mathrm{Se}$ obtuvieron extractos proteicos de estos cultivos, que fueron procesados por electroforesis en SDS-PAGE y analizados por Western blot para la detección de hCdc25C, p21 y Cdk1 (control de carga). 
Por otra parte, pese a que los resultados anteriores son indicativos de que la activación de ATM y/o ATR podría estar implicada en el efecto "a largo plazo" de la sobreexpresión de hCdc14A sobre la transición G2/M, la reducción de hCdc25C y el incremento de p21 no son revertidos por la cafeína, y por lo tanto no parecen estar relacionados con la activación de ATM y/o ATR (Fig. 35B).

\section{Fosforilación de Histona H2AX: Consecuencia sólo "a largo plazo" de la sobre- expresión de hCdc14A}

Para descartar que la activación de ATM y/o ATR estuviese implicada en el papel desempeñado por hCdc14A en la entrada en mitosis, y de este modo, comprobar que sólo participa en el efecto "a largo plazo" de su sobre-expresión, analizamos la fosforilación de Histona H2AX, posible consecuencia de la activación de ATM en respuesta a daño al DNA (Burma et al., 2001), tras distintos tiempos de sobre-expresión de hCdc14A. En concreto, este análisis se realizó mediante inmunofluorescencia indirecta con un anticuerpo específico frente a la fosforilación de la $\operatorname{Ser}^{139}$ de Histona H2AX en células que habían sobre-expresado hCdc14A durante 12, 24 ó 48 horas y en células control. Como se observa en la Figura 36, tras 24 horas de sobre-expresión sólo alguna célula aislada muestra tinción positiva, y es después de 48 horas, cuando se produce un incremento significativo de la fosforilación de Histona H2AX. Estos datos sugieren que la activación de ATM es únicamente un efecto de la sobre-expresión de hCdc14A "a largo plazo".

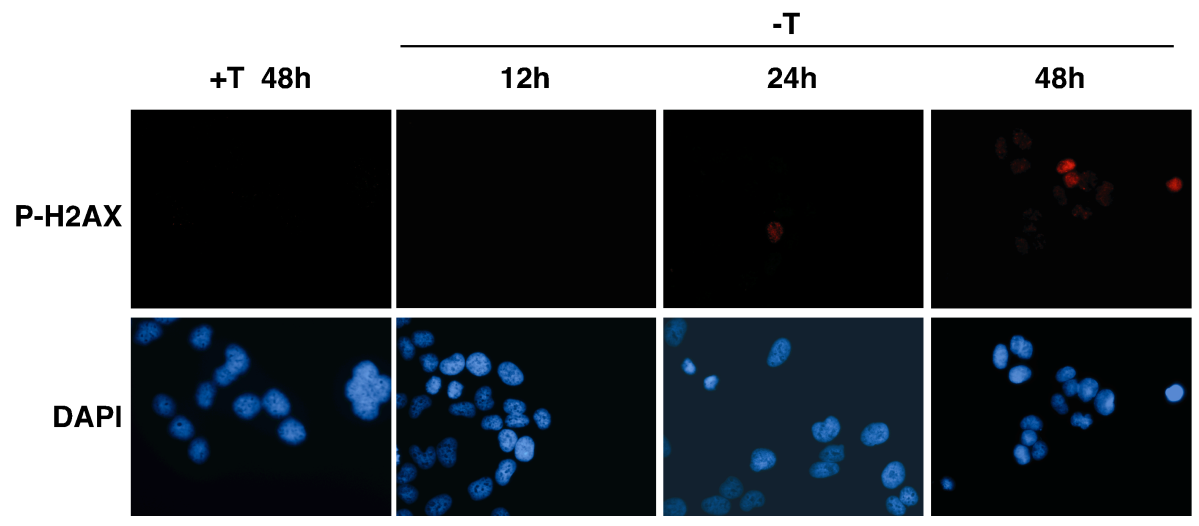

Figura 36. La sobre-expresión de hCdc14A sólo "a largo plazo" induce la fosforilación de Histona H2AX. Las células U2OS-Myc-hCdc14A fueron incubadas en presencia de tetraciclina $(+\mathrm{T})$ durante 48 horas, o en ausencia de ésta (-T), durante 12, 24 y 48 horas. Tras esto, fueron fijadas con paraformaldehído y sometidas a inmunocitoquímica con un anticuerpo específico frente a la fosforilación en $\mathrm{Ser}^{139}$ de la Histona H2AX. Los núcleos de estas células se tiñeron con DAPI (fotografías inferiores). 
En definitiva, parece que sólo la sobre-expresión prolongada de hCdc14A da lugar a una activación de ATM y/o ATR, y por lo tanto de una ruta de checkpoint, que constituiría una de las causas del retraso en G2/M descrito en estas condiciones, contribuyendo a evitar la inestabilidad genómica en estas células. Sin embargo, el efecto "a largo plazo" de la sobre-expresión de hCdc14A sobre los niveles de hCdc25C y p21 parece ser independiente de la activación de ATM y ATR.

\subsection{Estudio de la implicación de p38 en el efecto a "largo plazo" de la sobre-expresión de hCdc14A}

La familia de las proteínas p38 se ha relacionado con la respuesta celular a diversas formas de estrés y con el consecuente retraso que sufren dichas células, tanto en G2 como en G1. Además, recientemente se ha demostrado que p38 también está implicada en el checkpoint de "antefase", punto del ciclo en el que las células se retrasan a consecuencia de la sobre-expresión de hCdc14A. Estos datos nos llevaron a considerar la posibilidad de que alguna isoforma de p38 pudiese participar en los efectos producidos "a largo plazo" por la sobre-expresión de hCdc14A.

\subsubsection{Activación de p38: Consecuencia de la sobre-expresión de hCdc14A "a largo plazo"}

Para comprobar si p38 estaba implicado en el retraso en la transición G2/M producido tras 48 horas de sobre-expresión de hCdc14A, se emplearon dos aproximaciones, la inhibición de p38 mediante la adición de SB203580 (inhibidor de p38 $\alpha$ y $\beta$ ), para comprobar si revierte el retraso en G2/M de estas células, y el análisis directo de la posible activación de p38 en las condiciones de sobre-expresión descritas.

De este modo, en primer lugar comprobamos por análisis de FACS que la adición de SB203580 a cultivos asíncronos de U2OS-Myc-hCdc14A inducidos durante 48 horas, revertía parcialmente el retraso en la transición G2/M producido en estas condiciones (Fig. 37A). Sin embargo, la inhibición de p38 tampoco rescata la reducción de los niveles de hCdc25C observada en estas células (Fig. 37B).

A continuación, comprobamos la posible activación de p38 tras 48 horas de sobreexpresión de hCdc14A. Para ello, analizamos por Western blot la fosforilación de los residuos $\mathrm{Thr}^{180}$ y $\mathrm{Tyr}^{182}$ de p38 mediante un anticuerpo específico, lo que nos permitió observar que la proteína p38 se encuentra activada en las células que sobre-expresan hCdc14A de forma prolongada (Figura 37C). 
A

DMSO

+SB203580

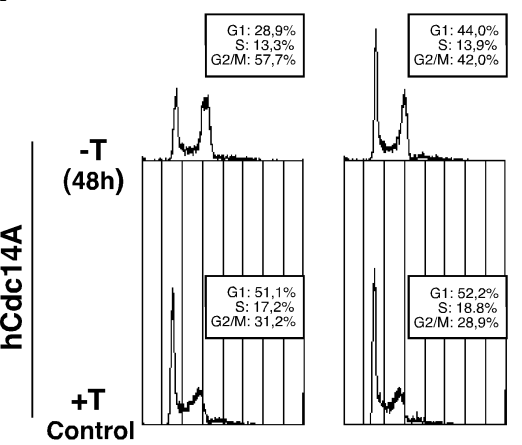

B

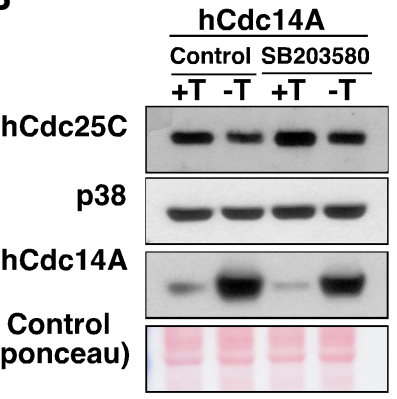

C

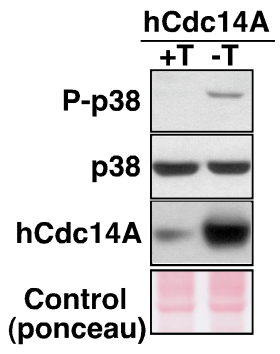

Figura 37. La activación de p38 está implicada en el retraso en G2/M producido "a largo plazo" por la sobre-expresión de hCdc14A. Las células U2OS-Myc-hCdc14A fueron incubadas con $(+\mathrm{T})$ o sin $(-\mathrm{T})$ tetraciclina durante 48 horas. Además, a la mitad de estas células se les añadió SB203580, inhibidor de p38, durante las 48 horas; al resto de las células se les añadió el mismo volumen del disolvente del compuesto (DMSO) $\boldsymbol{A}$ : Se recogieron muestras de estos cultivos para el análisis de su contenido de DNA por FACS, y se determinaron los porcentajes de células en las distintas fases del ciclo celular. B: A partir de estos cultivos se obtuvieron extractos proteicos, procesados por electroforesis, en los que analizamos los niveles de hCdc25C, p38 y hCdc14A mediante Western blot. C: En los extractos proteicos sin SB203580, analizamos mediante Western blot la activación de p38, por medio de un anticuerpo frente a p38 fosforilado en $\mathrm{Thr}^{180} \mathrm{y} \mathrm{Tyr}^{182}$, y los niveles de p38 (control) y hCdc14A. Los extractos también se tiñeron con Ponceau (control de carga).

A partir de estos resultados se puede concluir que el efecto a "largo plazo" que tiene la sobre-expresión de hCdc14A (durante más de un ciclo celular) sobre la transición G2/M se debe, en parte, a la activación de p38.

\subsubsection{El retraso en la transición $\mathrm{G} 2 / \mathrm{M}$ inducido por la sobre-expresión de hCdc14A a partir de fase $S$ no está asociado a la activación de p38}

Con el fin de descartar la participación de p38 en la función específica que hCdc14A desempeña en la transición G2/M, sincronizamos con timidina las células U2OS-MychCdc14A e inducimos su expresión a partir del segundo tratamiento con ésta (Fig. 16A). 


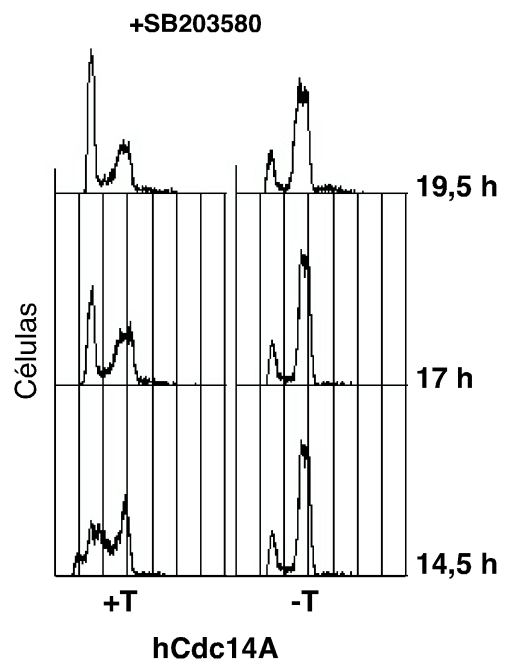

Figura 38. La activación de p38 no está implicada en el retraso en $\mathrm{G} 2 / \mathrm{M}$ producido por la sobre-expresión de hCdc14A en ese punto del ciclo celular. Los cultivos celulares U2OS-Myc-hCdc14A fueron sincronizados e inducidos como se indica en la Figura 16A. En el momento de la inducción se añadió SB203580, inhibidor de $\mathrm{p38}$, a la mitad de las células, mientras a la otra mitad se le añadió DMSO (disolvente de este compuesto), como control. Se recogieron muestras de células inducidas (T) y control (+T), a las $14,5,17$ y 19,5 horas tras la "liberación" del bloqueo en G1/S, para el análisis de su contenido de DNA por FACS. En la figura se muestran los perfiles de FACS correspondientes a las células tratadas con SB203580, similares a los de células $\sin$ tratar.

En estas células analizamos el efecto de la inhibición de p38 en la cinética de entrada en mitosis, así como su estado de activación en dicha transición.

La actividad de p38 fue inhibida mediante la adición de SB203580 a cultivos de U2OS-Myc-hCdc14A sincronizados como se ha indicado. El análisis del perfil de FACS de estas células demostró que el inhibidor de p38 (SB203580) no revierte el retraso en la transición G2/M, producido a consecuencia de la sobre-expresión de hCdc14A en ese punto del ciclo celular (Fig. 38).

En paralelo y para confirmar que la activación de p38 no está implicada en este efecto de la sobre-expresión de hCdc14A en la transición G2/M, se analizó mediante Western blot la activación esta quinasa (asociada a la fosforilación en $\mathrm{Thr}^{180}$ y $\mathrm{Tyr}^{182}$ ) en células sincronizadas en G2/M. En estas condiciones no se detectó activación de p38 (datos no mostrados).

Estos resultados indican que p38 no interviene en la función que hemos atribuido a hCdc14A en la regulación de la entrada en mitosis, consecuencia de su acción en este punto del ciclo celular. 


\section{FUNCIÓN DESEMPEÑADA POR hCdc14A EN LA REGULACIÓN DE LA SALIDA DE MITOSIS EN CÉLULAS HUMANAS}

A la vista de las importantes funciones desempeñadas por las proteínas Cdc14 y Flp1 en la regulación de la actividad CDK a la salida de mitosis en levaduras, parecía probable que los homólogos humanos, hCdc14A y hCdc14B, también pudiesen participar de forma similar en este proceso. De hecho, como se ha mencionado anteriormente, en el caso de la proteína hCdc14A se sabe que está implicada en la regulación del ciclo de división del centrosoma, de la segregación cromosómica y de la citoquinesis en células humanas (Kaiser et al., 2002; Mailand et al., 2002a). Además, se ha descrito que hCdc14A desfosforila diversos sustratos de CDK, y entre ellos Cdh1, induciendo su activación in vitro (Bembenek y Yu, 2001), lo que sugiere que esta fosfatasa podría actuar como antagonista de la actividad CDK a la salida de mitosis. Por otra parte, a raíz de nuestro trabajo anterior, sabemos que hCdc14A desfosforila también a hCdc25A y hCdc25C in vitro, y modula la actividad CDK mitótica, datos que apoyan una posible función de hCdc14A en la regulación de la salida de mitosis en células humanas.

\section{Efectos de la sobre-expresión de hCdc14A en la salida de mitosis en células humanas}

Con el objetivo de estudiar esta posible función de hCdc14A como regulador de la salida de mitosis, decidimos analizar los efectos de la sobre-expresión de esta fosfatasa en la cinética de salida de mitosis en dos líneas celulares humanas, HCT116 y U2OS.

\subsection{Cinética de la salida de mitosis en células HCT116 que sobre- expresan hCdc14A: Inactivación de los complejos Cdk1-Ciclina B1 y degradación de Ciclina B1}

En primer lugar, las células HCT116 fueron transfectadas con el cDNA de hCdc14A o con el correspondiente plásmido vacío (control) y, transcurridas 24 horas desde la transfección, se sincronizaron en una fase temprana de mitosis mediante el tratamiento con nocodazol. Las células mitóticas fueron recolectadas y cultivadas en un medio ya sin nocodazol, para así poder analizar su progresión por la transición M/G1. A continuación, a partir de los extractos proteicos obtenidos a distintos tiempos a lo largo de la salida de mitosis, se inmunoprecipitaron los complejos Cdk1-Ciclina B1, cuya actividad quinasa fue 


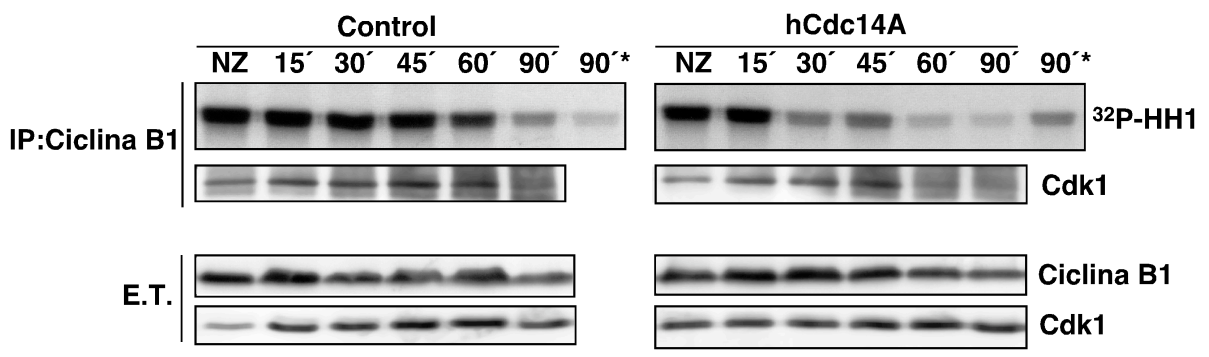

Figura 39. La sobre-expresión de hCdc14A acelera la inactivación de los complejos Cdk1-Ciclina B1 a la salida de mitosis en células HCT116. Las células HCT116 fueron transfectadas con el plásmido pcDNA3 vacío (control) o conteniendo el cDNA de hCdc14A. Tras 24 horas, las células se trataron con nocodazol durante 16 horas y fueron seleccionadas las células mitóticas (redondeadas), las cuales se incubaron en medio sin nocodazol ("liberación") durante $0,15,30,45,60$ y 90 minutos. Obtuvimos extractos proteicos totales (E.T.) de cada muestra. A partir de los extractos proteicos se inmunoprecipitaron los complejos Cdk1-Ciclina B1 con un anticuerpo específico anti-Ciclina B1 y se realizó un ensayo quinasa sobre Histona H1. Las proteínas de estas reacciones fueron separadas mediante electroforesis, y analizadas por auto-radiografía y por Western blot con un anticuerpo antiCdk1 (panel superior). Con el asterisco se señalan muestras cruzadas entre células control y células que sobre-expresan hCdc14A. En los extractos proteicos (E.T.) se detectaron los niveles la Ciclina B1 y Cdk1 (control de carga) por Western blot, mostrados en la parte inferior.

determinada sobre Histona H1. Como se observa en la Figura 39, la sobre-expresión de hCdc14A induce una reducción más rápida y pronunciada de la actividad CDK mitótica a la salida de mitosis.

También se analizaron los niveles de Ciclina B1, cuya degradación es característica de la salida de mitosis, lo que demostró que la caída de los niveles proteicos de Ciclina B1 es más rápida a consecuencia de la sobre-expresión de hCdc14A (Fig. 39).

Ambos resultados señalan que la sobre-expresión de hCdc14A acelera la salida de mitosis, promoviendo la inactivación de los complejos CDK en este punto del ciclo, lo que en definitiva sugiere que esta fosfatasa podría ejercer un papel en este proceso.

\subsection{Cinética de la salida de mitosis en células U2OS-Myc-hCdc14A que sobre-expresan hCdc14A: Degradación de hCdc25A y Ciclina B1}

Con el fin de comprobar el efecto de la sobre-expresión de hCdc14A a la salida de mitosis en otra línea celular, en concreto U2OS, utilizamos los clones estables de sobreexpresión inducible empleados anteriormente. Estas células fueron sincronizadas en mitosis, por medio del tratamiento con nocodazol y posterior selección de las células mitóticas. La sobre-expresión de hCdc14A fue inducida en la mitad de las células a partir de las 7 últimas horas del tratamiento con nocodazol. A continuación, retiramos el 
nocodazol del medio de cultivo y monitorizamos la cinética de salida de mitosis mediante el análisis de los niveles proteicos de la Ciclina B1 y hCdc25A, cuya degradación es característica de esta fase del ciclo. Así, comprobamos que la degradación de ambas proteínas se produce de forma más rápida en las células que sobre-expresan hCdc14A, indicativo de que éstas salen antes de mitosis (Fig. 40). Por otra parte, los cambios en la movilidad electroforética de la proteína hCdc25A nos indican que el estado de fosforilación de esta fosfatasa es relevante para su degradación a la salida de mitosis, como ya habían mencionado otros autores (Mailand et al., 2002b). Además, estas modificaciones en el estado de fosforilación de hCdc25A a la salida de mitosis sugieren una posible relación entre la degradación de hCdc25A en este punto del ciclo y la acción directa de hCdc14A, dado que esta última es capaz de desfosforilar in vitro a hCdc25A en residuos fosforilados por Cdk1-Ciclina B1, como ya hemos demostrado.

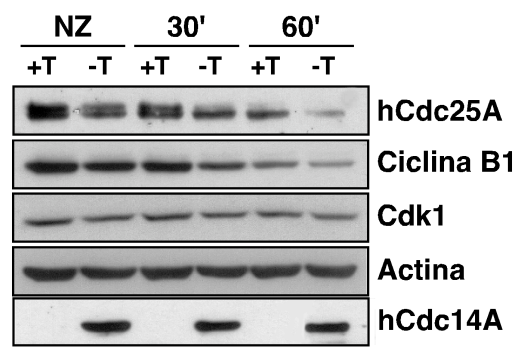

fueron separadas mediante electroforesis, y analizadas por Western blot con anticuerpos frente a hCdc25A, Ciclina B1, Cdk1, hCdc14A y Actina (control de carga).

Figura 40. La sobre-expresión de hCdc14A acelera la salida de mitosis en células U2OS. Las células U2OS-Myc-hCdc14A fueron tratadas con nocodazol durante 19 horas, y durante las 7 últimas horas la sobre-expresión fue inducida (T) en la mitad de las células, mientras la otra mitad, empleada como control, se mantuvo en presencia de tetraciclina $(+T)$. Las células mitóticas (redondeadas) fueron seleccionadas e incubadas en medio sin nocodazol ("liberación") durante 0,30 y 60 minutos. Obtuvimos extractos proteicos de cada muestra y las proteínas

En conclusión, como cabía esperar en base a nuestros datos y a los de otros autores, la sobre-expresión de hCdc14A acelera la salida de mitosis en células HCT116 y U2OS. Por otra parte, la degradación de hCdc25A en este punto del ciclo podría ser dependiente de su estado de fosforilación, que a su vez puede estar modulado por la fosfatasa hCdc14A.

\section{Efectos de la desfosforilación de los residuos $\operatorname{Ser}^{115}$ y $\operatorname{Ser}^{320}$ en la estabilidad de la proteína hCdc25A}

Se ha descrito que la estabilidad de hCdc25A en la transición G2/M depende de la fosforilación de esta proteína en al menos dos residuos, $\operatorname{Ser}^{17}$ y $\operatorname{Ser}^{115}$ (S17 y S115) por los complejos Cdk1-Ciclina B1 (Mailand et al., 2002b). Por otra parte, a raíz de nuestro trabajo sabemos que hCdc14A es capaz de desfosforilar in vitro a hCdc25A en los 
residuos $\operatorname{Ser}^{115}$ y Ser ${ }^{320}$ (fosforilados previamente por Cdk1-Ciclina B1), y que elevados niveles de nuestra fosfatasa en células humanas inducen una aceleración en la desfosforilación y la degradación de hCdc25A a la salida de mitosis. Estos resultados sugieren que la desfosforilación de los residuos $\operatorname{Ser}^{115}$ y $\operatorname{Ser}^{320}$ por parte de hCdc14A podría afectar a la estabilidad de hCdc25A, pudiendo promover, a su vez, su degradación al final de mitosis.

Para comprobar esta hipótesis se co-transfectaron células HEK293T con los cDNAs de hCdc25A $A^{\text {wt }}$ o los mutantes hCdc25A $A^{\text {S115E }}$, hCdc25A ${ }^{\text {S320E }}$ y hCdc25A $A^{\text {S115E-S320E }}$ (en los cuales las Serinas indicadas han sido sustituidas por Ácido glutámico, lo que simula su fosforilación permanente), junto con el cDNA de hCdc14A, hCdc14A(PD) o con el plásmido vacío (control). A las 40 horas tras la transfección, analizamos en estas células los niveles de cada uno de los mutantes de hCdc25A o de la proteína de tipo silvestre, comparando la cantidad de esta proteína presente en células control, transfectadas con el plásmido vacío, y en células que sobre-expresan hCdc14A o hCdc14A(PD). En primer lugar, comprobamos que los niveles de la proteína ectópica $h C d c 25 A^{\text {wt }}$ se reducen al sobre-expresar la fosfatasa $\mathrm{hCdc} 14 \mathrm{~A}$, pero no su forma sin actividad catalítica, hCdc14A(PD) (Fig. 41A). Esta reducción de los niveles de hCdc25A, debida a la sobreexpresión de hCdc14A, se sigue produciendo en los mutantes simples, hCdc25A ${ }^{\mathrm{S} 115 \mathrm{E}}$ y hCdc25A ${ }^{\mathrm{S} 320 \mathrm{E}}$, pero se encuentra prácticamente anulada en el caso del doble mutante

A

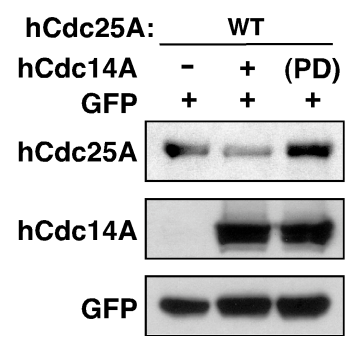

B

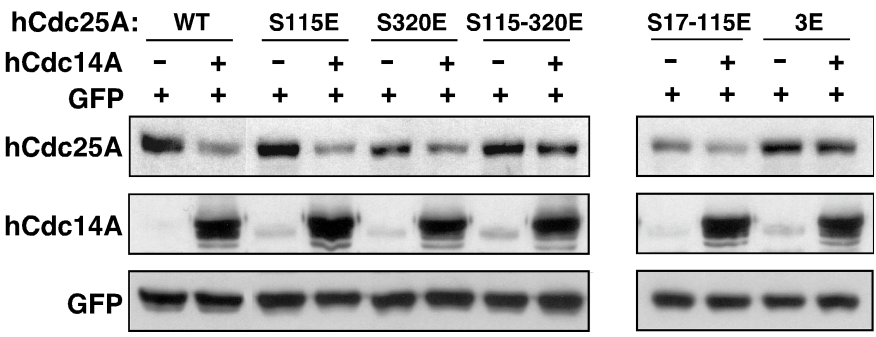

Figura 41. La sobre-expresión de hCdc14A reduce los niveles de hCdc25A a través de su desfosforilación. Las células HEK293T fueron transfectadas con plásmidos que contienen el cDNA de la proteína hCdc25A de tipo silvestre (wt) $(\boldsymbol{A}$ y $\boldsymbol{B})$, o los mutantes de esta proteína en los que residuos Serina específicos (Ser, S) han sido sustituidos por Ácido glutámico (Glu, E), S115E, S320E, S115-320E, S17-115E y S17-115-320E (3E) (B), junto con el plásmido pcDNA3 vacío (-), o que contiene el cDNA de hCdc14A $(\boldsymbol{A}$ y $\boldsymbol{B})$ o de hCdc14A(PD) $(\boldsymbol{A})$. Las células también fueron cotransfectadas en todos los casos con un plásmido que expresaba la proteína GFP, empleado como control de eficiencia de transfección y de carga. Transcurridas 40 horas desde la transfección, obtuvimos extractos proteicos de estas células, cuyas proteínas se separaron mediante electroforesis. Analizamos los niveles de hCdc25A y sus mutantes, de hCdc14A o hCdc14A(PD) y GFP, mediante Western blot con anticuerpos especificos anti-hCdc25A, anti-hCdc14A y anti-GFP. 
hCdc25A $\mathrm{S}^{\mathrm{S115-320E}}$. Por último, también se co-transfectaron células HEK293T, del mismo modo indicado, con los cDNAs del doble mutante hCdc25 $\mathrm{A}^{\text {S17-115E }}$ (forma estable en mitosis, (Mailand et al., 2002b) o del triple mutante hCdc25A $A^{\text {S17-115-320E }}(3 E)$, junto con el cDNA de hCdc14A o el correspondiente plásmido vacío. En el caso del mutante hCdc25A ${ }^{\text {S17-115E }}$, la sobre-expresión de hCdc14A causaba una reducción en sus niveles, aunque de forma más leve que en el caso de $h C d c 25 A^{\text {wt }}$, reducción que no observamos prácticamente en el caso del triple mutante (Fig. 41B). Estos datos también fueron corroborados en la línea celular HCT116 (datos no mostrados).

Los resultados mostrados indican que hCdc14A podría regular la estabilidad de hCdc25A, por medio de la desfosforilación de los residuos descritos $\left(\operatorname{Ser}^{115}\right.$ y $\operatorname{Ser}^{320}$ ) en este punto del ciclo, hecho que sugiere, junto con los resultados mostrados en el anterior apartado, que hCdc14A podría desempeñar una función a la salida de mitosis. 



\section{CONSERVACIÓN EVOLUTIVA DE LAS PROTEÍNAS Cdc14}

Han sido identificadas proteínas de la familia Cdc14 en diversas especies de organismos eucariotas, desde levaduras hasta mamíferos, y todas ellas presentan características comunes, ya que son fosfatasas de especificidad dual que contienen una región conservada de 350 aminoácidos en el extremo amino, donde se encuentra el dominio fosfatasa (PTP) (Gray et al., 2003). Además, las fosfatasas Cdc14 estudiadas son capaces de desfosforilar a sustratos de los complejos CDK, lo que les convierte en antagonistas de la actividad CDK. Sin embargo, dado el papel central desempeñado por los complejos Cdk-Ciclina en la regulación del ciclo celular en eucariotas, las distintas proteínas de la familia Cdc14 pueden participar en el control de procesos diferentes durante el ciclo. En este sentido, se ha demostrado que la proteína Cdc14 en S. cerevisiae es esencial para la salida de mitosis (Visintin et al., 1998; Jaspersen et al., 1999; Bardin y Amon, 2001), proceso en el que también se ha implicado a su homólogo en S. pombe, Flp1/Clp1, aunque a través de un mecanismo de acción diferente (Wolfe y Gould, 2004). Si bien, datos obtenidos en nuestro laboratorio sugieren que Flp1 no participa propiamente en este proceso, sino en la coordinación entre la segregación cromosómica y la septación (citoquinesis) (Esteban et al., 2004; Esteban et al, 2008). Además, algunas de las proteínas Cdc14 están implicadas en la regulación de la citoquinesis, como es el caso de CeCDC14 en C. elegans, XCdc14A en Xenopus (Gruneberg et al., 2002; Krasinska et al., 2007) y Flp1 en S. pombe, que participa en el checkpoint de citoquinesis (Trautmann et al., 2001; Trautmann y McCollum, 2005). Por otra parte, recientemente se ha demostrado que CeCDC14 es esencial para que ocurra la parada en G1 de determinadas células, necesaria durante el desarrollo de C. elegans (Kipreos, 2004; Saito et al., 2004).

Al inicio de nuestro estudio, se disponía de escasos datos acerca de las funciones de las fosfatasas humanas Cdc14. En concreto se había descrito la participación de la fosfatasa hCdc14A en la regulación del ciclo de división del centrosoma, la segregación cromosómica y la citoquinesis (Kaiser et al., 2002; Mailand et al., 2002a), aunque no se conocía su mecanismo de acción y se habían identificado pocos sustratos de esta proteína, siendo p53 y Cdh1 dos de ellos (Li et al., 2000; Bembenek y Yu, 2001). Una buena estrategia para obtener más información acerca de las funciones y mecanismos de acción de los Cdc14 humanos era el estudio de su posible homología funcional con las proteínas Cdc14 de levaduras, Cdc14 y Flp1, cuyas funciones y mecanismos de acción habían sido estudiados de forma más amplia. En este sentido, de forma previa al comienzo de nuestro trabajo se había demostrado que hCdc14A es capaz de 


\section{Discusión}

complementar la falta de Cdc14 en el mutante termosensible $c d c 14-1^{\text {ts }}$ de la levadura $S$. cerevisiae (Li et al., 1997b). Además, como hemos indicado, se sabía que hCdc14A desfosforila in vitro a Cdh1, cuyo homólogo en $S$. cerevisiae, Hct1/Cdh1, es un importante sustrato de Cdc14 a la salida de mitosis (Jaspersen et al., 1999; Bembenek y Yu, 2001).

Por nuestra parte, ante la reducido conocimiento existente acerca de las proteínas Cdc14 humanas, decidimos comenzar el presente trabajo con el análisis de la posible homología funcional entre las fosfatasas hCdc14 y Flp1 (de S. pombe) (Vazquez-Novelle et al., 2005). Este estudio nos permitió demostrar que ambas proteínas humanas, hCdc14A y hCdc14B, son capaces de complementar el fenotipo correspondiente a la ausencia de Flp1 en células de $S$. pombe, aunque por medio de mecanismos de acción diferentes. En este sentido, hemos determinado que la proteína Cdc25 de S. pombe es sustrato de hCdc14A, pudiendo esto explicar la complementación de la falta de Flp1 observada en este caso, como detallaremos más adelante. Mientras en el caso de hCdc14B, no hemos determinado el mecanismo por el que se produce dicha complementación, el cual, en base a nuestros datos parece ser independiente de la desfosforilación de Cdc25. Sin embargo, la complementación de la carencia de Flp1 llevada a cabo por hCdc14B, sí podría estar relacionada con su interacción in vivo con Cdc25, que a su vez parece promover la exclusión nuclear de la proteína Cdc25 en S. pombe, impidiendo de esta forma su actividad sobre Cdc2. De todos modos, este posible mecanismo de acción no parece ser el único, ya que la expresión de hCdc14B complementa de forma más eficiente la carencia de Flp1 que la forma inactiva $\mathrm{hCdc} 14 \mathrm{~B}(\mathrm{PD})$, a pesar de que esta última también interacciona in vivo con Cdc25, con una eficiencia similar a la fosfatasa activa. Esto indica que hCdc14B posiblemente complementa alguna función de Flp1, independiente de su acción directa sobre Cdc25, a través de la desfosforilación de sustratos no identificados.

\section{Las fosfatasas hCdc25: Posibles sustratos de hCdc14A}

A raíz de que hCdc14A es capaz de desfosforilar in vitro e in vivo a la proteína Cdc25 de S.pombe (datos de este trabajo), hemos considerado que el mecanismo de acción de Flp1, promoviendo la inactivación de los complejos CDK mitóticos a través de la desfosforilación de Cdc25 (activador esencial de dichos complejos), podría estar conservado en células humanas.

Con el fin de comprobar si hCdc14A podía desempeñar alguna de sus funciones en células humanas a través de los hCdc25s, en primer lugar analizamos si estas proteínas humanas ( $\mathrm{hCdc} 25 \mathrm{~A}, \mathrm{hCdc} 25 \mathrm{~B}$ y/o $\mathrm{hCdc} 25 \mathrm{C}$ ) eran también sustratos in vitro de las fosfatasas humanas Cdc14, lo que nos permitió demostrar que efectivamente hCdc14A es 
capaz de desfosforilar in vitro a hCdc25A y hCdc25C, previamente fosforilados por Cdk1. Además, como mostraremos más adelante, la desfosforilación de determinados residuos de hCdc25A por hCdc14A está relacionada con la regulación de su estabilidad, mientras que, por el momento, desconocemos el significado funcional de la desfosforilación de hCdc25C por nuestra fosfatasa.

A continuación, dado que disponíamos de esta información sobre el posible mecanismo de acción de hCdc14A, centramos nuestro estudio en las funciones desempeñadas por esta fosfatasa en células humanas, llevando a cabo experimentos de sobre-expresión y silenciamiento de la expresión de hCdc14A en varias líneas celulares humanas.

\section{II. hCdc14A REGULA LA ENTRADA EN MITOSIS A TRAVÉS DE hCdc25A}

\section{hCdc14A regula negativamente la entrada en mitosis de forma dependiente de su actividad fosfatasa}

Para estudiar las funciones de hCdc14A en células humanas, analizamos en primer lugar los efectos de su sobre-expresión. De este modo, observamos que elevados niveles de esta fosfatasa, pero no de su forma inactiva, dan lugar a un retraso en la transición $\mathrm{G} 2 / \mathrm{M}$, hecho que sugiere una posible implicación de la actividad de hCdc14A en la regulación de la entrada en mitosis. A continuación, mediante la caracterización de este efecto sobre la transición G2/M, pudimos demostrar que la presencia de altos niveles de hCdc14A a partir de fase $\mathrm{S}$ es suficiente para inducir un retraso en la entrada en mitosis, que se produce de forma previa a la condensación cromosómica, concretamente antes y, sobre todo, durante "antefase", momento en el cual se ha iniciado la fosforilación de la Histona H3, necesaria para la iniciación de la condensación de los cromosomas, pero no para su mantenimiento (Van Hooser et al., 1998). Estos resultados indican que, efectivamente, la sobre-expresión de hCdc14A tiene un efecto en ese punto del ciclo, impidiendo la completa condensación de los cromosomas. A continuación, para comprobar que realmente este efecto es reflejo de una función fisiológica de esta proteína, también estudiamos las consecuencias de la falta o reducción de hCdc14A sobre la transición G2/M, demostrando así que ésta no sólo se ve afectada por la presencia de niveles anormalmente elevados de esta fosfatasa en la célula, sino que la reducción de los niveles endógenos de hCdc14A da lugar a una entrada acelerada en mitosis, efecto opuesto al causado por la sobre-expresión. 
En definitiva, nuestros resultados demuestran que hCdc14A, de forma dependiente de su actividad catalítica, participa en la regulación de la entrada en mitosis en células humanas, ejerciendo una función inhibidora sobre procesos tempranos, como la condensación cromosómica.

A pesar de que inicialmente se consideró que las funciones de hCdc14A afectaban principalmente a la salida de mitosis y a la citoquinesis (Kaiser et al., 2002; Mailand et al., 2002a), la función reguladora de hCdc14A a la entrada en mitosis que hemos descrito es coherente con resultados obtenidos por otros autores recientemente. Así, se ha observado que la sobre-expresión de hCdc14A y de forma más eficiente la sobre-expresión de una forma truncada, considerada constitutivamente activa, dan lugar a un retraso en la entrada en mitosis (Yuan et al., 2007), del mismo modo que la sobre-expresión de la proteína XCdc14A en células humanas Hela y en oocitos de Xenopus (Krasinska et al., 2007). Si bien, no se conocía el mecanismo de acción mediante el que la sobre-expresión de hCdc14A podría ejercer su efecto en la transición G2/M, ni las características de dicho retraso (Yuan et al., 2007).

El efecto de hCdc14A sobre la entrada en mitosis se asocia a la inactivación de los complejos CDK mitóticos, promovida a través de la inhibición de hCdc25A

A continuación, nuestro objetivo fue determinar el mecanismo de acción mediante el cual hCdc14A retrasa la transición G2/M. Para ello, en primer lugar comprobamos que elevados niveles de la proteína hCdc14A en la célula inducen la inactivación de los complejos CDK mitóticos, tanto de Cdk1-Ciclina B1 como de Cdk-Ciclina A. Este resultado sugiere que la inhibición de la actividad CDK mitótica puede ser la causa última del efecto observado a la entrada en mitosis, hecho que, por otra parte, es perfectamente coherente con las funciones desempeñadas por las demás proteínas de la familia Cdc14.

Tras comprobar que hCdc14A no es capaz de desfosforilar a los complejos CDK mitóticos de forma directa (mediante ensayos in vitro no mostrados), consideramos, basándonos en nuestros resultados iniciales, que los sustratos más probables de hCdc14A y responsables de su efecto sobre la actividad CDK mitótica, eran las proteínas Cdc25 humanas. Esta posibilidad se veía apoyada también por el hecho de que Flp1 desfosforila a Cdc25 en S. pombe a la salida de mitosis (Esteban et al., 2004; Wolfe y Gould, 2004).

En consecuencia, decidimos comprobar si hCdc14A podía ejercer su acción inhibidora sobre alguna de las isoformas de hCdc25 en células humanas y si ésta es la causa de la reducción de la actividad de los complejos CDK mitóticos en la transición G2/M. De este modo, mediante estudios de sobre-expresión y de silenciamiento de hCdc14A, hemos 
demostrado que esta fosfatasa inhibe la actividad catalítica de hCdc25A sobre Cdk1 a la entrada en mitosis.

A raíz de estos resultados, consideramos que la inactivación de hCdc25A a la entrada en mitosis puede formar parte del mecanismo de acción por el que hCdc14A ejerce su efecto inhibidor sobre los complejos CDK en este punto del ciclo. Esta posibilidad se vió apoyada por datos obtenidos por otros autores, los cuales demuestran que hCdc25A participa en la regulación de la entrada en mitosis (Mailand et al., 2002b; Lindqvist et al., 2005). Concretamente, se ha relacionado el silenciamiento de la expresión de hCdc25A con un retraso en la condensación cromosómica, a su vez acompañado por la reducción de la actividad de los complejos Cdk-Ciclina A y Cdk1-Ciclina B1 (Lindqvist et al., 2005), efectos idénticos a los causados por los elevados niveles de hCdc14A, que sabemos que inducen la inactivación de hCdc25A en la transición G2/M. Además, recientemente en un estudio realizado en células humanas Hela y extractos de oocitos de Xenopus se ha propuesto un mecanismo similar, de inactivación de XCdc25, para explicar el retraso en la transición G2/M promovido por la sobre-expresión de XCdc14A (Krasinska et al., 2007).

Nuestros resultados ponen de manifiesto también un nuevo modo de regulación de hCdc25A en la transición G2/M, ya que hCdc14A modula de forma directa o indirecta su actividad catalítica sobre los complejos CDK, sin afectar a sus niveles proteicos. Hasta el momento, el único mecanismo de regulación de hCdc25A descrito a la entrada en mitosis consistía en la estabilización de esta proteína a través de su fosforilación por parte de Cdk1-Ciclina B1 (Mailand et al., 2002b).

En conclusión, todos estos datos sugieren que hCdc14A ejerce su función reguladora de la entrada en mitosis a través, al menos en parte, de la inactivación de hCdc25A, lo que constituye un mecanismo de control de esta proteína no descrito hasta el momento en este punto del ciclo (Modelo I). Así, en el modelo que proponemos la fosfatasa hCdc14A podría estar ejerciendo en un ciclo celular normal una acción inhibidora sobre la transición G2/M, contribuyendo de este modo al correcto balance entre proteínas activadoras e inhibidoras de los complejos CDK mitóticos, con el fin de garantizar que la entrada en mitosis ocurra en el momento adecuado y no antes. 


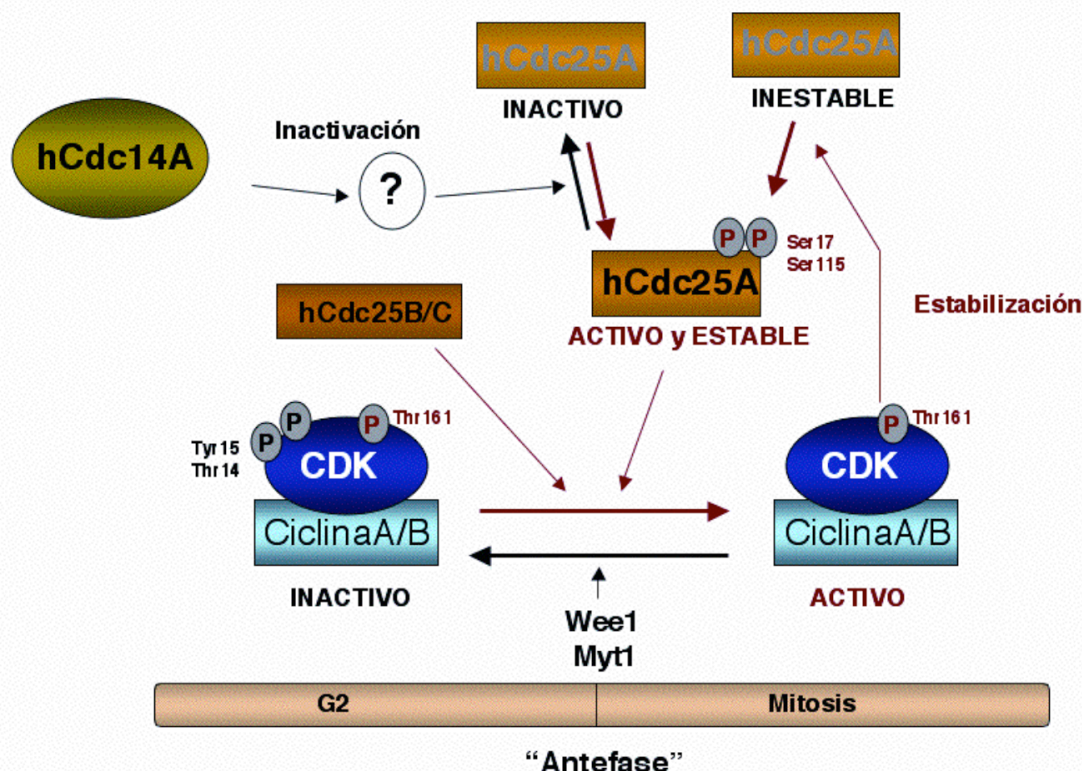

Modelo I. Función de hCdc14A en la regulación de la entrada en mitosis. A la entrada en mitosis se produce la activación de los complejos CDK mitóticos. La fosfatasa hCdc14A directa o indirectamente promueve la inhibición de la actividad catalítica de hCdc25A en la transición G2/M, proteína que, por otra parte, es estabilizada en mitosis a través de la fosforilación de determinados residuos por los complejos CDK mitóticos. La fosfatasa hCdc25A, junto con los otros hCdc25s, promueve la activación de los complejos CDK, mediante la desfosforilación de los residuos $\operatorname{Thr}^{14}$ y $\operatorname{Tyr}^{15}$, fosforilados por Wee1 y Myt1. En definitiva, hCdc14A induce la inactivación de hCdc25A en la transición G2/M, participando así (como inhibidor) en la regulación de los complejos Cdk1-Ciclina B1 durante la transición G2/M. En este esquema, las flechas y residuos fosforilados indicados en color rojo promueven la activación de los complejos, al contrario que aquellas en color negro.

Por otra parte, en nuestro laboratorio hemos comprobado recientemente que el control ejercido por hCdc14A sobre la transición G2/M, puede no estar ejercido exclusivamente a través de hCdc25A, sino también a través de la desfosforilación de la quinasa inhibidora Wee1, que según nuestros datos in vivo parece estabilizar a dicha proteína a la entrada en mitosis. En concreto, los niveles de Wee1 se mantienen elevados en este punto del ciclo en células que sobre-expresan hCdc14A, al contrario que en las células control, en las cuales esta quinasa se comienza a fosforilar y degradar a la entrada en mitosis. Estos datos sugieren, por lo tanto, que hCdc14A podría estar ejerciendo su acción inhibidora sobre la transición G2/M para de evitar una entrada en mitosis prematura, regulando tanto a proteínas activadoras (hCdc25A), como inhibidoras (Wee1) de los complejos CDK mitóticos. 


\section{Mecanismo mediante el que hCdc14A inhibe la actividad catalítica de hCdc25A}

A continuación quisimos dilucidar si la inactivación de hCdc25A inducida por hCdc14A a la entrada en mitosis ocurre de forma directa o indirecta. Dado que habíamos demostrado que hCdc14A es capaz de desfosforilar in vitro a hCdc25A en dos residuos fosforilados por Cdk1, $\operatorname{Ser}^{115}$ y $\operatorname{Ser}^{320}$, afectando a su estabilidad. En primer lugar, estudiamos si estas desfosforilaciones podían modular también la actividad catalítica de esta proteína. Para ello analizamos la actividad fosfatasa de mutantes de esta proteína, en los cuales los citados residuos habían sido sustituídos por aminoácidos que simulaban su desfosforilación o bien su fosforilación permanente, sin obtener a raíz de estos experimentos un resultado claro (datos no mostrados). A pesar de ello, sospechamos, en base a datos previos, que es poco probable que hCdc14A regule la actividad catalítica de hCdc25A por medio de estas desfosforilaciones. En concreto, Mailand et al. habían sugerido que la fosforilación por parte de complejos CDK mitóticos está implicada en la regulación de la estabilidad hCdc25A en mitosis, pero no de su actividad catalítica (Mailand et al., 2002b), y además, como ya hemos indicado, nuestros propios resultados demuestran que la desfosforilación de estos dos residuos $\left(\operatorname{Ser}^{115}\right.$ y $\operatorname{Ser}^{320}$ ) afecta a la estabilidad de la proteína (Esteban et al., 2006).

La siguiente posibilidad que nos planteamos es que hCdc14A pudiese inhibir la actividad de hCdc25A de forma directa pero no a través de la desfosforilación de los residuos $\operatorname{Ser}^{115}$ y $\operatorname{Ser}^{320}$ fosforilados por CDK, sino de residuos fosforilados por otras quinasas. Este mecanismo tampoco es muy probable, dado que todos los sustratos in vivo y la mayoría de los sustratos in vitro de hCdc14A identificados hasta el momento, son sutratos de CDK (Li et al., 2000; Bembenek y Yu, 2001; Kaiser et al., 2002; Gruneberg et al., 2004; Lanzetti et al., 2007; North y Verdin, 2007; Hansen et al., 2008), puesto que estas fosfatasas reconocen secuencias fosforilables por CDKs o MAPKs (Kaiser et al., 2002; Gray et al., 2003).

Por otra parte, en el caso de que el efecto sobre hCdc25A fuese directo, ambas proteínas deberían interaccionar en la célula, por lo que también analizamos su posible interacción in vivo, detectándola en condiciones de sobre-expresión de ambas proteínas (datos obtenidos en nuestro laboratorio).

En definitiva, los datos que acabo de citar nos hacen pensar que este efecto de hCdc14A sobre la actividad de hCdc25A a la entrada en mitosis podría ocurrir de forma indirecta (Modelo I). Posibles candidatos para mediar dicho efecto son Chk1 o las quinasas de la familia Polo, como Plk1 ó Plk3. Hemos considerado que estas proteínas podrían ser sustratos de hCdc14A capaces de modular a su vez la actividad hCdc25A, 


\section{Discusión}

dada su capacidad para regular alguno de los hCdc25s a la entrada en mitosis, por tratarse de sustratos de CDK y/o porque co-localizan con hCdc14A durante G2/M.

La proteína Chk1 desempeña importantes funciones relacionadas con la activación de distintos tipos de checkpoint, pero en los últimos años también se ha descrito que está implicada en la regulación de la entrada en mitosis de un ciclo celular normal (Zachos y Gillespie, 2007). Así, durante interfase una fracción de la proteína Chk1 se localiza en el centrosoma, donde fosforila a hCdc25B, impidiendo la activación de los complejos CDK y evitando de este modo una entrada prematura en mitosis (Kramer et al., 2004; Schmitt et al., 2006). Además, Chk1 fosforila determinados residuos de hCdc25A durante interfase en un ciclo celular normal, promoviendo su unión a proteínas 14-3-3 e impidiendo su interacción con la Ciclina B1 (Chen et al., 2003). Por otra parte, Chk1 es fosforilado en mitosis, posiblemente por Cdk1, y parece que esta fosforilación podría estar relacionada con una reducción en su actividad catalítica ( $\mathrm{Ng}$ et al., 2004; Shiromizu et al., 2006). De este modo, cabe la posibilidad de que hCdc14A, en un ciclo celular normal, sea capaz de desfosforilar a Chk1 promoviendo su actividad en la transición G2/M, lo que a su vez podría explicar una menor actividad de hCdc25A sobre los complejos CDK.

Como ya hemos mencionado, otros posibles sustratos de hCdc14A podrían ser las quinasas de la familia Polo, en concreto Plk1 y Plk3, que participan en la regulación de la entrada en mitosis de células humanas (Barr et al., 2004). En este sentido, ambas proteínas son capaces de fosforilar a hCdc25C (Barr et al., 2004; Myer et al., 2005) y también se ha propuesto que al menos Plk3 fosforila a hCdc25A en la región de unión a Ciclina B1, posiblemente promoviendo su unión a los complejos CDK mitóticos (Myer et al., 2005). Con respecto a la posible acción directa de hCdc14A sobre estas proteínas, ha sido descrita recientemente su interacción con Plk1 (Yuan et al., 2007), y además, la localización subcelular de ambas Plks y hCdc14A es coincidente a lo largo de G2/M (Golsteyn et al., 1995; Dai et al., 2002; Kaiser et al., 2002; Wang et al., 2002; Yuan et al., 2007). De especial interés para nuestro estudio resulta también que el tratamiento con un compuesto inhibidor de Plk1 provoque un retraso en "antefase" similar al que nosotros hemos observado (comunicación personal del Dr. Mark Petronczki, "Clare Hall”, Londres). Sin embargo, en contra de la posibilidad de que hCdc14A pudiera desfosforilar e inactivar a Plk1 está el hecho de que no parece que Plk1 sea sustrato de CDK (Barr et al., 2004).

Por último, y siempre con el fin de determinar cual es el mecanismo por el que hCdc14A inhibe a hCdc25A, también nos gustaría analizar en un futuro inmediato el estado de fosforilación in vivo de la proteína hCdc25A en células con elevados niveles de hCdc14A. La identificación de los residuos fosforilados en estas circunstancias nos daría 
información clave para conocer el mecanismo de regulación de su actividad catalítica. También sería interesante identificar las proteínas con las que interacciona hCdc25A en estas circunstancias.

El retraso en G2/M inducido por la sobre-expresión de hCdc14A desde fase S no se debe a la activación de un checkpoint

Puesto que una posible causa de retraso en G2/M es la activación de un checkpoint, nos planteamos inicialmente si el retraso inducido por la sobre-expresión de hCdc14A correspondía a esta situación. Sin embargo, el hecho de que el silenciamiento de la expresión de la proteína endógena dé lugar al efecto opuesto sobre la transición G2/M, una entrada en mitosis más rápida y una mayor actividad de hCdc25A, nos permitió identificar una función desempeñada por hCdc14A en este punto del ciclo celular, que ocurre de forma independiente de la activación de un checkpoint. Esta función de hCdc14A en un ciclo celular normal, se ha visto apoyada además por nuestro análisis de la cinética de entrada en mitosis, el cual pone de manifiesto que elevados niveles de hCdc14A a partir de fase S no parecen inducir la activación de un checkpoint de daño al DNA o de "antefase", a juzgar por marcadores como los niveles proteicos de hCdc25C, p53 y p21, o la activación de p38 en estas células (mostrados en este trabajo).

Pese a esto, sí hemos comprobado que la sobre-expresión de forma prolongada de hCdc14A (durante más de un ciclo celular) da lugar a la activación de un checkpoint en el que parecen estar implicadas proteínas como, ATM y/o ATR, p38 y posiblemente p53, este último promoviendo la acumulación de p21 e inhibiendo la transcripción de hCdc25C. Esto nos llevó a considerar que quizás los efectos producidos por los elevados niveles de hCdc14A sobre el huso mitótico, la segregación cromosómica y/o la citoquinesis, así como otros efectos aún no descritos, podrían ser la causa de la activación de un checkpoint en estas condiciones.

\section{FUNCIÓN DESEMPEÑADA POR hCdc14A EN LA REGULACIÓN DE LA SALIDA DE MITOSIS}

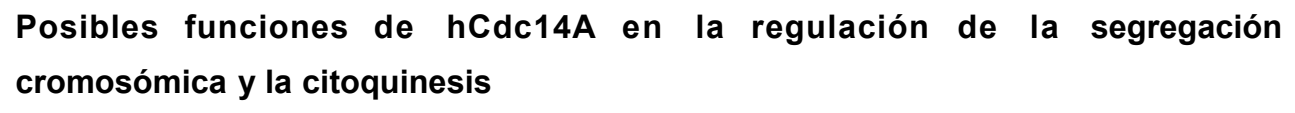

Como ya hemos mencionado, previamente se había descrito que la fosfatasa hCdc14A está implicada en la salida de mitosis a través de la regulación de la segregación cromosómica y la citoquinesis (Kaiser et al., 2002; Mailand et al., 2002a). Además, 
hCdc14A se localiza en la zona central del huso mitótico junto con proteínas como INCENP-Aurora B, Mklp2 y Plk1, estando relacionada dicha localización con el control de la coordinación entre la segregación cromosómica y la citoquinesis (Gruneberg et al., 2004). En este sentido, los mismos autores demostraron que hCdc14A puede desfosforilar a INCENP, hecho que podría inducir el cambio de localización del complejo INCENPAurora B desde centrómeros a la zona central del huso en la transición metafase/anafase, de forma similar a lo que se había indicado respecto a Cdc14 en S. cerevisiae (Pereira y Schiebel, 2003; Gruneberg et al., 2004).

La participación de hCdc14A en la regulación de la segregación cromosómica también fue sugerida inicialmente en nuestro estudio a raíz de los efectos de la sobre-expresión de hCdc14A en células de $S$. pombe, que da lugar a fenotipos de anafase propios de una segregación anómala de los cromosomas y de falta de coordinación de ésta con la septación.

Por otra parte, la sobre-expresión de hCdc14A en células humanas también induce problemas de coordinación entre la segregación cromosómica y la citoquinesis, promoviendo la aparición de fenotipos aberrantes, característicos de inestabilidad genómica. Además, en relación con la función de hCdc14A en este punto del ciclo, hemos observado que elevados niveles de esta proteína generan un cierto retraso en la transición metafase/anafase, descrito también por otros autores al sobre-expresar una versión mutante de esta proteína, considerada activa de forma constitutiva (Yuan et al., 2007). Sin embargo, no podemos descartar que este desajuste en la transición metafase/anafase sea consecuencia de efectos previos, relacionados con el propio retraso en la entrada en mitosis causado por la sobre-expresión de hCdc14A.

\section{Posibles funciones de hCdc14A en la regulación de la degradación de determinados sustratos de APC a la salida de mitosis}

Otros autores habían descrito previamente que hCdc14A es capaz de desfosforilar in vitro a Cdh1 dando lugar a la activación del complejo APC ${ }^{\text {Ch1 } 1}$ (Bembenek y Yu, 2001), de forma similar a lo que ocurre en el caso de Cdc14 en S.cerevisiae a la salida de mitosis (Jaspersen et al., 1999).

Para estudiar la posible implicación de hCdc14A en este proceso, en nuestro trabajo analizamos la cinética de salida de mitosis (a partir de su sincronización con nocodazol) de células que presentan elevados niveles de hCdc14A, observando que en estas condiciones se produce una inactivación más rápida de la actividad CDK mitótica, acompañada por una degradación acelerada de la Ciclina B1 y hCdc25A, que a su vez podría contribuir a la propia inactivación de los complejos. Esta cinética de salida de 
mitosis podría ser explicada en parte por la posible activación del complejo APC ${ }^{\text {dh } 1}$ por hCdc14A (Bembenek y Yu, 2001), que puede inducir la degradación acelerada de sustratos específicos de APC ${ }^{\text {chn1 }}$ en este punto del ciclo. Sin embargo, esto no explicaría la rápida desaparición de la Ciclina $\mathrm{B} 1$, por tratarse de un sustrato de $\mathrm{APC}^{\mathrm{Cdc20}}$, lo cual nos lleva a pensar que hCdc14A ejerce un efecto específico sobre determinadas proteínas implicadas en la regulación de mitosis, permitiendo así la correcta progresión por las últimas etapas de esta fase. Por otro lado, también detectamos con esta estrategia de sobre-expresión de hCdc14A, que la proteína hCdc25A parece ser desfosforilada de forma previa a su degradación, efecto ya observado por Mailand et al. (Mailand et al., 2002b), que indica que la desfosforilación de determinados residuos de esta proteína puede estar implicada en su degradación a la salida de mitosis, del mismo modo que ocurre en el caso de Cdc6, cuya fosforilación por CDK interfiere con su reconocimiento por parte de APC ${ }^{\text {Chn1 }}$ (Mailand y Diffley, 2005). Dado que hCdc14A es capaz de desfosforilar dos residuos de hCdc25A fosforilados por CDK promoviendo su degradación, nuestra propuesta es que posiblemente la desfosforilación de estos residuos sea necesaria para la degradación de esta proteína a la salida de mitosis (Modelo II). Experimentos de ubiquitinación in vitro de los correspondientes mutantes de hCdc25A, así como el análisis de la interacción de cada uno de ellos con Cdh1, o el estudio de su cinética de degradación en este punto del ciclo, darán más información acerca de esta posibilidad.

Otro sustrato in vitro de hCdc14A es hCdc25C (Fig. 9C de Resultados), que participa en la activación de los complejos CDK mitóticos. A su vez, hCdc25C es activado a la entrada de mitosis a través de su fosforilación, llevada a cabo por Cdk1 entre otras quinasas (Hoffmann et al., 1993; Roshak et al., 2000; Wang et al., 2007). Por el contrario, se ha propuesto que a la salida de mitosis hCdc25C se desfosforila, de forma paralela a la inactivación de los complejos CDK (D'Angiolella et al., 2007). Según datos recientes, la fosfatasa PP2A podría estar implicada en la inactivación de hCdc25C a la salida de mitosis (Forester et al., 2007), sin embargo, cabe la posibilidad de que hCdc14A pudiera tener también un papel directo en la inhibición de esta proteína en el citado punto del ciclo. Futuros experimentos enfocados a determinar el efecto de la desfosforilación llevada a cabo por hCdc14A sobre la actividad de hCdc25C son necesarios para apoyar esta hipótesis. 


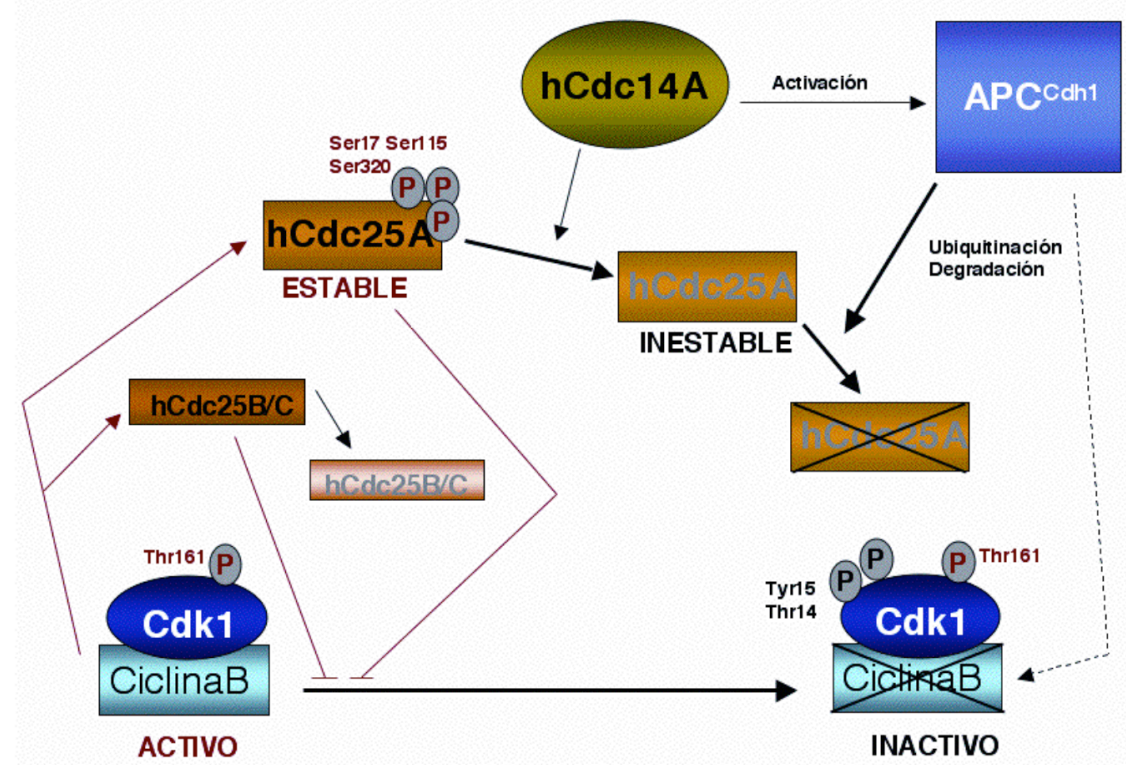

Modelo II. Función de hCdc14A en la regulación de la salida de mitosis. A la salida de mitosis ha de producirse la inactivación de los complejos CDK mitóticos, en cuya regulación puede participar la fosfatasa hCdc14A.. Esto podría ocurrir, en parte a través de la activación de APC ${ }^{\mathrm{cdh} 1}$, observada in vitro por otros autores (derecha del esquema), que a su vez promueve la degradación de proteínas activadoras, como hCdc25A. Además, en base a nuestros datos in vitro, hCdc14A también podría estar implicada en la regulación de la salida de mitosis, a través de la desfosforilación de residuos de hCdc25A fosforilados por CDK, promoviendo así su reconocimiento por APC y consiguiente degradación de una de las proteínas activadoras de los complejos Cdk1-Ciclina B1. En este esquema, las flechas y fosforilaciones señaladas en color negro indican procesos que conllevan la activación de los complejos, al contrario que las de color negro.

Por otra parte, también consideramos que el efecto que tiene hCdc14A sobre el estado de fosforilación y la estabilidad de Wee1, comprobado en la transición G2/M, podría afectar a esta proteína a la salida de mitosis, induciendo un aumento de la actividad asociada a Wee1, que a su vez contribuiría a la inactivación de los complejos CDK en este punto del ciclo.

En conclusión, nuestros resultados sugieren que hCdc14A podría participar en la inhibición de los complejos Cdk1-Ciclina B1 a la salida de mitosis, mediante diversos mecanismos, como son la desfosforilación de hCdc25A, hCdc25C y/o Wee1, con un posible efecto inhibidor sobre la estabilidad o actividad catalítica de dichas proteínas en este punto del ciclo, y la activación del complejo APC ${ }^{\mathrm{Cdh} 1}$, responsable de la degradación ordenada de diversos sustratos a la salida de mitosis. 


\section{POSIBLES FUNCIONES DE hCdc14B}

A raíz de nuestro trabajo realizado con hCdc14B en la levadura $S$. pombe, y pese a que no hemos podido deducir el mecanismo mediante el que complementa la falta de Flp1 en la levadura de fisión, sí comprobamos que su sobre-expresión en esta levadura daba lugar a cambios en la morfología nuclear e interfería con la formación del huso mitótico. En concreto, elevados niveles de hCdc14B inducen cambios importantes en la estructura nuclear, que conllevan la "atomización" del núcleo en pequeños fragmentos. Este efecto es indicativo de una posible función de hCdc14B en la regulación de la estructura nuclear, confirmada posteriormente en células humanas, en las que se ha descrito la asociación de esta fosfatasa a los filamentos intranucleares y su contribución al mantenimiento de la estructura del núcleo en colaboración con Plk1 (Nalepa y Harper, 2004). Por otra parte, la sobre-expresión de hCdc14B también impide la formación del huso mitótico en S. pombe, hecho claramente relacionado con la función desempeñada por hCdc14B, de forma independiente de su actividad catalítica, en la estabilización de los microtúbulos, la regulación de la dinámica de éstos y la formación del huso mitótico, que ha sido comprobada posteriormente en células humanas (Cho et al., 2005). En definitiva, estos datos prueban la importancia de nuestros hallazgos en el estudio de complementación de la falta de Flp1 en S. pombe por parte de las proteínas Cdc14 humanas.

En el transcurso de la escritura de esta Tesis, nuevas funciones han sido atribuidas a hCdc14B. Se ha descrito su participación en el control de la duración de G1, promoviendo la degradación de CKIs como p27 o p21, (Rodier et al., 2008) y su implicación en la regulación del ciclo de división del centrosoma (Wu et al., 2008), funciones relacionadas con un posible papel de hCdc14B como supresor tumoral (Rodier et al., 2008; Wu et al., 2008). Sin embargo, por otra parte se ha sugerido que hCdc14B no es esencial para la segregación cromosómica ni la citoquinesis, a raíz del análisis de células humanas KO hCdc14B ${ }^{-/}$(Berdougo et al., 2008). 

Conclusiones 

- La expresión de las fosfatasas humanas, hCdc14A o hCdc14B, complementa la falta de la proteína Flp1 en células $\Delta f l p 1$ de la levadura $S$. pombe. La proteína hCdc14A desfosforila in vitro e in vivo a la proteína Cdc25 de S. pombe.

- La fosfatasa hCdc14A desfosforila in vitro a hCdc25A (en $\operatorname{Ser}^{115}$ y $\operatorname{Ser}^{320}$ ) y a hCdc25C, en residuos no determinados experimentalmente. La desfosforilación de hCdc25A por hCdc14A en los dos residuos citados promueve su degradación.

- La proteína hCdc14A, de forma dependiente de su actividad fosfatasa, participa en la regulación de los complejos CDK mitóticos a la entrada en mitosis, a través de la inhibición de la actividad catalítica de hCdc25A.

- hCdc14A induce la inactivación de los complejos CDK mitóticos a la salida de mitosis en parte, posiblemente, a través de la desfosforilación y degradación de hCdc25A. 



\section{Materiales y Métodos}





\section{CULTIVO Y TRANSFORMACIÓN DE CÉLULAS DE S. pombe}

\section{Cepas de Schizosaccharomyces pombe empleadas}

Las cepas de S. pombe empleadas en este trabajo están detalladas en la Tabla M-I, en la que se indica su genotipo y su procedencia. La mayoría de las cepas de $S$. pombe utilizadas en este estudio fueron construidas en el laboratorio del Dr. Avelino Bueno, mediante métodos genéticos descritos anteriormente (Moreno et al., 1991; Norbury y Moreno, 1997). En concreto, las características de las cepas en las que se ha delecionado

\begin{tabular}{|c|c|c|}
\hline \multicolumn{3}{|l|}{ Cepas de S. pombe } \\
\hline Genotipo & Cepario & Procedencia \\
\hline$h^{\cdot}$ ade6-704 leu1-32 ura4-d18 & 15.58 & Dr. Avelino Bueno \\
\hline$h^{+}$flp1::KanMX6 ${ }^{+}$ade6-M210 leu1-32 ura4-d18 & 30.21 & Dr. Avelino Bueno \\
\hline$h^{+}$cdc25-22 ade6-M210 leu1-32 ura4-d18 & 35 & Dr. Paul Nurse \\
\hline$h^{+}$cdc25-22 flp1::KanMX6 ${ }^{+}$ade6-M210 leu1-32 ura4-d18 & 32.37 & Dr. Avelino Bueno \\
\hline$h^{+}$cdc25::ura4 ${ }^{+} c d c 2-3 w$ leu1-32 ura4-259 & 4.50 & Dr. Avelino Bueno \\
\hline$h^{+}$cdc25-12myc leu1-32 & 34.29 & Dr. Avelino Bueno \\
\hline$h \cdot$ ade6-704 leu1-32 ura4-d18 pREPKZ & MS-1.69 & Este trabajo \\
\hline$h \cdot$ ade6-704 leu1-32 ura4-d18 pREPKZ-hCDC14A & MS-1.71 & Este trabajo \\
\hline$h \cdot$ ade6-704 leu1-32 ura4-d18 pREPKZ-hCDC14AC/S & MS-1.75 & Este trabajo \\
\hline$h \cdot$ ade6-704 leu1-32 ura4-d18 pREPKZ-hCDC14B & MS-1.03 & Este trabajo \\
\hline$h \cdot$ ade6-704 leu1-32 ura4-d18 pREPKZ-hCDC14BC/S & MS-2.25 & Este trabajo \\
\hline$h^{+}$flp1::KanMX6 + ade6-M210 leu1-32 ura4-d18 pREPKZ & MS-1.10 & Este trabajo \\
\hline$h^{+}$flp1::KanMX6 ${ }^{+}$ade6-M210 leu1-32 ura4-d18 pREPKZ-hCDC14A & MS-1.61 & Este trabajo \\
\hline$h^{+}$flp1::KanMX6 ${ }^{+}$ade6-M210 leu1-32 ura4-d18 pREPKZ-hCDC14AC/S & MS-1.65 & Este trabajo \\
\hline$h^{+}$flp1::KanMX6 ${ }^{+}$ade6-M210 leu1-32 ura4-d18 pREPKZ-hCDC14B & MS-1.12 & Este trabajo \\
\hline$h^{+}$flp1::KanMX6 + ade6-M210 leu1-32 ura4-d18 pREPKZ-hCDC14BC/S & MS-2.28 & Este trabajo \\
\hline$h^{+}$cdc25-22 ade6-M210 leu1-32 ura4-d18 pREPKZ & MS-1.81 & Este trabajo \\
\hline$h^{+}$cdc25-22 flp1::KanMX6 + ade6-M210 leu1-32 ura4-d18 pREPKZ & MS-1.45 & Este trabajo \\
\hline$h^{+}$cdc25-22 flp1::KanMX6 + ade6-M210 leu1-32 ura4-d18 pREPKZ-flp1 + & MS-1.79 & Este trabajo \\
\hline$h^{+}$cdc25-22 flp1::KanMX6 + ade6-M210 leu1-32 ura4-d18 pREPKZ-hCDC14A & MS-1.47 & Este trabajo \\
\hline$h^{+}$cdc25-22 flp1::KanMX6 + ade6-M210 leu1-32 ura4-d18 pREPKZ-hCDC14AC/S & MS-1.51 & Este trabajo \\
\hline$h^{+}$cdc25-22 flp1::KanMX6 + ade6-M210 leu1-32 ura4-d18 pREPKZ-hCDC14B & MS-1.55 & Este trabajo \\
\hline$h^{+}$cdc25-22 flp1::KanMX6 + ade6-M210 leu1-32 ura4-d18 pREPKZ-hCDC14BC/S & MS-2.40 & Este trabajo \\
\hline$h^{+}$cdc25::ura4 +cdc2-3w leu1-32 ura4-259 pREPKZ & MS-1.36 & Este trabajo \\
\hline$h^{+}$cdc25::ura4 ${ }^{+}$cdc2-3w leu1-32 ura4-259 pREPKZ-hCDC14A & MS-1.37 & Este trabajo \\
\hline$h^{+}$cdc25::ura4 ${ }^{+}$cdc2-3w leu1-32 ura4-259 pREPKZ-hCDC14AC/S & MS-1.41 & Este trabajo \\
\hline$h^{+}$cdc25::ura4 ${ }^{+}$cdc2-3w leu1-32 ura4-259 pREPKZ-hCDC14B & MS-2.37 & Este trabajo \\
\hline$h^{+} c d c 25:: u r a 4{ }^{+} c d c 2-3 w$ leu1-32 ura4-259 pREPKZ-hCDC14BC/S & MS-2.31 & Este trabajo \\
\hline$h^{+}$cdc25-12myc leu1-32 pREPKZ & MS-2.05 & Este trabajo \\
\hline$h^{+}$cdc25-12myc leu1-32 pREPKZ-hCDC14A & MS-2.07 & Este trabajo \\
\hline$h+c d c 25-12 m y c$ leu1-32 pREPKZ-hCDC14AC/S & MS-2.09 & Este trabajo \\
\hline$h^{+}$cdc25-12myc leu1-32 pREPKZ-hCDC14B & MS-2.11 & Este trabajo \\
\hline$h{ }^{+}$cdc25-12myc leu1-32 pREPKZ-hCDC14BC/S & MS-2.34 & Este trabajo \\
\hline
\end{tabular}

Tabla M-I. Cepas de S. pombe empleadas en este trabajo 
el gen flp $1^{+}$fueron detalladas previamente (Cueille et al., 2001). En la Tabla M-I también hemos incluido las cepas transformadas con plásmidos no integrados en el genoma, que fueron empleadas en este trabajo.

\section{Medios y condiciones de cultivo}

La composición de los medios de cultivo empleados ha sido descrita previamente (Moreno et al., 1991).

Las células de $S$. pombe se incubaron en medio rico con extracto de levadura, YES (del inglés Y Yeast Exxtract with Supplement), o en medio mínimo (MM), a $32^{\circ} \mathrm{C}$ (salvo que se indique lo contrario en el experimento). El medio mínimo fue suplementado con aminoácidos (Leucina, Leu) y/o bases nitrogenadas (adenina y/o uracilo) a una concentración final de $225 \mu \mathrm{g} / \mathrm{ml}$, según las auxotrofías de cada cepa. El cultivo de las células en medio líquido se inició con una densidad óptica, medida a $\lambda=595 \mathrm{~nm}$, de 0,2-0,4 (aproximadamente $2-4 \times 10^{6}$ células $/ \mathrm{ml}$ ), que corresponde a cultivos creciendo en fase exponencial.

El cultivo de células que contienen el plásmido pREPKZ, en el que la expresión de genes se encuentra bajo el control del promotor $n m t 1$, se realizó en medio mínimo sin Leucina (para seleccionar células que contienen el plásmido pREPKZ, cuyo marcador es LEU2), y en presencia de una concentración $10 \mu \mathrm{M}$ de tiamina, para reprimir la expresión controlada por el promotor $n m t 1$. Para inducir la expresión de los DNAs clonados en este vector, se elimina la tiamina mediante tres lavados con agua miliQ estéril, y finalmente se añade medio sin tiamina o con menores concentraciones de ésta $(0,2 \mu \mathrm{M}$ ó $2 \mu \mathrm{M})$, en función del grado de expresión que pretendamos obtener.

\section{Ensayo de viabilidad}

Para comprobar la complementación de la falta del gen $f l p 1^{+}$en el doble mutante termosensible $\Delta$ flp1 cdc25-22 llevada a cabo por la expresión de las proteínas Cdc14 humanas se realizó un ensayo de viabilidad. Las cepas transformadas con el plásmido pREPKZ se incubaron en medio mínimo líquido sin Leucina (MM-Leu) a $25^{\circ} \mathrm{C}$, hasta alcanzar una densidad poblacional de $10^{7}$ células $/ \mathrm{ml}$. Posteriormente, contamos el número de células de cada uno de los cultivos y se realizaron diluciones seriadas de éstos. Así, se inocularon gotas de $5 \mu \mathrm{l}$ de cada una de estas diluciones seriadas, que contenían $10^{6}, 10^{5}$, $10^{4}, 10^{3}$ y $10^{2}$ células, en varias placas de MM-Leu sólido (con agar) a diversas temperaturas (desde $25^{\circ} \mathrm{C}$ hasta $36^{\circ} \mathrm{C}$ ) y en una placa con medio YES sólido a $25^{\circ} \mathrm{C}$, empleada como control. 


\section{Transformación de células de S. pombe}

La transformación de S. pombe con las distintas construcciones de DNA plasmídico se realizó utilizando células competentes preparadas con acetato de litio (Norbury y Moreno, 1997).

\section{CULTIVO Y TRANSFECCIÓN DE LÍNEAS CELULARES HUMANAS}

\section{Líneas celulares humanas empleadas}

Las líneas celulares adherentes humanas que fueron utilizadas en este trabajo se muestran en la Tabla M-II, en la que se detalla el nombre, procedencia, características y medio empleado para el cultivo de cada una de ellas.

\section{Medios y condiciones de cultivo}

Las líneas celulares adherentes empleadas en este estudio (Tabla M-II) se incubaron en placas para cultivo celular, creciendo en monocapa a $37^{\circ} \mathrm{C}$ y en una atmósfera de $5 \%$ de $\mathrm{CO}_{2}$ y $98 \%$ de humedad relativa. Los medios de cultivo empleados, DMEM (del inglés

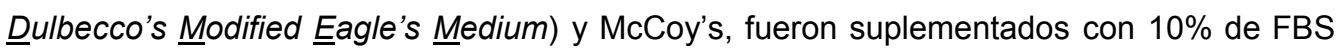

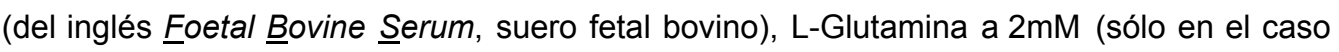
del DMEM) y los antibióticos, penicilina (100 unidades $/ \mathrm{ml})$ y estreptomicina $(100 \mu \mathrm{g} / \mathrm{ml})$, para evitar la contaminación del cultivo con microorganismos.

Con el fin de evitar el sobre-crecimiento de las células, antes de que éstas alcanzasen

\begin{tabular}{|cccc|}
\hline & \multicolumn{4}{c|}{ Líneas celulares humanas } & Características & Medio de cultivo* \\
\hline \hline Línea & Procedencia & $\begin{array}{c}\text { p53 wt } \\
\text { Carencia de p16 }\end{array}$ & $\begin{array}{c}\text { DMEM + } \\
10 \% \text { FBS }\end{array}$ \\
\hline U2OS & Osteosarcoma & $\begin{array}{c}\text { Expresión inducible de } \\
\text { Myc-hCdc14A (Tet-off) }\end{array}$ & $\begin{array}{c}\text { DMEM + 10\%FBS+ } \\
\text { Tetraciclina }\end{array}$ \\
\hline U2OS-Myc-hCdc14A(PD) & Osteosarcoma & $\begin{array}{c}\text { Expresión inducible de } \\
\text { Myc-hCdc14A(PD) (Tet-off) }\end{array}$ & $\begin{array}{c}\text { DMEM + 10\%FBS+ } \\
\text { Tetraciclina }\end{array}$ \\
\hline HCT116 & Carcinoma colorrectal & $\begin{array}{c}\text { Mutación en el codón } \\
\text { 13 de Ras }\end{array}$ & $\begin{array}{c}\text { McCoy's + } \\
10 \% \text { FBS }\end{array}$ \\
\hline HEK293T & $\begin{array}{c}\text { Células de riñón } \\
\text { embrionarias }\end{array}$ & $\begin{array}{c}\text { Alta transfectabilidad } \\
\text { 293 con SV40-T insertado }\end{array}$ & $\begin{array}{c}\text { DMEM + } \\
10 \% \text { FBS }\end{array}$ \\
\hline
\end{tabular}

*para más detalle consultar texto

Tabla M-Il. Líneas celulares empleadas 
un $100 \%$ de confluencia en la placa se realizaron pases cada 3 ó 4 días, empleando Tripsina-EDTA (GIBCO Invitrogen), lo que comúnmente se denomina "tripsinización", para eliminar la adhesión de las células y así poder sembrar éstas a una menor confluencia en nuevas placas. Todos los medios y suplementos utilizados fueron de GIBCO Invitrogen.

La manipulación de estas células se realizó en condiciones de esterilidad, en campanas de flujo laminar y empleando materiales estériles para el contacto directo con el cultivo celular.

La observación de las células en cultivo se llevó a cabo por medio de un microscopio óptico invertido "Zeiss Axiovert 135" con una camara digital (Hamamatsu) asociada al mismo.

\section{Condiciones de cultivo e inducción de los clones estables U2OS-Myc-hCdc14A y U2OS-Myc-hCdc14A(PD)}

Estos clones estables de U2OS se mantuvieron del mismo modo que las otras líneas celulares, pero en este caso al medio de cultivo, DMEM ya complementado con FBS y con los antibióticos estreptomicina y penicilina, también se le añadieron geneticina a $400 \mu \mathrm{g} / \mathrm{ml}$ (G418, GIBCO Invitrogen), puromicina a $1 \mu \mathrm{g} / \mathrm{ml}$ (Sigma) y tetraciclina a $2 \mu \mathrm{g} / \mathrm{ml}$ (Sigma) (Lukas et al, 1999b; Mailand et al, 2002a). Para inducir la sobre-expresión de las proteínas $\mathrm{hCdc} 14 \mathrm{~A}$ o $\mathrm{hCdc} 14 \mathrm{~A}(\mathrm{PD})$, estas células se incubaron en medio sin tetraciclina, tras haberlas lavado dos veces con el mismo medio (para eliminar completamente la tetraciclina presente).

\section{Congelación y descongelación de las células}

Las células se conservan a largo plazo en nitrógeno líquido $\left(-195^{\circ} \mathrm{C}\right)$, para lo que han de congelarse siguiendo un protocolo específico en el que se emplea DMSO (Dimetilsulfóxido) con el fin de evitar que las células se dañen por la formación de cristales intracelulares durante el proceso de congelación. Las células deben ser descongeladas para su utilización, también siguiendo un protocolo que evite al máximo la muerte celular.

De este modo, para llevar a cabo la congelación de las células, éstas fueron "tripsinizadas" con Tripsina-EDTA (GIBCO Invitrogen) y centrifugadas (1200 rpm 5 min a temperatura ambiente), tras lo que se resuspendieron en medio de cultivo con $20 \%$ de FBS, al que se le añadió DMSO (Sigma) a una concentración final del 10\%. Las células fueron congeladas a $-70^{\circ} \mathrm{C}$ en contenedores con isopropanol durante una semana y a continuación fueron introducidas en el tanque de nitrógeno líquido. 
En el momento de su utilización, las células congeladas en $\mathrm{N}_{2}$ líquido se mantuvieron en hielo seco hasta su descongelación en un baño a $37^{\circ} \mathrm{C}$, tras lo que se realizó un lavado con medio con $10 \%$ FBS y posteriormente, las células se plaquearon en el mismo medio fresco (para eliminar todo el DMSO presente).

\section{Sincronización de las células}

\subsection{Sincronización de las células en G1/S por doble tratamiento con timidina}

La timidina es un nucleósido que en exceso inhibe la replicación del DNA, lo que permite sincronizar las células en G1/S.

Las células se sembraron en placas p100 (100 mm de diámetro) y una vez adheridas se les añadió medio de cultivo con timidina (Sigma) a una concentración de 2,5 mM. Durante el primer tratamiento o "bloqueo", las células se mantuvieron en presencia de esa concentración de timidina durante 24 horas. Tras este tiempo, la timidina fue eliminada, por medio de dos lavados con PBS o medio de cultivo, y se añadió medio fresco sin timidina durante 12 horas, tiempo que denominamos de "liberación", en el que las células progresan a lo largo del ciclo. A continuación, los cultivos celulares se volvieron a incubar en medio con timidina 2,5 mM durante otras 24 horas, lo que constituyó el segundo tratamiento. Una vez concluido este tratamiento, se tomaron muestras de células paradas en la transición G1/S (tiempo de 0 horas), y se llevó a cabo la "liberación" del resto de las células, eliminando la timidina del medio como se ha descrito (por medio de dos lavados), lo que permitió la posterior recogida de muestras a los distintos tiempos deseados a lo largo del ciclo celular.

\subsection{Sincronización de las células en mitosis por tratamiento con nocodazol}

El nocodazol es un agente químico que se une a la $\beta$-Tubulina e inhibe la polimerización y dinámica de los microtúbulos, impidiendo la correcta formación del huso mitótico, lo que en definitiva induce una parada de las células previa a metafase.

Las células se sembraron en placas p100 y una vez adheridas se les añadió medio de cultivo con nocodazol (Sigma) a una concentración final de $100 \mathrm{ng} / \mathrm{ml}$, durante 16 horas (19 horas en el caso de inducción de las células U2OS-Myc-hCdc14A). Tras el tratamiento con nocodazol, seleccionamos las células mitóticas (redondeadas, no adheridas), sacudiendo las placas (Shake off) y recogiendo el medio con las células no adheridas. Estas células mitóticas podían ser recogidas para su procesamiento (muestra 
correspondiente a 0 horas) o incubadas en medio sin nocodazol ("liberación") y recogidas a distintos tiempos para el estudio de la salida de mitosis.

\section{Tratamiento de células con determinados reactivos}

\section{Tratamiento con MG132}

Los cultivos celulares en ocasiones fueron sometidos a un tratamiento con el compuesto MG132, inhibidor del proteasoma. Este tratamiento permite comprobar si la reducción de los niveles de una determinada proteína se produce a consecuencia de su degradación por parte del proteasoma, en función de si dicha reducción se ve compensada al tratar las células con MG132 o no. El compuesto MG132 (Calbiochem) se añadió al medio de cultivo a una concentración final de $10 \mu \mathrm{M}$ y las células se incubaron en su presencia durante 8 horas.

\section{Tratamiento con cafeína}

Para comprobar si en las células U2OS-Myc-hCdc14A se encuentran activas las quinasas de tipo sensor de checkpoint, ATM y ATR, se empleó la cafeína (Sigma), sustancia inhibidora de ambas quinasas. En este tratamiento se añadió la cafeína (a una concentración $3 \mathrm{mM}$ ) al medio de cultivo y las células fueron incubadas en presencia de ésta desde el momento de su inducción hasta su recogida.

\section{Tratamiento con SB203580}

Con el fin de analizar si en las células U2OS-Myc-hCdc14A se encuentra activo p38 (proteína MAPK implicada en el checkpoint de "antefase"), se empleó el producto SB203580, inhibidor de p38. En este tratamiento se añadió SB203580 (Sigma) al medio de cultivo a una concentración final de $10 \mu \mathrm{M}$, y las células fueron incubadas en su presencia desde el momento de su inducción hasta su recogida.

\section{Transfecciones transitorias con DNA o RNA}

Puesto que la membrana plasmática de las células humanas constituye una barrera frente a la entrada de elementos, para que las células incorporen un DNA o RNA exógeno es necesario un vehículo que atraviese dicha membrana.

De entre las distintas estrategias existentes, en nuestro estudio empleamos la transfección por medio de lipofección, que permite la formación de pequeños liposomas que contienen el DNA o RNA que queremos introducir en la célula. 
Las células se sembraron 24 horas antes de la transfección, de forma que estuviesen a un $50 \%$ ó $60 \%$ de confluencia en el momento de ésta. La transfección se llevó a cabo empleando el reactivo comercial Lipofectamine 2000 (GIBCO Invitrogen) según las instrucciones del fabricante.

\subsection{Transfección con DNA}

Estas transfecciones se llevaron a cabo manteniendo una relación $\mu \mathrm{g}$ de DNA / $\mu \mathrm{l}$ de Lipofectamina de 1/2. Estas transfecciones nos permitieron introducir en las células construcciones generadas en los plásmidos tipo pcDNA3, pCEFL-HA o pCMV, para la expresión de diversas proteínas.

La cantidad total de DNA transfectado fue $8 \mu \mathrm{g}$ en el caso de cultivos sembrados en placas p60 (60 mm de diámetro), y la cantidad proporcional en placas de otros tamaños.

Como control de la eficiencia de transfección, se empleó un vector para la expresión en células humanas de la proteína fluorescente verde GFP en proporción 1/10 respecto al total de DNA transfectado $(0,8 \mu \mathrm{g}$ en la placa $\mathrm{p} 60)$.

\subsection{Transfección con siRNAs}

Con el fin de reducir los niveles de expresión de la proteína hCdc14A, empleamos RNAs de interferencia (RNAi). Esta tecnología se utiliza con frecuencia con fines científicos o terapéuticos, y permite el silenciamiento de genes de manera específica a nivel post-transcripcional, mediante pequeñas moleculas de RNA de doble cadena que se unen a la secuencia específica diana del RNA mensajero (mRNA) promoviendo su degradación.

En concreto, en nuestro estudio empleamos siRNA (del inglés short interfering $\underline{R N A}$ ), suministrados por Dharmacon RNA technologies, frente a la proteína hCdc14A, (secuencia diana: NNGCACAGUAAAUACCCACUAUU). Utilizamos un siRNA diseñado frente a Luciferasa como control negativo (secuencia diana: NNACGUACGCGGAAUACUUCGAA).

La cantidad de RNA transfectado fue 120 pmoles en cultivos sembrados en placas p60 y la cantidad proporcional en placas de otros tamaños.

Como control de la eficiencia de transfección, se empleó de nuevo el plásmido pCMVGFP en idénticas cantidades a las empleadas en el caso de la transfección con DNA $(0,8$ $\mu \mathrm{g}$ en placa p60 y cantidades proporcionales en otras placas). 


\section{TÉCNICAS DE MANIPULACIÓN DE ÁCIDOS NUCLEICOS}

\section{Construcción de plásmidos de DNA recombinante}

Los plásmidos y construcciones utilizados en este trabajo se detallan en la Tabla M-III. Con estas construcciones se amplificaron por transformación de células competentes de E. coli $(\mathrm{DH} 5 \alpha)$, seleccionando las colonias transformantes con la resistencia asociada a cada vector (generalmente a ampicilina). La confirmación de que las colonias contenían el plásmido deseado se realizó mediante el aislamiento del DNA plasmídico a partir de esas células y su análisis con enzimas de restricción y electroforesis de los fragmentos de DNA obtenidos, y posteriormente, mediante la secuenciación de dicho DNA.

\begin{tabular}{|c|c|c|c|}
\hline \multicolumn{4}{|c|}{ Construcciones de DNA recombinante } \\
\hline Construcción o plásmido & Vector (características) & Inserto & Procedencia \\
\hline pREPKZ (GST) & Expresión en S. pombe & & Dr. Avelino Bueno \\
\hline pREPKZ-flp1 ${ }^{+}$ & pREPKZ & flp1 + (Ndel/Notl) & Dr. Avelino Bueno \\
\hline pREPKZ-hCdc14A & pREPKZ & hCdc14A (Ndel/Notl) & Este trabajo \\
\hline pREPKZ-hCdc14B & pREPKZ & hCdc14B (Ndel/Notl) & Este trabajo \\
\hline pREPKZ-hCdc14A(PD) & pREPKZ & hCdc14AC/S (Ndel/Notl) & Este trabajo \\
\hline pREPKZ-hCdc14B(PD) & pREPKZ & hCdc14BC/S (Ndel/Notl) & Este trabajo \\
\hline pDNA3 (His6Myc) & Expresión en células humanas & & Dr. Jiri Lukas \\
\hline pcDNA3-hCdc14A & pcDNA3 & hCdc14A (Ndel/Notl) & Este trabajo \\
\hline pcDNA3-hCdc14A(PD) & pcDNA3 & hCdc14AC/S (Ndel/Notl) & Dr. Jiri Lukas \\
\hline PCEFL-HA & Expresión en células humanas & & Dr. Pedro Lazo \\
\hline pCEFL-hCdc25A wt & pCEFL $(\sin \mathrm{HA})$ & hCdc25A (wt) (BamHI/EcoRI) & Este trabajo (Dra. Esteban) \\
\hline pCEFL-hCdc25A (S115E) & PCEFL ( $\sin \mathrm{HA})$ & hCdc25A (S115E) (BamHI/EcoRI) & Este trabajo (Dra. Esteban) \\
\hline pCEF-hCdc25A (S320E) & PCEFL $(\sin H A)$ & hCdc25A (S320E) (BamHI/EcoRI) & Este trabajo (Dra. Esteban) \\
\hline pCEFL-hCdc25A (S115-320E) & PCEFL ( $\sin \mathrm{HA})$ & hCdc25A (S115-320E)(BamHl/EcoRI) & Este trabajo (Dra. Esteban) \\
\hline pCEFL-hCdc25A (S17-115E) & PCEFL ( $\sin \mathrm{HA})$ & hCdc25A (S17-115E)(BamHI/EcoRI) & Este trabajo (Dra. Esteban) \\
\hline pCEFL-hCdc25A (S17-115-320E) & PCEFL $(\sin H A)$ & hCdc25A (3E)(BamHI/EcoRI) & Este trabajo (Dra. Esteban) \\
\hline pCMV & Expresión en células humanas & & Dr. Felipe Pimentel \\
\hline PCMV-GFP & pCMV & GFP & Dr. Felipe Pimentel \\
\hline pGEX-3T (GST) & Expresión en E.coli & & Dr. Pedro Lazo \\
\hline pGEX3T-hCdc25A & pGEX3T & hCdc25A & Dr. Pedro Lazo \\
\hline pGEX3T-hCdc25C & PGEX3T & hCdc25C & Dr. Pedro Lazo \\
\hline
\end{tabular}

Tabla M-III. Construcciones y plásmidos empleados en este trabajo.

\subsection{Aislamiento de DNA plasmídico a partir de células de $E$. coli}

La obtención de DNA plasmídico a partir de E. coli a pequeña escala se llevó a cabo mediante el método de la lisis alcalina (Birnboim y Doly, 1979), conocido comúnmente como "Miniprep". Para obtener una preparación de DNA de más calidad, por ejemplo para su secuenciación, este DNA se trató con el sistema Miniprep Express (Bio 101). Para la obtención de DNA de calidad a gran escala (Maxiprep) se emplearon sistemas 
comerciales como JetStar Maxi (Genomed) y Pure Yield MaxiPrep System (Promega). En todos los casos se siguieron las especificaciones del fabricante.

\subsection{Determinación de la concentración de ácidos nucleicos}

La concentración de DNA se determinó midiendo la absorbancia a $\lambda=260 \mathrm{~nm}$ (en cubeta de cuarzo) en un espectrofotómetro U-2001 (Hitachi), y considerando la relación de absorbancia a $\lambda=260 / 280 \mathrm{~nm}$ para estimar el grado de pureza de la preparación. Posteriormente, se corroboró la concentración de DNA por medio del análisis de la fluorescencia emitida por la muestra tras la electroforesis en un gel de agarosa (con bromuro de etidio).

\subsection{Digestión de DNA con endonucleasas de restricción}

La digestión con enzimas de restricción permite la caracterización física de fragmentos de DNA y, por tanto, la comprobación de construcciones plasmídicas de DNA recombinante. Las enzimas de restricción y el DNA se incubaron a $37^{\circ} \mathrm{C}$ en el tampón adecuado, suministrado por el fabricante junto con las enzimas. Roche Diagnostics, Fermentas y New England Biolabs fueron las casas comerciales que suministraron las enzimas de restricción empleadas en este trabajo.

En algunos casos, el vector vacío lineal, obtenido por digestión, fue tratado con fosfatasa alcalina (calf intestine alkaline phosphatase, Roche Diagnostics) para eliminar los grupos fosfato de los extremos 5', y así evitar la religación de los extremos del plásmido lineal y favorecer el proceso de clonaje.

\subsection{Electroforesis de fragmentos de DNA}

Los fragmentos de DNA se separaron en función de su tamaño mediante electroforesis en geles de agarosa, preparados a la concentración adecuada (entre el $0,7 \%$ y el $1,5 \%$, según el tamaño de los fragmentos a separar). A las muestras de DNA se les añadió tampón de carga $6 x$ (glicerol al $30 \%$ y el colorante azul de bromofenol al $0,25 \%$ ) que permite seguir la migración del DNA en los geles. La electroforesis se llevó a cabo a voltaje constante $(60-100 \mathrm{~V})$ y se empleó como tampón de carrera TAE (Trisacetato $40 \mathrm{mM}$, EDTA $1 \mathrm{mM}$ ). Para la visualización del DNA, a los geles se les añadió bromuro de etidio $(0,3 \mu \mathrm{g} / \mathrm{ml})$ (Sigma), que se intercala entre las bases nitrogenadas del DNA y emite fluorescencia al exponerse a luz ultravioleta. Como marcador de tamaño se usó DNA $1 \mathrm{~Kb}$ DNA Ladder (Invitrogen) y las imágenes se captaron con una cámara digital acoplada al analizador de imagen Gel Doc 2000 de Bio Rad. 


\subsection{Purificación y ligación de fragmentos de DNA}

La purificación de fragmentos de DNA a partir de geles de agarosa se llevó a cabo cortando la banda en cuestión y procesándola con el sistema Jet Quick Gel Extraction Spin kit de Genomed según las instrucciones del fabricante.

Las construcciones de DNA recombinante se obtuvieron mediante ligación de los fragmentos purificados (el inserto y el vector plasmídico). En la reacción de ligación se utilizó la ligasa de DNA del fago T4 siguiendo las especificaciones del fabricante (Fermentas). La mezcla de la ligación se utilizó para transformar directamente E. coli.

\subsection{Transformación de E. coli}

El método empleado para la transformación de E. coli $(\mathrm{DH} 5 \alpha)$ competentes fue el descrito por Kushner en 1978. La transformación de las células competentes con plásmidos ya purificados se llevó a cabo siguiendo el protocolo de "transformación de un minuto" (Golub, 1988). Las células transformadas se sembraron en una placa Petri con LB-agar que contenía el antibiótico de selección correspondiente (en nuestro caso ampicilina $100 \mu \mathrm{g} / \mathrm{ml}$ ) y se incubaron toda la noche a $37^{\circ} \mathrm{C}$. Una vez transformadas estas células, a partir de ellas se amplificaron nuestras construcciones de DNA recombinante, que fueron comprobadas mediante digestión y secuenciación.

\subsection{Reacciones de amplificación de DNA (PCR)}

Las reacciones de amplificación de DNA o PCR (del inglés Polymerase $\underline{\text { Chain }}$ $\underline{R}$ eaction, reacción en cadena de la polimerasa) se realizaron en un termociclador Minicycler de Eppendorf. Las condiciones programadas fueron diferentes en función del tamaño de la secuencia a amplificar y de los oligonucleótidos utilizados. La PCR se llevó a cabo en presencia de los oligonucleótidos diseñados en cada caso, el DNA molde, los dNTPs (desoxinucleósido trifosfato) y la Taq polimerasa (una polimerasa termorresistente). Dependiendo de la finalidad del producto de PCR se utilizó la polimerasa High Fidelity de Roche Diagnostics, la Pfu de Stratagene o la polimerasa de Biotools. El resultado de la PCR se analizó mediante electroforesis en un gel de agarosa, y los productos obtenidos se purificaron usando el sistema Jet Quick PCR Product Purification Spin Kit de Genomed.

A continuación se detalla la secuencia de los oligonucleótidos utilizados para la obtención de construcciones de DNA recombinante, su nombre y las aplicaciones para las que fueron diseñados. 
- Oligonucleótidos empleados para la mutagénesis de las ORFs (del inglés Open Reading Frame, marco de lectura abierta) de hCdc14A(PD) y hCdc14B (construcciones cedidas por el Dr. Jiri Lukas). Proceso que permite la obtención de hCdc14A y hCdc14B(PD), respectivamente:

\section{Cdc14A wt}

5'-GCCATCGCCGTTCACTGCAAAGCTGGTC-3'

Cdc14A wt compl

5'-GACCAGCTTTGCAGTGAACGGCGATGGC-3'

5'hCdc14B mut

5'-CATTGCAGTACATAGCAAAGCTGGCCTTG-3'

\section{3'hCdc14B mut com}

5'-CAAGGCCAGCTTTGCTATGTACTGCAATG-3'

- Oligonucleótidos empleados para obtener construcciones en pREPKZ (expresión en $S$. pombe) y pGEX-KG (expresión en E. coli), introduciendo secuencias reconocidas por las enzimas Ndel y Notl:

5'Cdc14A-Ndel

5'-GGAATTCCATATGGCAGCGGAGTCAGGGGAAC-3'

3'Cdc14A-Notl

5'-AATATCAAATGCGGCCGCCTAGGGAAAACTTACCTCTC-3'

3'Cdc14B-Ndel

5'-GGAATTCCATATGAAGCGGAAAAGCGAGCG-3'

\section{3'Cdc14B-Notl}

5'-AATATCAAATGCGGCCGCTTAACGCAAGACTGTTTTAG-3'

- Las construcciones en el plásmido pCEFL-HA (de expresión en células humanas) que contienen las ORFs de hCdc25A-wt y las distintas formas mutantes de esta proteína utilizadas, fueron generadas por la Dra. Verónica Esteban en nuestro laboratorio.

- Varios oligonucleótidos fueron empleados para la comprobación por secuenciación de las construcciones obtenidas mediante secuenciación.

\subsection{Secuenciación de DNA}

Las construcciones de DNA recombinante obtenidas, en las que el inserto fue sometido a amplificación por la técnica de PCR, fueron comprobadas mediante 
secuenciación. La secuenciación de DNA se realizó de forma automática utilizando un secuenciador ABI Prism 377 de Perkin-Elmer en el Servicio de Análisis Genómico del Centro de Investigación del Cáncer.

\section{Análisis de mRNA}

\subsection{Extracción de RNA total}

La obtención del RNA total se realizó empleando el sistema RNAspin Mini (Amersham) y siguiendo las recomendaciones del fabricante.

\subsection{Análisis tipo "Northern" (Northern blot)}

$12 \mu \mathrm{g}$ de RNA total de cada muestra se desnaturalizaron en tampón de RNA (formamida desionizada al 50\%,6,4\% de formaldehído 37\%, 1xMOPS) y se cargaron en un gel de agarosa al $1 \%$ (1xMOPS, formaldehído al 1,1\%) para su separación. El RNA contenido en el gel se transfirió a membranas de nylon GeneScreen Plus (NEF1017) utilizando el sistema de vacío Vacugene pump de Amersham. El RNA fue fijado a la membrana mediante radiación ultravioleta en un UV Stratalinker (Stratagene). Las membranas se hibridaron con la sonda marcada radiactivamente a $65^{\circ} \mathrm{C}$ durante 2,5 horas en la solución Rapid-hyb de Amersham, y fueron lavadas siguiendo las instrucciones del fabricante. EI RNA se detectó mediante auto-radiografía en películas (BioMax MR film de Kodak) o en pantallas de revelado de Phosphor-Imager de Fuji utilizando el aparato Molecular Imager FX de Bio Rad.

Las sondas de DNA fueron marcadas radiactivamente y purificadas utilizando columnas ProbeQuant G-50 de Amersham, según las instrucciones del fabricante. Para detectar el mRNA de hCdc25A y hCdc25C se emplearon como sondas, el fragmento de $700 \mathrm{pb}$. Bgl-II/Ndel de hCdc25A, y el cDNA correspondiente a toda la ORF (full length) en el caso de hCdc25C. La sonda utilizada para detectar el mRNA de Actina, como control de carga, es comercial (S0130 de Beckton-Dickinson).

\section{CITOMETRÍA DE FLUJO (FACS)}

La citometría de flujo o FACS (del inglés Fluorescence $\underline{\text { Activated }}$ Cell $\underline{\text { Sorter) permite }}$ determinar el contenido de DNA de las células, lo que nos informa acerca de la fase del ciclo celular en que se encuentran. 
Este análisis nos permitió diferenciar distintas poblaciones dentro de las partículas analizadas, en nuestro caso células humanas o de $S$. pombe, en función de su tamaño y de su contenido en DNA. Para determinar el contenido en DNA de las células se empleó como fluorocromo el yoduro de propidio (Sigma), que se une a la doble cadena de DNA. Este análisis por FACS se realizó en un equipo FACScalibur (Becton-Dickinson).

\section{Análisis mediante FACS de muestras de la levadura $S$. pombe}

En el perfil de FACS típico de células de S. pombe creciendo asincrónicamente sólo se aprecia claramente un pico de contenido $2 \mathrm{C}$ de DNA a consecuencia de la corta duración de las fases $\mathrm{G} 1$ y $\mathrm{S}$ en el ciclo celular de esta levadura.

La preparación de las muestras para su análisis por FACS se llevó a cabo del siguiente modo: se recogieron muestras de $10^{7}$ células por centrifugación, que se lavaron con $1 \mathrm{ml}$ de agua miliQ estéril, y fueron resuspendidas en $1 \mathrm{ml}$ de etanol al $70 \%$ para su fijación y guardadas a $4^{\circ} \mathrm{C}$. La mitad de estas células, una vez fijadas, fueron lavadas con $1 \mathrm{ml}$ de citrato sódico $50 \mathrm{mM}$, y se resuspendieron e incubaron en $0,5 \mathrm{ml}$ de citrato sódico $50 \mathrm{mM}$ con $50 \mu \mathrm{g}$ de RNAsa (Roche) durante 2 horas a $37^{\circ} \mathrm{C}$. Finalmente, añadimos 0,5 $\mathrm{ml}$ de citrato sódico $50 \mathrm{mM}$ y $2 \mu \mathrm{g}$ de yoduro de propidio y analizamos las muestras.

\section{Análisis mediante FACS de muestras de cultivos de líneas celulares humanas}

En el perfil de FACS típico de células humanas creciendo de forma asíncrona, se aprecia un pico mayoritario con un contenido de DNA 2n (correspondiente a células en G1), y un pico menor correspondiente a células en G2/M, con doble contenido de DNA $(4 n)$; entre ambos picos se distingue una meseta que corresponde a células con un contenido intermedio de DNA (entre $2 n$ y $4 n$ ), células en fase $S$. El pico denominado pre$\mathrm{G} 1$, de células con un contenido en DNA inferior a $2 \mathrm{n}$, corresponde principalmente a células apoptóticas.

Las muestras para análisis citométrico fueron recogidas por medio de la adición de Tripsina-EDTA, se lavaron con PBS y se recogieron mediante centrifugaciones a 1200 rpm durante 5 minutos. Las células se resuspendieron en $1 \mathrm{ml}$ de etanol al $70 \%$ frío y se incubaron 1 hora en hielo o durante la noche a $4^{\circ} \mathrm{C}$ para fijarlas. Tras esto, se llevaron a cabo dos nuevos lavados con PBS (centrifugaciones a $2000 \mathrm{rpm}$ durante 10 minutos) y las células se resuspendieron en $0,5 \mathrm{ml}$ de solución de marcaje con yoduro de propidio $(4 \mu \mathrm{g})$ 
y RNAsa (10 $\mu \mathrm{g})$ (Roche), y se incubaron durante 1 hora a $37^{\circ} \mathrm{C}$ en agitación y oscuridad, tras lo que finalmente fueron analizadas.

\section{ANÁLISIS DE PROTEÍNAS}

\section{Obtención de extractos proteicos totales}

Para poder analizar las proteínas celulares es necesario obtenerlas mediante un tampón de extracción. Hemos utilizado diversos tipos de soluciones de extracción o lisis para este fin, con mayor o menor concentración de detergentes en función de cada situación experimental.

\subsection{Obtención de extractos proteicos de $S$. pombe}

Los extractos proteicos obtenidos en condiciones más desnaturalizantes se utilizaron para el posterior análisis de proteínas, mientras que para los experimentos de inmunoprecipitación se prepararon extractos proteicos totales en condiciones menos severas (apartado VI).

Preparación de extractos para análisis proteico en condiciones desnaturalizantes:

Se recogieron $3 \times 10^{8}$ células (creciendo exponencialmente) por centrifugación y fueron lavadas con agua miliQ estéril. A continuación, estas células se mantuvieron en hielo y se les añadieron $50 \mu \mathrm{l}$ del tampón RIPA (fosfato sódico $\mathrm{Na}_{2} \mathrm{HPO}_{4} 10 \mathrm{mM}$, Tritón X-100 1\%, SDS 0,1\%, EDTA $10 \mathrm{mM}, \mathrm{NaCl} 150 \mathrm{mM} \mathrm{pH} \mathrm{7,} \mathrm{con} \mathrm{los} \mathrm{siguientes} \mathrm{inhibidores} \mathrm{de} \mathrm{proteasas}$ y fosfatasas: leupeptina $20 \mu \mathrm{g} / \mathrm{ml}$, aprotinina $20 \mu \mathrm{g} / \mathrm{ml}$, PMSF $1 \mathrm{mM}$ y ortovanadato sódico $0,1 \mathrm{mM})$. Las células con RIPA se mezclaron con bolas de vidrio $(0,4 \mathrm{~mm}$ de Sigma) y se rompieron en la Fast-Prep (Bio101) durante 15 segundos a una potencia de 5,5, operación que se repitió tres veces. Tras esto, añadimos otros $500 \mu$ l de tampón RIPA con inhibidores de proteasas y fosfatasas, y los extractos proteicos totales obtenidos se centrifugaron dos veces a máxima velocidad para desechar los restos celulares no solubles.

\subsection{Obtención de extractos proteicos totales a partir de células humanas}

Los extractos proteicos se obtuvieron a partir de células en cultivo, que fueron lavadas con PBS frío y recogidas directamente en tampón de lisis; o bien, a partir de muestras de células que habían sido tripsinizadas, recogidas por centrifugación, lavadas, y congeladas en hielo seco y guardadas a $-70^{\circ} \mathrm{C}$ hasta su procesamiento. 
En ambos casos, las células se mezclaron bien con el tampón de lisis (Tris $20 \mathrm{mM}$ a $\mathrm{pH} 7,5, \mathrm{NaCl} 250 \mathrm{mM}$, NP40 0,5\%, EDTA 0,1 mM e inhibidores de proteasas y fosfatasas: ortovanadato sódico $1 \mathrm{mM}$, NaF $10 \mathrm{mM}$, PMSF $1 \mathrm{mM}$, aprotinina $10 \mu \mathrm{g} / \mathrm{ml}$ y leupeptina 10 $\mu \mathrm{g} / \mathrm{ml}$ ) y se incubaron durante 30 minutos en hielo. A continuación, estos extractos se centrifugaron durante 15 minutos a máxima velocidad para desechar los restos celulares no solubles.

\section{Valoración de la concentración de proteína en los extractos totales}

Para cuantificar la concentración de proteína de los extractos totales utilizamos el sistema colorimétrico BCA (Pierce), siguiendo las indicaciones del fabricante. La intensidad de color de cada reacción colorimétrica, que depende de la cantidad de proteína presente en cada muestra, fue cuantificada en espectrofotómetro a $\lambda=562 \mathrm{~nm}$. A continuación, la concentración de proteínas de cada muestra se determinó extrapolando los valores a partir de una recta patrón de concentraciones conocidas de albúmina sérica bovina (BSA).

\section{Electroforesis de proteínas en SDS-PAGE}

Mediante la electroforesis en una dimensión en geles de SDS-PAGE (del inglés Sodium-ㅁodecyl S Sulfate-Polyacrilamide gel electrophoresis, geles de SDS-poliacrilamida) se pueden separar las proteínas de una muestra en función de su peso molecular (Laemmli, 1970), ya que el SDS es un detergente aniónico que rodea a las proteínas confiriéndoles una carga negativa proporcional a su tamaño.

Antes de cargar las muestras de extracto proteico en el gel, se les añadió un tampón de carga que contiene DTT (Ditiotreitol) como agente reductor, en concreto (Tris- $\mathrm{HCl} \mathrm{pH}$ $6,8,80 \mathrm{mM}$, DTT 5mM, SDS $2 \%$, glicerol 7,5\%, EDTA $5 \mathrm{mM}$, azul de bromofenol 0,002\%) y se hirvieron durante 5 minutos a $95^{\circ} \mathrm{C}$. Este proceso favorece la desnaturalización de las muestras.

Los geles SDS-PAGE pueden contener distintos porcentajes de poliacrilamida, de modo que altos porcentajes de poliacrilamida son adecuados para separar proteínas de bajo peso molecular y viceversa. Por consiguiente, en función del peso molecular de las proteínas que deseamos analizar se utilizaron geles con distintos porcentajes (entre 8 y $16 \%)$.

En cada gel SDS-PAGE, cargamos cantidades de extracto proteicos equivalentes de todas las muestras, en el caso de extractos proteicos de células humanas entre 15 y 40 
$\mu \mathrm{g}$, dependiendo de la proteína a detectar y de la línea celular, y en el caso de extractos proteicos de $S$. pombe se cargaron $75 \mu \mathrm{g}$. También se cargaron marcadores de peso molecular, preteñidos (en caso de Western blot) o no (en caso de tinción con azul de Coomassie), de GIBCO Invitrogen. La electroforesis en una dimensión se llevó a cabo utilizando el sistema Mini-Protean de Bio Rad, en condiciones desnaturalizantes, debido al tampón de carrera empleado (Tris-HCl 25 mM, glicina 192 mM, SDS 0,1\%, a pH 8,3).

Una vez finalizada la electroforesis, estos geles se podían fijar y teñir con azul de Coomassie, o bien ser sometidos a electrotransferencia e inmunodetección, por la técnica de Western blot.

\section{Análisis de proteínas por la técnica de Western blot}

Los geles SDS-PAGE se electrotransfirieron durante 1,5-2 horas a voltaje constante (100V) a una membrana de nitrocelulosa (Hybond ECL de Amersham) utilizando el sistema Mini-Transblot de Bio Rad. Empleamos como tampón de transferencia CAPS (ácido 3-(ciclohexil-amino)-1-propanosulfónico $10 \mathrm{mM}$, metanol 10\%, a pH 11).

A continuación, la membrana de nitrocelulosa fue "bloqueada" (saturada) durante 1 hora a temperatura ambiente ( $\mathrm{RT}$, del inglés $\underline{R}$ oom Iemperature) en una solución que contiene PBS (Tampón fosfato $10 \mathrm{mM} \mathrm{pH} \mathrm{7,2,} \mathrm{NaCl} 145 \mathrm{mM}$ ) y leche en polvo al $5 \%$ (Sveltesse Nestlé) y detergente Tween-20 al 0,1\%.

La inmunodetección de proteínas consiste en su detección utilizando anticuerpos monoclonales o policlonales especificos (Tabla M-IV). Se utilizan dos anticuerpos, uno primario que reconoce específicamente a la proteína problema, y otro secundario que reconoce al anterior y que está conjugado con una enzima, como la peroxidasa, que cataliza la reacción de detección. La incubación con el anticuerpo primario se llevó a cabo en la solución de bloqueo durante 2 horas a RT o toda la noche a $4^{\circ} \mathrm{C}$. Tras esto, se lavó la membrana cuatro veces durante 5 minutos con una solución que contiene PBS con Tween-20 al 0,1\%. La incubación con el anticuerpo secundario se realizó también en solución de bloqueo durante una hora a temperatura ambiente, y después, la membrana primero se lavó en PBS con Tween-20 al 0,1\% (dos veces durante 10 minutos) y por último sólo con PBS.

Para revelar el Western blot se utilizó, en función de la proteína, el sistema de quimioluminiscencia $E C L$ de Amersham o Supersignal de Pierce, siguiendo las instrucciones de los fabricantes. La quimioluminiscencia se detectó mediante exposición de películas de auto-radiografía (Hyperfilm ECL de Amersham). 
En algunos casos se cuantificó la intensidad de las bandas proteicas de interés con el programa Quantity One de Bio Rad.

\begin{tabular}{|c|c|c|c|c|}
\hline \multicolumn{5}{|c|}{ Anticuerpos WB } \\
\hline Anticuerpo primario & Antígeno & Tipo/Especie & Dilución & Procedencia \\
\hline Anti-Cdc2 C2 & Cdc2 (S. pombe ) & Policlonal/Conejo & $1 / 250$ & Dr. Gull \\
\hline Cdc25 & Cdc25 (S. pombe ) & Policlonal/Conejo & $1 / 250$ & Dr. Moreno \\
\hline Anti-TAT1 & Tubulina (S. pombe ) & Monoclonal/Ratón & $1 / 3000$ & Dr. Moreno \\
\hline Anti- $\beta$ Actina (AC-15) & $\beta$-Actina & Monoclonal/Ratón & $1 / 5000$ & Sigma \\
\hline Anti-Cdc14A (DCS-291) & hCdc14A & Monoclonal/Ratón & $1 / 500$ & NeoMarkers \\
\hline Anti-Cdc25A (F-6) & hCdc25A & Monoclonal/Ratón & $1 / 250$ & Sta Cruz \\
\hline Anti-Cdc25B (H-85) & hCdc25B & Policlonal/Conejo & $1 / 1000$ & Sta Cruz \\
\hline Anti-Cdc25C (H-6) & hCdc25C & Monoclonal/Ratón & $1 / 500$ & Sta Cruz \\
\hline Anti-Cdc2 (17) & Cdk1 & Monoclonal/Ratón & $1 / 1000$ & Sta Cruz \\
\hline Anti-P-Tyr15-Cdc2 (9111) & P-Tyr15-Cdk1 & Policlonal/Conejo & $1 / 1000$ & Cell Signaling \\
\hline Anti-Ciclina A (H-432) & Ciclina A2 & Policlonal/Conejo & $1 / 1000$ & Sta Cruz \\
\hline Anti-Ciclina B (H-433) & Ciclina B1 & Policlonal/Conejo & $1 / 1000$ & Sta Cruz \\
\hline Anti- $\gamma$-Tubulina (GTU-88) & $\gamma$-Tubulina & Monoclonal/Ratón & $1 / 10000$ & Sigma \\
\hline Anti-GFP (JL-8) & GFP & Monoclonal/Ratón & $1 / 1000$ & Becton-Dickinson \\
\hline Anti- p21 (F-5) & p21 & Monoclonal/Ratón & $1 / 1000$ & Sta Cruz \\
\hline Anti- p38 (9212) & p38 & Policlonal/Conejo & $1 / 1000$ & Cell Signaling \\
\hline Anti-P-p38 (9211) & P-Thr180/Tyr182-p38 & Policlonal/Conejo & $1 / 1000$ & Cell Signaling \\
\hline Anti-PCNA (PC-10) & PCNA & Monoclonal/Ratón & $1 / 500$ & Sta Cruz \\
\hline Anticuerpo secundario & Antígeno & Enzima asociada & Dilución & Procedencia \\
\hline Anti-Ratón & IgG Ratón & HRP Peroxidasa & $1 / 2000$ & Amersham \\
\hline Anti-Conejo & IgG Conejo & HRP Peroxidasa & $1 / 3500$ & Amersham \\
\hline
\end{tabular}

Tabla M-IV. Anticuerpos empleados en Western blot

\section{Tinción con azul de Coomassie}

Tras la electroforesis, los geles de poliacrilamida se tiñeron con solución de azul de Coomassie (azul de Coomassie al 0,5\%, metanol al 20\% y ácido acético al 10\%) durante 10 minutos en agitación a RT. A continuación se destiñeron en solución de destinción (metanol al $20 \%$ y ácido acético al $10 \%$ ) en agitación a RT, cambiando periódicamente dicha solución, hasta distinguir con nitidez las bandas correspondientes a las proteínas de interés.

\section{PURIFICACIÓN DE PROTEÍNAS FUSIONADAS A GST}

\section{Purificación a partir de células de $S$. pombe}

La purificación de las proteínas GST-hCdc14 a partir de células de S. pombe se llevó a cabo empleando una matriz de glutatión-sefarosa según el protocolo descrito por Shiozaki y Russell (Shiozaki y Russell, 1997). 


\section{Purificación a partir de células de E. coli}

La purificación de las proteínas de fusión con GST se realizó a partir de células de $E$. coli transformadas con plásmidos pGEX que contienían el cDNA de la proteína a purificar. Para ello, las células de E. coli se cultivaron primero en LB con $100 \mu \mathrm{g} / \mathrm{ml}$ de ampicilina y posteriormente se indujo la síntesis de la proteína por medio de la incubación de este cultivo, durante 4 horas a $37^{\circ} \mathrm{C}$, en presencia de IPTG $(0,5 \mathrm{mM})$. Tras este tiempo, las células fueron recogidas por centrifugación (a 10000 x g durante 10 minutos) y se resuspendieron en un tampón de lisis (PBS frío, Tritón X-100 al 1\%, Lisozima 0,2 $\mu \mathrm{g} / \mathrm{ml}$, DTT $2 \mathrm{mM}$, y los inhibidores de proteasas PMSF $1 \mathrm{mM}$, aprotinina $10 \mu \mathrm{g} / \mathrm{ml}$ y leupeptina 10 $\mu \mathrm{g} / \mathrm{ml})$. Tras la incubación de la suspensión celular durante 30 minutos a $4^{\circ} \mathrm{C}$, ésta fue sonicada con el sonicador Misonic XL2010, y después se centrifugó a 30000 x g durante 30 minutos a $4^{\circ} \mathrm{C}$. El sobrenadante fue incubado con bolas de glutatión-sefarosa (Amersham) durante 1 hora a $4^{\circ} \mathrm{C}$, las cuales fueron recuperadas y lavadas posteriormente 5 veces con PBS (al que se le añadieron inhibidores de proteasas). La pureza de la proteína y el rendimiento del proceso se comprobaron mediante electroforesis en SDS-PAGE y posterior tinción con azul de Coomassie.

\section{INMUNOPRECIPITACIÓN}

Las inmunoprecipitaciones permiten purificar proteínas por su unión a un anticuerpo específico (Tabla $\mathrm{M}-\mathrm{V}$ ), formando inmunocomplejos. La purificación de estos inmunocomplejos se realiza gracias a la utilización de la proteína $A$ o la proteína $G$ (unidas a una matriz de sefarosa), que presentan afinidad por la región constante de las cadenas de las inmunoglobulinas.

\begin{tabular}{|c|c|c|c|c|}
\hline \multicolumn{5}{|c|}{ Anticuerpos IP } \\
\hline Anticuerpo primario & Antígeno & Tipo/Especie & Proporción & Procedencia \\
\hline Anti-Cdc13 SP4 suero & Cdc13 (S. pombe ) & Policlonal/Conejo & $2 \mu \mathrm{l}$ suero/ $750 \mu \mathrm{g}$ proteína fotal & Dra. Hayles \\
\hline Anti-Cdc25A (M-191) & hCdc25A & Policlonal/Conejo & $2 \mu \mathrm{g} \mathrm{IgG} / 1 \mathrm{mg}$ proteína total & Sta Cruz \\
\hline Anti-Cdc25B (H-85) & hCdc25B & Policlonal/Conejo & $2 \mu \mathrm{g} \mathrm{IgG/1mg} \mathrm{proteína} \mathrm{total}$ & Sta Cruz \\
\hline Anti-Cdc25C (C-20) & hCdc25C & Policlonal/Conejo & $2 \mu \mathrm{g} \operatorname{lgG} / 1 \mathrm{mg}$ proteína total & Sta Cruz \\
\hline Anti-Ciclina A (H-432) & Ciclina A2 & Policlonal/Conejo & $1 \mu \mathrm{glg} / 100 \mu \mathrm{g}$ proteína total & Sta Cruz \\
\hline Anti-Ciclina B (H-433) & Ciclina B1 & Policlonal/Conejo & $1 \mu \mathrm{g} \lg \mathrm{G} / 100 \mu \mathrm{g}$ proteína total & Sta Cruz \\
\hline
\end{tabular}

Tabla M-V. Anticuerpos empleados para la inmunoprecipitación (IP) de proteínas 


\section{Inmunoprecipitación de los complejos Cdc2-Cdc13 a partir de células de $S$. pombe}

Los extractos proteicos totales de $S$. pombe se prepararon en una solución tampón específica para inmunoprecipitaciones (Tris-HCl $50 \mathrm{mM} \mathrm{pH} \mathrm{8,} \mathrm{NaCl} \mathrm{400mM,} \mathrm{EDTA} 1 \mathrm{mM}$, 2- $\beta$-mercaptoetanol $1 \mathrm{mM}$, glicerol 10\% e inhibidores de proteasas y fosfatasas: $\mathrm{NaF} 50$ $\mathrm{mM}$, ortovanadato sódico $1 \mathrm{mM}$ y PMSF $1 \mathrm{mM}$, además de un inhibidor comercial completo de proteasas de Roche Applied Science).

En estos experimentos se emplearon $750 \mu \mathrm{g}$ de extracto proteico total, que inicialmente fueron incubados con $2 \mu \mathrm{l}$ del suero anti-Cdc13 (SP4) durante 1 hora en hielo, y a continuación, en presencia también de $20 \mu \mathrm{l}$ de proteína A-sefarosa (Amersham) durante otras 2 horas a $4^{\circ} \mathrm{C}$. Las bolas de sefarosa, unidas a los inmunocomplejos, se lavaron 5 veces con $1 \mathrm{ml}$ de la solución tampón de inmunoprecipitación, y después fueron lavadas dos veces en tampón quinasa (Tris $50 \mathrm{mM}$ a pH 7,5, $\mathrm{MgCl}_{2} 10 \mathrm{mM}$, EGTA $1 \mathrm{mM}$, DTT $1 \mathrm{mM}$ y ATP $50 \mathrm{mM}$ ), en el que se resuspendieron.

\section{Inmunoprecipitaciones realizadas a partir de células humanas}

En este estudio realizamos inmunoprecipitaciones de complejos Cdk1-Ciclina B1 y Cdk-Ciclina A a partir de $100 \mu \mathrm{g}$ de extractos proteicos totales (preparados como se ha indicado), y empleando anticuerpos específicos frente a la Ciclina B1 y la Ciclina A, respectivamente. Las inmunoprecipitaciones de las proteínas $\mathrm{hCdc} 25$ se realizaron a partir de $1 \mathrm{mg}$ de extracto total.

La cantidad de extracto proteico indicada en cada caso fue incubada inicialmente con una determinada cantidad del anticuerpo correspondiente (anti-hCdc25: $2 \mu \mathrm{g}$ de IgG/1 mg proteína del extracto total, y anti-Ciclinas: $1 \mu \mathrm{g}$ de $\mathrm{IgG} / 100 \mu \mathrm{g}$ proteína del extracto total) durante 3 horas o toda la noche, a $4^{\circ} \mathrm{C}$ en agitación orbital. A continuación se añadió la proteína A-sefarosa (Amersham), $15 \mu \mathrm{l} / 2 \mu \mathrm{g}$ de IgG (anticuerpo), durante otra hora a $4^{\circ} \mathrm{C}$. Las bolas de sefarosa, unidas a los inmunocomplejos, se lavaron 5 veces con $1 \mathrm{ml} \mathrm{del}$ tampón de lisis (sin inhibidor de fosfatasas en el caso de la inmunoprecipitación de los hCdc25s). 


\section{ENSAYOS in vitro: ANÁLISIS DE LA ACTIVIDAD QUINASA Y/O FOSFATASA}

\section{Ensayos in vitro de la actividad quinasa de los complejos CDK sobre Histona $\mathrm{H} 1$}

Una vez inmunoprecipitados los complejos Cdk1-Ciclina B1 o Cdk-Ciclina A humanos (a partir de $100 \mu \mathrm{g}$ de proteína total), o los complejos Cdc2-Cdc13 de S. pombe (a partir de $750 \mu \mathrm{g}$ de proteína total). En el caso de Cdk1-Ciclina B1, la muestra inmunoprecipitada fue dividida, de forma que la mitad se utilizó en la reacción quinasa y la otra mitad para analizar la cantidad de Cdk1 inmunoprecipitada mediante Western blot. En el caso de Cdk-Ciclina A o Cdc2-Cdc13, la cantidad inmunoprecipitada fue empleada íntegramente para la reacción quinasa.

Para el ensayo quinasa, los complejos inmunoprecipitados se lavaron dos veces y fueron resuspendidos en tampón quinasa (Tris $50 \mathrm{mM}$ a $\mathrm{pH} 7,5, \mathrm{MgCl}_{2} 10 \mathrm{mM}$, EGTA 1 mM, DTT $1 \mathrm{mM}$ y ATP $50 \mathrm{mM})$ en presencia de $0,15 \mu \mathrm{Ci}$ de $\gamma\left({ }^{32} \mathrm{P}\right) \mathrm{ATP}$ y $5 \mu \mathrm{g}$ de Histona $\mathrm{H} 1$ (Calbiochem) como sustrato, e incubados a $30^{\circ} \mathrm{C}$ durante 30 minutos. La reacción quinasa se paró añadiendo tampón de carga (Tris- $\mathrm{HCl}$ pH 6,8, 80mM, DTT 5mM, SDS $2 \%$, glicerol $7,5 \%$, EDTA $5 \mathrm{mM}$, azul de bromofenol $0,002 \%$ ) y hervimos las muestras durante 5 minutos a $95^{\circ} \mathrm{C}$. En estas muestras las proteínas se separaron mediante electroforesis en SDS-PAGE, y se realizó la tinción del gel con azul de Coomassie y su posterior secado a $80^{\circ} \mathrm{C}$ durante 2 horas (Gel Dryer de Bio Rad). Los resultados se analizaron mediante auto-radiografía en películas (BioMax MR film de Kodak), o en pantallas de revelado de Phosphor-Imager de Fuji en el aparato Molecular Imager FX de Bio Rad.

La intensidad de las bandas correspondiente a la auto-radiografía se cuantificó con el programa Quantity One de Bio Rad, y esta señal fue normalizada respecto a la cantidad de proteína Cdk1 inmunoprecipitada, o la cantidad de Cdc2 de S. pombe o Ciclina A presente en el extracto proteico total correspondiente, determinadas mediante la técnica de Western blot (también cuantificadas con el programa Quantity One de Bio Rad).

\section{Ensayos in vitro de la actividad fosfatasa de proteínas hCdc25 sobre complejos CDK}

Una vez inmunoprecipitados los hCdc25s a partir de la cantidad indicada (1 $\mathrm{mg}$ de proteína total) de cada muestra, estas proteínas fueron lavadas dos veces y resuspendidas en un tampón fosfatasa (Tris 20mM pH 8,3, NaCl 150 mM, EDTA 2mM, 
Tritón X-100 0,1\% y DTT $5 \mathrm{mM}$ ). A cada muestra se le añadió idéntica cantidad de complejos Cdk1-Ciclina B1 inactivos, inmunoprecipitados a partir de $100 \mu \mathrm{g}$ de extracto proteicos de células tratadas con timidina (sincronizadas en $\mathrm{G} 1 / \mathrm{S}$ ), que previamente fueron lavados también con este tampón fosfatasa. A continuación, se realizó el ensayo fosfatasa incubando los inmunoprecipitados de las proteínas hCdc25 y los complejos CDK en $50 \mu \mathrm{l}$ de tampón fosfatasa a $30^{\circ} \mathrm{C}$ durante 1 hora. Tras esto, los inmunoprecipitados se lavaron 2 veces con $1 \mathrm{ml}$ de tampón quinasa, y se llevó a cabo un ensayo quinasa sobre Histona $\mathrm{H} 1$ como se ha descrito en el apartado anterior. La reacción también fue parada al añadir tampón de carga y hervir $\left(5\right.$ minutos a $\left.95^{\circ} \mathrm{C}\right)$, y las proteínas se separaron mediante electroforesis en SDS-PAGE. Los geles fueron divididos en dos partes, de forma que la parte superior (en la que se encuentran los hCdc25s inmunoprecipitados) se utilizó para la detección de estas proteínas por Western blot y la parte inferior del gel, en la que se encuentra la Histona $\mathrm{H} 1$, se tiñó con azul de Coomassie, se secó y se visualizó la incorporación de ${ }^{32} \mathrm{P}$ por auto-radiografía con películas (BioMax MR film de Kodak) o con pantallas de revelado de Phosphor-Imager de Fuji en el aparato Molecular Imager FX de Bio Rad.

Se realizó la cuantificación de las bandas de auto-radiografía y de Western blot, empleando el programa Quantity One de "Bio-Rad". La señal de auto-radiografía fue normalizada con respecto a la cantidad de hCdc25 inmunoprecipitada (detectada por Western blot).

\section{Ensayos in vitro de la actividad fosfatasa de hCdc14 sobre las proteínas Cdc25}

Las proteínas GST-hCdc14 o GST-hCdc14(PD) se purificaron a partir de la cepa $\Delta c d c 25 c d c 2-3 w$ de $S$. pombe, para evitar la co-purificación de Cdc25 por interacción con las proteínas hCdc14, y los GST-Cdc25s (humanos o de S. pombe) a partir de células de E. coli.

En primer lugar, las proteínas GST-Cdc25 fueron incubadas con 2 unidades de complejos Cdk1-Ciclina B1 (New England Biolabs) en tampón quinasa (Tris $50 \mathrm{mM} \mathrm{pH}$ $7,5, \mathrm{MgCl}_{2} 10 \mathrm{mM}$, EGTA $1 \mathrm{mM}$, DTT $1 \mathrm{mM}$ y ATP $50 \mathrm{mM}$ ) en presencia de 0,15 $\mu \mathrm{Ci}$ de $\gamma\left({ }^{32} \mathrm{P}\right) \mathrm{ATP}$, a $30^{\circ} \mathrm{C}$ durante 30 minutos. Tras el ensayo quinasa, las proteínas GST-Cdc25 se lavaron 3 veces y se resuspendieron en tampón fosfatasa (imidazol 50mM a pH 6,9, EDTA $1 \mathrm{mM}$ y DTT $1 \mathrm{mM}$ ), y se añadió la proteína GST-hCdc14 estudiada en cada caso. Esta mezcla $(30 \mu \mathrm{l})$ se incubó durante 45 minutos a $30^{\circ} \mathrm{C}$. La reacción fue parada al añadir el tampón de carga y hervir $\left(5\right.$ minutos a $\left.95^{\circ} \mathrm{C}\right)$, tras lo que las proteínas fueron separadas 
mediante electroforesis en SDS-PAGE. Los geles se tiñeron con azul de Coomassie y fueron secados para ver el resultado de la reacción mediante auto-radiografía en películas (BioMax MR film de Kodak) o en pantallas de revelado de Phosphor-Imager de Fuji analizadas en el aparato Molecular Imager FX de Bio Rad.

\section{INMUNOCITOQUÍMICA}

Esta técnica nos permitió analizar la localización subcelular de diversas proteínas mediante su observación con microscopio de fluorescencia. Con este fin, en primer lugar se fijaron las células y a continuación se llevó a cabo el marcaje de la proteína por medio de inmunofluorescencia indirecta, con un anticuerpo primario específico y un anticuerpo secundario conjugado a un fluorocromo que emite fluorescencia (CY3, rojo). En paralelo se realizó la tinción del DNA con DAPI (Sigma). En la Tabla M-VI se muestran los anticuerpos empleados para inmunofluorescencia indirecta en este trabajo.

\begin{tabular}{|ccccc|}
\hline \multicolumn{4}{c}{ Anticuerpos } & IF \\
\hline Anticuerpo primario & Antígeno & Tipo/Especie & Proporción & Procedencia \\
\hline \hline Anti-GST & GST & Policlonal/Conejo & $1 / 500$ & Dr. A. Pandiella \\
\hline Anti-cMyc (9E10) & C-Myc & Monoclonal/Ratón & $1 / 100$ & Sigma \\
\hline Anti-TAT1 & Tubulina (S. pombe ) & Monoclonal/Ratón & $1 / 100$ & Dr. Moreno \\
Anti-Cdc25A (F-6) & hCdc25A & Monoclonal/Ratón & $1 / 100$ & Sta Cruz \\
\hline Anti-P-HH3 (H-85) & P-Ser10-Histona H3 & Policlonal/Conejo & $1 / 200$ & Cell Signaling \\
\hline Anti-P-HH2AX (C-20) & P-Ser139-Histona H2AX & Policlonal/Conejo & $1 / 150$ & Cell Signaling \\
\hline Anticuerpo secundario & Antígeno & Fluorocromo & Dilución & Procedencia \\
\hline Anti-Ratón Cy3 & IgG Ratón & Cy3 & $1 / 500$ & Jackson \\
\hline Anti-Conejo Cy3 & IgG Conejo & Cy3 & $1 / 500$ & Jackson \\
\hline
\end{tabular}

Tabla M-VI. Anticuerpos empleados para inmunofluorescencia indirecta (IF)

\section{Técnica de inmunofluorescencia en células de $S$. pombe}

Las células (aproximadamente $10^{8}$ ) se fijaron durante 20 minutos con paraformaldehído al $4 \%$ a $25^{\circ} \mathrm{C}$. Las células fijadas se lavaron 3 veces con $1 \mathrm{ml}$ de solución PEM (PIPES 100 mM, EGTA 1mM, MgSO, $\mathrm{pH}$ 6,9). Una fracción de estas células se resuspendió en PEMS (PEM con 1,2 M de sorbitol) con $1 \mathrm{mg} / \mathrm{ml}$ de zimoliasa $20 \mathrm{~T}$ (Seikagaku C., LTD) y se incubó a $37^{\circ} \mathrm{C}$ durante 5-30 minutos (en función de la 
proteína) para crear poros en la pared celular que permitieron la penetración de los anticuerpos. Tras esto, la membrana celular se permeabilizó mediante un tratamiento de 30 segundos con Triton X-100 al 1\% en PEMS y se lavaron las células 3 veces con PEM. Para evitar uniones inespecíficas de los anticuerpos, las células se bloquearon con PEMBAL (L-Lisina de Sigma $100 \mathrm{mM}$, azida sódica al 0,1\%, BSA 1\% en PEM, pH 6,9) durante 30 minutos en agitación orbital a RT. A una parte de estas células se les añadió el anticuerpo primario y se incubaron de nuevo en agitación orbital a RT durante toda la noche. El exceso de anticuerpo se eliminó mediante 3 lavados con PEMBAL. La incubación con el anticuerpo secundario se realizó durante 4 horas a una dilución 1:300 en PEMBAL a RT. El exceso de anticuerpo secundario se eliminó mediante dos lavados con PEM y PBS. Finalmente se resuspendieron las células en PBS con DAPI ( $2 \mu \mathrm{g} / \mathrm{ml})$, y las células se extendieron en un cubreobjetos, se dejaron secar y se añadió una gota de glicerol al $50 \%$ con $1 \mathrm{mg} / \mathrm{ml}$ de para-fenilendiamina (que evita que la fluorescencia se desvanezca rápidamente). Para la observación de las muestras se emplearon microscopios (Zeiss Axiovert-2 y Leica DM6000B) acoplados a una cámara (Hamamatsu ORCA-ER).

\section{Técnica de inmunofluorescencia en células humanas}

Las células se siembran e incuban sobre cubreobjetos, que en el caso de células HCT116 son tratados previamente con una solución de colágeno a $50 \mu \mathrm{g} / \mathrm{ml}$ (Sigma) para mejorar la adherencia. A continuación las células adheridas a los cubreobjetos fueron lavadas con $\mathrm{PBS} / \mathrm{Ca}^{+2} \mathrm{Mg}^{+2}$ (PBS con $\mathrm{CaCl}_{2} 1 \mathrm{mM}$ y $\mathrm{MgCl}_{2} 0,5 \mathrm{mM}$ ) y fijadas con paraformaldehído $2 \%$ en PBS, durante 30 minutos a RT en agitación suave. Tras esto, se realizaron dos lavados con PBS, se permeabilizaron las células con Tritón X-100 al 0,1\% en PBS durante 10 minutos a $\mathrm{RT}$ y se trataron con $\mathrm{NH}_{4} \mathrm{Cl} 50 \mathrm{mM}$ en PBS durante otros 10 minutos a RT. A continuación, llevamos a cabo el bloqueo de las células con BSA al 0,2\% en PBS, para evitar uniones inespecíficas del anticuerpo. La incubación con el anticuerpo primario en solución de bloqueo con BSA se llevó a cabo durante 1 hora, tras la cual las células se lavaron tres veces, durante 10 minutos cada vez, con la propia solución de bloqueo. Tras esto, se llevó a cabo la incubación con el anticuerpo secundario unido al fluorocromo, diluído en solución de bloqueo durante 30 minutos a RT y en oscuridad. Por último, realizamos tres lavados con abundante solución de bloqueo y la incubación con DAPI $(2 \mu \mathrm{g} / \mathrm{ml})$ en PBS durante 5 minutos, todo ello en oscuridad. Los cubreobjetos se lavaron con agua y se montaron sobre los portaobjetos usando SlowFade (Invitrogen). 
Para la observación de las muestras se emplearon microscopios (Zeiss Axiovert-2 y Leica DM6000B) acoplados a una cámara (Hamamatsu ORCA-ER).

\section{PURIFICACIÓN DE CENTROSOMAS}

Llevamos a cabo la purificación de centrosomas mediante la centrifugación de extractos celulares en un colchón de Ficoll PM 400, como se indica en el protocolo descrito por Blomberg-Wirschel y Doxsey en 1998 (Blomberg-Wirschell y Doxsey, 1998).

Según este método, las células fueron sometidas a un tratamiento previo con nocodazol y citocalasina $B$, ambos a una concentración final de $100 \mu \mathrm{g} / \mathrm{ml}$. A continuación, se lavaron las células y fueron preparados los extractos celulares empleando el tampón de

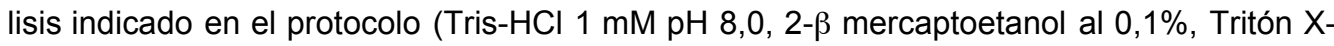
100 al $0,5 \%$ e inhibidores de proteasas). Por último, se realizó el aislamiento de los centrosomas en el colchón de Ficoll y a estos centrosomas se les añadieron PIPES (10 $\mathrm{mM}$ ) y EDTA (1 mM), además de inhibidores de proteasas.

Los núcleos de células adherentes no son liberados de la placa (se observan al microcopio) tras la incubación de éstos con el tampón de lisis, de modo que también se pueden obtener extractos nucleares a partir de ellos. 
Bibliografía 

Adams, R.R., A.A. Tavares, A. Salzberg, H.J. Bellen, and D.M. Glover. 1998. pavarotti encodes a kinesin-like protein required to organize the central spindle and contractile ring for cytokinesis. Genes Dev. 12:1483-94.

Alcorta, D.A., Y. Xiong, D. Phelps, G. Hannon, D. Beach, and J.C. Barrett. 1996. Involvement of the cyclin-dependent kinase inhibitor p16 (INK4a) in replicative senescence of normal human fibroblasts. Proc Natl Acad Sci U S A. 93:13742-7.

Andersen, S.S. 1999. Balanced regulation of microtubule dynamics during the cell cycle: a contemporary view. Bioessays. 21:53-60.

Ando, T., T. Kawabe, H. Ohara, B. Ducommun, M. Itoh, and T. Okamoto. 2001. Involvement of the interaction between p21 and proliferating cell nuclear antigen for the maintenance of G2/M arrest after DNA damage. J Biol Chem. 276:42971-7.

Azzam, R., S.L. Chen, W. Shou, A.S. Mah, G. Alexandru, K. Nasmyth, R.S. Annan, S.A. Carr, and R.J. Deshaies. 2004. Phosphorylation by cyclin B-Cdk underlies release of mitotic exit activator Cdc14 from the nucleolus. Science. 305:516-9.

Bahassi el, M., R.F. Hennigan, D.L. Myer, and P.J. Stambrook. 2004. Cdc25C phosphorylation on serine 191 by Plk3 promotes its nuclear translocation. Oncogene. 23:2658-63.

Baker, D.J., J. Chen, and J.M. van Deursen. 2005. The mitotic checkpoint in cancer and aging: what have mice taught us? Curr Opin Cell Biol. 17:583-9.

Baldassarre, G., C.M. Croce, and A. Vecchione. 2007. Take your "M" time. Cell Cycle. 6:2087-90.

Baldin, V., C. Cans, M. Knibiehler, and B. Ducommun. 1997. Phosphorylation of human CDC25B phosphatase by CDK1-cyclin A triggers its proteasome-dependent degradation. $\mathrm{J}$ Biol Chem. 272:32731-4

Baldin, V., and B. Ducommun. 1995. Subcellular localisation of human wee1 kinase is regulated during the cell cycle. J Cell Sci. 108 ( Pt 6):2425-32.

Baldin, V., N. Theis-Febvre, C. Benne, C. Froment, M. Cazales, O. Burlet-Schiltz, and B. Ducommun. 2003. PKB/Akt phosphorylates the CDC25B phosphatase and regulates its intracellular localisation. Biol Cell. 95:547-54.

Bardin, A.J., and A. Amon. 2001. Men and sin: what's the difference? Nat Rev Mol Cell Biol. 2:81526.

Bardin, A.J., R. Visintin, and A. Amon. 2000. A mechanism for coupling exit from mitosis to partitioning of the nucleus. Cell. 102:21-31.

Barr, A.R., and F. Gergely. 2007. Aurora-A: the maker and breaker of spindle poles. J Cell Sci. 120:2987-96.

Barr, F.A., H.H. Sillje, and E.A. Nigg. 2004. Polo-like kinases and the orchestration of cell division. Nat Rev Mol Cell Biol. 5:429-40.

Bassermann, F., C. Peschel, and J. Duyster. 2005a. Mitotic entry: a matter of oscillating destruction. Cell Cycle. 4:1515-7.

Bassermann, F., C. von Klitzing, S. Munch, R.Y. Bai, H. Kawaguchi, S.W. Morris, C. Peschel, and J. Duyster. 2005b. NIPA defines an SCF-type mammalian E3 ligase that regulates mitotic entry. Cell. 122:45-57.

Bembenek, J., and H. Yu. 2001. Regulation of the anaphase-promoting complex by the dual specificity phosphatase human Cdc14a. J Biol Chem. 276:48237-42.

Berdougo, E., M.V. Nachury, P.K. Jackson, and P.V. Jallepalli. 2008. The nucleolar phosphatase Cdc14B is dispensable for chromosome segregation and mitotic exit in human cells. Cell Cycle. 7.

Bhowmick, N.A., M. Ghiassi, M. Aakre, K. Brown, V. Singh, and H.L. Moses. 2003. TGF-beta-induced RhoA and p160ROCK activation is involved in the inhibition of Cdc25A with resultant cellcycle arrest. Proc Natl Acad Sci U S A. 100:15548-53.

Birnboim, H.C., and J. Doly. 1979. A rapid alkaline extraction procedure for screening recombinant plasmid DNA. Nucleic Acids Res. 7:1513-23.

Blanco, M.A., A. Sanchez-Diaz, J.M. de Prada, and S. Moreno. 2000. APC(ste9/srw1) promotes degradation of mitotic cyclins in $\mathrm{G}(1)$ and is inhibited by cdc2 phosphorylation. Embo $\mathrm{J}$. 19:3945-55. 


\section{Bibliografía}

Blomberg, I., and I. Hoffmann. 1999. Ectopic expression of Cdc25A accelerates the G(1)/S transition and leads to premature activation of cyclin E- and cyclin A-dependent kinases. Mol Cell Biol. 19:6183-94.

Blomberg-Wirschell, M., and S.J. Doxsey. 1998. Rapid isolation of centrosomes. Methods Enzymol. 298:228-38.

Booher, R.N., C.E. Alfa, J.S. Hyams, and D.H. Beach. 1989. The fission yeast cdc2/cdc13/suc1 protein kinase: regulation of catalytic activity and nuclear localization. Cell. 58:485-97.

Booher, R.N., P.S. Holman, and A. Fattaey. 1997. Human Myt1 is a cell cycle-regulated kinase that inhibits Cdc2 but not Cdk2 activity. J Biol Chem. 272:22300-6.

Boutros, R., C. Dozier, and B. Ducommun. 2006. The when and wheres of CDC25 phosphatases. Curr Opin Cell Biol. 18:185-91.

Boutros, R., V. Lobjois, and B. Ducommun. 2007. CDC25 phosphatases in cancer cells: key players? Good targets? Nat Rev Cancer. 7:495-507.

Brandeis, M., I. Rosewell, M. Carrington, T. Crompton, M.A. Jacobs, J. Kirk, J. Gannon, and T. Hunt. 1998. Cyclin B2-null mice develop normally and are fertile whereas cyclin B1-null mice die in utero. Proc Natl Acad Sci U S A. 95:4344-9.

Bulavin, D.V., Y. Higashimoto, Z.N. Demidenko, S. Meek, P. Graves, C. Phillips, H. Zhao, S.A. Moody, E. Appella, H. Piwnica-Worms, and A.J. Fornace, Jr. 2003. Dual phosphorylation controls Cdc25 phosphatases and mitotic entry. Nat Cell Biol. 5:545-51.

Bulavin, D.V., Y. Higashimoto, I.J. Popoff, W.A. Gaarde, V. Basrur, O. Potapova, E. Appella, and A.J. Fornace, Jr. 2001. Initiation of a G2/M checkpoint after ultraviolet radiation requires p38 kinase. Nature. 411:102-7.

Bullough, W.S., and M. Johnson. 1951. The energy relations of mitotic activity in adult mouse epidermis. Proc $R$ Soc Lond B Biol Sci. 138:562-75.

Bunz, F., A. Dutriaux, C. Lengauer, T. Waldman, S. Zhou, J.P. Brown, J.M. Sedivy, K.W. Kinzler, and B. Vogelstein. 1998. Requirement for p53 and p21 to sustain G2 arrest after DNA damage. Science. 282:1497-501.

Burma, S., B.P. Chen, M. Murphy, A. Kurimasa, and D.J. Chen. 2001. ATM phosphorylates histone H2AX in response to DNA double-strand breaks. J Biol Chem. 276:42462-7.

Busino, L., M. Donzelli, M. Chiesa, D. Guardavaccaro, D. Ganoth, N.V. Dorrello, A. Hershko, M. Pagano, and G.F. Draetta. 2003. Degradation of Cdc25A by beta-TrCP during S phase and in response to DNA damage. Nature. 426:87-91.

Calzada, A., M. Sacristan, E. Sanchez, and A. Bueno. 2001. Cdc6 cooperates with Sic1 and Hct1 to inactivate mitotic cyclin-dependent kinases. Nature. 412:355-8.

Canela, N., A. Rodriguez-Vilarrupla, J.M. Estanyol, C. Diaz, M.J. Pujol, N. Agell, and O. Bachs. 2003. The SET protein regulates G2/M transition by modulating cyclin B-cyclin-dependent kinase 1 activity. J Biol Chem. 278:1158-64.

Carujo, S., J.M. Estanyol, A. Ejarque, N. Agell, O. Bachs, and M.J. Pujol. 2006. Glyceraldehyde 3phosphate dehydrogenase is a SET-binding protein and regulates cyclin B-cdk1 activity. Oncogene. 25:4033-42.

Cazales, M., E. Schmitt, E. Montembault, C. Dozier, C. Prigent, and B. Ducommun. 2005. CDC25B phosphorylation by Aurora-A occurs at the G2/M transition and is inhibited by DNA damage. Cell Cycle. 4:1233-8.

Chan, T.A., H. Hermeking, C. Lengauer, K.W. Kinzler, and B. Vogelstein. 1999. 14-3-3Sigma is required to prevent mitotic catastrophe after DNA damage. Nature. 401:616-20.

Chang, F., and I. Herskowitz. 1990. Identification of a gene necessary for cell cycle arrest by a negative growth factor of yeast: FAR1 is an inhibitor of a G1 cyclin, CLN2. Cell. 63:9991011.

Charrier-Savournin, F.B., M.T. Chateau, V. Gire, J. Sedivy, J. Piette, and V. Dulic. 2004. p21Mediated nuclear retention of cyclin B1-Cdk1 in response to genotoxic stress. Mol Biol Cell. 15:3965-76.

Chen, M.S., C.E. Ryan, and H. Piwnica-Worms. 2003. Chk1 kinase negatively regulates mitotic function of Cdc25A phosphatase through 14-3-3 binding. Mol Cell Biol. 23:7488-97. 
Cho, H.P., Y. Liu, M. Gomez, J. Dunlap, M. Tyers, and Y. Wang. 2005. The dual-specificity phosphatase CDC14B bundles and stabilizes microtubules. Mol Cell Biol. 25:4541-51.

Ciosk, R., W. Zachariae, C. Michaelis, A. Shevchenko, M. Mann, and K. Nasmyth. 1998. An ESP1/PDS1 complex regulates loss of sister chromatid cohesion at the metaphase to anaphase transition in yeast. Cell. 93:1067-76.

Clute, P., and J. Pines. 1999. Temporal and spatial control of cyclin B1 destruction in metaphase. Nat Cell Biol. 1:82-7.

Coqueret, O., G. Berube, and A. Nepveu. 1998. The mammalian Cut homeodomain protein functions as a cell-cycle-dependent transcriptional repressor which downmodulates p21WAF1/CIP1/SDI1 in S phase. Embo J. 17:4680-94.

Correa-Bordes, J., and P. Nurse. 1995. p25rum1 orders S phase and mitosis by acting as an inhibitor of the p34cdc2 mitotic kinase. Cell. 83:1001-9.

Creanor, J., and J.M. Mitchison. 1996. The kinetics of the B cyclin p56cdc13 and the phosphatase p80cdc25 during the cell cycle of the fission yeast Schizosaccharomyces pombe. J Cell Sci. 109 ( Pt 6):1647-53.

Crosio, C., G.M. Fimia, R. Loury, M. Kimura, Y. Okano, H. Zhou, S. Sen, C.D. Allis, and P. SassoneCorsi. 2002. Mitotic phosphorylation of histone H3: spatio-temporal regulation by mammalian Aurora kinases. Mol Cell Biol. 22:874-85.

Cueille, N., E. Salimova, V. Esteban, M. Blanco, S. Moreno, A. Bueno, and V. Simanis. 2001. Flp1, a fission yeast orthologue of the $\mathrm{s}$. cerevisiae CDC14 gene, is not required for cyclin degradation or rum1p stabilisation at the end of mitosis. J Cell Sci. 114:2649-64.

D'Angiolella, V., L. Palazzo, C. Santarpia, V. Costanzo, and D. Grieco. 2007. Role for non-proteolytic control of M-phase promoting factor activity at M-phase exit. PLOS ONE. 2:e247.

Dai, W., Q. Wang, and F. Traganos. 2002. Polo-like kinases and centrosome regulation. Oncogene. 21:6195-200.

Dalal, S.N., C.M. Schweitzer, J. Gan, and J.A. DeCaprio. 1999. Cytoplasmic localization of human cdc25C during interphase requires an intact 14-3-3 binding site. Mol Cell Biol. 19:4465-79.

Dash, B.C., and W.S. El-Deiry. 2005. Phosphorylation of p21 in G2/M promotes cyclin B-Cdc2 kinase activity. Mol Cell Biol. 25:3364-87.

Davezac, N., V. Baldin, J. Blot, B. Ducommun, and J.P. Tassan. 2002. Human pEg3 kinase associates with and phosphorylates CDC25B phosphatase: a potential role for $\mathrm{pEg} 3$ in cell cycle regulation. Oncogene. 21:7630-41.

Davezac, N., V. Baldin, B. Gabrielli, A. Forrest, N. Theis-Febvre, M. Yashida, and B. Ducommun. 2000. Regulation of CDC25B phosphatases subcellular localization. Oncogene. 19:2179-85.

De Souza, C.P., K.A. Ellem, and B.G. Gabrielli. 2000. Centrosomal and cytoplasmic Cdc2/cyclin B1 activation precedes nuclear mitotic events. Exp Cell Res. 257:11-21.

den Elzen, N., and J. Pines. 2001. Cyclin A is destroyed in prometaphase and can delay chromosome alignment and anaphase. J Cell Biol. 153:121-36.

Diaz-Cuervo, H., and A. Bueno. 2008. Cds1 Controls the Release of Cdc14-like Phosphatase Flp1 from the Nucleolus to Drive Full Activation of the Checkpoint Response to Replication Stress in Fission Yeast. Mol Biol Cell.

Donzelli, M., and G.F. Draetta. 2003. Regulating mammalian checkpoints through Cdc25 inactivation. EMBO Rep. 4:671-7.

Donzelli, M., M. Squatrito, D. Ganoth, A. Hershko, M. Pagano, and G.F. Draetta. 2002. Dual mode of degradation of Cdc25 A phosphatase. Embo J. 21:4875-84.

Dryden, S.C., F.A. Nahhas, J.E. Nowak, A.S. Goustin, and M.A. Tainsky. 2003. Role for human SIRT2 NAD-dependent deacetylase activity in control of mitotic exit in the cell cycle. Mol Cell Biol. 23:3173-85.

Ducommun, B., G. Draetta, P. Young, and D. Beach. 1990. Fission yeast cdc25 is a cell-cycle regulated protein. Biochem Biophys Res Commun. 167:301-9.

Ducruet, A.P., A. Vogt, P. Wipf, and J.S. Lazo. 2005. Dual specificity protein phosphatases: therapeutic targets for cancer and Alzheimer's disease. Annu Rev Pharmacol Toxicol. 45:725-50. 


\section{Bibliografía}

Dulic, V., G.H. Stein, D.F. Far, and S.I. Reed. 1998. Nuclear accumulation of p21Cip1 at the onset of mitosis: a role at the G2/M-phase transition. Mol Cell Biol. 18:546-57.

Dutertre, S., M. Cazales, M. Quaranta, C. Froment, V. Trabut, C. Dozier, G. Mirey, J.P. Bouche, N. Theis-Febvre, E. Schmitt, B. Monsarrat, C. Prigent, and B. Ducommun. 2004. Phosphorylation of CDC25B by Aurora-A at the centrosome contributes to the G2-M transition. J Cell Sci. 117:2523-31.

Dyson, M.H., S. Thomson, M. Inagaki, H. Goto, S.J. Arthur, K. Nightingale, F.J. Iborra, and L.C. Mahadevan. 2005. MAP kinase-mediated phosphorylation of distinct pools of histone $\mathrm{H} 3$ at S10 or S28 via mitogen- and stress-activated kinase 1/2. J Cell Sci. 118:2247-59.

el-Deiry, W.S., T. Tokino, V.E. Velculescu, D.B. Levy, R. Parsons, J.M. Trent, D. Lin, W.E. Mercer, K.W. Kinzler, and B. Vogelstein. 1993. WAF1, a potential mediator of p53 tumor suppression. Cell. 75:817-25.

Elia, A.E., L.C. Cantley, and M.B. Yaffe. 2003. Proteomic screen finds pSer/pThr-binding domain localizing Plk1 to mitotic substrates. Science. 299:1228-31.

Esteban, V., M. Blanco, N. Cueille, V. Simanis, S. Moreno, and A. Bueno. 2004. A role for the Cdc14family phosphatase Flp1p at the end of the cell cycle in controlling the rapid degradation of the mitotic inducer Cdc25p in fission yeast. $J$ Cell Sci. 117:2461-8.

Esteban, V., M.D. Vazquez-Novelle, E. Calvo, A. Bueno, and M.P. Sacristan. 2006. Human Cdc14A reverses CDK1 phosphorylation of Cdc25A on serines 115 and 320. Cell Cycle. 5:2894-8.

Esteban, V., M. Sacristan, S. Andres, and A. Bueno. 2008. The Flp1/Clp1 phosphatase cooperates with HECT-type Pub1/2 protein-ubiquitin ligases in Schizosaccharomyces pombe. Cell Cycle. 7:1269-76.

Eto, M., E. Elliott, T.D. Prickett, and D.L. Brautigan. 2002. Inhibitor-2 regulates protein phosphatase-1 complexed with NimA-related kinase to induce centrosome separation. J Biol Chem. 277:44013-20.

Evans, T., E.T. Rosenthal, J. Youngblom, D. Distel, and T. Hunt. 1983. Cyclin: a protein specified by maternal mRNA in sea urchin eggs that is destroyed at each cleavage division. Cell. 33:389-96.

Eymin, B., P. Claverie, C. Salon, C. Brambilla, E. Brambilla, and S. Gazzeri. 2006. p14ARF triggers G2 arrest through ERK-mediated Cdc25C phosphorylation, ubiquitination and proteasomal degradation. Cell Cycle. 5:759-65.

Falck, J., N. Mailand, R.G. Syljuasen, J. Bartek, and J. Lukas. 2001. The ATM-Chk2-Cdc25A checkpoint pathway guards against radioresistant DNA synthesis. Nature. 410:842-7.

Featherstone, C., and P. Russell. 1991. Fission yeast $\mathrm{p} 107$ wee1 mitotic inhibitor is a tyrosine/serine kinase. Nature. 349:808-11.

Ferguson, A.M., L.S. White, P.J. Donovan, and H. Piwnica-Worms. 2005. Normal cell cycle and checkpoint responses in mice and cells lacking Cdc25B and Cdc25C protein phosphatases. Mol Cell Biol. 25:2853-60.

Forester, C.M., J. Maddox, J.V. Louis, J. Goris, and D.M. Virshup. 2007. Control of mitotic exit by PP2A regulation of Cdc25C and Cdk1. Proc Natl Acad Sci U S A. 104:19867-72.

Fry, A.M., P. Meraldi, and E.A. Nigg. 1998. A centrosomal function for the human Nek2 protein kinase, a member of the NIMA family of cell cycle regulators. Embo J. 17:470-81.

Fu, J., M. Bian, Q. Jiang, and C. Zhang. 2007. Roles of Aurora kinases in mitosis and tumorigenesis. Mol Cancer Res. 5:1-10.

Fung, T.K., H.T. Ma, and R.Y. Poon. 2007. Specialized roles of the two mitotic cyclins in somatic cells: cyclin A as an activator of M phase-promoting factor. Mol Biol Cell. 18:1861-73.

Furuno, N., N. den Elzen, and J. Pines. 1999. Human cyclin A is required for mitosis until mid prophase. J Cell Biol. 147:295-306.

Gabrielli, B.G., J.M. Clark, A.K. McCormack, and K.A. Ellem. 1997. Hyperphosphorylation of the Nterminal domain of Cdc25 regulates activity toward cyclin B1/Cdc2 but not cyclin A/Cdk2. $J$ Biol Chem. 272:28607-14

Gabrielli, B.G., C.P. De Souza, I.D. Tonks, J.M. Clark, N.K. Hayward, and K.A. Ellem. 1996 Cytoplasmic accumulation of cdc25B phosphatase in mitosis triggers centrosomal microtubule nucleation in HeLa cells. J Cell Sci. 109 ( Pt 5):1081-93. 
Galaktionov, K., X. Chen, and D. Beach. 1996. Cdc25 cell-cycle phosphatase as a target of c-myc. Nature. 382:511-7.

Garner-Hamrick, P.A., and C. Fisher. 1998. Antisense phosphorothioate oligonucleotides specifically down-regulate cdc25B causing S-phase delay and persistent antiproliferative effects. Int $J$ Cancer. 76:720-8.

Geley, S., E. Kramer, C. Gieffers, J. Gannon, J.M. Peters, and T. Hunt. 2001. Anaphase-promoting complex/cyclosome-dependent proteolysis of human cyclin A starts at the beginning of mitosis and is not subject to the spindle assembly checkpoint. J Cell Biol. 153:137-48.

Giet, R., and D.M. Glover. 2001. Drosophila aurora B kinase is required for histone H3 phosphorylation and condensin recruitment during chromosome condensation and to organize the central spindle during cytokinesis. J Cell Biol. 152:669-82.

Gil-Bernabe, A.M., F. Romero, M.C. Limon-Mortes, and M. Tortolero. 2006. Protein phosphatase 2A stabilizes human securin, whose phosphorylated forms are degraded via the SCF ubiquitin ligase. Mol Cell Biol. 26:4017-27.

Giles, N., A. Forrest, and B. Gabrielli. 2003. 14-3-3 acts as an intramolecular bridge to regulate cdc25B localization and activity. J Biol Chem. 278:28580-7.

Gimenez-Abian, J.F., I. Sumara, T. Hirota, S. Hauf, D. Gerlich, C. de la Torre, J. Ellenberg, and J.M. Peters. 2004. Regulation of sister chromatid cohesion between chromosome arms. Curr Biol. 14:1187-93.

Golan, A., Y. Yudkovsky, and A. Hershko. 2002. The cyclin-ubiquitin ligase activity of cyclosome/APC is jointly activated by protein kinases Cdk1-cyclin B and Plk. J Biol Chem. 277:15552-7.

Goldstone, S., S. Pavey, A. Forrest, J. Sinnamon, and B. Gabrielli. 2001. Cdc25-dependent activation of cyclin A/cdk2 is blocked in $G 2$ phase arrested cells independently of ATM/ATR. Oncogene. 20:921-32.

Goloudina, A., H. Yamaguchi, D.B. Chervyakova, E. Appella, A.J. Fornace, Jr., and D.V. Bulavin. 2003. Regulation of human Cdc25A stability by Serine 75 phosphorylation is not sufficient to activate a S phase checkpoint. Cell Cycle. 2:473-8.

Golsteyn, R.M., K.E. Mundt, A.M. Fry, and E.A. Nigg. 1995. Cell cycle regulation of the activity and subcellular localization of Plk1, a human protein kinase implicated in mitotic spindle function. J Cell Biol. 129:1617-28.

Golub, E.I. 1988. 'One minute' transformation of competent E. coli by plasmid DNA. Nucleic Acids Res. 16:1641.

Gong, D., J.R. Pomerening, J.W. Myers, C. Gustavsson, J.T. Jones, A.T. Hahn, T. Meyer, and J.E. Ferrell, Jr. 2007. Cyclin A2 regulates nuclear-envelope breakdown and the nuclear accumulation of cyclin B1. Curr Biol. 17:85-91.

Gorr, I.H., D. Boos, and O. Stemmann. 2005. Mutual inhibition of separase and Cdk1 by two-step complex formation. Mol Cell. 19:135-41.

Goto, H., Y. Yasui, E.A. Nigg, and M. Inagaki. 2002. Aurora-B phosphorylates Histone H3 at serine28 with regard to the mitotic chromosome condensation. Genes Cells. 7:11-7.

Gray, C.H., V.M. Good, N.K. Tonks, and D. Barford. 2003. The structure of the cell cycle protein Cdc14 reveals a proline-directed protein phosphatase. Embo J. 22:3524-35.

Gruneberg, U., M. Glotzer, A. Gartner, and E.A. Nigg. 2002. The CeCDC-14 phosphatase is required for cytokinesis in the Caenorhabditis elegans embryo. J Cell Biol. 158:901-14.

Gruneberg, U., R. Neef, R. Honda, E.A. Nigg, and F.A. Barr. 2004. Relocation of Aurora B from centromeres to the central spindle at the metaphase to anaphase transition requires MKIp2. J Cell Biol. 166:167-72.

Hagting, A., N. Den Elzen, H.C. Vodermaier, I.C. Waizenegger, J.M. Peters, and J. Pines. 2002. Human securin proteolysis is controlled by the spindle checkpoint and reveals when the APC/C switches from activation by Cdc20 to Cdh1. J Cell Biol. 157:1125-37.

Hagting, A., C. Karlsson, P. Clute, M. Jackman, and J. Pines. 1998. MPF localization is controlled by nuclear export. Embo J. 17:4127-38.

Hames, R.S., S.L. Wattam, H. Yamano, R. Bacchieri, and A.M. Fry. 2001. APC/C-mediated destruction of the centrosomal kinase Nek2A occurs in early mitosis and depends upon a cyclin A-type D-box. Embo J. 20:7117-27. 
Hannak, E., M. Kirkham, A.A. Hyman, and K. Oegema. 2001. Aurora-A kinase is required for centrosome maturation in Caenorhabditis elegans. J Cell Biol. 155:1109-16.

Hansen, C.A., J. Bartek, and S. Jensen. 2008. A functional link between the human cell cycleregulatory phosphatase $\mathrm{Cdc} 14 \mathrm{~A}$ and the atypical mitogen-activated kinase Erk3. Cell Cycle. 7:325-34

Harper, J.W. 1997. Cyclin dependent kinase inhibitors. Cancer Surv. 29:91-107.

Hassepass, I., R. Voit, and I. Hoffmann. 2003. Phosphorylation at serine 75 is required for UVmediated degradation of human Cdc25A phosphatase at the S-phase checkpoint. J Biol Chem. 278:29824-9.

Hauf, S., E. Roitinger, B. Koch, C.M. Dittrich, K. Mechtler, and J.M. Peters. 2005. Dissociation of cohesin from chromosome arms and loss of arm cohesion during early mitosis depends on phosphorylation of SA2. PLoS Biol. 3:e69.

Hayes, M.J., Y. Kimata, S.L. Wattam, C. Lindon, G. Mao, H. Yamano, and A.M. Fry. 2006. Early mitotic degradation of Nek2A depends on Cdc20-independent interaction with the APC/C. Nat Cell Biol. 8:607-14.

Heald, R., M. McLoughlin, and F. McKeon. 1993. Human wee1 maintains mitotic timing by protecting the nucleus from cytoplasmically activated Cdc2 kinase. Cell. 74:463-74.

Hermeking, H., C. Lengauer, K. Polyak, T.C. He, L. Zhang, S. Thiagalingam, K.W. Kinzler, and B. Vogelstein. 1997. 14-3-3 sigma is a p53-regulated inhibitor of G2/M progression. Mol Cell. 1:3-11.

Higuchi, T., and F. Uhlmann. 2005. Stabilization of microtubule dynamics at anaphase onset promotes chromosome segregation. Nature. 433:171-6.

Hirota, T., N. Kunitoku, T. Sasayama, T. Marumoto, D. Zhang, M. Nitta, K. Hatakeyama, and H. Saya. 2003. Aurora-A and an interacting activator, the LIM protein Ajuba, are required for mitotic commitment in human cells. Cell. 114:585-98.

Hoffmann, I., P.R. Clarke, M.J. Marcote, E. Karsenti, and G. Draetta. 1993. Phosphorylation and activation of human cdc25-C by cdc2--cyclin B and its involvement in the self-amplification of MPF at mitosis. Embo J. 12:53-63.

Hoffmann, I., G. Draetta, and E. Karsenti. 1994. Activation of the phosphatase activity of human cdc25A by a cdk2-cyclin E dependent phosphorylation at the G1/S transition. Embo J. 13:4302-10.

Holland, A.J., and S.S. Taylor. 2006. Cyclin-B1-mediated inhibition of excess separase is required for timely chromosome disjunction. J Cell Sci. 119:3325-36.

Hsu, J.Y., Z.W. Sun, X. Li, M. Reuben, K. Tatchell, D.K. Bishop, J.M. Grushcow, C.J. Brame, J.A Caldwell, D.F. Hunt, R. Lin, M.M. Smith, and C.D. Allis. 2000. Mitotic phosphorylation of histone $\mathrm{H} 3$ is governed by Ipl1/aurora kinase and Glc7/PP1 phosphatase in budding yeast and nematodes. Cell. 102:279-91.

Huang, J., and J.W. Raff. 1999. The disappearance of cyclin B at the end of mitosis is regulated spatially in Drosophila cells. Embo J. 18:2184-95.

Huang, J.N., I. Park, E. Ellingson, L.E. Littlepage, and D. Pellman. 2001. Activity of the APC(Cdh1) form of the anaphase-promoting complex persists until $\mathrm{S}$ phase and prevents the premature expression of Cdc20p. J Cell Biol. 154:85-94.

Izumi, T., and J.L. Maller. 1991. Phosphorylation of Xenopus cyclins B1 and B2 is not required for cell cycle transitions. Mol Cell Biol. 11:3860-7.

Jackman, M., C. Lindon, E.A. Nigg, and J. Pines. 2003. Active cyclin B1-Cdk1 first appears on centrosomes in prophase. Nat Cell Biol. 5:143-8.

Jang, Y.J., J.H. Ji, Y.C. Choi, C.J. Ryu, and S.Y. Ko. 2007. Regulation of Polo-like kinase 1 by DNA damage in mitosis. Inhibition of mitotic PLK-1 by protein phosphatase 2A. J Biol Chem. 282:2473-82.

Jaspersen, S.L., J.F. Charles, and D.O. Morgan. 1999. Inhibitory phosphorylation of the APC regulator Hct1 is controlled by the kinase Cdc28 and the phosphatase Cdc14. Curr Biol. 9:227-36. 
Jaspersen, S.L., J.F. Charles, R.L. Tinker-Kulberg, and D.O. Morgan. 1998. A late mitotic regulatory network controlling cyclin destruction in Saccharomyces cerevisiae. Mol Biol Cell. 9:280317.

Jensen, S., M. Geymonat, and L.H. Johnston. 2002. Mitotic exit: delaying the end without FEAR. Curr Biol. 12:R221-3.

Jin, P., S. Hardy, and D.O. Morgan. 1998. Nuclear localization of cyclin B1 controls mitotic entry after DNA damage. J Cell Biol. 141:875-85.

Jinno, S., K. Suto, A. Nagata, M. Igarashi, Y. Kanaoka, H. Nojima, and H. Okayama. 1994. Cdc25A is a novel phosphatase functioning early in the cell cycle. Embo J. 13:1549-56.

Kaiser, B.K., M.V. Nachury, B.E. Gardner, and P.K. Jackson. 2004. Xenopus Cdc14 alpha/beta are localized to the nucleolus and centrosome and are required for embryonic cell division. BMC Cell Biol. 5:27.

Kaiser, B.K., Z.A. Zimmerman, H. Charbonneau, and P.K. Jackson. 2002. Disruption of centrosome structure, chromosome segregation, and cytokinesis by misexpression of human Cdc14A phosphatase. Mol Biol Cell. 13:2289-300.

Kallstrom, H., A. Lindqvist, V. Pospisil, A. Lundgren, and C.K. Rosenthal. 2005. Cdc25A localisation and shuttling: characterisation of sequences mediating nuclear export and import. Exp Cell Res. 303:89-100.

Kanemori, Y., K. Uto, and N. Sagata. 2005. Beta-TrCP recognizes a previously undescribed nonphosphorylated destruction motif in Cdc25A and Cdc25B phosphatases. Proc Natl Acad Sci U S A. 102:6279-84.

Kang, D., J. Chen, J. Wong, and G. Fang. 2002. The checkpoint protein Chfr is a ligase that ubiquitinates Plk1 and inhibits Cdc2 at the G2 to M transition. J Cell Biol. 156:249-59.

Karlsson-Rosenthal, C., and J.B. Millar. 2006. Cdc25: mechanisms of checkpoint inhibition and recovery. Trends Cell Biol. 16:285-92.

Khmelinskii, A., C. Lawrence, J. Roostalu, and E. Schiebel. 2007. Cdc14-regulated midzone assembly controls anaphase B. J Cell Biol. 177:981-93.

Kieffer, I., C. Lorenzo, C. Dozier, E. Schmitt, and B. Ducommun. 2007. Differential mitotic degradation of the CDC25B phosphatase variants. Oncogene. 26:7847-58.

Kimura, K., M. Hirano, R. Kobayashi, and T. Hirano. 1998. Phosphorylation and activation of $13 S$ condensin by Cdc2 in vitro. Science. 282:487-90.

Kipreos, E.T. 2004. Developmental quiescence: Cdc14 moonlighting in G1. Nat Cell Biol. 6:693-5.

Kitajima, T.S., T. Sakuno, K. Ishiguro, S. lemura, T. Natsume, S.A. Kawashima, and Y. Watanabe. 2006. Shugoshin collaborates with protein phosphatase $2 \mathrm{~A}$ to protect cohesin. Nature. 441:46-52.

Kobayashi, H., E. Stewart, R. Poon, J.P. Adamczewski, J. Gannon, and T. Hunt. 1992. Identification of the domains in cyclin A required for binding to, and activation of, p34cdc2 and p32cdk2 protein kinase subunits. Mol Biol Cell. 3:1279-94.

Kong, M., E.A. Barnes, V. Ollendorff, and D.J. Donoghue. 2000. Cyclin F regulates the nuclear localization of cyclin B1 through a cyclin-cyclin interaction. Embo J. 19:1378-88.

Kovelman, R., and P. Russell. 1996. Stockpiling of Cdc25 during a DNA replication checkpoint arrest in Schizosaccharomyces pombe. Mol Cell Biol. 16:86-93.

Kramer, A., N. Mailand, C. Lukas, R.G. Syljuasen, C.J. Wilkinson, E.A. Nigg, J. Bartek, and J. Lukas. 2004. Centrosome-associated Chk1 prevents premature activation of cyclin-B-Cdk1 kinase. Nat Cell Biol. 6:884-91.

Kramer, E.R., N. Scheuringer, A.V. Podtelejnikov, M. Mann, and J.M. Peters. 2000. Mitotic regulation of the APC activator proteins CDC20 and CDH1. Mol Biol Cell. 11:1555-69.

Krasinska, L., G. de Bettignies, D. Fisher, A. Abrieu, D. Fesquet, and N. Morin. 2007. Regulation of multiple cell cycle events by Cdc14 homologues in vertebrates. Exp Cell Res. 313:1225-39.

Kumada, K., R. Yao, T. Kawaguchi, M. Karasawa, Y. Hoshikawa, K. Ichikawa, Y. Sugitani, I. Imoto, J. Inazawa, M. Sugawara, M. Yanagida, and T. Noda. 2006. The selective continued linkage of centromeres from mitosis to interphase in the absence of mammalian separase. $J$ Cell Biol. 172:835-46. 


\section{Bibliografía}

Kunitoku, N., T. Sasayama, T. Marumoto, D. Zhang, S. Honda, O. Kobayashi, K. Hatakeyama, Y. Ushio, H. Saya, and T. Hirota. 2003. CENP-A phosphorylation by Aurora-A in prophase is required for enrichment of Aurora-B at inner centromeres and for kinetochore function. Dev Cell. 5:853-64.

Kurose, A., T. Tanaka, X. Huang, F. Traganos, and Z. Darzynkiewicz. 2006. Synchronization in the cell cycle by inhibitors of DNA replication induces histone H2AX phosphorylation: an indication of DNA damage. Cell Prolif. 39:231-40.

Laemmli, U.K. 1970. Cleavage of structural proteins during the assembly of the head of bacteriophage T4. Nature. 227:680-5.

Lammer, C., S. Wagerer, R. Saffrich, D. Mertens, W. Ansorge, and I. Hoffmann. 1998. The cdc25B phosphatase is essential for the G2/M phase transition in human cells. J Cell Sci. $111(\mathrm{Pt}$ 16):2445-53.

Landsverk, H.B., M. Kirkhus, M. Bollen, T. Kuntziger, and P. Collas. 2005. PNUTS enhances in vitro chromosome decondensation in a PP1-dependent manner. Biochem J. 390:709-17.

Lanzetti, L., V. Margaria, F. Melander, L. Virgili, M.H. Lee, J. Bartek, and S. Jensen. 2007. Regulation of the Rab5 GTPase-activating protein RN-tre by the dual specificity phosphatase Cdc14A in human cells. J Biol Chem. 282:15258-70.

Lee, K., and K. Song. 2008. Basal C-Jun N-terminal kinases promote mitotic progression through histone $\mathrm{H} 3$ phosphorylation. Cell Cycle. 7:216-21.

Lees, E. 1995. Cyclin dependent kinase regulation. Curr Opin Cell Biol. 7:773-80.

Lees, E.M., and E. Harlow. 1993. Sequences within the conserved cyclin box of human cyclin A are sufficient for binding to and activation of cdc2 kinase. Mol Cell Biol. 13:1194-201.

Lemaire, M., C. Froment, R. Boutros, O. Mondesert, A.R. Nebreda, B. Monsarrat, and B. Ducommun. 2006. CDC25B phosphorylation by p38 and MK-2. Cell Cycle. 5:1649-53.

Li, J., A.N. Meyer, and D.J. Donoghue. 1997a. Nuclear localization of cyclin B1 mediates its biological activity and is regulated by phosphorylation. Proc Natl Acad Sci U S A. 94:502-7.

Li, L., B.R. Ernsting, M.J. Wishart, D.L. Lohse, and J.E. Dixon. 1997b. A family of putative tumor suppressors is structurally and functionally conserved in humans and yeast. $J$ Biol Chem. 272:29403-6.

Li, L., M. Ljungman, and J.E. Dixon. 2000. The human Cdc14 phosphatases interact with and dephosphorylate the tumor suppressor protein p53. J Biol Chem. 275:2410-4.

Li, Y., C.W. Jenkins, M.A. Nichols, and Y. Xiong. 1994. Cell cycle expression and p53 regulation of the cyclin-dependent kinase inhibitor p21. Oncogene. 9:2261-8.

Lincoln, A.J., D. Wickramasinghe, P. Stein, R.M. Schultz, M.E. Palko, M.P. De Miguel, L. Tessarollo, and P.J. Donovan. 2002. Cdc25b phosphatase is required for resumption of meiosis during oocyte maturation. Nat Genet. 30:446-9.

Lindon, C., and J. Pines. 2004. Ordered proteolysis in anaphase inactivates Plk1 to contribute to proper mitotic exit in human cells. J Cell Biol. 164:233-41.

Lindqvist, A., H. Kallstrom, A. Lundgren, E. Barsoum, and C.K. Rosenthal. 2005. Cdc25B cooperates with Cdc25A to induce mitosis but has a unique role in activating cyclin B1-Cdk1 at the centrosome. J Cell Biol. 171:35-45.

Liu, F., C. Rothblum-Oviatt, C.E. Ryan, and H. Piwnica-Worms. 1999. Overproduction of human Myt1 kinase induces a G2 cell cycle delay by interfering with the intracellular trafficking of Cdc2cyclin B1 complexes. Mol Cell Biol. 19:5113-23.

Liu, F., J.J. Stanton, Z. Wu, and H. Piwnica-Worms. 1997. The human Myt1 kinase preferentially phosphorylates Cdc2 on threonine 14 and localizes to the endoplasmic reticulum and Golgi complex. Mol Cell Biol. 17:571-83.

Lohka, M.J., M.K. Hayes, and J.L. Maller. 1988. Purification of maturation-promoting factor, an intracellular regulator of early mitotic events. Proc Natl Acad Sci U S A. 85:3009-13.

Lolli, G., and L.N. Johnson. 2005. CAK-Cyclin-dependent Activating Kinase: a key kinase in cell cycle control and a target for drugs? Cell Cycle. 4:572-7.

Lopez-Girona, A., B. Furnari, O. Mondesert, and P. Russell. 1999. Nuclear localization of Cdc25 is regulated by DNA damage and a 14-3-3 protein. Nature. 397:172-5. 
Losada, A., M. Hirano, and T. Hirano. 1998. Identification of Xenopus SMC protein complexes required for sister chromatid cohesion. Genes Dev. 12:1986-97.

Lowe, M., C. Rabouille, N. Nakamura, R. Watson, M. Jackman, E. Jamsa, D. Rahman, D.J. Pappin, and G. Warren. 1998. Cdc2 kinase directly phosphorylates the cis-Golgi matrix protein GM130 and is required for Golgi fragmentation in mitosis. Cell. 94:783-93.

Lukas, C., C.S. Sorensen, E. Kramer, E. Santoni-Rugiu, C. Lindeneg, J.M. Peters, J. Bartek, and J. Lukas. 1999a. Accumulation of cyclin B1 requires E2F and cyclin-A-dependent rearrangement of the anaphase-promoting complex. Nature. 401:815-8.

Lukas, J., C.S. Sorensen, C. Lukas, E. Santoni-Rugiu, and J. Bartek. 1999b. p16INK4a, but not constitutively active pRb, can impose a sustained G1 arrest: molecular mechanisms and implications for oncogenesis. Oncogene. 18:3930-5.

Lundgren, K., N. Walworth, R. Booher, M. Dembski, M. Kirschner, and D. Beach. 1991. mik1 and wee1 cooperate in the inhibitory tyrosine phosphorylation of cdc2. Cell. 64:1111-22.

Mailand, N., and J.F. Diffley. 2005. CDKs promote DNA replication origin licensing in human cells by protecting Cdc6 from APC/C-dependent proteolysis. Cell. 122:915-26.

Mailand, N., C. Lukas, B.K. Kaiser, P.K. Jackson, J. Bartek, and J. Lukas. 2002a. Deregulated human Cdc14A phosphatase disrupts centrosome separation and chromosome segregation. Nat Cell Biol. 4:317-22.

Mailand, N., A.V. Podtelejnikov, A. Groth, M. Mann, J. Bartek, and J. Lukas. 2002b. Regulation of $\mathrm{G}(2) / \mathrm{M}$ events by Cdc25A through phosphorylation-dependent modulation of its stability. Embo J. 21:5911-20.

Malumbres, M., and M. Barbacid. 2005. Mammalian cyclin-dependent kinases. Trends Biochem Sci. 30:630-41.

Manke, I.A., A. Nguyen, D. Lim, M.Q. Stewart, A.E. Elia, and M.B. Yaffe. 2005. MAPKAP kinase-2 is a cell cycle checkpoint kinase that regulates the G2/M transition and $S$ phase progression in response to UV irradiation. Mol Cell. 17:37-48.

Marumoto, T., S. Honda, T. Hara, M. Nitta, T. Hirota, E. Kohmura, and H. Saya. 2003. Aurora-A kinase maintains the fidelity of early and late mitotic events in HeLa cells. J Biol Chem. 278:51786-95.

Masui, Y., and C.L. Markert. 1971. Cytoplasmic control of nuclear behavior during meiotic maturation of frog oocytes. J Exp Zool. 177:129-45.

Matsuoka, S., M. Huang, and S.J. Elledge. 1998. Linkage of ATM to cell cycle regulation by the Chk2 protein kinase. Science. 282:1893-7.

Matsusaka, T., and J. Pines. 2004. Chfr acts with the p38 stress kinases to block entry to mitosis in mammalian cells. J Cell Biol. 166:507-16.

Mei, J., X. Huang, and P. Zhang. 2001. Securin is not required for cellular viability, but is required for normal growth of mouse embryonic fibroblasts. Curr Biol. 11:1197-201.

Meraldi, P., R. Honda, and E.A. Nigg. 2004. Aurora kinases link chromosome segregation and cell division to cancer susceptibility. Curr Opin Genet Dev. 14:29-36.

Michaelis, C., R. Ciosk, and K. Nasmyth. 1997. Cohesins: chromosomal proteins that prevent premature separation of sister chromatids. Cell. 91:35-45.

Mikhailov, A., M. Shinohara, and C.L. Rieder. 2005. The p38-mediated stress-activated checkpoint. A rapid response system for delaying progression through antephase and entry into mitosis. Cell Cycle. 4:57-62.

Millar, J.B., C.H. McGowan, G. Lenaers, R. Jones, and P. Russell. 1991. p80cdc25 mitotic inducer is the tyrosine phosphatase that activates p34cdc2 kinase in fission yeast. Embo J. 10:4301-9.

Minshull, J., R. Golsteyn, C.S. Hill, and T. Hunt. 1990. The A- and B-type cyclin associated cdc2 kinases in Xenopus turn on and off at different times in the cell cycle. Embo J. 9:2865-75.

Mirey, G., I. Chartrain, C. Froment, M. Quaranta, J.P. Bouche, B. Monsarrat, J.P. Tassan, and B. Ducommun. 2005. CDC25B phosphorylated by pEg3 localizes to the centrosome and the spindle poles at mitosis. Cell Cycle. 4:806-11.

Mishima, M., V. Pavicic, U. Gruneberg, E.A. Nigg, and M. Glotzer. 2004. Cell cycle regulation of central spindle assembly. Nature. 430:908-13. 


\section{Bibliografía}

Mishra, M., J. Karagiannis, M. Sevugan, P. Singh, and M.K. Balasubramanian. 2005. The 14-3-3 protein rad24p modulates function of the cdc14p family phosphatase clp $1 \mathrm{p} / \mathrm{flp} 1 \mathrm{p}$ in fission yeast. Curr Biol. 15:1376-83.

Mitra, J., and G.H. Enders. 2004. Cyclin A/Cdk2 complexes regulate activation of Cdk1 and Cdc25 phosphatases in human cells. Oncogene. 23:3361-7.

Mitra, J., G.H. Enders, J. Azizkhan-Clifford, and K.L. Lengel. 2006. Dual regulation of the anaphase promoting complex in human cells by cyclin A-Cdk2 and cyclin A-Cdk1 complexes. Cell Cycle. 5:661-6.

Miyazaki, T., and S. Arai. 2007. Two distinct controls of mitotic cdk1/cyclin B1 activity requisite for cell growth prior to cell division. Cell Cycle. 6:1419-25.

Moreno, S., J. Hayles, and P. Nurse. 1989. Regulation of p34cdc2 protein kinase during mitosis. Cell. 58:361-72.

Moreno, S., A. Klar, and P. Nurse. 1991. Molecular genetic analysis of fission yeast Schizosaccharomyces pombe. Methods Enzymol. 194:795-823.

Morgan, D.O. 1995. Principles of CDK regulation. Nature. 374:131-4.

Mori, D., Y. Yano, K. Toyo-oka, N. Yoshida, M. Yamada, M. Muramatsu, D. Zhang, H. Saya, Y.Y. Toyoshima, K. Kinoshita, A. Wynshaw-Boris, and S. Hirotsune. 2007. NDEL1 phosphorylation by Aurora-A kinase is essential for centrosomal maturation, separation, and TACC3 recruitment. Mol Cell Biol. 27:352-67.

Mueller, P.R., T.R. Coleman, A. Kumagai, and W.G. Dunphy. 1995. Myt1: a membrane-associated inhibitory kinase that phosphorylates Cdc2 on both threonine-14 and tyrosine-15. Science. 270:86-90.

Musacchio, A., and E.D. Salmon. 2007. The spindle-assembly checkpoint in space and time. Nat Rev Mol Cell Biol. 8:379-93.

Myer, D.L., M. Bahassi el, and P.J. Stambrook. 2005. The Plk3-Cdc25 circuit. Oncogene. 24:299-305.

Nakajima, H., F. Toyoshima-Morimoto, E. Taniguchi, and E. Nishida. 2003. Identification of a consensus motif for Plk (Polo-like kinase) phosphorylation reveals Myt1 as a Plk1 substrate. J Biol Chem. 278:25277-80.

Nalepa, G., and J.W. Harper. 2004. Visualization of a highly organized intranuclear network of filaments in living mammalian cells. Cell Motil Cytoskeleton. 59:94-108.

Nebreda, A.R. 2006. CDK activation by non-cyclin proteins. Curr Opin Cell Biol. 18:192-8.

Ng, C.P., H.C. Lee, C.W. Ho, T. Arooz, W.Y. Siu, A. Lau, and R.Y. Poon. 2004. Differential mode of regulation of the checkpoint kinases $\mathrm{CHK} 1$ and $\mathrm{CHK} 2$ by their regulatory domains. $J$ Biol Chem. 279:8808-19.

Nguyen, T.B., K. Manova, P. Capodieci, C. Lindon, S. Bottega, X.Y. Wang, J. Refik-Rogers, J. Pines, D.J. Wolgemuth, and A. Koff. 2002. Characterization and expression of mammalian cyclin b3, a prepachytene meiotic cyclin. J Biol Chem. 277:41960-9.

Nigg, E.A. 1995. Cyclin-dependent protein kinases: key regulators of the eukaryotic cell cycle. Bioessays. 17:471-80.

Nigg, E.A. 2001. Mitotic kinases as regulators of cell division and its checkpoints. Nat Rev Mol Cell Biol. 2:21-32.

Norbury, C., and S. Moreno. 1997. Cloning cell cycle regulatory genes by transcomplementation in yeast. Methods Enzymol. 283:44-59.

North, B.J., and E. Verdin. 2007. Mitotic regulation of SIRT2 by cyclin-dependent kinase 1-dependent phosphorylation. J Biol Chem. 282:19546-55.

O'Connell, M.J., M.J. Krien, and T. Hunter. 2003. Never say never. The NIMA-related protein kinases in mitotic control. Trends Cell Biol. 13:221-8.

O'Regan, L., J. Blot, and A.M. Fry. 2007. Mitotic regulation by NIMA-related kinases. Cell Div. 2:25.

Parker, L.L., and H. Piwnica-Worms. 1992. Inactivation of the p34cdc2-cyclin B complex by the human WEE1 tyrosine kinase. Science. 257:1955-7.

Paulsen, M.T., A.M. Starks, F.A. Derheimer, S. Hanasoge, L. Li, J.E. Dixon, and M. Ljungman. 2006. The p53-targeting human phosphatase hCdc14A interacts with the Cdk1/cyclin B complex and is differentially expressed in human cancers. Mol Cancer. 5:25. 
Pavletich, N.P. 1999. Mechanisms of cyclin-dependent kinase regulation: structures of Cdks, their cyclin activators, and Cip and INK4 inhibitors. J Mol Biol. 287:821-8.

Peng, C.Y., P.R. Graves, S. Ogg, R.S. Thoma, M.J. Byrnes, 3rd, Z. Wu, M.T. Stephenson, and H. Piwnica-Worms. 1998. C-TAK1 protein kinase phosphorylates human Cdc25C on serine 216 and promotes 14-3-3 protein binding. Cell Growth Differ. 9:197-208.

Peng, C.Y., P.R. Graves, R.S. Thoma, Z. Wu, A.S. Shaw, and H. Piwnica-Worms. 1997. Mitotic and G2 checkpoint control: regulation of 14-3-3 protein binding by phosphorylation of Cdc25C on serine-216. Science. 277:1501-5.

Pereira, G., and E. Schiebel. 2003. Separase regulates INCENP-Aurora B anaphase spindle function through Cdc14. Science. 302:2120-4.

Perry, J.A., and S. Kornbluth. 2007. Cdc25 and Wee1: analogous opposites? Cell Div. 2:12.

Peters, J.M. 2006. The anaphase promoting complex/cyclosome: a machine designed to destroy. Nat Rev Mol Cell Biol. 7:644-56.

Petronczki, M., M. Glotzer, N. Kraut, and J.M. Peters. 2007. Polo-like kinase 1 triggers the initiation of cytokinesis in human cells by promoting recruitment of the RhoGEF Ect2 to the central spindle. Dev Cell. 12:713-25.

Pfleger, C.M., and M.W. Kirschner. 2000. The KEN box: an APC recognition signal distinct from the D box targeted by Cdh1. Genes Dev. 14:655-65.

Pfleghaar, K., S. Heubes, J. Cox, O. Stemmann, and M.R. Speicher. 2005. Securin is not required for chromosomal stability in human cells. PLOS Biol. 3:e416.

Pines, J. 2006. Mitosis: a matter of getting rid of the right protein at the right time. Trends Cell Biol. 16:55-63.

Pines, J., and T. Hunter. 1989. Isolation of a human cyclin cDNA: evidence for cyclin mRNA and protein regulation in the cell cycle and for interaction with p34cdc2. Cell. 58:833-46.

Pines, J., and T. Hunter. 1990. Human cyclin A is adenovirus E1A-associated protein p60 and behaves differently from cyclin B. Nature. 346:760-3.

Pines, J., and T. Hunter. 1991. Human cyclins A and B1 are differentially located in the cell and undergo cell cycle-dependent nuclear transport. J Cell Biol. 115:1-17.

Pines, J., and C.L. Rieder. 2001. Re-staging mitosis: a contemporary view of mitotic progression. Nat Cell Biol. 3:E3-6.

Potapova, T.A., J.R. Daum, B.D. Pittman, J.R. Hudson, T.N. Jones, D.L. Satinover, P.T. Stukenberg, and G.J. Gorbsky. 2006. The reversibility of mitotic exit in vertebrate cells. Nature. 440:9548.

Prinz, S., E.S. Hwang, R. Visintin, and A. Amon. 1998. The regulation of Cdc20 proteolysis reveals a role for APC components $\mathrm{Cdc} 23$ and $\mathrm{Cdc} 27$ during S phase and early mitosis. Curr Biol. 8:750-60.

Queralt, E., C. Lehane, B. Novak, and F. Uhlmann. 2006. Downregulation of PP2A(Cdc55) phosphatase by separase initiates mitotic exit in budding yeast. Cell. 125:719-32.

Raich, W.B., A.N. Moran, J.H. Rothman, and J. Hardin. 1998. Cytokinesis and midzone microtubule organization in Caenorhabditis elegans require the kinesin-like protein ZEN-4. Mol Biol Cell. 9:2037-49.

Raj, K., P. Ogston, and P. Beard. 2001. Virus-mediated killing of cells that lack p53 activity. Nature. 412:914-7.

Rape, M., S.K. Reddy, and M.W. Kirschner. 2006. The processivity of multiubiquitination by the APC determines the order of substrate degradation. Cell. 124:89-103.

Reed, S.I., J. Ferguson, and J.C. Groppe. 1982. Preliminary characterization of the transcriptional and translational products of the Saccharomyces cerevisiae cell division cycle gene CDC28. Mol Cell Biol. 2:412-25.

Reed, S.I., J.A. Hadwiger, and A.T. Lorincz. 1985. Protein kinase activity associated with the product of the yeast cell division cycle gene CDC28. Proc Natl Acad Sci U S A. 82:4055-9.

Riedel, C.G., V.L. Katis, Y. Katou, S. Mori, T. Itoh, W. Helmhart, M. Galova, M. Petronczki, J. Gregan, B. Cetin, I. Mudrak, E. Ogris, K. Mechtler, L. Pelletier, F. Buchholz, K. Shirahige, and K. Nasmyth. 2006. Protein phosphatase 2A protects centromeric sister chromatid cohesion during meiosis I. Nature. 441:53-61. 
Rieder, C.L. 1981. Effect of hypothermia (20-25 degrees C) on mitosis in PtK1 cells. Cell Biol Int Rep. 5:563-73.

Rieder, C.L., and R. Cole. 2000. Microtubule disassembly delays the G2-M transition in vertebrates. Curr Biol. 10:1067-70.

Rodier, G., P. Coulombe, P.L. Tanguay, C. Boutonnet, and S. Meloche. 2008. Phosphorylation of Skp2 regulated by CDK2 and Cdc14B protects it from degradation by $\mathrm{APC}(\mathrm{Cdh} 1)$ in $\mathrm{G} 1$ phase. Embo J. 27:679-91.

Roig, J., A. Groen, J. Caldwell, and J. Avruch. 2005. Active Nercc1 protein kinase concentrates at centrosomes early in mitosis and is necessary for proper spindle assembly. Mol Biol Cell. 16:4827-40.

Roshak, A.K., E.A. Capper, C. Imburgia, J. Fornwald, G. Scott, and L.A. Marshall. 2000. The human polo-like kinase, PLK, regulates cdc2/cyclin B through phosphorylation and activation of the cdc25C phosphatase. Cell Signal. 12:405-11.

Russell, P., and P. Nurse. 1986. cdc25+ functions as an inducer in the mitotic control of fission yeast. Cell. 45:145-53.

Russell, P., and P. Nurse. 1987. Negative regulation of mitosis by wee1+, a gene encoding a protein kinase homolog. Cell. 49:559-67.

Saito, R.M., A. Perreault, B. Peach, J.S. Satterlee, and S. van den Heuvel. 2004. The CDC-14 phosphatase controls developmental cell-cycle arrest in C. elegans. Nat Cell Biol. 6:777-83.

Salic, A., J.C. Waters, and T.J. Mitchison. 2004. Vertebrate shugoshin links sister centromere cohesion and kinetochore microtubule stability in mitosis. Cell. 118:567-78.

Santamaria, D., C. Barriere, A. Cerqueira, S. Hunt, C. Tardy, K. Newton, J.F. Caceres, P. Dubus, M. Malumbres, and M. Barbacid. 2007. Cdk1 is sufficient to drive the mammalian cell cycle. Nature. 448:811-5.

Schmitt, E., R. Boutros, C. Froment, B. Monsarrat, B. Ducommun, and C. Dozier. 2006. CHK1 phosphorylates CDC25B during the cell cycle in the absence of DNA damage. J Cell Sci. 119:4269-75

Schwindling, S.L., A. Noll, M. Montenarh, and C. Gotz. 2004. Mutation of a CK2 phosphorylation site in cdc25C impairs importin alpha/beta binding and results in cytoplasmic retention. Oncogene. 23:4155-65.

Schwob, E., T. Bohm, M.D. Mendenhall, and K. Nasmyth. 1994. The B-type cyclin kinase inhibitor p40SIC1 controls the G1 to S transition in S. cerevisiae. Cell. 79:233-44.

Shannon, K.B., and E.D. Salmon. 2002. Chromosome dynamics: new light on Aurora B kinase function. Curr Biol. 12:R458-60.

Shiozaki, K., and P. Russell. 1997. Stress-activated protein kinase pathway in cell cycle control of fission yeast. Methods Enzymol. 283:506-20.

Shiromizu, T., H. Goto, Y. Tomono, J. Bartek, G. Totsukawa, A. Inoko, M. Nakanishi, F. Matsumura, and M. Inagaki. 2006. Regulation of mitotic function of Chk1 through phosphorylation at novel sites by cyclin-dependent kinase 1 (Cdk1). Genes Cells. 11:477-85.

Shou, W., J.H. Seol, A. Shevchenko, C. Baskerville, D. Moazed, Z.W. Chen, J. Jang, A. Shevchenko, H. Charbonneau, and R.J. Deshaies. 1999. Exit from mitosis is triggered by Tem1dependent release of the protein phosphatase Cdc14 from nucleolar RENT complex. Cell. 97:233-44.

Simanis, V., and P. Nurse. 1986. The cell cycle control gene cdc2+ of fission yeast encodes a protein kinase potentially regulated by phosphorylation. Cell. 45:261-8.

Skoufias, D.A., R.L. Indorato, F. Lacroix, A. Panopoulos, and R.L. Margolis. 2007. Mitosis persists in the absence of Cdk1 activity when proteolysis or protein phosphatase activity is suppressed. J Cell Biol. 179:671-85.

Smith, A., S. Simanski, M. Fallahi, and N.G. Ayad. 2007. Redundant ubiquitin ligase activities regulate wee1 degradation and mitotic entry. Cell Cycle. 6:2795-9.

Smits, V.A., R. Klompmaker, T. Vallenius, G. Rijksen, T.P. Makela, and R.H. Medema. 2000. p21 inhibits Thr161 phosphorylation of Cdc2 to enforce the G2 DNA damage checkpoint. J Biol Chem. 275:30638-43. 
Solomon, M.J., T. Lee, and M.W. Kirschner. 1992. Role of phosphorylation in p34cdc2 activation: identification of an activating kinase. Mol Biol Cell. 3:13-27.

Sorensen, C.S., C. Lukas, E.R. Kramer, J.M. Peters, J. Bartek, and J. Lukas. 2000. Nonperiodic activity of the human anaphase-promoting complex-Cdh1 ubiquitin ligase results in continuous DNA synthesis uncoupled from mitosis. Mol Cell Biol. 20:7613-23.

Sorensen, C.S., R.G. Syljuasen, J. Falck, T. Schroeder, L. Ronnstrand, K.K. Khanna, B.B. Zhou, J. Bartek, and J. Lukas. 2003. Chk1 regulates the S phase checkpoint by coupling the physiological turnover and ionizing radiation-induced accelerated proteolysis of Cdc25A. Cancer Cell. 3:247-58.

Squire, C.J., J.M. Dickson, I. Ivanovic, and E.N. Baker. 2005. Structure and inhibition of the human cell cycle checkpoint kinase, Wee1A kinase: an atypical tyrosine kinase with a key role in CDK1 regulation. Structure. 13:541-50.

St Clair, S., L. Giono, S. Varmeh-Ziaie, L. Resnick-Silverman, W.J. Liu, A. Padi, J. Dastidar, A. DaCosta, M. Mattia, and J.J. Manfredi. 2004. DNA damage-induced downregulation of Cdc25C is mediated by p53 via two independent mechanisms: one involves direct binding to the cdc25C promoter. Mol Cell. 16:725-36.

Stearns, T., L. Evans, and M. Kirschner. 1991. Gamma-tubulin is a highly conserved component of the centrosome. Cell. 65:825-36.

Steen, R.L., M. Beullens, H.B. Landsverk, M. Bollen, and P. Collas. 2003. AKAP149 is a novel PP1 specifier required to maintain nuclear envelope integrity in G1 phase. J Cell Sci. 116:223746.

Steen, R.L., S.B. Martins, K. Tasken, and P. Collas. 2000. Recruitment of protein phosphatase 1 to the nuclear envelope by A-kinase anchoring protein AKAP149 is a prerequisite for nuclear lamina assembly. J Cell Biol. 150:1251-62.

Stegmeier, F., R. Visintin, and A. Amon. 2002. Separase, polo kinase, the kinetochore protein Slk19, and Spo12 function in a network that controls Cdc14 localization during early anaphase. Cell. 108:207-20.

Stemmann, O., H. Zou, S.A. Gerber, S.P. Gygi, and M.W. Kirschner. 2001. Dual inhibition of sister chromatid separation at metaphase. Cell. 107:715-26.

Strausfeld, U., J.C. Labbe, D. Fesquet, J.C. Cavadore, A. Picard, K. Sadhu, P. Russell, and M. Doree. 1991. Dephosphorylation and activation of a p34cdc2/cyclin B complex in vitro by human CDC25 protein. Nature. 351:242-5.

Sullivan, M., and D.O. Morgan. 2007. Finishing mitosis, one step at a time. Nat Rev Mol Cell Biol. 8:894-903.

Sumara, I., E. Vorlaufer, P.T. Stukenberg, O. Kelm, N. Redemann, E.A. Nigg, and J.M. Peters. 2002. The dissociation of cohesin from chromosomes in prophase is regulated by Polo-like kinase. Mol Cell. 9:515-25.

Summers, M.K., J. Bothos, and T.D. Halazonetis. 2005. The CHFR mitotic checkpoint protein delays cell cycle progression by excluding Cyclin B1 from the nucleus. Oncogene. 24:2589-98.

Takizawa, C.G., K. Weis, and D.O. Morgan. 1999. Ran-independent nuclear import of cyclin B1-Cdc2 by importin beta. Proc Natl Acad Sci U S A. 96:7938-43.

Tang, Z., H. Shu, W. Qi, N.A. Mahmood, M.C. Mumby, and H. Yu. 2006. PP2A is required for centromeric localization of Sgo1 and proper chromosome segregation. Dev Cell. 10:575-85.

Taylor, W.R., and G.R. Stark. 2001. Regulation of the G2/M transition by p53. Oncogene. 20:180315.

Theis-Febvre, N., O. Filhol, C. Froment, M. Cazales, C. Cochet, B. Monsarrat, B. Ducommun, and V. Baldin. 2003. Protein kinase CK2 regulates CDC25B phosphatase activity. Oncogene. 22:220-32.

Tonks, N.K., and B.G. Neel. 1996. From form to function: signaling by protein tyrosine phosphatases. Cell. 87:365-8.

Toyoshima, F., T. Moriguchi, A. Wada, M. Fukuda, and E. Nishida. 1998. Nuclear export of cyclin B1 and its possible role in the DNA damage-induced G2 checkpoint. Embo J. 17:2728-35.

Toyoshima-Morimoto, F., E. Taniguchi, and E. Nishida. 2002. Plk1 promotes nuclear translocation of human Cdc25C during prophase. EMBO Rep. 3:341-8. 


\section{Bibliografía}

Toyoshima-Morimoto, F., E. Taniguchi, N. Shinya, A. Iwamatsu, and E. Nishida. 2001. Polo-like kinase 1 phosphorylates cyclin B1 and targets it to the nucleus during prophase. Nature. 410:215-20

Trautmann, S., and D. McCollum. 2005. Distinct nuclear and cytoplasmic functions of the S. pombe Cdc14-like phosphatase Clp1p/Flp1p and a role for nuclear shuttling in its regulation. Curr Biol. 15:1384-9.

Trautmann, S., S. Rajagopalan, and D. McCollum. 2004. The S. pombe Cdc14-like phosphatase Clp1p regulates chromosome biorientation and interacts with Aurora kinase. Dev Cell. 7:755-62.

Trautmann, S., B.A. Wolfe, P. Jorgensen, M. Tyers, K.L. Gould, and D. McCollum. 2001. Fission yeast Clp1p phosphatase regulates G2/M transition and coordination of cytokinesis with cell cycle progression. Curr Biol. 11:931-40.

Trinkle-Mulcahy, L., and A.I. Lamond. 2006. Mitotic phosphatases: no longer silent partners. Curr Opin Cell Biol. 18:623-31.

Turowski, P., C. Franckhauser, M.C. Morris, P. Vaglio, A. Fernandez, and N.J. Lamb. 2003. Functional cdc25C dual-specificity phosphatase is required for S-phase entry in human cells. Mol Biol Cell. 14:2984-98.

Uhlmann, F., F. Lottspeich, and K. Nasmyth. 1999. Sister-chromatid separation at anaphase onset is promoted by cleavage of the cohesin subunit Scc1. Nature. 400:37-42.

Vagnarelli, P., D.F. Hudson, S.A. Ribeiro, L. Trinkle-Mulcahy, J.M. Spence, F. Lai, C.J. Farr, A.I. Lamond, and W.C. Earnshaw. 2006. Condensin and Repo-Man-PP1 co-operate in the regulation of chromosome architecture during mitosis. Nat Cell Biol. 8:1133-42.

Van Hooser, A., D.W. Goodrich, C.D. Allis, B.R. Brinkley, and M.A. Mancini. 1998. Histone H3 phosphorylation is required for the initiation, but not maintenance, of mammalian chromosome condensation. J Cell Sci. 111 ( Pt 23):3497-506.

van Vugt, M.A., A. Bras, and R.H. Medema. 2004. Polo-like kinase-1 controls recovery from a G2 DNA damage-induced arrest in mammalian cells. Mol Cell. 15:799-811.

van Vugt, M.A., and R.H. Medema. 2005. Getting in and out of mitosis with Polo-like kinase-1. Oncogene. 24:2844-59.

Vazquez-Novelle, M.D., V. Esteban, A. Bueno, and M.P. Sacristan. 2005. Functional homology among human and fission yeast Cdc14 phosphatases. J Biol Chem. 280:29144-50.

Vecchione, A., G. Baldassarre, H. Ishii, M.S. Nicoloso, B. Belletti, F. Petrocca, N. Zanesi, L.Y. Fong, S. Battista, D. Guarnieri, R. Baffa, H. Alder, J.L. Farber, P.J. Donovan, and C.M. Croce. 2007. Fez1/Lzts 1 absence impairs Cdk1/Cdc25C interaction during mitosis and predisposes mice to cancer development. Cancer Cell. 11:275-89.

Vigo, E., H. Muller, E. Prosperini, G. Hateboer, P. Cartwright, M.C. Moroni, and K. Helin. 1999. CDC25A phosphatase is a target of E2F and is required for efficient E2F-induced S phase. Mol Cell Biol. 19:6379-95.

Visintin, R., K. Craig, E.S. Hwang, S. Prinz, M. Tyers, and A. Amon. 1998. The phosphatase Cdc14 triggers mitotic exit by reversal of Cdk-dependent phosphorylation. Mol Cell. 2:709-18.

Waizenegger, I.C., S. Hauf, A. Meinke, and J.M. Peters. 2000. Two distinct pathways remove mammalian cohesin from chromosome arms in prophase and from centromeres in anaphase. Cell. 103:399-410.

Wang, Q., S. Xie, J. Chen, K. Fukasawa, U. Naik, F. Traganos, Z. Darzynkiewicz, M. Jhanwar-Uniyal, and W. Dai. 2002. Cell cycle arrest and apoptosis induced by human Polo-like kinase 3 is mediated through perturbation of microtubule integrity. Mol Cell Biol. 22:3450-9.

Wang, R., G. He, M. Nelman-Gonzalez, C.L. Ashorn, G.E. Gallick, P.T. Stukenberg, M.W. Kirschner, and J. Kuang. 2007. Regulation of Cdc25C by ERK-MAP kinases during the G2/M transition. Cell. 128:1119-32.

Wang, Y., and T.Y. Ng. 2006. Phosphatase 2A negatively regulates mitotic exit in Saccharomyces cerevisiae. Mol Biol Cell. 17:80-9.

Watanabe, N., H. Arai, J. Iwasaki, M. Shiina, K. Ogata, T. Hunter, and H. Osada. 2005. Cyclindependent kinase (CDK) phosphorylation destabilizes somatic Wee1 via multiple pathways. Proc Natl Acad Sci U S A. 102:11663-8. 
Watanabe, N., H. Arai, Y. Nishihara, M. Taniguchi, N. Watanabe, T. Hunter, and H. Osada. 2004. Mphase kinases induce phospho-dependent ubiquitination of somatic Wee1 by SCFbetaTrCP. Proc Natl Acad Sci U S A. 101:4419-24.

Wells, N.J., N. Watanabe, T. Tokusumi, W. Jiang, M.A. Verdecia, and T. Hunter. 1999. The Cterminal domain of the Cdc2 inhibitory kinase Myt1 interacts with Cdc2 complexes and is required for inhibition of G(2)/M progression. J Cell Sci. 112 ( Pt 19):3361-71.

Williams, B.C., M.F. Riedy, E.V. Williams, M. Gatti, and M.L. Goldberg. 1995. The Drosophila kinesinlike protein KLP3A is a midbody component required for central spindle assembly and initiation of cytokinesis. J Cell Biol. 129:709-23.

Wirth, K.G., R. Ricci, J.F. Gimenez-Abian, S. Taghybeeglu, N.R. Kudo, W. Jochum, M. VasseurCognet, and K. Nasmyth. 2004. Loss of the anaphase-promoting complex in quiescent cells causes unscheduled hepatocyte proliferation. Genes Dev. 18:88-98.

Wirth, K.G., G. Wutz, N.R. Kudo, C. Desdouets, A. Zetterberg, S. Taghybeeglu, J. Seznec, G.M. Ducos, R. Ricci, N. Firnberg, J.M. Peters, and K. Nasmyth. 2006. Separase: a universal trigger for sister chromatid disjunction but not chromosome cycle progression. J Cell Biol. 172:847-60.

Wolf, F., R. Sigl, and S. Geley. 2007. '... The end of the beginning': cdk1 thresholds and exit from mitosis. Cell Cycle. 6:1408-11.

Wolf, F., C. Wandke, N. Isenberg, and S. Geley. 2006. Dose-dependent effects of stable cyclin B1 on progression through mitosis in human cells. Embo J. 25:2802-13.

Wolfe, B.A., and K.L. Gould. 2004. Fission yeast Clp1p phosphatase affects $G(2) / M$ transition and mitotic exit through Cdc25p inactivation. Embo J. 23:919-29.

Wolfe, B.A., W.H. McDonald, J.R. Yates, 3rd, and K.L. Gould. 2006. Phospho-regulation of the Cdc14/Clp1 phosphatase delays late mitotic events in S. pombe. Dev Cell. 11:423-30.

Wu, J., H.P. Cho, D.B. Rhee, D.K. Johnson, J. Dunlap, Y. Liu, and Y. Wang. 2008. Cdc14B depletion leads to centriole amplification, and its overexpression prevents unscheduled centriole duplication. J Cell Biol. 181:475-83.

Xie, S., H. Wu, Q. Wang, J. Kunicki, R.O. Thomas, R.E. Hollingsworth, J. Cogswell, and W. Dai. 2002. Genotoxic stress-induced activation of Plk3 is partly mediated by Chk2. Cell Cycle. 1:424-9.

Yan, Y., C.P. Black, and K.H. Cowan. 2007. Irradiation-induced G2/M checkpoint response requires ERK1/2 activation. Oncogene. 26:4689-98.

Yanagida, M. 2000. Cell cycle mechanisms of sister chromatid separation; roles of Cut1/separin and Cut2/securin. Genes Cells. 5:1-8.

Yang, J., E.S. Bardes, J.D. Moore, J. Brennan, M.A. Powers, and S. Kornbluth. 1998. Control of cyclin B1 localization through regulated binding of the nuclear export factor CRM1. Genes Dev. 12:2131-43.

Yuan, J., F. Eckerdt, J. Bereiter-Hahn, E. Kurunci-Csacsko, M. Kaufmann, and K. Strebhardt. 2002. Cooperative phosphorylation including the activity of polo-like kinase 1 regulates the subcellular localization of cyclin B1. Oncogene. 21:8282-92.

Yuan, K., H. Hu, Z. Guo, G. Fu, A.P. Shaw, R. Hu, and X. Yao. 2007. Phospho-regulation of HsCdc14A By Polo-like kinase 1 is essential for mitotic progression. J Biol Chem. 282:27414-23.

Zachariae, W., M. Schwab, K. Nasmyth, and W. Seufert. 1998. Control of cyclin ubiquitination by CDK-regulated binding of Hct1 to the anaphase promoting complex. Science. 282:1721-4.

Zachos, G., and D.A. Gillespie. 2007. Exercising restraints: role of Chk1 in regulating the onset and progression of unperturbed mitosis in vertebrate cells. Cell Cycle. 6:810-3.

Zachos, G., M.D. Rainey, and D.A. Gillespie. 2003. Chk1-deficient tumour cells are viable but exhibit multiple checkpoint and survival defects. Embo J. 22:713-23.

Zhao, H., J.L. Watkins, and H. Piwnica-Worms. 2002. Disruption of the checkpoint kinase $1 /$ cell division cycle $25 \mathrm{~A}$ pathway abrogates ionizing radiation-induced $\mathrm{S}$ and $\mathrm{G} 2$ checkpoints. Proc Natl Acad Sci U S A. 99:14795-800. 

Abreviaturas 



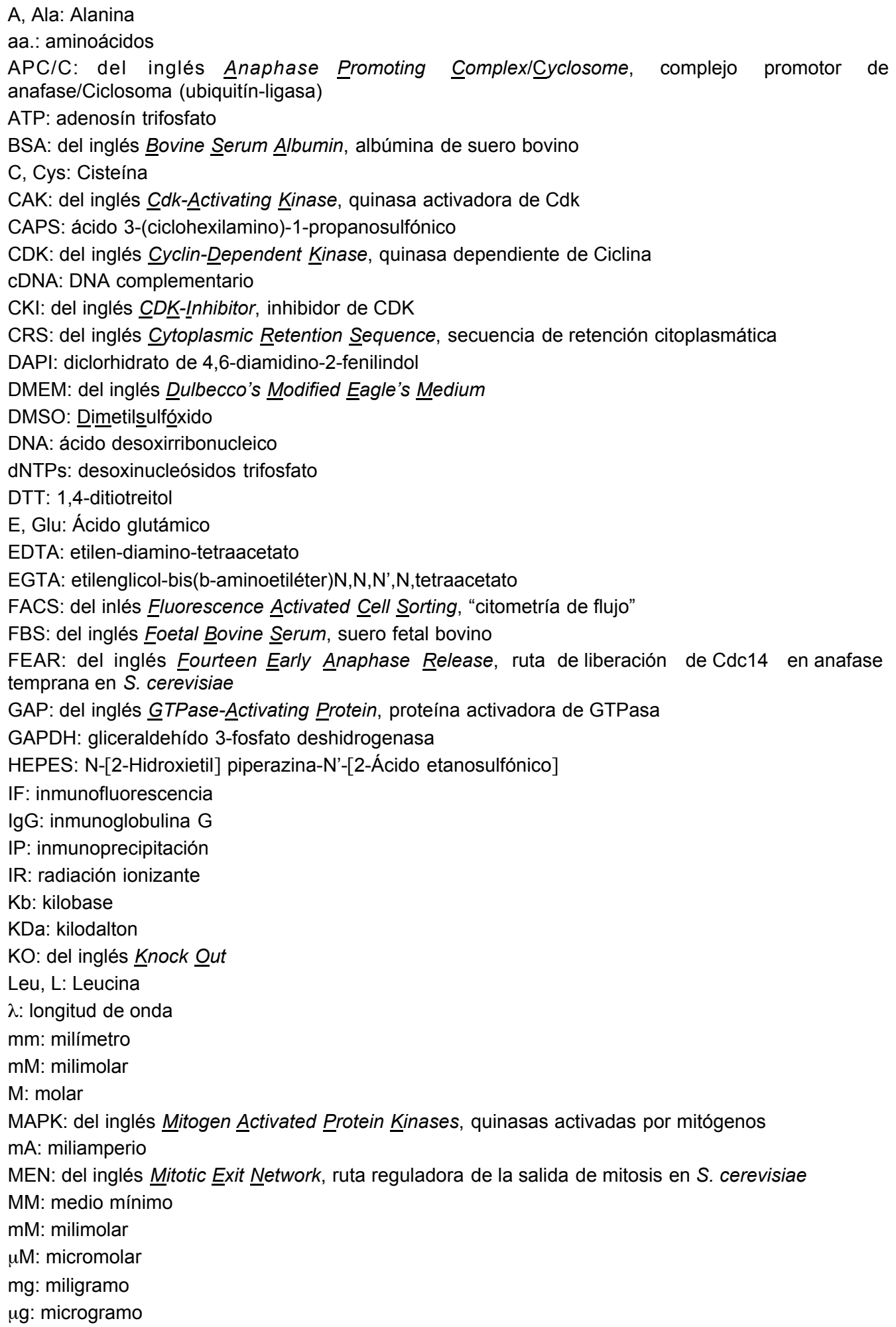


$\mathrm{ml}$ : mililitro

$\mu \mathrm{g}$ : microlitro

MOPS: ácido (3-[N-Morfolino] propanosulfónico)

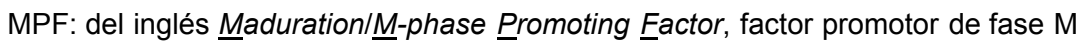

mRNA: RNA mensajero

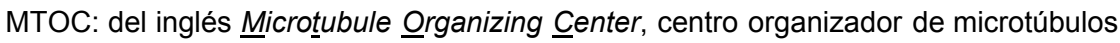

$\mathrm{mU}$ : miliunidades

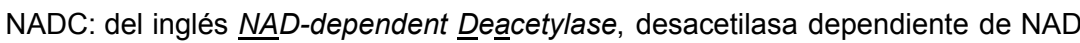

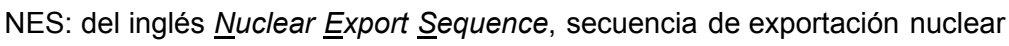

ng: nanogramo

NLS: del inglés Nuclear Localization Signal, señal de localización nuclear

nm: nanómetro

NZ: nocodazol

ORF: del inglés Open Reading Frame, "fase de lectura abierta"

${ }^{32} \mathrm{P}$ : fósforo 32

pb: pares de bases

PBS: tampón fosfato salino

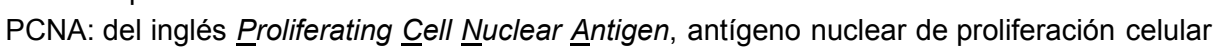

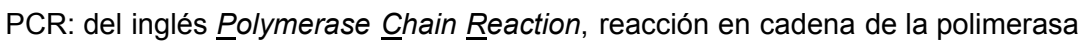

(PD): del inglés $\underline{P}$ hosphatase $\underline{D} e a d$, se refiere a mutantes de fosfatasas en los que se ha suprimido

su actividad catalítica

P-HH3: Histona H3 fosforilada

PIPES: piperazina-N,N'-bis-2-ácido etanosulfónico

$\mathrm{pH}: \log 1 /[\mathrm{H}+]$

pmoles: picomoles

PMSF: fluoruro de fenil-sulfonil

PTP: del inglés $\underline{P}$ rotein-Tyrosine $\underline{P}$ hosphatases, fosfatasas de tipo proteín-tirosina

RNA: ácido ribonucleico

RNAi: RNA de interferencia

RNasa: ribonucleasa

rpm: revoluciones por minuto

$\mathrm{RT}$ : del inglés Room temperature, temperatura ambiente

$\mathrm{S}$, Ser: Serina

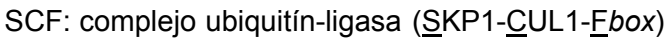

SDS: dodecil sulfato sódico

SDS-PAGE: del inglés SDS-Polyacrilamide gel electrophoresis, gel de electroforesis de SDSpoliacrilamida

SIN: del inglés Septation Initiation Network, ruta de inicio de la citoquinesis en S. pombe

siRNA: del inglés short interference RNA

SPB: del inglés Spindle Pole Body, cuerpo polar del huso

TAE: Tris Acetato- DTAE

Thr, T: Treonina

Tris: hidroximetil aminometano

Tyr, Y:Tirosina

UV: radiación ultravioleta

V: voltio

WB: del inglés Western $\underline{\text { blot }}$

wt: del inglés wild type, tipo silvestre

YES: del inglés Yeast Extract with $\underline{\text { Supplement }}$ 
